\title{
The anticoagulant activity of heparin : biochemical studies in purified systems
}

Citation for published version (APA):

Schoen, P. J. (1991). The anticoagulant activity of heparin : biochemical studies in purified systems. [Doctoral Thesis, Maastricht University]. Rijksuniversiteit Limburg. https://doi.org/10.26481/dis.19910503ps

Document status and date:

Published: 01/01/1991

DOI:

10.26481/dis.19910503ps

Document Version:

Publisher's PDF, also known as Version of record

\section{Please check the document version of this publication:}

- A submitted manuscript is the version of the article upon submission and before peer-review. There can be important differences between the submitted version and the official published version of record.

People interested in the research are advised to contact the author for the final version of the publication, or visit the DOI to the publisher's website.

- The final author version and the galley proof are versions of the publication after peer review.

- The final published version features the final layout of the paper including the volume, issue and page numbers.

Link to publication

\footnotetext{
General rights rights.

- You may freely distribute the URL identifying the publication in the public portal. please follow below link for the End User Agreement:

www.umlib.nl/taverne-license

Take down policy

If you believe that this document breaches copyright please contact us at:

repository@maastrichtuniversity.nl

providing details and we will investigate your claim.
}

Copyright and moral rights for the publications made accessible in the public portal are retained by the authors and/or other copyright owners and it is a condition of accessing publications that users recognise and abide by the legal requirements associated with these

- Users may download and print one copy of any publication from the public portal for the purpose of private study or research.

- You may not further distribute the material or use it for any profit-making activity or commercial gain

If the publication is distributed under the terms of Article $25 \mathrm{fa}$ of the Dutch Copyright Act, indicated by the "Taverne" license above, 
THE ANTICOAGULANT ACTIVITY OF HEPARIN BIOCHEMICAL STUDIES IN PURIFIED SYSTEMS 


\title{
THE ANTICOAGULANT ACTIVITY OF HEPARIN BIOCHEMICAL STUDIES IN PURIFIED SYSTEMS
}

\author{
PROEFSCHRIFT
}

ter verkrijging van de graad van doctor aan de Rijksuniversiteit Limburg te Maastricht, op gezag van de Rector Magnificus, Prof.Mr. M.J. Cohen, volgens het besluit van het College van Dekanen, in het openbaar te verdedigen op vrijdag, 3 mei 1991 om 16.00 uur

$$
\text { door }
$$

Pieter Joseph Schoen 
Promotor

Co-promotor

Beoordelingscommissie
Prof.Dr. H.C. Hemker

Dr. Th. Lindhout

Dr. W. Hermens, voorzitter

Prof.Dr. E. Briët (Rijksuniversiteit Leiden)

Prof.Dr. J.A. Flendrig

Prof.Dr. D. Lane (University of London)

Prof.Dr. G.J. van der Vusse

CIP-GEGEVENS KONINKLIJKE BIBLIOTHEEK, DEN HAAG

Schoen, Pieter Joseph

The anticoagulant activity of heparin : biochemical

studies in purified systerns / Pieter Joseph Schoen. -

Maastricht : Datawyse. - III.

Proetschrilt Maastricht. - Met lit. opg. - Met

samenvatting in het Nederlands.

ISBN 90-5291-046-4

NUGI 743

Trefw:: heparine / bloedstolling / trombinevorming.

Financial support by the Netherlands Heart Foundation and SANOFI for the publication of this thesis is gratefully acknowledged.

Omslag: Jan Eggen, Maastricht

Druk: Datawyse, Maastricht / Krips Repro, Meppel 
Duizend mooie woorden wegen niet op tegen een tarwekorrel

(Iraanse zegswijze) 


\section{Voorwoord}

In de biomedische wetenschappen wordt een wetenschappelijke publikatie zelden geproduceerd door één enkel persoon. Deze dissertatie is hier geen uitzondering op. Daarom heb ik op de eerste bladzijde van ieder hoofdstuk de mede-auteurs voor het voetlicht gehaald. Daarnaast wil ik graag iedereen bedanken die, in meer of mindere mate, bij het tot stand komen van dit proefschrift betrokken is geweest. In het bijzonder gaat mijn dank uit naar de volgende personen.

Degene die het meest belangrijk voor mij is geweest in het maken van dit proefschrift was mijn co-promotor. Beste Theo, een betere term dan assistent-inopleiding om onze relatie te beschrijven is nauwelijks denkbaar. Jouw kennis en inzicht, en onze vele gesprekken, hebben mij altijd zeer weten te inspireren. Bedankt.

Mijn promotor, Coen Hemker; Jou bedank ik voar de mogelijkheden die je me gegeven hebt, en het vertrouwen dat je in me gesteld hebt om te kunnen promoveren. Coen en Theo, zonder jullie was dit proefschrift niet geworden wat het geworden is.

Lieve Femia, zonder jouw niet aflatende steun en hulp zou dit proefschrift nóóit iets geworden zijn.

Beste George, jouw hulp was onontbeerlijk voor het welslagen van de meeste studies die in dit proefschrift zijn opgenomen, bovendien heb je veel bijgedragen aan mijn opleiding. Bedankt hiervoor.

Ron, Jo, Truus, Simone, Trees en Mariet, jullie vele werk en steun zijn van onschatbare waarde geweest voor mij en mijn promotie.

De leden van de beoordelingscommissie, Dr. Wim Hermens, Prof. Lane, Prof. Briêt, Prof. Flendrig en Prof. vd Vusse, ben ik erkentelijk voor hetgeen zij voor dit proefschrift betekend hebben.

Alhoewel zij de laatste tijd niet nauw bij dit onderzoek betrokken zijn geweest, wil ik toch ook Dominique Baruch, Hans Soons en Jean Pieters bedanken voor het voorbeeld dat zij gesteld hebben.

De overige, hier niet met naam gencemde leden van de vakgroep Biochemie bedank ik voor hun collegialiteit en samenwerking.

Tot slot wil ik mijn paranimfen, Gaby en Peter bedanken voor de ruggesteun tijdens de laatste fase van deze voor mij belangrijke gebeurtenis.

Bedankt allemaal.

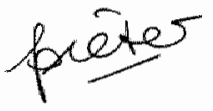



Chapter 1 General Introduction.

Chapter 2 The Effect of Sulfation on the Anticoagulant and Antithrombin III-Binding Properties of a Heparin Fraction with Low Affinity for Antithrombin III.

Thrombosis Research 57:415-423, 1990

Chapter 3 Low Molecular Weight Heparin-Catalyzed Inactivation of Factor $\mathrm{Xa}$ and Thrombin by Antithrombin III. Effect of Platelet Factor 4.

To be published in Thrombisis and Haemostasis 1991

Chapter 4 The in Situ Inhibition of Prothrombinase-formed Human $\alpha$-Thrombin and Meizothrombin (Des Fragment 1) by Antithrombin III and Heparin. Journal of Blological Chemistry 262:11268-11274, 1987

Chapter 5 Thrombin Generation and Inactivation in the Presence of Antithrombin III and Heparin. Blochemistry 25:5962-5969, 1986

Chapter 6 Antithrombin III-Dependent Anti-Prothrombinase Activity of Heparin and Heparin Fragments. Journal of Biological Chemistry 264:10002-10007, 1989

Chapter 7 Continuous Flow and the Prothrombinase-Catalyzed Activation of Prothrombin.

Thrombosis and Haemostasis 64.542.547, 1990

Chapter 8 Flow and the Inhibition of Prothrombinase by Antithrombin III and Heparin.

To be published in Blood 1991

Chapter 9 General Discussion.

References 


\section{Abbreviations}

$\begin{array}{ll}\text { APTT } & \text { Activated Partial Thromboplastin Time } \\ \text { ATIII } & \text { Antithrombin III } \\ \text { HA } & \text { High Affinity } \\ \text { HSA } & \text { Human Serum Albumin } \\ \text { ISH } & 4^{\text {th }} \text { International Standard for Heparin } \\ \text { KCCT } & \text { Kaolin-Cephalin Clotting Time } \\ \text { LA } & \text { Low Affinity } \\ \text { LMW } & \text { Low Molecular Weight } \\ \text { MMW } & \text { Medium Molecular Weight } \\ \text { PC } & \text { Phosphatidylcholine } \\ \text { PS } & \text { Phosphatidylserine } \\ \text { PSPC } & \text { Vesicles of PS and PC } \\ \text { PF4 } & \text { Platelet Factor } 4 \\ \text { pNPGB } & \text { p-nitrophenyl p"-guanidinobenzoate hydrochloride } \\ \text { S2238 } & \text { D-phenylalanyl-L-pipecolyl-L-arginine-p-nitroanilide } \\ & \text { dihydrochloride } \\ \text { S2337 } & \text { benzoyl-L-isoleucyl-L-glutamyl-( }(\gamma \text {-piperidyl)-L-glycyl-p-nitroanilide } \\ & \text { hydrochloride } \\ \text { SD } & \text { Standard Deviation } \\ \text { SDS } & \text { Sodium Dodecyl Sulfate } \\ \text { SE } & \text { Standard Error } \\ \text { STI } & \text { Soybean Trypsin Inhibitor } \\ \text { UF } & \text { Unfractionated }\end{array}$




\section{General Introduction}

At the beginning of this century, it was realized that treatment of tissues by organic solvents yielded extracts, which, after removal of the solvent, promoted coagulation (thromboplastic activity). In 1911, Howell published his theory of blood coagulation: prothrombin in plasma does not spontaneously convert into thrombin because it is bound by an inhibitor substance, antiprothrombin. The thromboplastic action of tissues was supposed to neutralize the antiprothrombin. allowing activation of prothrombin to occur. In 1916, McLean prepared phosphatides from tissues by ether extraction. Most cephalins showed the usual thromboplastic activity, but aged preparations, and certain extracts from heart or liver tissue had anticoagulant activity. Two years later the term heparin was introduced to identify the material from liver, and in 1921 Howell indicated that the antiprothrombin in plasma was the phosphatid heparin (see Reference 1 for an overview). In 1922, anticoagulant material, also denoted heparin, was prepared from dog liver by aqueous extraction. However, as the solubility properties of this substance were so completely different from those of the former "heparim" it obviously was a new substance. This material, identified as a sulfur containing carbohydrate, was purified and characterized in 1933. Hereafter beef lung was established as a suitable, commercial, source and sufficient material was prepared for use in clinical trials. Since its first use in 1936, the efficacy of heparin as an antithrombotic has been well established in man and experimental animals (2-5), and nowadays, it is widely used in the treatment and prophylaxis of thrombotic and thromboembolic disorders (6-8).

Brinkhous et al (9) demonstrated that heparin was effective as an anticoagulant only in the presence of a plasma component, which they termed heparin cofactor. Since 1968 this activity is attributed to the plasma protein antithrombin III (ATIII) (10). It has been well established, that only about one-third of the molecules, present in commercial, unfractionated (UF) heparin preparations, bind with high affinity to ATIII (HA heparin) and have potent anticoagulant activities $(11-13)$.

Heparin has many biological effects (14), therefore the anticoagulant and antithrombotic properties of heparin need not necessarily arise from the same activity of the substance. However, it has been demonstrated in an experimental rabbit model that the antithrombotic potential of UF heparin has to be ascribed to the HA heparin fraction, and that the low affinity (LA) heparin fraction has, on its 
own, no antithrombotic properties (15). So it has at present become generally accepted that the antithrombotic action of heparin is mediated through its ATII. dependent anticoagulant activity.

This is, however, the limit of the existing consensus on the in vivo mode of action of heparin. Despite many fundamental investigations during the last two decades, the therapeutic action of heparin is still not yet fully understood. It is against this background, that the study described in this thesis was initiated.

\section{THE STRUCTURE AND BIOSYNTHESIS OF HEPARIN}

Heparin is a heterogeneous mixture of glycosaminoglycans, which consists of repeating disaccharide units of uronic acid (D-glucuronic acid or L-iduronic acid) and glucosamine residues (16). The main constituent of heparin is a trisulfated disaccharide sequence (Figure 1), which forms regular regions in the polysaccharide. The L-iduronic acid residues can have various 3 dimensional structures (17), and the monosaccharide units can contain various $N$ and $O$ substitutes, which allows the formation of at least 27 different disaccharide sequences (18). Hence, heparin molecules are also marked by highly irregular regions.

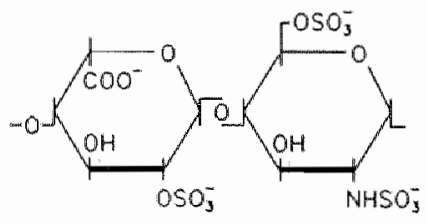

Figure I. Trisulfated disaccharide repeating unit in the regular regions of heparin. The sequence is denoted as 1-4[2-O-sulfate- $\alpha$-L-iduronate] $1-4[\mathrm{~N}$-sulfate-6-O-sulfale- $\alpha$-D-glucosamine] (see Felerence 14).

Heparin is synthesized as a proteoglycan in connective-tissue-type mast cells (see Reference 18 for a detailed review). The core protein, with a molecular weight of approximately 17,000 contains a region with alternating serine and glycine residues. The serine residues are xylosylated and then additional sugar units are transferred from UDP-sugar precursors to the elongating saccharide chain. The alternating hexuronic acid, glucosamine sequence is the consequence of substrate specificities of the corresponding glycosyltransferases. The polysaccharide chains formed have a molecular weight varying between 60,000 and 100,000 .

The polysaccharide chains are then modified in a rapid, but ordered, sequential manner through $\mathrm{N}$-deacetylation, $\mathrm{N}$-sulfation, $\mathrm{C} 5$-epimerization and $\mathrm{O}$ - 
sulfation. The sites at which the modifications take place are determined by substrate specificities of the enzymatic systems involved. The enzymatic conversions however are not complete; at the end of the synthesis a significant amount of saccharides will have a low degree of modification. Within hours after biosynthesis, the extended polysaccharide chains are degraded by an endo- $B-\mathrm{D}$-glucoronidase, to fragments with a molecular weight between 5,000 and $30,000(19)$.

Due to the modification reactions, irregular regions are generated. A number of these sites, when they have a specifically required structure, facilitate the binding of heparin to ATIII. Because of the random degradation of the mature polysaccharide chains by the endoglucoronidase, heparin preparations contain ATIII-binding saccharides (HA heparin) and non-ATlll-binding saccharides (LA heparin). Studies by Choay et al (20), and Thunberg et al (21) suggested that the major features of the ATIII-binding site of heparin are contained within a pentasaccharide sequence. In 1983 (22), the (hypothetical) structure was proved unambiguously, by chemical synthesis of this sequence (Figure 2). The pentasaccharide consists of well defined residues, containing specific sulfate groups essential for the binding to ATIII (23).

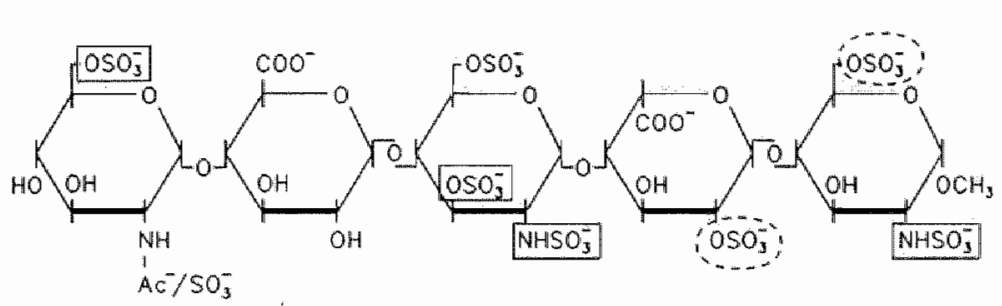

Figure 2. The ATIII-binding domain of heparin. The $\mathrm{O}$ - and $\mathrm{N}$-sulfate groups crilical for the binding to ATIll are marked by solid boxes. Two other O-sulfate groups important for optimal binding to ATIII are indicated by dashed ellipses (see Relerence 17).

In summary, then: the polysaccharide heparin is constituted of linearly aligned, specifically modified hexuronic acid and glucosamine residues. Heparin molecules present in unfractionated preparations are heterogeneous with respect to:

1) The chemical composition of the monosaccharide units (24). Hence they vary markedly in their degree of sulfation, and thus in their charge density.

2) Molecular weight. The molecular weights of the individual heparin molecules is distributed between 5,000 and 30,000 , with a mean value between 12,500 and $18,000(25)$.

3) Affinity for ATIII. Only about one-third of the molecules contain one or more correct ATIII-binding pentasaccharide sequences $(11,12)$. 


\section{ANTITHROMBIN III}

ATIII is a circulating blood coagulation inhibitor, which is a member of the SERPIN (serine protease inhibitor) superfamily (26). The proteins of this family have a common mechanism of inhibition: they offer their cognate proteases a high-affinity substrate that resists complete conversion. The reaction between a serine protease of the blood coagulation system and ATill terminates at an acylenzyme intermediate, in which the calalytic serine residue of the enzyme remains covalently bound to a carboxyl-terminal arginyl residue of the large fragment of the cleaved ATIII molecule (27). In the presence of heparin the rates of covalent bond formation between ATIII and the proteases (mainly factor Xa and thrombin) are enhanced.

Rosenberg \& Damus made the first attempts to elucidate the features of the heparin-binding site in ATIII , by chemical modification of lysine residues (28). Since then, numerous investigations have been made to locate the heparinbinding site in ATIII (see Reference 29, and references therein). From these studies two regions in the amino-terminal part of ATIII can be identified as the constituents of the heparin-binding site. The first region contains Pro ${ }^{41}, \mathrm{Arg}^{47}$, and Trp ${ }^{49}$, while the second region includes Lys ${ }^{107}$, Lys $^{114}$, Lys $^{125}$, and Lys ${ }^{136}$. These two regions are contained within a large loop, crosslinked by 2 disulfide bonds. It is thought that in the three-dimensional structure of ATIII, the basic amino acids (lysine and arginine) are clustered, to form a positively charged patch on the surface of ATIII, to which heparin binds (26). The other critical amino acids, and at least one of the disulfide bonds are thought to be essential for the integrity of the heparin binding site (29).

\section{THIS THESIS; CHAPTER 2}

The modification reactions occurring during the biosynthesis of heparin are generally incomplete, so a significant amount of the heparin molecules remain at lower levels of modification. Therefore, it is to be expected that in the non-ATII-binding fraction of heparin a number of molecules are present which lack one, or a number of the specific sulfate groups of an otherwise fully assembled pentasaccharide structure. This hypothesis was investigated in Chapter 2, in which a ATIII low affinity heparin preparation was chemically oversulfated, and the product obtained was investigated for its ATII-binding and anticoagulant properties. 
THE HEPARIN-CATALYZED INHIBITION OF FACTOR Xa AND THROMBIN BY ANTITHROMBIN III

In the absence of heparim, the inhibition of factor Xa or thrombin by ATIII is considered in terms of a two-step reaction scheme:

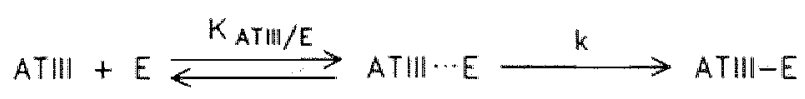

in which the formation of the covalent inhibitor-enzyme complex (ATIII-E) involves

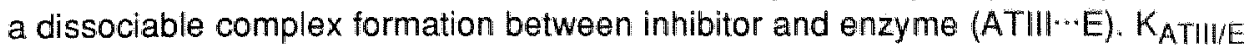

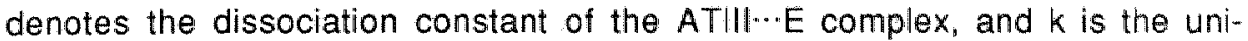
molecular rate constant for conversion of the intermediate ATIII $\cdots E$ complex into the product, ATIII-E.

The rate-limiting step in the inactivation process is the conversion of ATIII $\cdots E$. The rate at which this conversion takes place equals:

$$
w=k[A T\|\| \cdot \cdots]
$$

Heparin enhances the rates of inactivation of factor Xa and thrombin by increasing the amount of (heparin-bound) intermediate. The mechanisms by which these ternary complexes are formed, however, differ.

First of all, heparin-binding of ATIII induces a conformational change in the protein $(30,31)$. There is appreciable evidence that their mutual interaction is a two step mechanism, which involves the initial formation of a relatively weak complex, followed by a conformational change, which stabilizes the heparin-ATIII complex, and results in tight binding $(31,32)$. It has been demonstrated, that only heparin molecules which possess the specific pentasaccharide sequence, are able to induce the conformational change (23). The conformational change leads to an increased affinity of ATIll for factor Xa $(33,34)$. Hence at given protein concentrations, the presence of heparin largely increases the concentration of intermediate, and thus enhances the rate of factor $\mathrm{Xa}$ inactivation (Equation 2). At present, it is unclear whether the conformational change in ATIII also affects the rate of covalent bond formation between ATIII and factor Xa.

In the case of thrombin, however, the conformational change itself is insufficient to enhance inactivation. It has been demonstrated, that heparin oligosaccharides with a minimal length of 18 saccharide units are required for the catalysis of thrombin inactivation (35). Subsequently it was shown "that the activity of these heparin molecules requires the simultaneous binding of ATIII and thrombin (36). Hence in the case of thrombin, heparin primarily functions as a catalytic surface, to which both ATIII and thrombin bind, and it thus promotes the initial interaction between the two proteins (approximation mechanism) (37). 
The allosteric change in ATIIl contributes only nominally to the rate of covalent bond formation between ATIII and thrombin $(34,38)$.

The formation of the covalent bond between ATIll and enzyme is linked to a conformational change in the heparin-binding region of ATIII (39). Consequently, heparin, either concomitantly or in a step which is faster than the formation of the covalent bond, dissociates from the ATIII-E complex $(33,40)$. The heparin rebound is then free for a new cycle of enzyme inhibition, and hence heparin is, in chemical terms, a true catalyst.

Heparin molecules are heterogeneous with respect to molecular weight and charge density. The effect of these two parameters on the rate of heparincatalyzed inactivation of thrombin and factor Xa has been investigated. It was shown, that if the heparin size exceeds that of an octadecasaccharide, the effectiveness of heparin increases with increasing chain length, both for the inactivation of thrombin $(36,41)$, and factor $\mathrm{Xa}(34,36,42)$, although this effect is much more pronounced with thrombin. The heparin-protease interaction is ionic strength-dependent (43). Moreover, it has been shown that the anticoagulant activity of heparin (44), and the inactivation of thrombin by ATIII and heparin (45) is related to its anionic density. At present it is believed, that the interaction between heparin and protease requires no specific sequence of heparin saccharides, but rather that it is a pure electrostatic interaction. These findings are all consistent with an approximation mechanism, which is, however, of minimal importance for factor $X a$ inactivation.

Finally, under pseudo-first order conditions, i.e. when the ATIII concentration is in sufficient excess over the initial enzyme concentration, the complete reaction sequence is described by a first order rate constant. In the recent past, studies have appeared, which give a detailed kinetic description of the heparincatalyzed inactivation of factor $\mathrm{Xa} \mathrm{(33)} \mathrm{and} \mathrm{thrombin} \mathrm{(46).} \mathrm{In} \mathrm{these} \mathrm{studies}$ equations are provided which give the dependence of the observed pseudo-first order rate constants on the total ATIII, and heparin concentrations. It was concluded, that in the heparin-catalyzed inactivation reactions, the primary event is the formation of the heparin-ATIII complex. In addition, it was demonstrated, that the interactions of thrombin and ATIII with heparin are linked. That is, the affinity of thrombin for the heparin-ATIII complex is about 10 times higher than the affinity of thrombin for heparin alone. This implicates, that the ternary ATII//heparin/ thrombin complex will be formed at concentrations considerably lower than those predicted from models which fail to account for this linkage.

\section{LOW MOLECULAR WEIGHT HEPARIN}

Heparin is an effective antithrombotic agent " but its usage carries bleeding as a side effect (47). The range of dosages in which thrombosis is effectively 
prevented without inducing hemorrhage (therapeutic window) is relatively small. This has prompted many studies during the last decade, seeking to improve the benefit-risk ratio of hoparin.

In 1971, Yin et al postulated that "... the efficiency of activated factor $X$ inhibitor as an anticoagulant during normal blood coagulation (an action profoundly enhanced by heparin) may depend more on its preventing any generated activated factor $X$ from activating prothrombin than it may on preventing thrombin from attacking fibrinogen." (48). Consequently they renamed ATIII, activated factor $X$ inhibitor (49). Because low molecular weight (LMW') heparin preparations had little effect on tests of overall clotting, as compared to unfractionated (UF) heparin, but maintained their potency as measured by anti-factor $\mathrm{Xa}$ assays, it was hypothesized that LMW heparin could have a favorable benefit-risk ratio (see Reference 50 ). This hypothesis appears to be supported by early animal studies (51).

However, despite numerous clinical investigations during the past 10 years it still remains an open question whether LMW heparin widens the therapeutic window of heparin treatment (53). LMW heparin does seem to be more useful than UF heparin in certain clinical states in well defined patient groups (54). This may however be equally well due to the fact that their pharmokinetic properties are more favorable as compared to those of UF heparin. Their half-life times in the circulation are longer, and their bioavailability is increased $(55,56)$. Further clinical investigations will be needed to further investigate whether the therapeutic effect of LMW heparin is indeed superior to that of UF heparin.

At present, attention is returning to the question how LMW and UF heparins actually influence coagulation. First of all, the hypothesis that LMW heparin inhibits thrombosis and thromboembolism as a result of its prominent anti-factor $X a$ activity could not be sustained. (Very) low molecular weight heparins which only express anti-factor Xa activity are poor antithrombotic drugs (57-59). Secondly, during the past few years investigations performed both in our laboratory $(60-63)$ and elsewhere $(64,65)$, have demonstrated that UF and LMW heparins inhibit in vitro coagulation primarilly through their ability to accelerate thrombin inactivation.

\section{THIS THESIS; CHAPTER 3}

Because studies with isolated ATIll-high affinity oligosaccharides (35, 36) have demonstrated that heparin molecules with molecular weights less than 5,400 (octadecasaccharides) have largely reduced anti-thrombin

1 LMW heparin preparations are produced from depolymerized UF heparin; the molecules have a molecular weight which is lower than 10,000 . Commercially available LMW heparin preparations have a mean molecular weight between 3,000 and 7,000 (52). 
activities and retained anti-factor Xa activities, it is generally taken for granted that $L M W$ heparin preparations have a high anti-factor Xa/antithrombin specific activity ratio, as compared to UF heparin. It was also shown (35), that as the molecular weights of heparin oligosaccharides decrease from 5,400 downwards, their anti-factor Xa activities become increasingly resistant towards neutralization by platelet factor 4 (PF4) 5 . LMW heparin preparations, however, are complex mixtures of oligosaccharides, with unknown distributions of their ATIl-high affinity molecules. Therefore we, in Chapter 3 investigated the catalytic capacity of a selection of LMW heparin preparations towards the ATIII-dependent inactivation of factor Xa and thrombin, and we investigated the extent of PF4-dependent neutralization of these LMW heparins. Our results showed that the specific anti-factor Xa/anti-thrombin ratios of the LMW heparin preparations were indistinguishable from each other, and from that of standard UF heparin. We also found circumstantial evidence, that the anti-thrombin and anti-factor $X a$ activities of $L M W$ heparins are predominantly to be found among the larger heparin chains.

$\$$ PF4 is a heparin neutralizing protein present in platelet $\alpha$-granules (66). It consists of 4 identical subunits, each containing a heparin binding site $(67)$, and it binds tightly to heparin molecules with a chain length of 16 saccharides and more (68).

\section{THE PROCESS OF BLOOD COAGULATION}

In vivo blood coagulation is a complex series of events, which requires actions of, and interactions between the vascular wall, blood platelets and the coagulation system (69). The coagulation system $(70,71)$ is responsible for the formation of insoluble fibrin strands, which stabilize the hemostatic plug. Basically, the coagulation system can be thought of as a cascade system which has four distinct features:

Initlation-Coagulation can be triggered by two pathways, historically denoted as extrinsic and intrinsic. The extrinsic pathway is followed, when tissue factor, a lipoprotein, becomes exposed to the blood. This pathway is factor VIIdependent and is currently thought to be the physiologic mechanism by which coagulation is initiated (72). The intrinsic, or contact activation, pathway is dependent on the proteins factor XII, prekallikrein and high molecular weight kininogen. Via this pathway, blood coagulates when brought in contact with nonhemocompatible surfaces.

Zymogen Conversion - In native blood, the enzymes of the coagulation system circulate as non active precursors (zymogens). During coagulation the 
zymogens are converted into enzymes, through an ordered sequence of reactions ${ }^{2}$.

Cofactor Dependence- The activity of the enzymes in free solution is low. However, in the presence of cofactors, which have no enzymatic activity, the rates at which the zymogen-enzyme conversions take place are dramatically enhanced. In native blood, also the cofactors exist in a non-active form. During coagulation these cofactors become activated through positive feedback reactions ${ }^{2}$.

Procoagulant Surfaces - In addition to the cofactor dependence, the zymogen-enzyme conversions are also dependent on the exposure of a procoagulant surface, to which the enzymes and their cofactors bind (71). It has been found, that these surfaces can be provided by activated platelets (73), a perturbed endothelial cell layer $(74,75)$, monocytes $(76,77)$, lymphocytes $(77)$ or neutrophils (77). The surface provided by activated platelets is thought to play a crucial role in normal hemostatic plug formation (78). The dependency of blood coagulation on the exposure of a procoagulant surface contributes to localization of hemostatic plug formation.

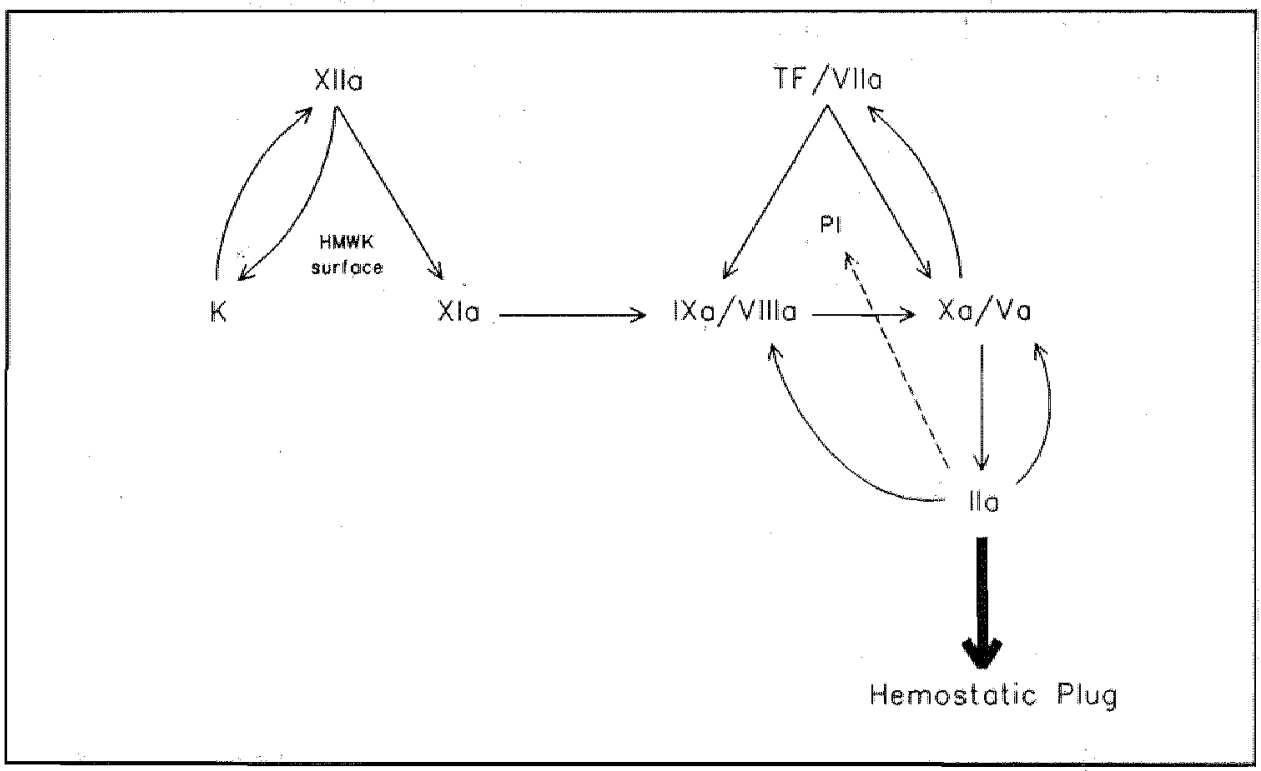

Figure 3. Blood coagulation scheme. Roman numerals indicate coagulation factors ${ }^{2}$; thrombin is represented by lla. Abbreviations: $K_{\text {, }}$ kallikrein; HMWK, high molecular weight kininogen; $T F$ " tissue factor: Pl, procoagulant phospholipid surface (see Reference 83).

2 In accordance with common practice precursor forms of active proteins are denoted by a roman numeral. The active forms are indicaled by an index " $a$ ". 
Either of the two pathways of initiation of coagulation leads to the generation of activated factor $X$, factor $X a$ (Figure 3). Factor $X a$ is not only involved in the feedback activation of factor Vil, but it is also the enzyme which converts the zymogen prothrombin into thrombin (lla). Thrombin, which specifically converts fibrinogen into fibrin $(79,80)$, has many activities. Two of these are essential to the explosive thrombin formation necessary to establish the formation of a stable hemostatic plug. In plasma it has been shown that thrombin is the key enzyme for the feedback activation of the cofactors factor $V$ and factor VIII (81), and thrombin is, together with collagen a potent platelet activator (73), and a strong endothelial cell agonist (82). The sequence of zymogen activation events in coagulation provides the potential for explosive amplification ultimately leading to massive thrombin formation.

\section{PROTHROMBINASE-CATALYZED ACTIVATION OF PROTHROMBIN}

Prothrombinase is the enzymatic complex, composed of factor $\mathrm{Xa}$ and factor $\mathrm{Va}$ bound to the procoagulant surface; its assembly is dependent on the presen-

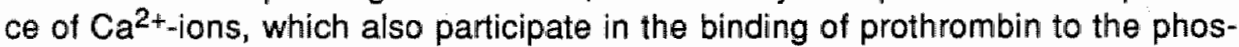
pholipid surface (84). This complex is a highly efficient activator of prothrombin. In well-defined reaction systems, utilizing purified proteins, the influence of the components of prothrombinase on the kinetic parameters of prothrombin activation, has been thoroughly investigated. In most studies small unilaminar, negatively charged phospholipid vesicles have been used as procoagulant surface. From these studies it has emerged, that phospholipids and factor Va profoundly stimulate prothrombin conversion by, respectively, lowering the Michaelis-Menten constant, $\mathrm{K}_{\mathrm{M}}$, and largely increasing the turnover rate, $\mathrm{k}_{\text {cat }}$ of the reaction, as compared to the activity of factor $\mathrm{Xa}$ alone (85-87).

Prothrombin is a single chain glycoprotein of 581 amino acids, with a molecular weight of 72,000 (88). The prothrombin molecule has been discriminated into three functional domains (Figure 4). A phospholipid-binding domain, fragment 1 , is located at the amino-terminal side of the molecule. The domain, prethrombin 2, which is the structural "precursor" of thrombin is located at the carboxy-terminal side. The remaining part of the molecule, fragment 2 , is thought to be involved in an interaction with factor $\mathrm{Va}$. The prothrombinase-catalyzed activation of prothrombin involves two cleavages by factor Xa (Figure 4). In addition, thrombin can also cleave prothrombin at a number of sites (89). A particular cleavage, relevant for the scope of this thesis, is indicated in Figure 4. 


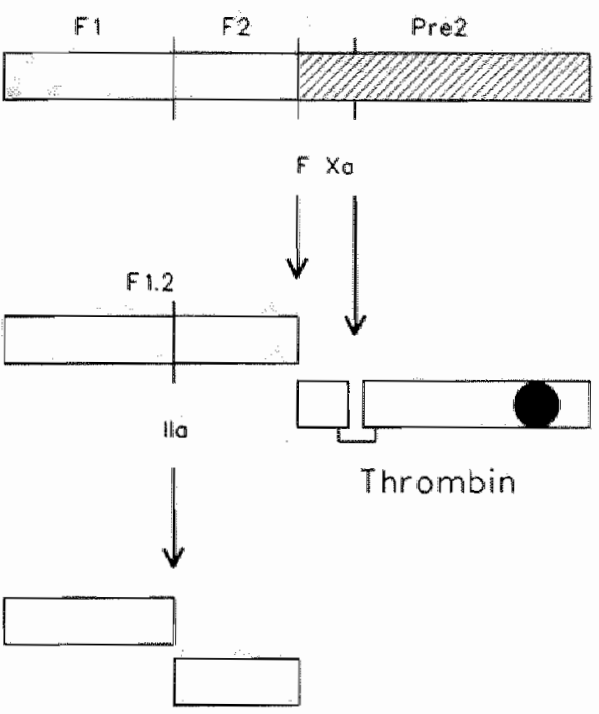

Figure 4. Prothrombin, and its limited proteolysis by factor $X a$ and thrombin. In the native prothrombin molecule (PT) the three functional domains fragment 1 (F1), fragment 2 (F2), and prethrombin 2 (Pre2) are indicated, as well as three cleavage sites (vertical bars), The cleavages by factor Xa lead to the generation of thrombin, with an exposed active site (O). The remnant part of prothrombin (fragment 1.2, F1.2) can be cleaved by thrombin (llla), through which fragment 1 and fragment 2 are generated (see Reference 89).

Af present it is thought that factor $\mathrm{Va}$, but not phospholipid, also alters the order in which factor Xa cleaves the two bonds in prothrombin (89-91). In the absence of factor Va large amounts of prethrombin 2 are formed, whereas in its presence, meizothrombin is observed. Meizothrombin has an exposed thrombin active site, while the fragment 1.2 part of prothrombin is still covalently attached to its thrombin region. If one takes no precautions to inhibit the thrombin activity, meizothrombin becomes rapidly cleaved at the thrombin cleavage site as indicated in Figure 4, which leads to the formation of fragment 1 and meizothrombin (des fragment 1). Although meizothrombin and meizothrombin(des fragment 1) have an functional active site, they differ from thrombin in their reactivity with macromolecular substrates such as fibrinogen, factor $V$, platelets (92), and also ATIII. Because meizothrombin(des fragment 1) lacks the phospholipid-binding domain, it is not as good a substrate for prothrombinase as prothrombin is, hence it is considered a dead-end product. 


\begin{abstract}
THIS THESIS; CHAPTER 4
Prothrombin activation by prothrombinase in model reaction systems leads to the generation of thrombin and meizothrombin (des fragment 1). These products are present in a mixture of accessory components, non converted prothrombin and remnant prothrombin activation fragments. The heparin-catalyzed. ATIII-dependent inactivation of thrombin requires the formation of a ternary thrombin/ATII//heparin complex. In Chapter 4 a study is described in which the kinetics of inactivation of in situ prothrombinaseformed thrombin and meizothrombin(des fragment 1) are compared to those of purified thrombin. Our findings indicated that the ternary complex formation of heparin, ATII and generated thrombin is hampered in such a reaction mixture, and that ternary complex formation is virtually impossible with meizothrombin'des fragment 1).
\end{abstract}

\title{
REGULATION OF THROMBIN FORMATION
}

Thrombin is the most powerful trigger for hemostatic plug formation; it converts fibrinogen into fibrin, and it accelerates its own rate of formation, by the feedback activation of factor $\mathrm{V}$ and factor VIII, and by generating a procoagulant surface (platelet activation). Thrombin is also the physiological activator of factor XIII (93). Factor XIIla crosslinks tibrin, by catalyzing intermolecular isopeptide bond formation between polymerizing fibrin monomers (see Reference 94, and references therein). In addition to the strengthening of the fibrin clot, the crosslinking also increases the resistance of the clot to fibrinolysis. Thus, trace amounts of initially formed thrombin, leads to up-regulation of the blood coagulation system, resulting in the formation of a stable hemostatic plug.

In healthy individuals the coagulation system is very effectively controlled, and in the absence of any thrombogenic challange the balance clearly lies in favor of the negative regulation of this process (95). As the hemostatic process is dependent on the formation of surface-bound macromolecular complexes, consisting of a zymogen, a cofactor, and a converting enzyme, suppression of the hemostatic process can be achieved by inhibiting the macromolecular complexes, and the generation of their components. At present a number of natural controlling mechanisms have been identified. Although a number of them are not yet fully understood, basically, they can be divided in three types: masking of the phospholipid surfaces, destruction of the cofactors, inhibition of the enzymes.

Phospholipid Surface Masking-Recently a phospholipid-binding protein has been described (96). This protein $V A C \alpha$, or annexin $V$, which is found in endothelial cells, binds with high-affinity to procoagulant phospholipid surfaces (97), and inhibits the catalytic activity of these surfaces (98). The physiological role of $\mathrm{VAC} \alpha$ remains to be established. 
Cofactor Destruction- During in vivo coagulation, thrombin binds to thrombomodulin "an integral membrane protein located at the surface of endothelial celis (99). The thrombin-thrombomodulin complex rapidly activates the plasma protein, protein $\mathrm{C}$. Activated protein $\mathrm{C}$ complexes with plasma protein $\mathrm{S}$ on the surface of either platelets or the endothelium. These complexes catalyze the proteolytic inactivation of factor Va and factor VIIla (see Reference 100 for a review). In addition it has been reported that activated protein $\mathrm{C}$ can initiate fibrinolysis, which eventually will lead to the destruction of the fibrin clot (101).

During the last 5 years also a mechanism reguiating the activity of the factor Vla/tissue factor complex has been identified $(102,103)$. The lipoprotein-associated coagulation inhibitor (or extrinsic pathway inhibitor) forms, together with factor Xa formed during coagulation, in a $\mathrm{Ca}^{2+}$-dependent manner, a quaternary complex with factor VIla and tissue factor. Thus the complex formation traps (the limiting amount of) tissue factor, and terminates further activation of the coagulation system.

Enzyme Inhibition- Plasma contains a number of proteinase inhibitors, which inhibit the enzymes of the blood coagulation system: ATIII (factor XIla, factor Xla, factor IXa, factor Xa, thrombin), heparin cofactor II (thrombin), $\mathrm{Cl}$ inhibitor (kallikrein, factor XIla, factor Xla), $\alpha_{1}$-proteinase inhibitor (factor Xla, factor $\mathrm{Xa}$ ), and $\alpha_{2}$-macroglobulin (kallikrein, factor $\mathrm{Xa}$, thrombin). ATIII is considered to be the most important coagulation inhibitor, its main targets being thrombin and factor $\mathrm{Xa}$ (see Reference 104 for a complete overview).

Scavenging of thrombin can also be obtained by a binding to several structures on endothelial cells (105). If it binds by way of cell-bound heparan sulfates, its inactivation by ATIII is accelerated (106). If thrombin binds to thrombomodulin, resulting in protein $\mathrm{C}$ activation, loss of fibrinogen clotting activity, and platelet, factor $V$ and factor Vill activating activity occurs (99). Thrombin can also bind to an active site-dependent receptor, followed by internalization of the complex (105). Either way, by these mechanisms the activation of platelets, and the generation of factor Va and factor Villa is suppressed.

\section{THIS THESIS; CHAPTER 5, CHAPTER 6}

The heparin-catalyzed, ATIII-dependent inactivation of factor Xa could potentially contribute to the regulation of thrombin formation. In 1973, it was already recognized, that the accessory components of prothrombinase protect factor Xa from inactivation by ATIII (107). Therefore, we designed a study to investigate the kinetics of ATIII-dependent inhibition of factor $X_{a}$ under physiological conditions, i.e. during prothrombin activation (Chapter 5). Analysis of the experiments was based on a model in which the observed rate of thrombin formation was supposed to be the result of the 
rate of prothrombin activation (which was proportional to the factor Xa concentration) minus the rate of thrombin inactivation.

Published data on the ATIII-dependent inhibition of prothrombinase, catalyzed by heparins of different molecular size were conflicting, hence we extended the first work (Chapter 5), in the study described in Chapter 6, now using heparin fragments of variable size. In this paper we, following the reasoning of Chapter 5, described the thrombin generation curves as a time-dependent function of the initial rate of prothrombin activation, and the pseudo-first order rate constants of in situ inhibition of factor Xa and thrombin. This equation could be closely fitted to our experimental data.

From these studies we found that in the presence of both factor Va and phospholipid, factor Xa is protected from inactivation by ATIII both in the absence and presence of heparin. The extent of protection is independent on the heparin molecular size, and independent of the presence of prothrombin. In addition, we, in Chapter 6 , described a new phenomenon, namely that heparins with a molecular weight larger than 4,500 directly influence the initial rate of prothrombin activation by, most likely, the formation of the dissociable heparin/ATII/factor Xa complex.

\section{THE FUNCTIONING OF PROTHROMBINASE DURING CONTINUOUS FLOW}

The knowledge of the individual reactions of the blood coagulation system as described so far has all arrived from studies in static, closed systems. Blood, however, is a fluid flowing through the intravascular space. While the rheology of blood itself has been thoroughly investigated (see References 108,109), little is known about the progress of coagulation reactions occuring at a procoagulant surface during flow. Only recently, a first attempt was undertaken to describe the activation of factor $\mathrm{X}$ by membrane-bound tissue factor and factor VIla in an open, laminar flow system (110). An important conclusion of the work was that the kinetics of factor $X$ activation during flow cannot be extrapolated from static, closed systems.

\footnotetext{
THIS THESIS; ChAPTER 7, CHAPTER 8

By this we were challenged to design a study on the prothrombin activation by prothrombinase in a well-defined flow system (Chapter 7). A glass capillary was coated with phospholipid, perfused with factor Va and subsequently with factor $X a$ and prothrombin. The most remarkable finding was, that as long as factor Xa and prothrombin are present in the fluid
} 
phase, the prothrombinase remained assembled in a virtual irreversible manner.

A continuation of this study is described in Chapter 8 , where the inhibition of the surface-bound prothrombinase by ATIII/heparin was investigated during continuous flow. In this study, it was observed that, under conditions were free factor Xa has a half-life time of a few seconds, during continuous flow the inactivation of prothrombinase is markedly diminished. 


\section{The Effect of Sulfation on the Anticoagulant and Antithrombin III-binding Properties of a Heparin Fraction with low Affinity for Antithrombin III\$}

Heparin with low affinity for antithrombin III (ATIII) and devold of anticoagulant activity was chemically oversulfated and fractionated by affinity for ATIII. The oversulfated materlal showed ATIII-blnding properties, as monitored by Intrinsic fluorescence enhancement of ATIII. The fluorescence Increase was comparable to that of the ATIII high affinity fraction of native heparln. The estimated dissoclation constants, however, showed a 10 times weaker binding of the oversulfated material to ATIII, $K_{d}=6.4 \times 10^{-8}$ $M$, as compared to native heparin, $K_{d}=0.63 \times 10^{-8} \mathrm{M}$. Concomitant with the binding-Induced allosterlc change In ATIII, the oversulfated materlal stimulated the ATIII-thrombin and ATIII-factor Xa reactlons. The high affinlty fractions of natlve heparin and the sulfated materlall were almost equally effective In enhancing the rate of thrombln neutralization by ATIII. However, a 3 times faster rate of factor $X a$ Inactivation was found with the native high affinity materlal.

$\mathbf{H}_{\mathrm{e}}$ ine proteases of the blood coagulation system by the plasma protein antithrombin III (ATIII). It is, however, only about one-third of the molecules, present in commercial heparin preparations, which bind with high affinity to ATIII (HA heparin) and which are therefore responsible for the anticoagulant activity (1\%. 12). The ATIII-binding site, an unique pentasaccharide sequence, has been identified (20-22), and was shown to contain a 3-0 and a 6-0-sulfated glucosamine residue which are essential for the binding-induced conformational change in ATIII, intimately linked to the anticoagulant activity (23).

The biosynthesis of heparin involves, in order, the $\mathbb{N}$-sulfation of previously $\mathrm{N}$-deacetylated glucosamine units, C5-epimerization of D-glucuronic acid to Liduronic acid, and incorporation of $\mathrm{O}$-sulfate groups. It has been recognized that these reactions are generally incomplete, hence a portion of the saccharides will remain at lower levels of modification (see Reference 18, and references there-

\$ Schoen P, Wielders S, Petitou M, Lindhout T. Thromb Res 57:415-423, 1990 
in). This phenomenon is most likely the fundamental cause of the heterogeneity in aftinity for ATIII, present in commercial heparin.

By the use of chemical sulfation, chromatography on ATIII-Sepharose, fluorescence techniques, and determination of the kinetic constants of thrombin and factor Xa inactivation, we demonstrated in this work, that oversulfation of heparin with low affinity for ATill, generates a heparin species able to induce a conformational change in ATIII. Concomitant with the induction of this ATIII-binding. anti-thrombin and anti-factor Xa activities were shown to appear.

\section{EXPERIMENTAL PROCEDURES}

Protelns - Human thrombin was isolated and quantified as described (111). Human factor Xa was prepared from purified factor $X(112)$ and isolated as described for the bovine protein (1113). The molar concentration was determined by active site titration with PNPGB (114). Human ATIII was prepared as reported previously (115).

Heparins - Porcine mucosal heparin (UF heparin, lot 91820331, mean $M_{r}=12,700$ ) was from Institut Choay. Heparin fractions with How affinity (LA heparin, IC831436/lot 6160LP) and high aftinity (HA heparin, IC831435/lot 6158LP) for ATIII were obtained from UF heparin by aftinity chromatography on ATIII-Sepharose as described (12). Oversulfated low affinity heparin (sLA heparin, IC841545/lot BC13-162) was obtained by chemical sulfation. Briefly, LA heparin (50 mg) was converted into its tetrabutyl ammonium salt through passage on a Dowex $50-\mathrm{H}+$ column, followed by neutralization with tetrabutylammonium hydroxide. After lyophilization and drying, the product was dissolved in dimethylformamide $(3 \mathrm{ml})$ and sulfated at $0{ }^{\circ} \mathrm{C}$ lor two hours in the presence of pyridinesulfur trioxide complex $(190 \mathrm{mg})$. The $\mathrm{pH}$ was then adjusted to 10 with sodium hydroxide and the oversulfated material was obtained after dialysis and lyophilization. High (HA-sLA heparin, IC841545/lot BC13-162B; $8 \mathrm{mg}$ ) and low (LA-sLA heparin, IC841545/lot BC13-162A; 10 $\mathrm{mg}$ ) affinity fractions were obtained by fractionating part of the sLA heparin preparation on an ATIUI column (12). The sulfate and carboxyl contents of the heparin preparations were assessed by conductimetry (116).

Fluorescence Measurements - Fluorescence measurements were made with a SLMAminco SPF-500C spectrofluorometer at $25^{\circ} \mathrm{C}$. The functional heparin concentrations employed for equilibrium binding and kinetic studies were determined as ATIl-binding sites, by stoichiometric titration of a fixed concentration of ATIII (2.0 or $5.0 \mu \mathrm{M})$ in $50 \mathrm{mM} \mathrm{Tris}+\mathrm{HCl}(\mathrm{pH} 7.4), 100 \mathrm{mM} \mathrm{NaCl}$, and $0.1 \%$ polyethylene glycol 6000 as monitored by the intrinsic ATIll fluorescence enhancement at $\lambda_{\text {em }}=340 \mathrm{~nm}$ and $\lambda_{\text {ex }}=280 \mathrm{~nm}$. Equilibrium binding litrations of ATIll and heparin were performed by stepwise addition of theparin to a fixed concentration of ATIII (20 nM), and monitoring the fluorescence increase relative to the fluorescence determined in the absence of heparin $\left(F-F_{0}\right)$. The dissocialion constant $\left(K_{\mathrm{d}}\right)$ of the heparin-ATIII interaction, and the relative fluorescence increase at saturation $\left.\left(\left(F-F_{o}\right) / F_{o}\right)_{\text {max }}\right)$ were obtained from a fit of a quadratic binding function to the fluorescence data:

$$
F=\frac{\left(\left(F \cdot F_{0}\right) / F F_{0}\right)_{\max }\left\{\left(\left[A T_{0}+[H]_{0}+K_{0}\right)-\sqrt{ }\left(\left(\left[A T_{0}+[H]_{0}+K_{0}\right)^{2}-4[H]_{0}\left[A T_{0}\right)\right\}\right.\right.\right.}{2\left[A T_{0}\right.}
$$

where $[A T]_{b}$ and $[H]_{0}$ represent the lotal concentrations of ATIII and heparin (117). The $K_{d}$ and ( $F$ $\left.F_{0}\right) / F_{o} /$ max , and the corresponding SE values, were estimated by the computerized nonlinear least squares method according to Duggleby (118).

Inactivation of Thrombin and Factor $X a-$ The proteases (10 $\mathrm{nM})$ were inactivated by ATIII $(0.50 \mu \mathrm{M})$ in the presence of varying amounts of heparin, in $50 \mathrm{mM}$ Tris. HCl $(\mathrm{pH} 7.9), 175 \mathrm{mM}$ 
$\mathrm{NaCl}, 10 \mathrm{mM}$ EDTA, and $0.50 \mathrm{mg} \mathrm{HSAml} \mathrm{at} 37^{\circ} \mathrm{C}$. The chromogenic substrates 52238 and $\mathrm{S} 2337$ were used to determine residual thrombin and factor Xa activities, respectively. Pseudo-first order rate constants of inhibition were estimated as described previously (119).

\section{RESULTS}

Characterization of the Heparin Preparations - The concentrations of ATIll-binding material, in each of the heparin preparations used in this study, were determined by stoichiometric titration of a sufficiently thigh ATIll concentration, so as to result in an initially linear increase of fluorescence intensity with increasing amounts of heparin. Typical examples are shown in Figure 1. The intersections of the linear extrapolations were taken to calculate the functional ATIII-binding normality of heparin.
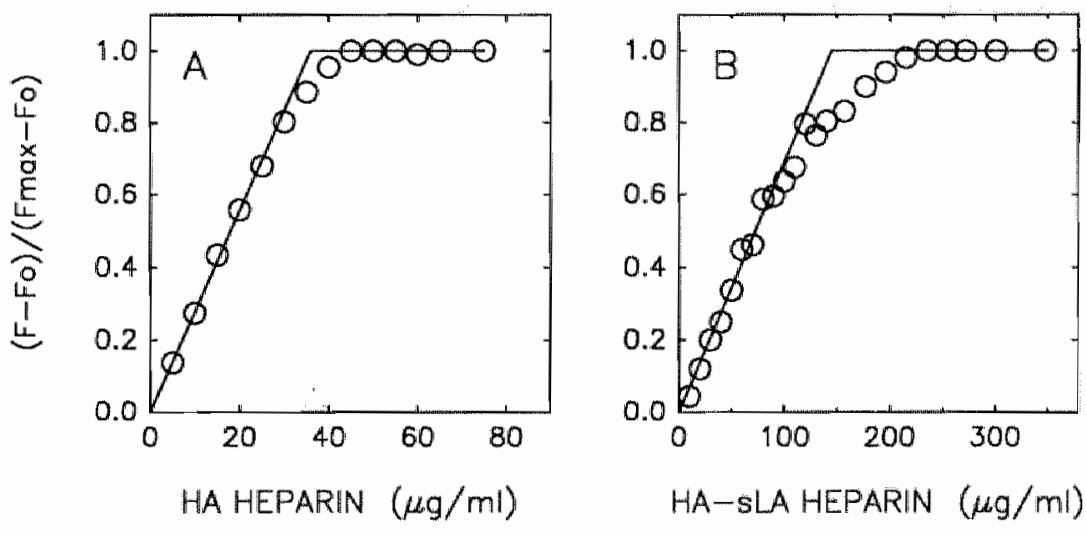

FIgure 1. Stoichiometric titration of ATIII as monitored by intrinsic fluorescence enhancement. $A$, titration of ATIII $(2.0 \mu \mathrm{M})$ with HA heparin, and B, titration of ATIII $(5.0 \mu \mathrm{M})$ with HA-sLA heparin.

UF heparin bound $2.6 \times 10^{-5} \mathrm{~mol}$ ATIII/g heparin. After ATIII-affinity fractionation the ATIII-binding material (HA heparin) bound $5.3 \times 10^{-5} \mathrm{~mol}$ ATIII/g. The remaining non-ATIII-binding material was sulfated (SLA heparin), which resulted in a heparin preparation which significantly bound ATIII $\left(2.2 \times 10^{-5} \mathrm{~mol}\right.$ ATIII/g). However, not all heparin molecules in the oversulfated preparation contained ATIII-binding sites. ATIII-affinity chromatography of SLA heparin resulted in a HA

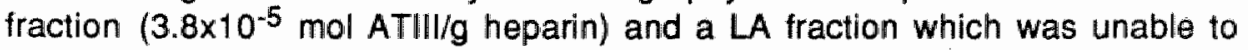
enhance intrinsic ATIII fluorescence up to a concentration of $1 \mathrm{mg} / \mathrm{ml}$.

Due to the sulfation procedure the sulfate (S) over carboxyl (C) ratio increased from 2.2 to 3.2 , and the HA and LA fractions had identical S/C ratio's 
as the non-fractionated preparations. Fractionation of the SLA heparin on ATIIISepharose showed that the sulfated material had chromatographic properties which were essentially indistinguishable from those of native heparin. In addition, the sulfation procedure and the fractionations by affinity for ATIII, did not influence the heparin molecular weight distributions, as monitored by HPLC.

The ATIII-Heparin Interaction as Monitored by Fluorescence Enhancement-Figure 2 depicts the enhancement of the intrinsic fluorescence of a low amount of ATIII (20 nM). A quadratic binding function, which assumes a 1:1 binding interaction, could be closely fitted to the experimental data points. The estimated $K_{d},\left(\left(F-F_{0}\right) / F_{o}\right)_{\text {max }}$ and their SE values are given in Table 1.
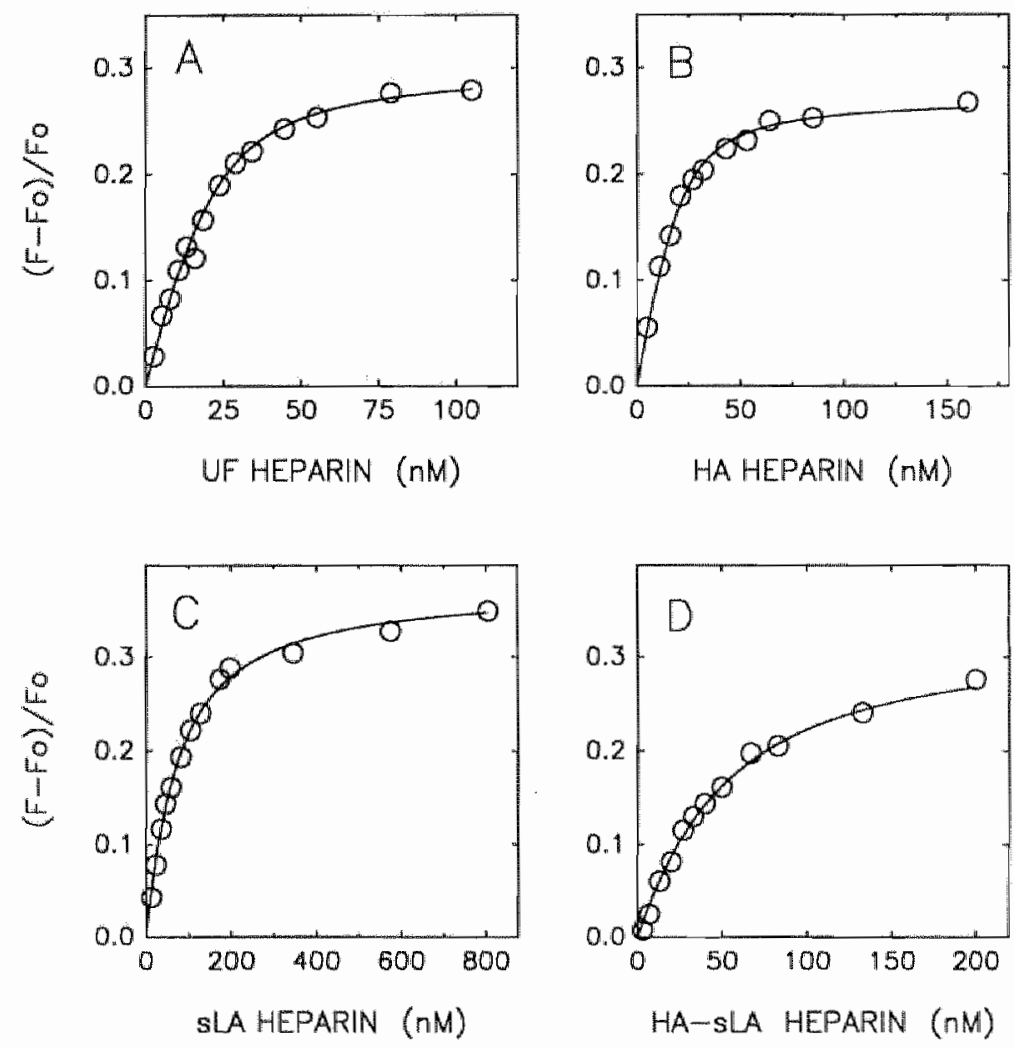

Figure 2. Equilibrium binding titration of ATIII as monitored by intrinsic fluorescence enhancement. A fixed amount of ATIII (20 nM was litrated with UF heparin (A), HA heparin (B), sLA heparin (C), or HA-SLA heparin (D). A quadratic binding function was fitted to the relative fluorescence increases $\left(\left(F-F_{0}\right) / F_{0}\right)$ and the results are indicated by the solid lines. Further experimental details are given under "Experimental Procedures". 
Table 1. Endpoints and dissociation constants determined from heparn titrations of ATII.

\begin{tabular}{lcr}
\hline Heparin & $\left.\left(\mathrm{F}-\mathrm{F}_{\mathrm{o}}\right) / \mathrm{F}_{\mathrm{o}}\right)_{\max }$ & \multicolumn{1}{c}{$\mathrm{K}_{\mathrm{d}}$} \\
\hline & & $(\mathrm{mM})$ \\
Unfractionated heparin & $0.300 \$$ & $6.3 \pm 0.8$ \\
HA heparin & 0.271 & $4.8 \pm 0.6$ \\
Sulfated LA heparin & 0.376 & $63.9 \pm 2.9$ \\
HA Sulfated LA heparin & 0.326 & $46.2 \pm 3.2$ \\
\hline
\end{tabular}

The SE values were smaller than $0.01 \%$ of the depicted relative fluorescence increases at saturation.

Our findings are that when low affinity heparin is oversulfated, ATIII-binding species are generated with a binding affinity of approximately $60 \mathrm{nM}$. The ATIII high affinity fraction of this heparin preparation (HA-sLA heparin) showed about the same binding affinity (approximately $50 \mathrm{nM}$ ). The ATIII-binding species present in the natural unfractionated heparin (HA heparin) bind with about a 10 times higher affinity $\left(K_{d}=5 \mathrm{nM}\right)$. The maximal intrinsic fluorescence change for the various heparin preparations varied around $30 \%$ which indicates that no significant differences in the conformation of ATIII exist when ATIII is complexed with the natural occurring heparin species or those obtained after oversulfation of the non-ATIll-binding moiety.

Acceleration of Factor $X a$ and Thrombin Inhibition- Rates of factor $\mathrm{Xa}$ and thrombin inhibition by ATIII were measured at varying heparin concentrations. For each heparin, except those with low affinity for ATIII, the pseudo-first order rate constants of inhibition of thrombin or factor $\mathrm{Xa}$ increased linearly with the heparin concentration. Table 2 summarizes the accelerating effects of the different heparins.

A comparison on weight basis, of the second order rate constants thus obtained, revealed marked differences. However, the apparent disparity between the rate constants of thrombin inhibition disappeared when the functional (ATIIIbinding) molar concentrations, as assessed by the stoichiometric titrations of ATIII (see Figure 1), were taken into account. Thus, the catalytic efficiency of HAsLA heparin in the ATIII/thrombin reaction appeared to be nearly the same as that of the HA fraction of natural occurring heparin. A 3-fold difference remained, however, between the native heparin and SLA heparin in their catalytic activity on factor $\mathrm{Xa}$ inactivation. 
Table 2. Abilfy of heparin to stimulate the inhibition of thrombin and factor Xa by ATIII. Rate constants of thrombin and factor Xa inhibition, per $\mu g$ heparin/ml $(k)$ or per molar functional heparin concentration $\left(\mathrm{k}^{*}\right)$, were determined as outlined under "Experimental Procedures". Errors represent the SE values of the estimates.

\begin{tabular}{lccccc}
\hline Heparin & \multicolumn{2}{c}{ Thrombin } & & \multicolumn{2}{c}{ Factor Xa } \\
\cline { 2 - 3 } \cline { 5 - 6 } & $\mathrm{k}$ & $10^{-8} \times \mathrm{k}^{*}$ & & $\mathrm{k}$ & $10^{-8} \times \mathrm{k}^{*}$ \\
\hline UF heparin & $12.5 \pm 1.1$ & $4.81 \pm 0.42$ & & $2.6 \pm 0.3$ & $1.05 \pm 0.09$ \\
HA heparin & $20.8 \pm 0.2$ & $3.96 \pm 0.04$ & & $4.1 \pm 0.5$ & $0.81 \pm 0.05$ \\
LA heparin & 0 & 0 & & 0 & 0 \\
SLA heparin & $5.7 \pm 0.3$ & $2.49 \pm 0.13$ & & $0.7 \pm 0.04$ & $0.30 \pm 0.02$ \\
HA-sLA heparin & $12.5 \pm 0.6$ & $3.25 \pm 0.20$ & & $1.4 \pm 0.05$ & $0.34 \pm 0.02$ \\
LA-SLA heparin & 0 & 0 & & 0 & 0 \\
\hline
\end{tabular}

\section{DISCUSSION}

It has been postulated that incomplete modifications of saccharides during the biosynthesis of heparin is the basis for the existence of polysaccharide sequences of different structure (18), and thus provides a reasonable explanation for the presence of non-ATIII-binding heparin molecules in commercial heparin. In addition, results on the enzymatic sulfation of a $\mathrm{O}$-desulfated octasaccharide have been reported, which suggest that, the 3-0-sulfation of the central glucosamine unit of the pentasaccharide sequence concludes the formation of the ATIII-binding region. Moreover the 6-O-sulfation of unit 1 was shown to be essential to the sulfation of unit $3(120)$.

Taking this together one can hypothesize that, at least part of, the low affinity heparin present in commercial heparin, has an incomplete ATIII-binding sequence because of the absence of the specific sulfate groups on unit 1 and 3 . Therefore we have investigated whether oversulfation of a heparin fraction unable to bind to ATIII, resulted in a polysaccharide able to 1] induce a conformational change in ATIII upon binding, and 2] accelerate the inhibition of factor $\mathrm{Xa}$ andior thrombin by ATIII.

Our study demonstrates, that when the sulfate content of LA heparin molecules was chemically increased from 2.2 to 3.2 sulfate groups per disaccharide unit, high affinity ATIII-binding sites were generated. Interaction between these newly generated binding sites and ATIII was established on basis of a $30 \%$ increase of ATIII intrinsic fluorescence. The binding affinity of the oversulfated material was about 10 times less when compared with native heparin. The overall $\mathrm{K}_{\mathrm{d}}$-values, calculated on basis of molarity of ATIII-binding heparin species in 
SLA heparin and UF heparin were $6.4 \times 10^{-8} \mathrm{M}$ and $0.63 \times 10^{-18} \mathrm{M}$, respectively. It can not be excluded that the abundant introduction of sulfate, disturbs secondary interactions of ATIII with heparin $(121,122)$, resulting in a 10 -fold higher $\mathrm{K}_{\mathrm{d}}$-value. These values are overall, because they apply for heparin saccharides from a range of molecular weights, which may not all have exactly the same affinity for ATIII. The molecular weight distributions of the heparin fractions however, are unaltered when compared to that of native heparin, so it seems appropriate to compare their $\mathrm{K}_{\mathrm{d}}$-values.

In addition, the affinities we found are in agreement with those reported for synthetic pentasaccharide heparin $\left(K_{d}=5 \times 10^{-8} \mathrm{M}\right)$ and the natural occurring octasaccharide fragment that contains the ATIII-binding sequence $\left(K_{d}=1 \times 10^{-8} \mathrm{M}\right)$ (123). The same authors also demonstrated that the loss of either the 6-O- or 3O-sulfated glucosamine residue resulted in a 40-50\% loss in binding energy $\left(K_{d}=5 \times 10^{-4} \mathrm{M}\right)$. Thus, taking these results together, it seems reasonable that $L A$ heparin indeed contains molecules which possess an incomplete pentasaccharide sequence, which specifically lacks sulfate substituted hydroxyl groups at 3-C and/or 6-C of glucosamine residues.

Further support for our notion that sulfation specifically alters the properties of LA heparin was obtained from protease inhibition experiments. Oversulfated LA heparin stimulated both thrombin and factor Xa inhibition. However, whereas thrombin inhibition was stimulated to almost the same extent as in the presence of native heparin, the ATIII/factor Xa reaction was less stimulated. It has been described that the heparin-thrombin interaction plays an extremely important role in the kinetics of inactivation of thrombin and that the so-called approximation effect plays a very small role in the kinetics of inactivation of factor $\mathrm{Xa}$ (34). Hence, the apparent lesser quality of the interaction between ATIII and SLA heparin we observed, could be masked by the important contribution of the heparin-thrombin interaction to the inhibition of this enzyme, whereas such an effect will not be seen for the inactivation of factor $\mathrm{Xa}$.

Acknowledgement-We wish to thank. Dr. Maman for providing the heparin fractions with low and high affinity for ATIII. 
Low Molecular Weight Heparin-catalyzed Inactivation of Factor $\mathrm{Xa}$ and Thrombin by Antithrombin III. Effect of Platelet Factor $4 \$$

Low molecular weight (LMW) heparin preparations have unknown distrlbutions of ATII-binding material, so mean molecular weights as such might bear little information on their anti-factor $X a$ and antl-thrombin activitles, and on the neutralization of these activitles by platelet factor 4 (PF4). These properties were Investigated in pure systems with protelns of human origin. Pseudo-first order rate constants of Inactlvation of factor $\mathrm{Xa}$ and thrombin by antithrombin III were determined as function of heparin concentration, in the presence of $4.0 \mathrm{mM} \mathrm{CaCl}{ }_{2}$. Despite a large variation in the mean molecular weights, the ratlos of the antl-factor $X a$ over the antithrombin activitles were essentlally the same for the $4^{\text {th }}$ International Stan-dard for heparin $(0.46)$, the $1^{\text {st }}$ International Standard for LMW heparin (0.32), CY216 $(0.42)$ and enoxaparln (0.50). The uitra LMW heparin CY222 had only a 2 times higher ratlo (0.98). Analysis of CY216 subfractlons, obtalned by gel flltration, showed that the heparin molecules of the upper region of the molecular weight distribution are responsible for the antl-thrombln, but also to a large extent for the antl-factor Xa activitles. The results indicate that depolymerization of unfractionated heparin does not result in an increased antl-factor Xa/antl-thrombin ratio, because in the presence of $\mathrm{Ca}^{2+}$-Ions the rate constants of inactivation of factor $\mathrm{Xa}$ are lowered as compared to those of native heparln. PF4-dependent neutralization of anti-factor $\mathrm{Xa}$ and anti-thrombin activitles of fixed concentratlons of the LMW heparins was studled by measuring rate constants as function of PF4 concentration. All antl-thrombin and $50 \%$ of the antl-factor $X a$ activitles were readily neutralized. Excess PF4 was required to neutralize another $35-50 \%$ of the antl-factor Xa actlvities. At PF4 levels obtained at maximal release of the content of platelet $\alpha$-granules, all antl-thrombin and most $(285 \%)$ of the antl-factor $X a$ activitles can be neutrallized.

Schoen P, Lindhout T, Franssen J, Hemker HC. Thromb Haemostas (in press), 1991 
U nfractionated (UF) and low molecular weight (LMW) heparins inhibit blood coagulation by potentiating the anti-protease activity of antithrombin III (ATIII) (10). Studies on the structure-function relationship of heparin demonstrated that its anti-factor Xa activity depends on the presence of the specific ATIIIbinding pentasaccharide domain (see Reference 16 for a review). The sole binding of heparin to ATIII, however, is not sufficient for catalysis of thrombin inactivation; this process also depends on the simultaneous binding of thrombin $(35,36)$. The smallest heparin fragment with a noticeable anti-thrombin activity is an octadecasaccharide (124-126). Studies, utilizing heparin fractions with high affinity for ATIII obtained by gel filtration and affinity chromatography on matrixbound ATIII, have indicated that as the molecular weights of heparin fractions decrease from 10,000 to 2,000 the anti-thrombin activities vanish, while the antifactor Xa activities diminish much less rapid.

LMW heparin preparations, as obtained by depolymerization of native heparin, largely consist of molecules with a length of 18 saccharides and less (52). The lesser ability of these short heparin chains to enhance thrombin inhibition has been thought to explain the decreased ability of LMW heparin preparations to prolong the clotting time of global coagulation tests like the APTT. LMW heparins, now clinically used or intended to be used so, encompass heparin chains in a vast range of molecular weights. In addition to information about the mollecular weight distribution of a particular LMW heparin preparation, it is of paramount importance to know the distribution of the heparin chains with affinity for ATIII. This is especially important, because the LMW heparins available at present are prepared using a variety of fragmentation methods, which is an important source for an increase of the inhomogeneity present in UF heparin (52). For instance, certain depolymerization methods (especially the nitrous acid hydrolysis) will also result in cleavage of ATIII-binding sites, which ultimately leads to nonrandom distribution of ATIII-high affinity saccharides throughout the molecular weight distribution profiles of LMW heparins.

Surprisingly, in spite of an extensive research for biological differences between different LMW heparin preparations, the distribution of the ATIII-binding oligosaccharides has not been evaluated. Moreover, anti-protease specific activities of (LMW) heparin preparations are still determined under rather aphysiological conditions: bovine factor $\mathrm{Xa}$ or thrombin in a citrated plasma milieu. At present it has to be realized that the anti-factor $X a$ and anti-thrombin activities of heparin are influenced by free $\mathrm{Ca}^{2+}$-ions. The extent to which the kinetics of inhibition of the proteases are affected by $\mathrm{Ca}^{2+}$ depends on the nature (factor $\mathrm{Xa}$ or thrombin) and origin (bovine or human) of the protease, and on structural features of the heparin species (chain length) $(119,127,128)$.

Differences between LMW heparin preparations, regarding their molecular weight profiles and the distribution patterns of their ATIII-high affinity saccharides, might have consequences for their overall anticoagulant activities, and may 
influence their overall sensitivities towards neutralization by heparin-binding proteins, like platelet factor 4 (PF4). From the work of Lane et al (35) it is known that the anti-thrombin and anti-factor Xa activities of heparin molecules with 18 or more monosaccharide units can be completely neutralized by PF4. However, as the heparin chain lengths decrease from 18 to 8 saccharides, increasing amounts of anti-factor $\mathrm{Xa}$ activity resist neutralization. The platelet protein PF4, stored in the $\alpha$-granules, consists of 4 identical subunits, each containing a heparin binding site (67). A strong non-specific electrostatic interaction has been reported between $\mathrm{PF} 4$ and heparin molecules with a chain length of 16 saccharides and more (68).

Thus, mean molecular weights as such, might actually have no predictive value for the anti-thrombin and anti-factor Xa specific activities of LMW heparins, and their neutralization by heparin-binding proteins like PF4. This provoked us to initiate a reinvestigation of these properties in well-defined buffer systems, utilizing LMW heparin preparations which are at present intended for clinical use and standardization.

\section{EXPERIMENTAL PROCEDURES}

Proteins - Human PF4 was purified by affinity chromatography on heparin-Sepharose (129). Briefly, outdated platelet concentrates were pooled, and the platelets were lysed by the addition of Triton $\times 100$ to a final concentration of $1 \%$. The suspension was healed at $56{ }^{\circ} \mathrm{C}$ for 45 min and centrifuged at $10,000 \times \mathrm{xg}$ for $30 \mathrm{~min}$ at $4^{\circ} \mathrm{C}$. Solid ammonium sulfate was added to the conlinuously stirred supernatant, to a final concentration of $40 \%$. After centrifugation, supernatant was collected and extensively dialysed against $50 \mathrm{mM}$ Tris- $\mathrm{HCl}(\mathrm{pH} 7.5)$ containing $0.50 \mathrm{M} \mathrm{NaCl}$. The material was applied to a heparin-Sepharose column (Pharmacia, Uppsala, Sweden) equilibrated in the same buffer. A linear sall gradient, from 0.50 to $2.0 \mathrm{M} \mathrm{NaCl}$ in $50 \mathrm{mM}$ Tris-HCl (pH 7.5), was applied and $\mathrm{PF} 4$, assessed by its anti-heparin activity, eluted at about $1.5 \mathrm{M} \mathrm{NaCl}$. The fractions with the highest PF4 activity were pooled, extensively dialysed against $50 \mathrm{mM}$ Tris-HCl $(\mathrm{pH} 8.0)$ containing $0.40 \mathrm{M} \mathrm{NaCl}$, and stored at $-70^{\circ} \mathrm{C}$. The preparation was neither contaminated with heparin nor with ATIII. The molar concentration was assessed utilizing $E_{1 \%}=2.9$ at a wavellength of $280 \mathrm{~nm}(130)$, and a molecular weight of $31_{1} 200$ for the PF4 tetramer.

Human factor $\mathrm{Xa}$ and human ATIII were prepared as reported previously (131). Thrombin was isolated, by chromatography of prothrombinase activated human prothrombin (132) on sulfopropyl* Sephadex (Pharmacia, Uppsala, Sweden) at $\mathrm{pH} \mathrm{7.4} \mathrm{(133).} \mathrm{The} \mathrm{molar} \mathrm{concentrations} \mathrm{of} \mathrm{the} \mathrm{factor} \mathrm{Xa}$ and thrombin preparations were determined by active site titration with pNPGB $(114,134)$. The molar concentration of ATHI was determined by titration with known amounts of factor Xa. The factor $\mathrm{Xa}$, thrombin and ATIII preparations were stored in $50 \mathrm{mM} \mathrm{Tris}-\mathrm{HCl}$ ( $\mathrm{pH} 7.9$ ) containing $175 \mathrm{mM} \mathrm{NaCl}$, at $-70^{\circ} \mathrm{C}$.

Heparins - The $4^{\text {th }}$ International Standard for heparin (UF standard heparin) and the $1^{\text {st }}$ International Standard for LMW heparin (LMW standard heparin) were a kind gift of Dr. T.W. Barrowcliffe from the National Institute for Biological Standards and Control (Potters Bar, United Kingdom). The LMW heparin preparations CY216 (batch P $795 \times \mathrm{HH}$ ) and CY222 (batch P 227 WH) were from Sanofi Recherche (Paris, France), and enoxaparin (PK10169) was obtained from RhônePoulenc (Gennevilliers, France). At the laboratory of Sanofi Recherche, CY216 was subjected to molecular weight fractionation by gel fittration, and the molecular weight distribution patterns of the 
obtained tractions ware established by (HPLC) gel permeation chromatography (135). Concentrations of ATIli binding material present in the heparin preparations, were determined by stoichiometric titration of ATIII as monitored by intrinsic fluorescence enhancement (131). The available molecular weight data of all heparn preparations used are given in Table 1.

Table 1. The mean molecular weights, and molecular weight distributions of the UF and LMW heparins used in the study.

\begin{tabular}{|c|c|c|c|c|c|}
\hline \multirow[t]{2}{*}{ Heparim } & \multirow[t]{2}{*}{ Mean $M_{r}$} & \multicolumn{4}{|c|}{$M_{1}$ Distribution } \\
\hline & & $<2,500$ & $>7,500$ & $M_{r}<9$ & $5 \%<M_{r}$ \\
\hline & & $(\%)$ & $(\%)$ & & \\
\hline UF standard heparin" & 12,500 & 0.5 & 86 & & \\
\hline LMW stuandard heparin & 6,400 & 4 & 24 & & \\
\hline $4 \times 2+6^{2}$ & 5,100 & 5 & 9 & 2,300 & 9,400 \\
\hline CY216 MMW rraction ${ }^{2}$ & 7,900 & 0.5 & 64 & 6,100 & 11,200 \\
\hline Cr216 LMW fraction ${ }^{2}$ & 4,400 & 0.5 & 0 & 3,300 & 5,500 \\
\hline Cr216 ultra LMW Iraction ${ }^{2}$ & 3,100 & 24 & 0 & 1,800 & 4.500 \\
\hline enoxaparin (PK10169) & 3,800 & 14 & 23 & & \\
\hline$C Y 222^{2}$ & 3,800 & 24 & 2 & 2,700 & 9,000 \\
\hline
\end{tabular}

1 See Reference 10

2 Welght average, and distribution provided by Sanofi Recherche

Inactivation of Factor $\mathrm{Xa}$ and Thrombin- The heparin-catalyzed inactivations of factor Xa and thrombin by ATIII were studied under pseudo-first order conditions. Either of the enzymes was added to a mixture of ATIII and heparin in $50 \mathrm{mmM}$ Tris-HCl (pH 7.9) containing $175 \mathrm{mM}$ $\mathrm{NaCl}, 4.0 \mathrm{mM} \mathrm{CaCl} 2$ and $0.5 \mathrm{mg} \mathrm{HSA} / \mathrm{ml}$ at $37^{\circ} \mathrm{C}$. The initial concentrations were $30 \mathrm{nM}$ factor Xa or thrombin and $400 \mathrm{nM}$ ATIII. The heparin concentrations were variable. After 2 min (lactor Xa) or 30 sec (thrombin) residual enzyme concentrations were determined by transferring $20 \mu$ samples to cuvettes containing $0.48 \mathrm{ml}$ of $50 \mathrm{mM}$ Tris-HCl (pH 7.9), $175 \mathrm{mM} \mathrm{NaCl}, 20 \mathrm{mM}$ EDTA, $0.5 \mathrm{mg} / \mathrm{ml}$ HSA and $0.22 \mathrm{mM}$ of the appropriate chromogenic substrate (factor Xa: $\$ 2337$; thrombin: $\mathrm{S2238}$ ).

The rates of absorbance increase were measured on a thermostated $\left(37^{\circ} \mathrm{C}\right)$ dual wavelength spectrophotometer at $405 \mathrm{~nm}$ (reference wavelength: $500 \mathrm{~nm}$ ). From the residual factor Xa and thrombin concentrations the pseudo-first order rate constants were determined. The inactivation reactions were shown to follow pseudo-first order kinetics up to at least a $90 \%$ inhibition of the initial enzymatic activities. Under the conditions used, i.e. ATIII concentrations in excess over the heparin concentrations, and larger than the dissociation constant of the interaction between heparin and ATIII, essentially all heparin molecules containing the ATIII-binding region are complexed with ATIII (119). Theretore, the pseudo-first order rate constants increase linearly with increasing heparin concentrations. The heparin-dependent increase of the rate constants, the antifactor Xa and anti-thrombin specific catalytic activities, were estimated by linear regression analysis.

Neutralization of Heparin Activity by PF4 - The heparin-catalyzed ATIII-dependent inactiva-tion of factor $X a$ or thrombin was studied in the presence of variable PF 4 concentrations. Pseudo-first order rate constants in the presence of $\mathrm{PF} 4\left(k_{\mathrm{obs}}\right)$ were determined as outlined above. From these values we calculated the extents of neutralization $(\%)$ of the anti-protease activities as follows:

NEUTAALIZATION $=\left(k-k_{\text {obs }}\right) /\left(k \cdot k_{0}\right) \times 100 \%$ 
where $\mathrm{k}$ is the pseudo-first order rate constant obtained in the absence of $\mathrm{PF} 4$, and $\mathrm{k}_{0}$ is the pseudo-first order rate constant obtained in the abserice of heparin.

\section{RESULTS}

\section{UF and LMW Heparin Catalyzed Inactivation of Factor Xa and} Thrombin by ATIII- The pseudo-first order rate constants of inhibition of factor $\mathrm{Xa}$ and thrombin as function of UF standard heparin concentrations, are shown in Figure 1. In addition, Figure 1 also illustrates the effect of $\mathrm{Ca}^{2+}$-ions on the heparin-dependent inhibition of thrombin and factor $\mathrm{Xa}$. Linear regression analysis of the data obtained in the presence of $4.0 \mathrm{~mm} \mathrm{CaCl}_{2}$ gave an anti-factor $X a$ specific catalytic activity of $9.8 \pm 0.4$ (SE) $\min ^{-1}(\mu \mathrm{g} \text { UF heparin } / \mathrm{m} /)^{-1}$ and an antithrombin specific catalytic activity of $21.2 \pm 1.8$ (SE) $\mathrm{min}^{-1}\left(\mu \mathrm{g}\right.$ UF heparin $/ \mathrm{ml}^{-1}$. The anti-factor $\mathrm{Xa}$ and anti-thrombin specific activities in the absence of $\mathrm{CaCl}_{2}$ were $4.1 \pm 0.2$ (SE) and $44.6 \pm 3.8$ (SE) $\mathrm{min}^{-1}(\mu \mathrm{g} \text { UF heparin } / \mathrm{ml})^{-1}$, respectively.
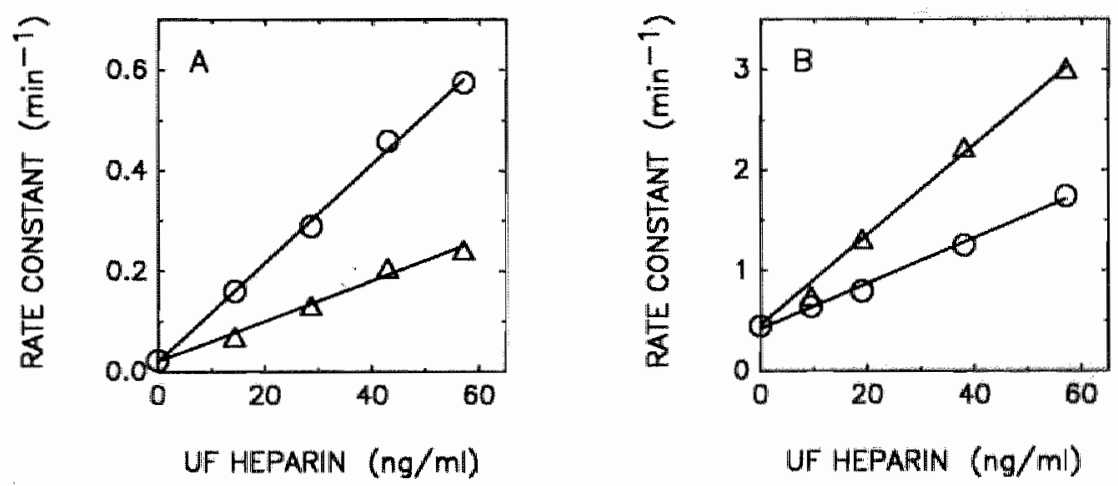

Figure 1. Rate constants of factor $X a$ and thrombin inactivation as function of the concentration of UF standard heparin. $30 \mathrm{nM}$ Factor Xa (panell A) or thrombin (panel B) was added to ATIII (400 nM) and heparin, either in the presence of $4.0 \mathrm{mM} \mathrm{CaCl}_{2}(\mathrm{O})$ or in absence of $\mathrm{CaCl}_{2}(\Delta)$. Rate conslants were determined as outlined under "Experimental Procedures". Solid lines were obtained by linear regression analysis of the data.

When the same determinations were performed at a higher ATIII concentration $(1.0 \mu \mathrm{M})$, the very same values were obtained, indicating that $0.40 \mu \mathrm{M}$ ATIII was sufficient high as to saturate all the ATIII-binding sites of heparin present (data not shown). Because of the stimulating effect of $\mathrm{Ca}^{2+}$-ions on the UF heparin-catalyzed inhibition of factor $\mathrm{Xa}$ and its negative effect on the inhibition 
of thrombin, all further experiments were performed in the presence of $4 \mathrm{~mm}$ $\mathrm{CaCl}_{2}$

The anti-factor Xa and anti-thrombin specific catalytic activities of a selecton of LMW heparin preparations were determined in the same way, and are depicted in Table 2. The data show that, concomitant with the decrease of mean molecular weights, both the anti-thrombin and anti-factor Xa catalytic activities decrease. Hence, except for CY222, the heparins tested, have rather invariable anti-factor $\mathrm{Xa}$ anti-thrombin specific activity ratios. They were found to vary between 0.3 and 0.5 . The ultra LMW heparin CY222 which, on a weight basis, consists for almost a quarter of saccharides with $M_{r}<2,500$ (Table 1), has the lowest specific catalytic activities, and deviates from the other heparin preparations, in that it has a significant higher anti-factor Xa over anti-thrombin ratio of 1.

Table 2. Anti-factor Xa (a-Xa) and anti-thrombin (a-lla) specific catalytic activities of UF and $L M W$ heparins. Errors represent SE of estimates.

\begin{tabular}{lcccc}
\hline Heparin & ATIII-Binding & \multicolumn{3}{c}{ Catalytic Activity } \\
\cline { 3 - 5 } & Capacity & a-Xa & a-lla & a-Xa/a-lla \\
\hline & nmol/mg & $\min ^{-1}(\mu \mathrm{g} / \mathrm{ml})^{-1}$ & \\
UF standard heparin & 29 & $9.8 \pm 0.4$ & $21.2 \pm 1.8$ & 0.46 \\
LMW standard heparin & 43 & $2.8 \pm 0.2$ & $8.7 \pm 0.4$ & 0.32 \\
CY216 & 48 & $1.5 \pm 0.1$ & $3.6 \pm 0.1$ & 0.42 \\
enoxaparin & 29 & $1.4 \pm 0.05$ & $2.8 \pm 0.1$ & 0.50 \\
CY222 & 41 & $0.44 \pm 0.02$ & $0.45 \pm 0.01$ & 0.98 \\
\hline
\end{tabular}

Thus, although the different LMW heparin preparations include significant amounts of molecules consisting of 18 saccharide units and less $\left(M_{r}<5,400\right)$, the preparations show a striking similarity with respect to their anti-factor $\mathrm{Xa}$ over anti-thrombin activity ratios.

Molecular Weight Fractionation of CY216- The fact that the anti-factor Xa specific activities decrease in conjunction with the anti-thrombin activities, with decreasing molecular weight as demonstrated in this study (Table 2) was somewhat unexpected. Besides a diminishing effect of $\mathrm{Ca}^{2+}$-ions on the inhibition of factor $\mathrm{Xa}$ when heparins are used with decreasing molecular weights $(119,127)$, the anti-factor Xa specific activities will also be influenced by the actual distribution of saccharides with high affinity for ATIII. We therefore investigated the distribution of the anti-factor $\mathrm{Xa}$ and anti-thrombin activities, and of the ATIII-high affinity heparin species, of one of the LMW heparin preparations (CY216), over its range of molecular weights. To this end, fractions obtained by 
gel filtration were studied. The mean molecular weights and molecular weight distributions of the obtained medium molecular weight (MMW), LMW, and ultra LMW fractions are given in Table 1. The anti-factor Xa and anti-thrombin catalytic activities as well as the ATIII-binding capacities of the three fractions, and of CY216 are given in Table 3.

Table 3. Anti-factor Xa (a*Xa) and anti-thrombin (a-lla) specific catalytic activities of subfractions of CY216. Errors represent SE of estimates.

\begin{tabular}{lcccc}
\hline Heparin & $\begin{array}{c}\text { ATIII-Binding } \\
\text { Capacity }\end{array}$ & \multicolumn{4}{c}{ Catalytic Activity } \\
\cline { 3 - 5 } & nmol/mg & $\mathrm{min}^{-1}(\mu \mathrm{g} / \mathrm{ml})^{-1}$ & a-Xa/a- \\
& 48 & $1.5 \pm 0.1$ & $3.6 \pm 0.1$ & 0.42 \\
CY216 & 68 & $3.9 \pm 0.2$ & $20.3 \pm 0.4$ & 0.19 \\
MMW fraction & 49 & $1.0 \pm 0.03$ & $0.03 \pm 0.01$ & 33.3 \\
LMW fraction & 20 & $0.3 \pm 0.05$ & 0 & $\infty$ \\
ultra LMW fraction & & & &
\end{tabular}

It is seen that, on a weight basis, the ATIII-binding capacities of the fractions decrease with decreasing mean molecular weights. We want to note here, that calculations on molar basis will not be realistic because of the dispersion of the ATIII-binding species in a certain fraction. However, a decrease of the ATIII-binding molarities with the decrease of the mean molecular weights of the fractions is evident. As a consequence of the decreased ATlll-binding capacities both the anti-factor $\mathrm{Xa}$ and anti-thrombin catalytic activities of the fractions will decrease with decreasing molecular weights. The more dramatic reduction of the antithrombin catalytic activity is the result of an abolished interaction between thrombin and heparin, due to the decreasing heparin chain lengths. As a result, the anti-factor Xa over anti-thrombin ratios of the fractions increase with decreasing mean molecular weights.

So far the data have clearly demonstrated a marked dispersion within a typical LMW heparin with respect to heparin species with different activities. The important question that remains to be answered, is whether or not the anticoagulant characteristics of a LMW heparin preparation are to be found in a particular subfraction. Regarding the anti-thrombin activity of CY216 it is clear that this activity is exclusively found in the fraction that contains heparin chains with a molecular weight between 6,100 and 11,200 (CY216 MMW traction, mean molecular weight 7,900 ). The anti-factor Xa activity is present in all heparin fractions. However, on weight basis, the MMW fraction has the highest specific activity. The data thus suggest that the distribution of the anticoagulant heparin molecules in 
the entire preparation could be shifted to the region of the higher molecular weights of the overall molecular weight distribution pattern. Because the relative proportions of the higher and lower molecular weight components do not differ significantly (52), we conclude that the average apparent molecular weight of the heparin species which contribute to the total anticoagulant activity of CY216, is significantly higher than the average apparent molecular weight $(5,100)$ of the complete CY216 preparation.

Neutrallzation of Anti-Factor $X a$ and Anti-Thrombin Activities of UF and LMW Standard Heparin by Platelet Factor 4- Fixed concentrations of UF and LMW standard heparin were titrated with PF4, and the extent of neutralization of the anti-factor $\mathrm{Xa}$ and anti-thrombin activities were determined as outlined under "Experimental Procedures". Typical neutralization curves are shown in Figure 2.

As expected for UF heparin, both the anti-factor Xa and anti-thrombin activities were readily neutralized (Figure $2 \mathrm{~A}$ ). The sharpness of the inflection points of the neutralization curves suggest a high affinity interaction between PF4 and the heparin molecules with these anti-protease activities. Because of this sharp transition, the inflection points, obtained from neutralization experiments at varying heparin concentrations, were taken as measure for the PF4-binding normality of UF standard heparin. A replot of these values against the heparin concentrations is depicted in Figure 3. From the slope, estimated by linear regression analysis, it follows that the anti-factor $X \mathrm{a}$ and anti-thrombin activities of $1 \mathrm{mg}$ of UF standard heparin are abolished by $91 \pm 2 \mathrm{nmol}$ PF4. From stoichiometric titrations of ATIII (see "Experimental Procedures"), it followed that $1 \mathrm{mg}$ of UF standard heparin was equivalent to $29 \mathrm{nmol}$ of ATIII-binding material. That a 3 times higher PF4binding normality was found, than could be expected on basis of the molar concentration of ATIII-binding heparin species can be readily explained. Although only about one-third of UF heparin binds to ATIII $(11,12)$, still UF standard heparin is largely ( $>95 \%$ ) composed of heparin molecules containing 18 saccharide residues or more, therefore each heparin molecule can bind with high affinity to PF4, irrespective of whether it contains the ATIII-binding pentasaccharide region or not $(68)$.

Typical curves of the neutralization of the anti-thrombin and anti-factor Xa activities of the LMW standard heparin are shown in Figure 2B. It is seen, that both the anti-thrombin and anti-factor $X a$ activities can be completely abolished, although the neutralization of anti-factor $\mathrm{Xa}$ activity requires somewhat higher amounts of PF4. 

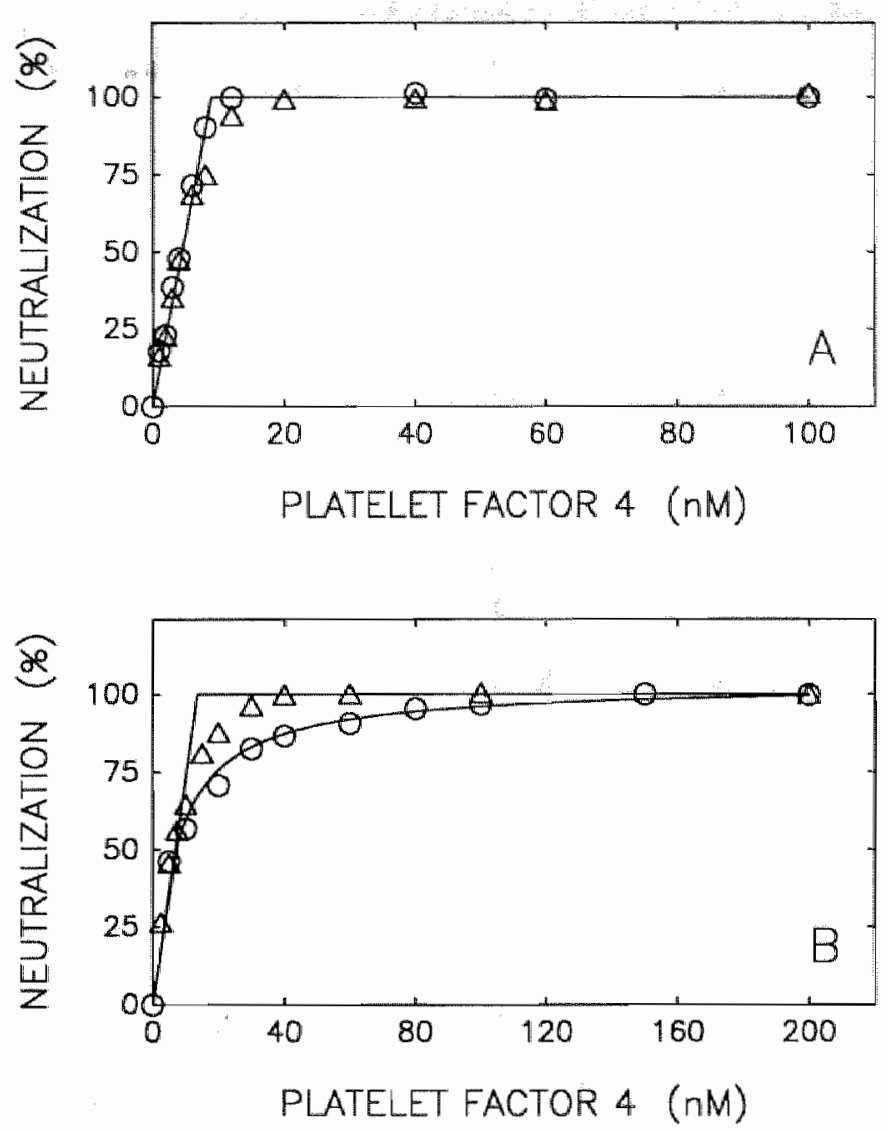

Flgure 2. Neutralizalion of UF and LMW standard heparin by PF4. Pseudo-first order rate constants of inacilivation of $30 \mathrm{nM}$ factor $\mathrm{Xa}(O)$ or $30 \mathrm{nM}$ thrombin $(A)$ by $400 \mathrm{nM}$ ATIII were deterinined in the presence of $100 \mathrm{ng} / \mathrm{ml}$ UF slandard heparin (panel A) or $320 \mathrm{ng} / \mathrm{ml}$ LMW standard heparin (panel B), and variable concentrations of PF4. Neutralization of the anti-protease activities was assessed as described under "Expenimental Procedures". Solid lines are linear approximations of the data.

The intersections of the linear extrapolations of the anti-thrombin neutralization curves, obtained at varying LMW standard heparin concentrations, were replotted (Figure 3). From the slope, estimated by linear regression analysis, it follows that the anti-thrombin activity of $1 \mathrm{mg}$ of LMW standard heparin is abolished by an equivalent amount of $43 \pm 1 \mathrm{nmol} P F 4$. On basis of a mean molecular weight of 6,400 (Table 1), $1 \mathrm{mg}$ of LMW standard heparin is estimated to correspond to about $160 \mathrm{nmol}$ of material. Thus, in contrast with UF standard heparin, 
only a small fraction of LMW standard heparin (approximately $25 \mathrm{~mol} \%$ ) has a high affinity for PF4. The molar concentration of the ATIll-binding species, as determined by the intrinsic fluorescence enhancement (see "Experimental Procedures"), was 43 nmol per $\mathrm{mg}$ LMW standard heparin. Evidently, part of the ATIll-binding saccharides have a lower affinity for PF4, which is (also) demonstrated by the more hyperbolic nature of the neutralization curves of the antifactor Xa activities (Figure 2B).

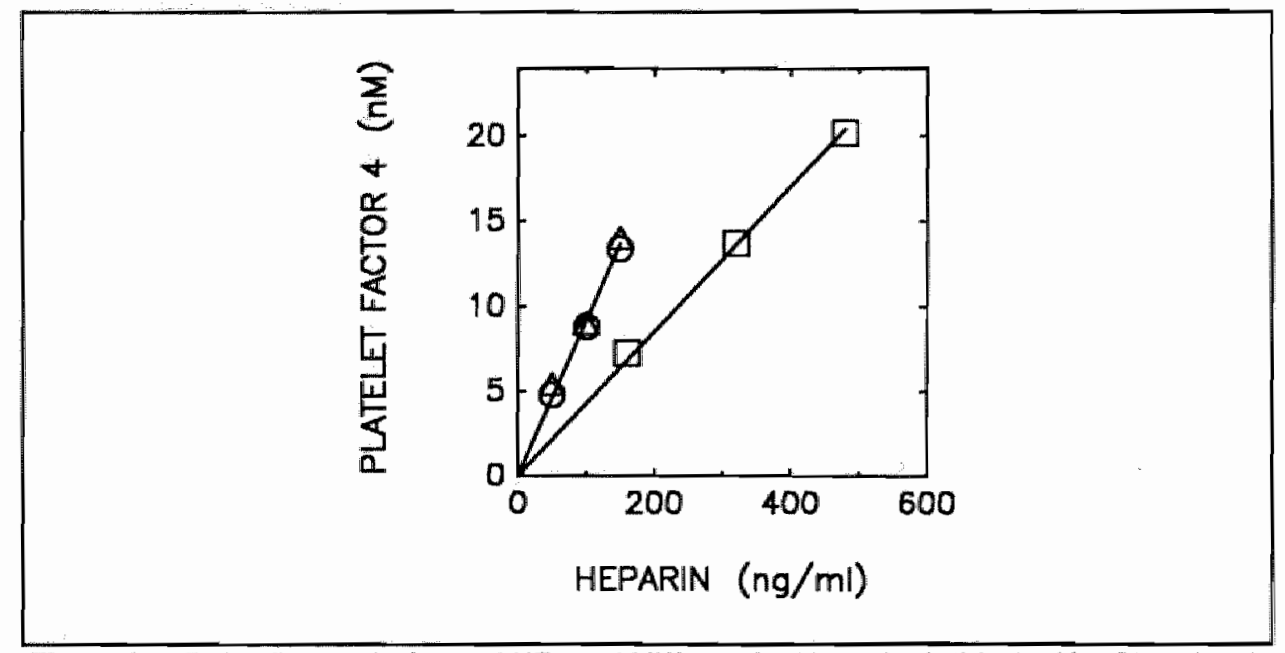

Flgure 3. PF4-binding equivalents of UF and $L M W$ standard heparin. Anti-factor $X a(O)$ and antithrombin $(\Delta)$ activities of variable concentrations of UF standard heparin, and anti-thrombin activities (C) of variable concentrations of LMW standard heparin were titrated with PF4, as in Figure 2. intersections of the linear extrapolations are shown as function of the heparin concentrations. Solid lines were obtained by linear regression analysis.

\section{Neutralization of Anti-Factor $\mathrm{Xa}$ and Anti-Thrombin Activities of} CY216, Enoxaparin, and CY222- Fixed amounts of CY216, enoxaparin, and CY222 were titrated with PF4. Neutralization of the anti-protease activities is shown in Figure 4 as function of PF4 concentrations. The heparin concentrations employed corresponded to $100 \mathrm{nM}$, as calculated from the weight amounts and the mean molecular weights depicted in Table 1. It is seen that the anti-thrombin activity of each LMW heparin is completely, and with high affinity, abrogated by low amounts of PF4. On basis of the intersections of the linear extrapolations, and utilizing their mean molecular weights, it can be calculated that CY216, enoxaparin, and CY222 contain about $10 \mathrm{~mol} \%, 7 \mathrm{~mol} \%$, and $5 \mathrm{~mol} \%$ material, respectively, which binds to PF4 with high affinity.

Neutralization of the anti-factor $\mathrm{Xa}$ activities of $\mathrm{CY} 216$, enoxaparin and CY222 follows a more complex pattern. The tirst $50 \%$ of the activities are readily neutralized and seem to behave the same as the neutralization of the anti- 
thrombin activities. However, maximum neutralization of the anti-factor Xa activities requires more PF4 as compared to the complete neutralization of the antithrombin activities, due to a pronounced hyperbolic nature of the neutralization curves of anti-factor Xa activities.
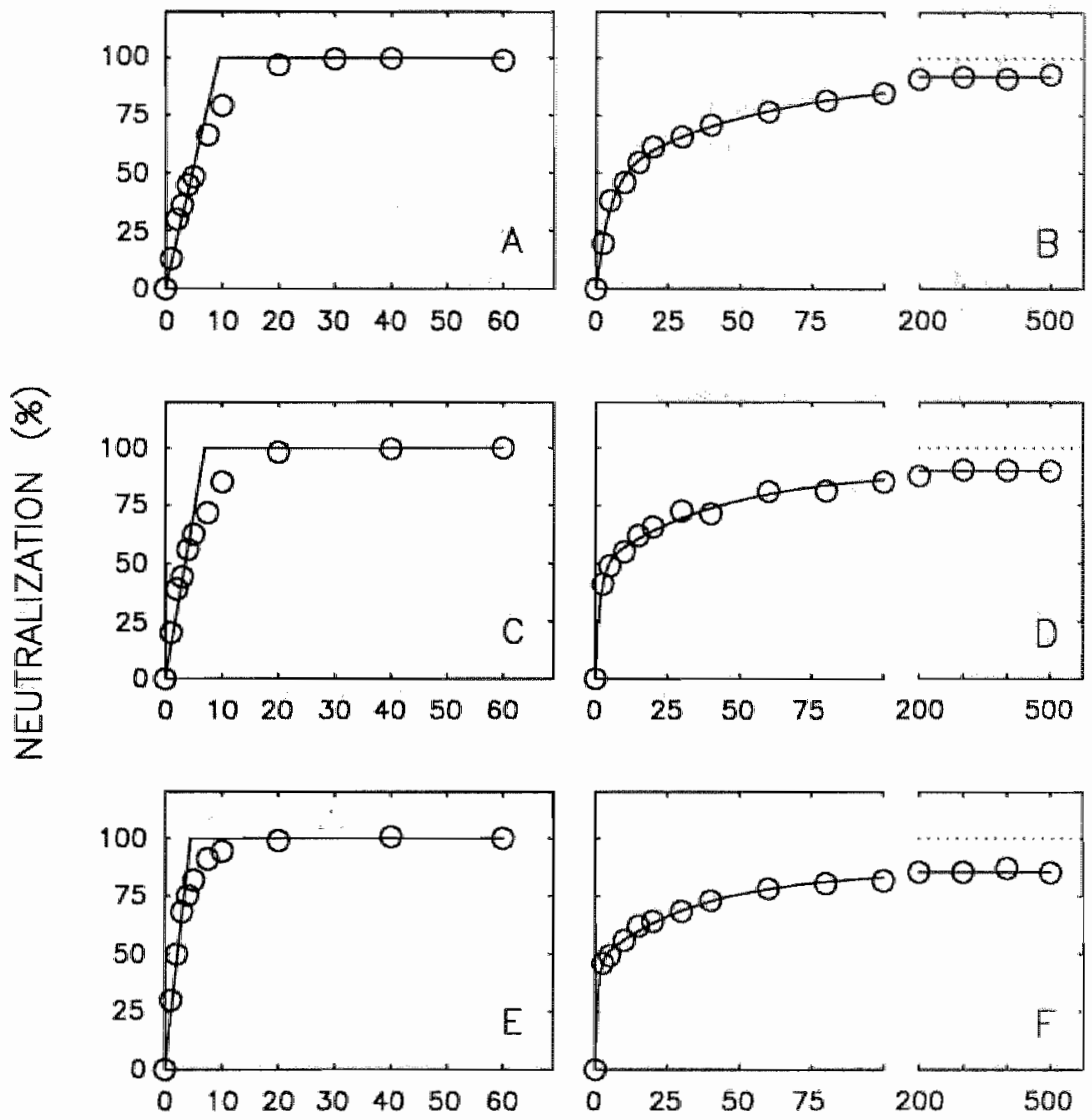

PLATELET FACTOR 4 (nM)

Figure 4. Neutralization of anti-thrombin and anti-factor Xa activitios of LMW hoparin preparations by PF4. The anti-thrombin (panels $A_{t} C$, and E) and anti-factor Xa (panels $B, D$, and F) activities were neutralized by increasing amounts of PF4, and expressed relative to the activities as determined in the absence of PF4. The initial heparin concentrations were $510 \mathrm{ng} C Y 216 / \mathrm{ml}(\mathrm{A}$ and $\mathrm{B}), 380 \mathrm{ng}$ enoxaparin/ml (C and $\mathrm{D})$, and $380 \mathrm{ng} \mathrm{Cr} 222 / \mathrm{ml}(\mathrm{E}$ and $\mathrm{F})$. 
In contrast with the LMW standard heparin, the anti-factor Xa activities of CY216, enoxaparin and CY222 are not completely abolished. From these neutralization curves (Figure's 4B, D, and F), it is determined that about $5 \%, 10 \%$, and $15 \%$ of the anti-factor $X a$ activities of CY216, enoxaparin, and CY222, respectively, cannot be neutralized by a large molar excess of PF4. This differential effect of increasing amounts of PF4 on the neutralization curves, can be explained by increasing amounts of saccharides with anti-factor $\mathrm{Xa}$ and no antithrombin activities $\left(M_{r}<5,400\right)$, which have a lower affinity for PF4, as compared to that of the saccharides with both anti-factor $\mathrm{Xa}$ and anti-thrombin activities.

We also investigated the extent to which the anti-factor $X a$ activities of the MMW, LMW, and ultra LMW fractions of CY216 could be neutralized by PF4. The relative amounts of the anti-factor $X a$ activities which could be neutralized were $100 \%, 40 \%$, and $0 \%$, respectively. This clearly demonstrates, that as the heparin size goes from octadecasaccharide downwards, increasing amounts of anti-factor Xa activity resist neutralization by PF4.

\section{DISCUSSION}

It is generally accepted that ATIII-high affinity heparin oligosaccharides with molecular weights less than 5,400 (octadecasaccharide) have negligible antithrombin activities, while their potency to accelerate the inactivation of factor $\mathrm{Xa}$ is preserved $(35,36)$. The work of Lane et al (35) has also indicated that the antithrombin and anti-factor $X a$ activities of these heparin molecules are less amenable to neutralization by PF4. We reasoned, that regarding LMW heparin preparations mean molecular weights as such might have no predictive value for their anti-protease activities and their neutralization by PF 4, because these preparations encompass theparin chains in a wide range of molecular weights, with unknown distributions of the ATIII high affinity molecules over the range of molecular weights. Therefore we, in the present study investigated whether or not LMW heparin preparations like the $1^{\text {st }}$ International Standard for LMW heparin, CY216, enoxaparin, and CY222 with mean molecular weights of 6,400 , $5,100,3,800$ and 3,800 , respectively, have identical properties with respect to factor $\mathrm{Xa}$ and thrombin inactivation, and neutralization by PF4. We determined anti-factor $X a$ and anti-thrombin specific catalytic activities, i.e. rate constants normalized for the heparin concentrations, and evaluated the PF4-dependent neutralization of these activities. Because free calcium ions affect the rates of heparin-dependent inhibition of factor Xa and thrombin by ATIII (Figure 1), 4.0 $\mathrm{mM} \mathrm{CaCl} 2$ was included in all our experiments.

We found that in a buffer system, using purified proteases and ATIII of human origin, the ratios of anti-factor $X a$ activity over anti-thrombin activity did not vary with average apparent molecular weights of the heparin preparations (Table 
2). Even the ultra LMW heparin CY222, which is prepared by exhaustive nitrous acid depolymerization of pig mucosal heparin and has the highest number of molecules with $M_{r}<2,500$, had only a 2-fold higher ratio than the other heparin preparations. The invariability of the specific activity ratios is caused by a parallel decrease of the anti-thrombin and anti-factor Xa activities, with decreasing mean molecular weights.

Because catalysis of the inactivation of thrombin requires a heparin chain length of at least octadecasaccharide, it is obvious that a decrease of the number of molecules with $M_{r}<5,400$ leads to a decrease of the anti-thrombin activity. At present two phenomena can be thought responsible for the decrease of the antifactor Xa activity. First of all, we (119) and others (42) have shown that when the heparin molecular weights decrease from about 15,000 to 1,714 (pentasaccharide) the rate constants of inhibition of human factor Xa by human ATIII in the presence of $\mathrm{CaCl}_{2}$ decrease. Secondly, and this in fact will contribute to the former effect, the $\mathrm{Ca}^{2+}$-dependent enhancement of anti-factor Xa activity decreases as the heparin molecular weight decreases from 12,000 downwards (127). Consequently, it is well possible, that an increase of the number of heparin molecules with only anti-factor Xa activity $\left(M_{r}<5,400\right)$ is counterbalanced by a lesser enhancement of the inactivation reaction with factor $\mathrm{Xa}$.

One of the LMW heparins (CY216) was fractionated by a gelpermeation procedure. Analysis of the obtained MMW, LMW, and ultra LMW fractions showed, that the anticoagulant heparin molecules present in Cr216 have an average apparent molecular weight higher than the average apparent molecular weight of all (ATIIIl high and low affinity) heparin species. Support of our reasoning above is found in the anti-protease activities of the MMW and LMW fractions. The MMW fraction $\left(6,100<M_{r}<11,200\right)$ has a relatively low anti-factor Xa activity as compared to its anti-thrombin activity (Table 3$)$. The LMW fraction $\left(3,300<M_{r}<\right.$ 5,500 ), which contributes for not more than $0.5 \%$ to the anti-thrombin activity of CY216 has considerable anti-factor Xa activity. Thus, admixture of the LMW frac. tion will restore the reduced anti-factor Xa specific activity of the MMW fraction, resulting in an unaltered specific anti-factor Xa/anti-thrombin ratio of CY216.

Thus, LMW heparin preparations are functionally equivalent to UF standard heparin on basis of their specific activity ratios. How does this compare with their sensitivity towards neutralization by PF4? First of all, we found that the antithrombin and anti-factor Xa activities of UF standard heparin were neutralized by stoichiometrical amounts of PF4. Neutralization of the anti-thrombin activities of the LMW heparin preparations followed the same pattern as obtained with UF standard heparin. From titrations with PF4 (Figure 2B, and Figure's $4 \mathrm{~A}, \mathrm{C}$, and $\mathrm{E}$ ) it was estimated, that LMW standard heparin, CY216, enoxaparin, and CY222, contain on molar basis about $25 \%, 10 \%, 7 \%$, and $5 \%$ material, respectively, which binds to PF4 with high affinity.

Titrations of the anti-factor Xa catalytic activities of the LMW heparin preparations with PF4 follow more complex patterns, especially those of CY216. 
enoxaparin, and CY222. At least 50\% of their anti-factor $X a$ activities are readily neutralized by PF4. Thus, these heparin molecules represent the fraction of the heparin preparations with both anti-factor $\mathrm{Xa}$ and anti-thrombin activity $\left\langle\mathrm{M}_{r}\right\rangle$ 5,400 ). Another $50 \%, 45 \%, 40 \%$, and $35 \%$, of the anti-factor Xa activities of LMW standard heparin, CY216, enoxaparin, and CY222, respectively, are neutralized by relative higher amounts of PF4. Hence, these heparin molecules, which have no anti-thrombin activity $\left(M_{r}<5,400\right)$, have a lower affinity for $P F 4$. The remaining anti-factor Xa activities, varying between 5 to $15 \%$ of CY216, enoxaparin, and CY222, could not be neutralized by PF4 even at high PF4/heparin ratios.

In conclusion, LMW heparin preparations are as sensitive as UF heparin regarding neutralization of their anti-thrombin activities. However, whereas the anti-factor Xa activity of UF heparin is equally well neutralized as its anti-thrombin activity, PF4-dependent neutralization of the anti-factor Xa activities of LMW heparin preparations suggests three pools of anti-factor Xa activity. The first pool of activity is, just as the anti-thrombin activities, readily neutralized by PF4, the second one is neutralized by excess PF4, and the remaining activities are rather insensitive to PF4. Therefore, PF4-dependent neutralization of the anti-factor $\mathrm{Xa}$ activity of a particular LMW heparin will strongly depend on the heparin molecular weight distribution pattern, and on the local PF4 and heparin concentrations.

Acknowledgement- We gratefully acknowledge Dr. J.C. Lormeau (Sanofi Recherche, France) for providing CY222, CY216 and its subtractions, and performing determinations of the molecular weight distributions. We thank Dr. D. v. Rheenen (Blood Transfusion Service Zuld-Limburg) for kindly providing platelet concentrates. 
\& 


\section{The in Situ Inhibition of Prothrombinase-formed Human $\alpha$-Thrombin and Meizothrombin(Des Fragment 1) by Antithrombin III and Heparin $\$$}

The Inhibition of thrombin by antithrombin III (ATIII) and heparin was studled in pure systems to determine the kinetics of inhlbition during human prothrombin actlvation. In this study prothrombinase-catalyzed prothrombin activation resulted in the generation of thrombin and melzothrombin (des fragment 1). In the absence of heparin the second order rate constants of Inactivation of both thrombin and meizothrombin(des fragment 1) formed in the reaction mixture were Identical, $k=3.7 \times 10^{5} \mathrm{M}^{-1} \mathrm{mln}^{-1}$. The rate constant of inhibition of purifled thrombin was $6.5 \times 10^{5} \mathrm{M}^{-1} \mathrm{mln}^{-1}$. In the presence of heparin the decay of amldolytic actlvity was bl-exponential and could be modelled by a 4-parameter equation to determine the pseudo-first order rate constants of Inhlbition of thrombin and melzothrombin(des fragment 1 ), as well as the composition of the reaction with respect to their levels. The ratio of thrombln over melzothrombin(des fragment 1) varled with the Initial prothrombin concentration. Heparin catalyzed the ATIII-dependent inhibition of thrombin, but not that of meizothrombin(des fragment 1) formed during prothrombin activation. Thrombin, generated by [Xa-Va-phosphollpld-Ca ${ }^{2+}$ ] was Inhiblted by ATIII/heparin more slowly than purified thrombin and the saturation kinetlcs of the Inhibition with respect to ATIII differed from those tound with purlfled thrombin.

Prothrombinase, a $\mathrm{Ca}^{2+}$-dependent enzymatic complex composed of the serine protease factor $\mathrm{Xa}$, and the non-enzymatic cofactors factor $\mathrm{Va}$ and phospholipid, catalyzes the cleavage of specific Arg-Thr and Arg-lle bonds in prothrombin, thereby generating thrombin (88). It has been previously recognized that during the initial phase of prothrombin activation by prothrombinase, meizothrombin (cleavage of the $\mathrm{Arg}^{323}-11 \mathrm{e}^{324}$ bond) is an important transient intermediate in thrombin formation $(89,90)$. Cleavage of the Arg-lle bond results in the generation of enzymatic activity. Meizothrombin, however, differs from thrombin as in to its reactivity towards macromolecular substrates, e.g. antithrombin III

S Schoen P. Lindhout T. J Blol Chem 262:11268-11274, 1987 
(ATIII), fibrinogen $(137,138)$, and factor $V(92)$. In addition, whereas heparin catalyzes the inactivation of thrombin by ATIII, heparin is unable to catalyze the bovine ATIII/meizothrombin reaction (139). Moreover, previous work has shown that meizothrombin does not interact with heparin (140).

Over the last decade, efforts to elucidate the catalytic function of heparin in the thrombin/ATIII reaction have resulted in a detailed knowledge of its kinetic mechanisms (see References 40 and 141, and references therein). However, direct kinetic data on the heparin-catalyzed ATIII-dependent inhibition of thrombin, during its generation are not currently available. Yet, several lines of evidence suggest that the kinetics of inhibition of thrombin are greatly affected by the prothrombin activation peptides fragment 1.2 and fragment 1 , either covalently or non-covalently bound to thrombin, and heparin neutralizing agents like

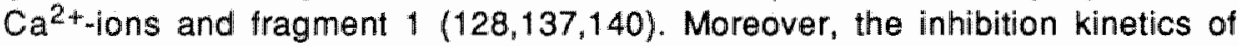
plasma generated proteases $(142,143)$, and the mode of action of heparin in plasma cannot readily be explained by its anticoagulant properties as determined with purified proteases.

Previous work showed that heparin was unable to catalyze the inactivation of the thrombin activity formed during bovine prothrombin activation (139). Apparently, the activation conditions in that study were such as to result in the formation of meizothrombin(des fragment 1), rather than in the generation of thrombin. In the present study, human prothrombin activation conditions were chosen which resulted in the formation of both meizothrombin(des fragment 1) and thrombin. We developed a method to quantitatively assess the amounts of thrombin and meizothrombin(des fragment 1) formed under different conditions of human prothrombin activation. This method is based on analysis of the biphasic ATIII/heparin-dependent decay of amidolytic thrombin activity that is observed when both thrombin and meizothrombin(des fragment 1) are present. The alterations in the kinetics of inhibition of thrombin caused by the presence of prothrombinase components and prothrombin activation fragments, e.g. fragment 1.2 , fragment 1 and/or fragment 2 could in this way be approached experimentally.

\section{EXPERIMENTAL PROCEDURES}

Materlais - The synthetic peptide substrate $\$ 2238$ was purchased from AB Kabi Diagnosticia (Stockholm, Sweden). Unfractionated heparin (168 USP U/mg) was from Pharmuka Laboratories (Gennevilliers, France). All other reagents were from sources described previously (139). The coagulation factors human prothrombin (132), human factor $\mathrm{Xa}$ (144), bovine factor Va (145), and human thrombin ( 111 ) were puritied as described. Human ATIII was prepared by polyethylene glycol precipitation of bariumcitrate-adsorbed plasma and affinity chromatography on a heparin-Sepharose column (146). The ATIII was subsequently freed of heparin contamination by ion-exchange chromatography (147). 
The molar concentrations of the proteins were determined as described previously (139). Phospholipid vesicles (PSPC) composed of $25 \%$ PS and $75 \%$ PC were prepared as previously described (145). Antibodies were from Dakopatts (Glostrup, Denmark).

Measurement of Purified Thrombin Neutralization- The time course of thrombin inactivation by ATIII $(25-600 \mathrm{nM})$, either in the absence or presence of heparin $(50 \mathrm{ng} / \mathrm{m})$ and prothrombinase components, was determined by adding thrombin $(2.5$ or $8.0 \mathrm{mM})$ to the reaction mixture in $50 \mathrm{mM}$ Tris- $\mathrm{HCl}(\mathrm{pH} 7.9), 175 \mathrm{mM} \mathrm{NaCl}$, and $0.5 \mathrm{mg} \mathrm{HSA} / \mathrm{ml}$ at $37^{\circ} \mathrm{C}$. Al various time: intervals $20 \mu$ laliquots were transterred to cuvettes containing a tinal wolume of $0.35 \mathrm{ml}$ of $50 \mathrm{mM}$ Tris- $\mathrm{HCl}(\mathrm{pH} 7.9), 175 \mathrm{mM} \mathrm{NaCl}, 20 \mathrm{mM} \mathrm{EDTA}, 0.5 \mathrm{mg} \mathrm{HSAml}$, and $0.23 \mathrm{mM} \mathrm{S2238}$ at $37^{\circ} \mathrm{C}$. Aiter 8 min, $0.15 \mathrm{ml}$ of $50 \%$ acetic acid ( $\mathrm{V} / \mathrm{v})$ was added and the absorbance at $405 \mathrm{~nm}$ was measured against a blank on an Aminco DW2 spectrophotometer (reference wavelength: $500 \mathrm{~nm}$ ). The rate of thrombin inhibition after sampling into the substrate solution was sufficiently slow to result in no measurable enzyme inhibition. The residual thrombin activities were calculated from a standard curve of known amounts of thrombin. constructed under the same conditions, and because pseudo-first order conditions apply, the logarithms of the residual thrombin concentrations were plotted versus reaction time. The apparent rate constants were calculated from the slopes of these linear plots.

Prothrombin Activation and Inactivation of the Amidolytic Active Products-. Prothrombin was activated by prothrombinase (factor $\mathrm{Xa}_{\text {, factor }} \mathrm{Va}_{1} \mathrm{PSPC}, \mathrm{CaCl}_{2}$ ) in $50 \mathrm{mM} \mathrm{Tris-HCl}$ (pH 7.9), $175 \mathrm{mM} \mathrm{NaCl}$ and $0.5 \mathrm{mg} \mathrm{HSA} / \mathrm{ml}$, either in the absence or presence of heparin. The final concentrations were $0.60 \mathrm{nM}$ factor $\mathrm{Va}_{1} 50 \mu \mathrm{MPSPC}$, and $5.0 \mathrm{mM} \mathrm{CaCl}_{2}$. Prothrombin, factor $\mathrm{Xa}$ and heparin were present at varying concentrations. At timed intervals prothrombin activation was completely and instantaneously blocked by the addition of $10 \mu$ of soybean trypsin inhibitor (STI) at a final concentration of $0.33 \mathrm{mg} / \mathrm{ml}$ as previousliy described (139). After $2 \mathrm{~min}$. ATIII (varying between 25-600 $\mathrm{nM}$ ) was added and the time course of disappearance of amidolytic activily was monitored as aforementioned by transferring samples to cuvettes containing the syrithetic peptide substrate S2238.

KInetic Analysis of the ATIII/Thrombin Reaction In Prothrombin Activation Mixtures- In all experiments the initial ATIII concentrations were significantly greater than the initial thrombin (meizothrombin(des fragmenl 1) plus $\alpha$-thrombin) concentrations, so that the inactivation reactions followed pseudo-first order kinetics. Because thrombin and meizothrombin(des fragment 1) have equal reactivity towards $S 2238$ (92) but have a different reactivity towards ATIII, the disappearance of amidolytic activity might be madelled by:

$$
[\|a+m-\| a]_{t}=[\|]_{0} e^{-k-1} t+[m-1 \| a]_{0} e^{-k g t}
$$

where $[\text { lla }+\mathrm{m}-\| \mathrm{la}]_{\mathrm{f}}$ is the concentration of thrombin plus meizothrombin(des fragment 1) at time t, [Ila] $]_{0}$ is the initial thrombin and [m-lla $]_{0}$ the initial meizothrombin(des fragment 1) concentration, $k_{\|}$is the pseudo-first order rate constant of inhibition of thrombin and $k_{2}$ that of meizothrombin(des fragment 1). The four parameters, $[\| l a]_{0},[\mathrm{~m}-\| l a]_{0}, k_{1}$, and $k_{2}$ were determined by fitting Equation 1 to the levels of residual thrombin plus meizothrombin(des iragment 1) concentrations observad at varying times. The fitting procedure is based upon a nonlinear least-squares regression method which uses a reiterative Gauss-Newton algorithm (148). Reported errors represent $95 \%$ confidence intervals, which are approximately twice the SD values of the estimates.

Immunoblotting Procedure- Essentially the same procedure was used as described previously (139). Briefly, prothrombin $(0.20 \mu \mathrm{M})$ was incubated with factor Xa $(3.0 \mathrm{pM})$, factor $\mathrm{Va}$ $(0.60 \mathrm{nM})$, PSPC $(50 \mu \mathrm{M})$, and $\mathrm{CaCl}_{2}(5.0 \mathrm{mM})$ in $50 \mathrm{mM}$ Tris-HCl $(\mathrm{pH} 7.9), 175 \mathrm{mM} \mathrm{NaCl}, 0.5 \mathrm{mg} / \mathrm{ml}$ HSA for $3 \mathrm{~min}$ at $37^{\circ} \mathrm{C}$, either in the absence or presence of heparin ( $\left.200 \mathrm{ng} / \mathrm{mil}\right)$. The prothrombin activation reaction was stopped by the addition of STI $(0.33 \mathrm{mg} / \mathrm{ml})$, followed by the addition of ATlII (315 nM). Subsequently, samples were taken at different time intervals and subjected to sodium dodecyl sulfate-polyacrylamide gel electrophoresis (6.5\% acrylamide) according to Laemmli (149). 
The proteins were then transferred to nitrocelulose sheets $(150)$. The electrophoretic blots were soaked in $10 \mathrm{mM} \mathrm{K} \mathrm{H}_{2} \mathrm{PO}_{4}$ ( $\mathrm{pH} 7.3$ ) containing $150 \mathrm{~mm} \mathrm{NaCl}, 0.1 \%$ bovine serum albumin, and $0.05 \%$ Tween 20. The immunological detection of ATII and ATIIIprotease complexes was performed with rabbil ant-human ATHI and horseradish perowdase-conjugated swine anti-rabbit lgo anibodies.

\section{RESULTS}

Inhibition of Prothrombinase-Generated Amidolytic Activity by ATIII and Heparin - Figure $1 \mathrm{~A}$ depicts typical examples of thrombin formation and inhibition curves in the absence or presence of heparin. Prothrombin is activated by the prothrombinase complex, followed by the addition of STI to prevent further thrombin formation, and the addition of ATIII (315 nM). When heparin was absent, thrombin activity decayed as a mono-exponential curve as indicated by a linear pseudo-first order plot with slope $0.081 \mathrm{~min}^{-1}$ (Figure 1B). In the presence of heparin, however, the semilogarithmic plat appeared to be biphasic which suggests the presence of a fast and slow decaying enzyme formed during prothrombin activation. To examine this phenomenon further, samples were removed from the prothrombin activation mixtures, after ATIII had been added and analyzed by an immunoblotting procedure (see "Experimental Procedures"). Figure 2 shows the time course of appearance of ATIIl-containing complexes in the absence (panel A) and the presence of heparin (panel B).

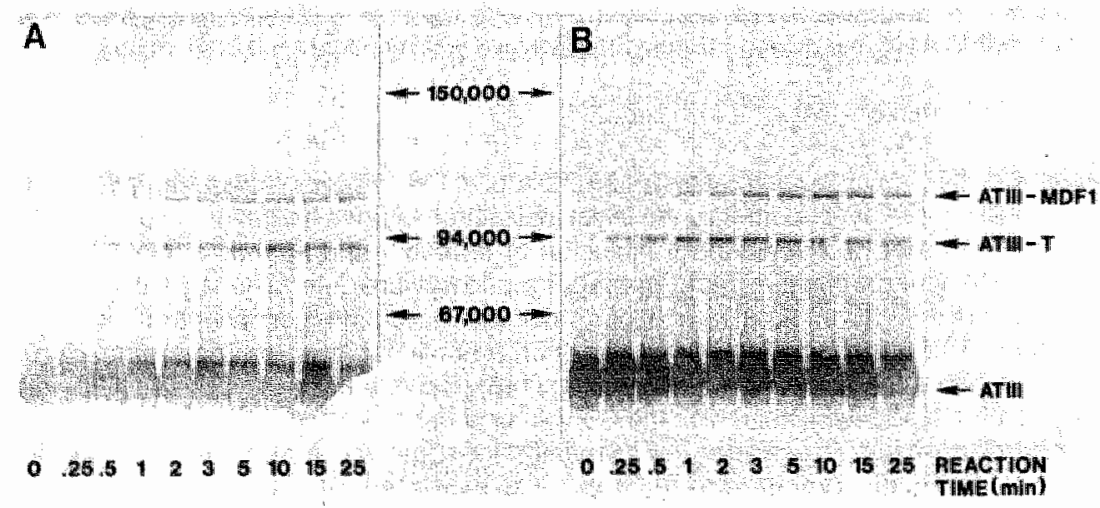

Figure 2. Identification of prothrombin activation products complexed with ATIII. Samples from the experiment depicted in Figure 1 were taken after the addition of ATIII and immunoblotted as described under "Experimental Procedures". Panel $A_{n}$ in the absence of heparin. Panel $B$, in the presence of heparin $(200 \mathrm{ng} / \mathrm{ml})$. Reaction times are indicated relatively to the time of addition of ATIII. MDF1, meizothrombin(des fragment 1); $T$, thrombin. 

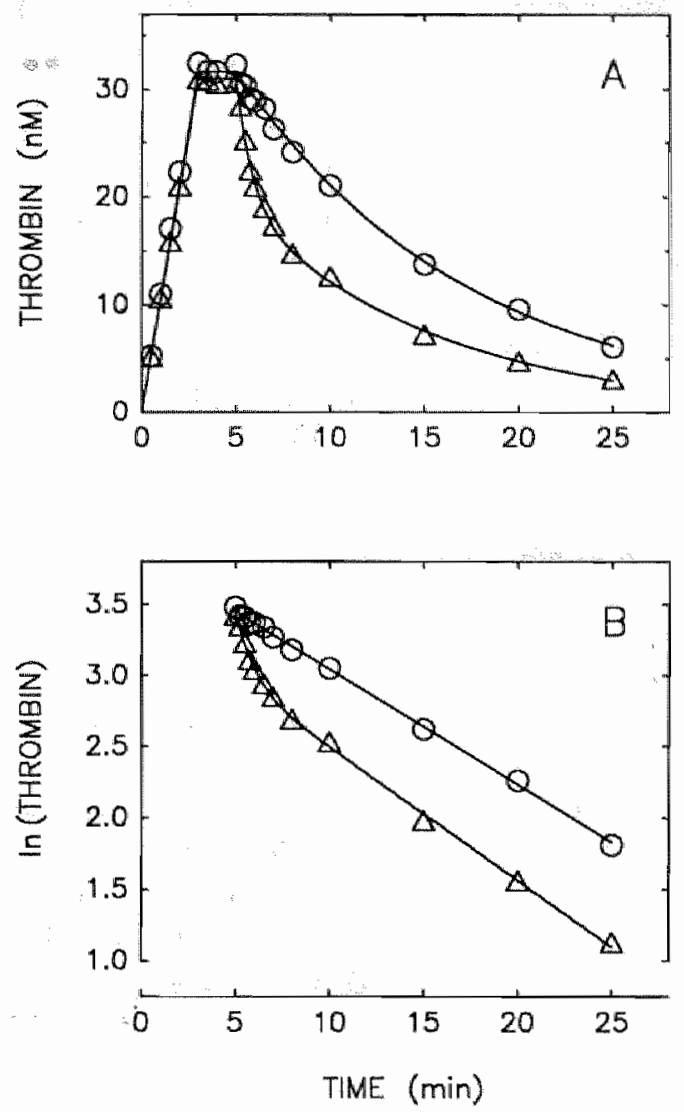

Figure 1. Time course of prothrombin activation and subsequent inhibition of the generated amidolytic activity. Prothrombin $(0.20 \mu \mathrm{M})$ was activated by factor Xa $(3.0 \mathrm{pM})$, factor $\mathrm{Va}, \mathrm{PSPC}$, and $\mathrm{CaCl}_{2}$ as described under "Experimental Procedures", in the absence (O) or presence (A) of heparin (200 $\mathrm{ng} / \mathrm{ml})$. After $3 \mathrm{~min}, \mathrm{STI}(0.33 \mathrm{mg} / \mathrm{ml})$ was added, followed by the addition of ATIII (315 nM) after an additional 2 min period. Panel $A$, thrombin generation and decay curves. $P a n e l$, semilogarithmic plots of the decay of amidolytic thrombin activily. Equation 1 was fitted to the data from the heparin containing experiment (solid lines).

Figure 2 shows that two ATIII-containing complexes were formed. One, comigrating with thrombin-ATIII $\left(M_{r}=95,000\right)$ and a second one of $M_{r}=115,000$ comigrating with the meizothrombin(des fragment 1)-ATIII complex. Interestingly, we could not detect a band that co-migrates with the ATIII-meizothrombin complex $\left(M_{r}=132,000\right)$. A further inspection of the immunoblot reveals another important feature. In the absence of heparin the appearances of the two bands show comparable time courses (Figure 2A), whereas in the presence of heparin 
the thrombin-ATlll complex is formed more quickly (Figure 2B). These observations compare very well with the finding that the total thrombin activity decayed mono-exponentially in the absence of heparin, but bi-exponentially in the presence of heparin (Figure 1).

The data obtained in the presence of heparin were fitted to Equation 1 using a non-linear least squares computer program. The solid lines (Figure 1) correspond to the computer fit. The adjustable parameters, initial thrombin concentration, initial meizothrombin(des fragment 1) concentration, and their pseudo first order rate constants of inhibition were $11.8 \pm 1.7 \mathrm{nM}, 19.3 \pm 1.3 \mathrm{nM}, 1.2 \pm 0.3$ $\mathrm{min}^{-1}$, and $0.093 \pm 0.006 \mathrm{~min}^{-1}$, respectively. The best fit of our data in the absence of heparin was obtained by using Equation 1 with the second exponential term set at zero. In this case, the initial total thrombin concentration and pseudo first order rate constant, were $31.4 \pm 0.4 \mathrm{~nm}$ and $0.081 \pm 0.002 \mathrm{~min}^{-1}$, respectively. It is seen that the total thrombin concentration equals the sum of the thrombin plus meizothrombin(des fragment 1) concentrations and that the decay constant equals the decay constant of meizothrombin(des fragment 1). Thus, the prothrombin activation products, thrombin and meizothrombin(des fragment 1), apparently exhibited identical rate constants of inhibition by ATIll when heparin was not present. In the presence of heparin, only the ATIII/thrombin reaction is enhanced.

The Effect of Prothrombin Concentration on the Generation and Inactivation of Thrombin and Meizothrombin(des fragment 1)-Prothrombin (0.05-1.0 $\mu \mathrm{M}$ ) was incubated for $3 \mathrm{~min}$ with the prothrombinase complex. STI was then added to stop further thrombin formation and after an additional 2 min period a small aliquot of ATIII was added to a final concentration of $315 \mathrm{nM}$. The amount of prothrombin consumed never exceeded $25 \%$ of the initial concentration. This set of experiments was performed in the absence and presence of heparin $(200 \mathrm{ng} / \mathrm{mll})$ and the results are depicted in Table 1.

In the absence of heparin, mono-exponential thrombin decay curves were obtained. The pseudo first order rate constant of inhibition was found not to vary with the amount of amidolytic activity formed at the time of addition of ATIII nor did it depend on the initial prothrombin concentration, on the average $k=0.081 \pm$ $0.002 \mathrm{~min}^{-1}$.

In the presence of heparin, biphasic decay curves were obtained. The curves were modelled according to Equation 1 to obtain the adjustable parameters depicted in Table 1. It is shown that the pseudo-first order rate constants of inhibition of thrombin $\left(k=1.05 \pm 0.27 \mathrm{~min}^{-1}\right)$ and those of meizothrombin(des fragment 1) ( $\left.k=0.087 \pm 0.014 \mathrm{~min}^{-1}\right)$ did not vary with the amount of thrombin plus meizothrombin(des fragment 1) formed, nor with the initial prothrombin concentration. Moreover, the rate constant of inhibition of meizothrombin(des fragment 1) is again identical to the rate constant determined in the absence of heparin. Table 1 also indicates that in this way reliable values for the amounts of thrombin 
and meizothrombin(des fragment 1) formed in prothrombin activation mixtures can be obtained.

Table 1. Inhibition of thrombin and meizothrombin(des tragment 1) at different prothrombin concentrations. Prothrombin was activated with factor Xa (3.0 pM), factor Va, PSPC and $\mathrm{CaCl}$. After a 3 min incubation period prothrombin activation was stopped by the addition of STI. After an additional 2 min period ATIII ( $315 \mathrm{nM})$ was added and the decay data from the heparin-containing experiments were fitted to Equation 1 of "Experimental Procedures" and those from experiments in the absence of theparin to $[11 \mathrm{a}+\mathrm{m}-\| \mathrm{la}]_{\mathrm{t}}=\left[1 \mathrm{a}+\mathrm{m}-\|_{\mathrm{a}}\right]_{0} \mathrm{e}^{-\mathrm{kt} t}$ to obtain the listed parameters.

\begin{tabular}{|c|c|c|c|c|c|c|}
\hline \multirow[t]{2}{*}{ Prothrombin } & \multicolumn{2}{|c|}{ No Heparin } & \multicolumn{4}{|c|}{$200 \mathrm{ng}$ Heparin/ml } \\
\hline & {$[11 a+m-\| l a]_{0}$} & $k$ & [lla & {$[\mathrm{m}-1 / \mathrm{a}]_{0}$} & $k_{1}$ & $k_{2}$ \\
\hline$(\mu \mathrm{M})$ & $(\mathrm{nM})$ & $\left(\min ^{-1}\right)$ & $(n M)$ & $(\mathrm{nM})$ & $\left(\min ^{-1}\right)$ & $\left(\min ^{-1}\right)$ \\
\hline 0.05 & $16.9 \pm 0.2$ & $0.107 \pm 0.002$ & $12.6 \pm 0.6$ & $4.0 \pm 0.7$ & $1.06 \pm 0.08$ & $0.118 \pm 0.015$ \\
\hline 0.10 & $21.8 \pm 0.5$ & $0.079 \pm 0.004$ & $12.9 \pm 1.5$ & $9.8 \pm 1.5$ & $1.22 \pm 0.25$ & $0.096 \pm 0.025$ \\
\hline 0.20 & $31.4 \pm 0.4$ & $0.081 \pm 0.002$ & $11.8 \pm 1.7$ & $19.3 \pm 1.3$ & $1.16 \pm 0.35$ & $0.093 \pm 0.006$ \\
\hline 0.60 & $41.0 \pm 0.7$ & $0.068 \pm 0.002$ & $9 . \| \pm 1.4$ & $30.8 \pm 1.3$ & $0.88 \pm 0.28$ & $0.078 \pm 0.003$ \\
\hline 1.00 & $43.2 \pm 0.7$ & $0.068 \pm 0.002$ & $6.6 \pm 3.4$ & $33.3 \pm 3.5$ & $0.88+0.27$ & $0.080 \pm 0.012$ \\
\hline
\end{tabular}

Kinetics of Inhibition of Endogenous-Formed Thrombin and Meizothrombin (des fragment 1) - The mechanism of the heparin enhanced ATIII/thrombin reaction is most readily described by a model in which heparin functions as a template upon which the protease and inhibitor can interact effectively $(41,151)$. Using steady state assumptions, the reaction velocity, $v$, is described by the following simple rate equation (152):

$$
v=k \cdot f a \cdot b \cdot[H]_{t}
$$

where $k$ is the intrinsic rate constant for the reaction between heparin bound thrombin and $A T I I I, f_{a}$ and $t_{b}$ are the respective fractional saturations of available binding sites on heparin by ATIII and thrombin, and $[\mathrm{H}]_{t}$ is the total heparin concentration. Thus, when the heparin-dependent reaction between ATIII and thrombin is analyzed by pseudo-first order kinetics, as in the present study, than the observed rate constant will be a function of the heparin, the ATIII and/or the thrombin concentration, depending on the selected conditions. When thrombin and ATIII are in excess over the heparin concentration and ATIII exceeds the thrombin concentration, Equation 2 predicts that the apparent first order rate constant will be direct proportional with the heparin concentration.

Effect of Heparin Concentration - In order to determine the efficiency of heparin in the inhibition of prothrombinase-formed thrombin activity, prothrombin $(0.10 \mu \mathrm{M})$ was activated with factor $\mathrm{Xa}(1.0 \mathrm{pM})$ in the presence of factor $\mathrm{Va}$, PSPC, $\mathrm{CaCl}_{2}$ and heparin for $8 \mathrm{~min}$. The thrombin decay data obtained in the 
presence of ATIII (100 nM) and varying heparin concentrations $(50-400 \mathrm{ng} / \mathrm{ml})$ were fitted to Equation 1. The apparent pseudo-first order rate constant of the ATIII/thrombin reaction increased linearly with the heparin concentration. The inhibition of meizothrombin(des fragment 1), however, was not catalyzed by heparin (Figure 3 ). In the latter case, the mean pseudo-first order rate constant was $0.028 \pm 0.003 \mathrm{~min}^{-1}$. Interestingly, the line that depicts the rate constant of inhibition of thrombin as a function of the heparin concentration, extrapolated to a higher heparin-independent rate constant $\left(0.061 \mathrm{~min}^{-1}\right)$. From the same analysis that produced the rate constants, the concentrations of thrombin and meizothrombin(des fragment 1) were found to be $9.3 \pm 0.4 \mathrm{nM}$ and $3.7 \pm 0.3 \mathrm{nM}$, respectively.

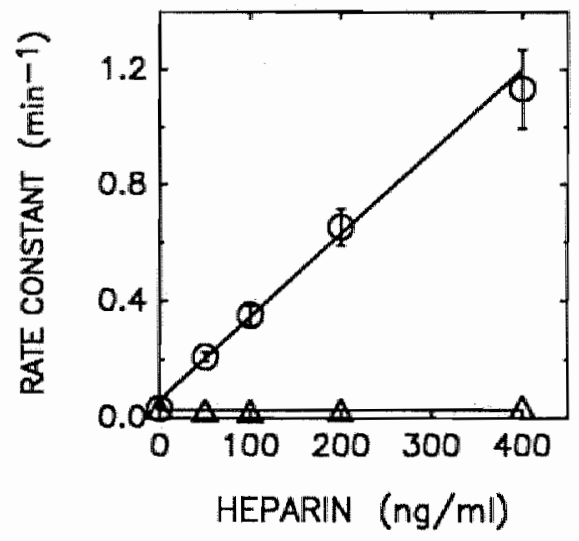

Flgure 3. Rate constants as function of heparin concentration. The effect of heparin on the pseudo-first order rate constant of inhibition of thrombin $(O)$ and meizothrombin(des fragment 1$)$ (A), formed upon prothrombin activation. The initial ATIll concentration was $100 \mathrm{nM}$. The rate constants were determined as outlined in Figure 1.

Effect of Thrombin Concentration - To study the protease saturation, prothrombin activation mixtures containing heparin $(200 \mathrm{ng} / \mathrm{ml})$ and variable levels of total amidolytic activity were prepared. The latter was obtained by adding STI at different time intervals, to block further thrombin formation. The thrombin decay data measured after the addition of ATIII $(315 \mathrm{nM})$ were fitted to Equation 1. The solutions for the thrombin and meizothrombin(des fragment 1 ) concentrations and their respective apparent pseudo-first order rate constants, $k_{1}$ and $k_{2}$, are depicted in Table 2.

The results indicate that during the initial stage of prothrombin activation both thrombin and meizothrombin(des fragment 1) formation are linear in time. It is also shown that, despite an 8-fold variation in the thrombin concentration, the 
apparent pseudo-first order rate constant of the heparin-dependent ATIII/thrombin reaction remains constant. The latter observation suggests that the fractional saturation of the availlable thrombin-binding sites on heparin remains constant within the range of thrombin concentrations studied. This observation is quite understandable if one takes into account the reported dissociation constant of heparin-thrombin complexes, $K_{d} \sim 1 \mu \mathrm{M}(153,154)$, and an estimated molar concentration of heparin in this experiment of about $7 \mathrm{nM}$. It is also shown that under these conditions the inhibition of thrombin is more than 10 times faster than the inhibition of meizothrombin(des fragment 1).

Table 2. Inhibition of thrombin and meizothrombin(des fragment 1) at different stages of prothrombin activation. Prothrombin $(0.10 \mu \mathrm{NM})$ was activated by factor $\mathrm{Xa}(1.0 \mathrm{pM})$ in the presence of factor $\mathrm{Va}, \mathrm{PSPC}$ and $\mathrm{CaCl}_{2}$. The prothrombin activation was stopped by the addition of STI at the times indicated. After the addition of ATIII $(315 \mathrm{nM})$ and heparin (200 $\mathrm{ng} / \mathrm{mil})$, the thrombin decay curves were fitted to Equation 1 of "Experimental Procedures" to obtain the listed paramelers.

\begin{tabular}{cccccc}
\hline Reaction Time & {$[\| \mathrm{lla}]_{0}$} & {$[\mathrm{~m}-\mathrm{lla}]_{0}$} & {$[\mathrm{lla}]_{\mathrm{o}} /[\mathrm{m}-\mathrm{lla}]_{0}$} & $\mathrm{k}_{1}$ & $\mathrm{k}_{2}$ \\
\hline$(\mathrm{min})$ & $(\mathrm{nM})$ & $(\mathrm{nM})$ & & $\left(\mathrm{min}^{-1}\right)$ & $\left(\mathrm{min}^{-1}\right)$ \\
& & & & & \\
1 & $1.84 \pm 0.18$ & $1.13 \pm 0.15$ & 1.6 & $1.18 \pm 0.25$ & $0.071 \pm 0.013$ \\
2 & $4.29 \pm 0.46$ & $2.24 \pm 0.36$ & 1.9 & $0.98 \pm 0.22$ & $0.076 \pm 0.013$ \\
3 & $5.97 \pm 0.50$ & $3.69 \pm 0.38$ & 1.6 & $0.92 \pm 0.16$ & $0.071 \pm 0.007$ \\
5 & $9.79 \pm 0.32$ & $5.95 \pm 0.56$ & 1.6 & $1.02 \pm 0.17$ & $0.083 \pm 0.007$ \\
8 & $15.79 \pm 1.06$ & $8.86 \pm 0.67$ & 1.8 & $0.94 \pm 0.12$ & $0.074 \pm 0.005$ \\
\hline
\end{tabular}

Effect of ATIII Concentration- Prothrombin $(0.20 \mu \mathrm{M})$ was activated by factor Xa (1.0 pM), in the presence of a fixed amount of heparin $(50 \mathrm{ng} / \mathrm{ml})$, factor $\mathrm{Va}_{\text {, }}$ PSPC, and $\mathrm{CaCl}_{2}$. After $1 \mathrm{~min}$, STI was added to stop the reaction. To this mixture varying amounts of ATIII (25-600 nM) were added. The pseudo-first order rate constants of inhibition of thrombin and meizothrombin(des fragment 1) and their initial concentrations ( $1.4 \pm 0.2$ and $1.5 \pm 0.2 \mathrm{~nm}$, respectively) at the time ATIII was added were obtained by the procedure used before. Saturation with respect to ATIII was not obtained with meizothrombin(des fragment 1). The second order rate constant was $3.7 \times 10^{5} \mathrm{M}^{-1} \mathrm{~min}^{-1}$ (Figure 4A). When the same set of experiments was performed in the absence of heparin, formed thrombin and meizothrombin(des fragment 1) were inhibited with indistinguishable rate constants, with a second order rate constant of $3.4 \times 10^{5} \mathrm{M}^{-1} \mathrm{~min}^{-1}$ ). 


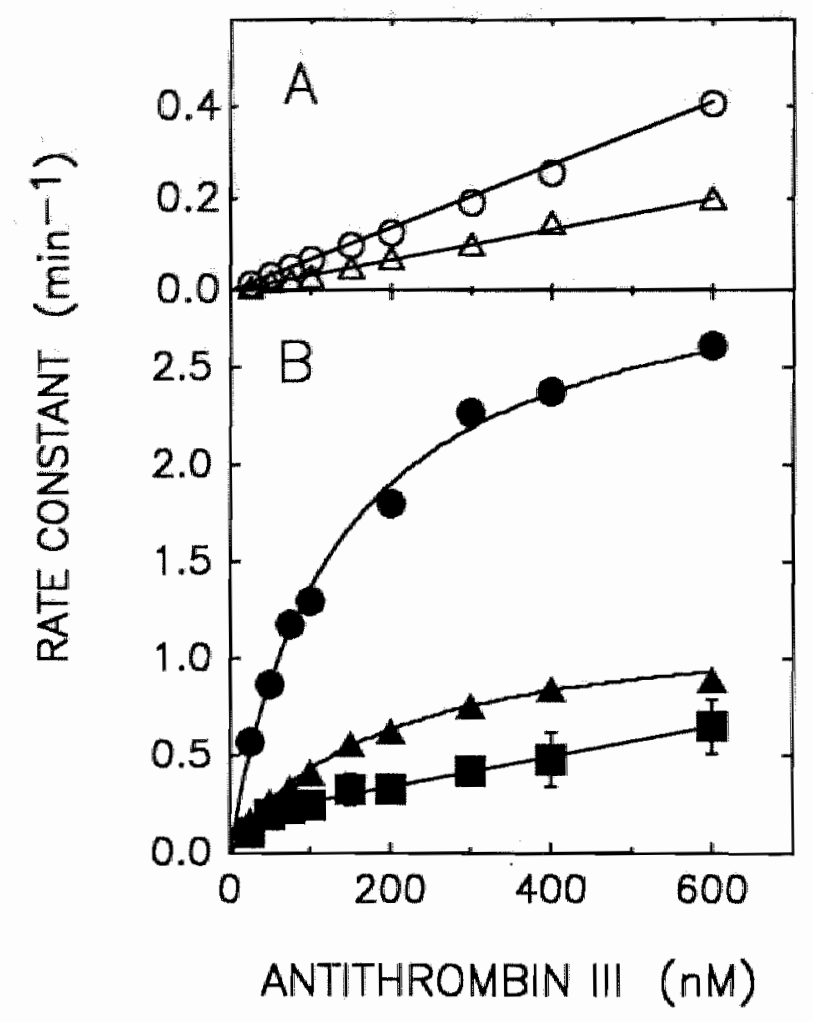

Figure 4. Rate constants as function of ATIII concentration. Panel $\mathrm{A}$, pseudo-first order rate constants of inhibition of purified thrombin in the absence of heparin $(O)$, and of prothrombinaseformed meizothrombin(des Iragment 1) in the presence of $50 \mathrm{ng} / \mathrm{ml}$ heparin ( $\Delta$ ). Panel B, pseudofirst order rate constants of inhibition of purified thrombin in the absence (9) or in the presence of $5.0 \mathrm{mM} \mathrm{Ca}{ }^{2 *}(\Delta)$ and of prothrombinase-formed thrombin (D). Heparin was present at $50 \mathrm{ng} / \mathrm{ml}$ and the rate constants were corrected for the heparin-independent reaction.

Figure $4 \mathrm{~B}$ indicates that the heparin-dependent inhibition reaction of prothrombinase formed thrombin was saturable with respect to ATIII. The data shown were corrected for the heparin-independent reaction. Although the error in resolving the rate constants at higher ATIII concentrations was substantial, a limiting linear dependence on the ATIII concentration was abserved $\left(k=8.0 \times 10^{5}\right.$ $\mathrm{M}^{-1} \mathrm{~min}^{-1}$ ): In order to investigate whether this phenomenon might be caused by the components that comprised the prothrombin activation mixture, i.e. phospholipid, prothrombin, factor $\mathrm{Va}$ and $\mathrm{Ca}^{2+}$, the kinetics of inhibition of purified thrombin were studied under the same conditions. We found that $\mathrm{Ca}^{2+}$, but none of the 
other components, reduced the rate constant of the heparin-dependent inhibition of thrombin.

Figure 4B also shows the rate constants of heparin-catalyzed inhibition of purified thrombin in the absence and presence of $\mathrm{Ca}^{2+}(5.0 \mathrm{~mm})$ as function of ATIII concentration. The data as shown were corrected for the heparin-independent reaction shown in Figure $4 \mathrm{~A}\left(\mathrm{k}=6.5 \times 10^{5} \mathrm{M}^{-1} \mathrm{~min}^{-1}\right)$ and they were subsequently analyzed according to the general rate equation for a random-order bireactant enzyme-catalyzed reaction (151). The result is depicted in Figure 5. With purified thrombin an apparent heparin-AT III dissociation constant of $160 \mathrm{nM}$, both in the absence and presence of $\mathrm{Ca}^{2}+(5.0 \mathrm{mM})$ was found. This value compares very well with reported ones (151). It is also shown that $\mathrm{Ca}^{2+}(5.0 \mathrm{mM})$ affects the interaction between heparin and thrombin as is indicated by a 3-fold decrease of the $V_{\max }$ value (from 8.6 to $2.9 \mathrm{~nm} / \mathrm{min}$ ). Evidently, the data obtained with in situ prothrombinase-formed thrombin cannot be analyzed in this way, which suggests a more complicated heparin-dependent reaction mechanism.

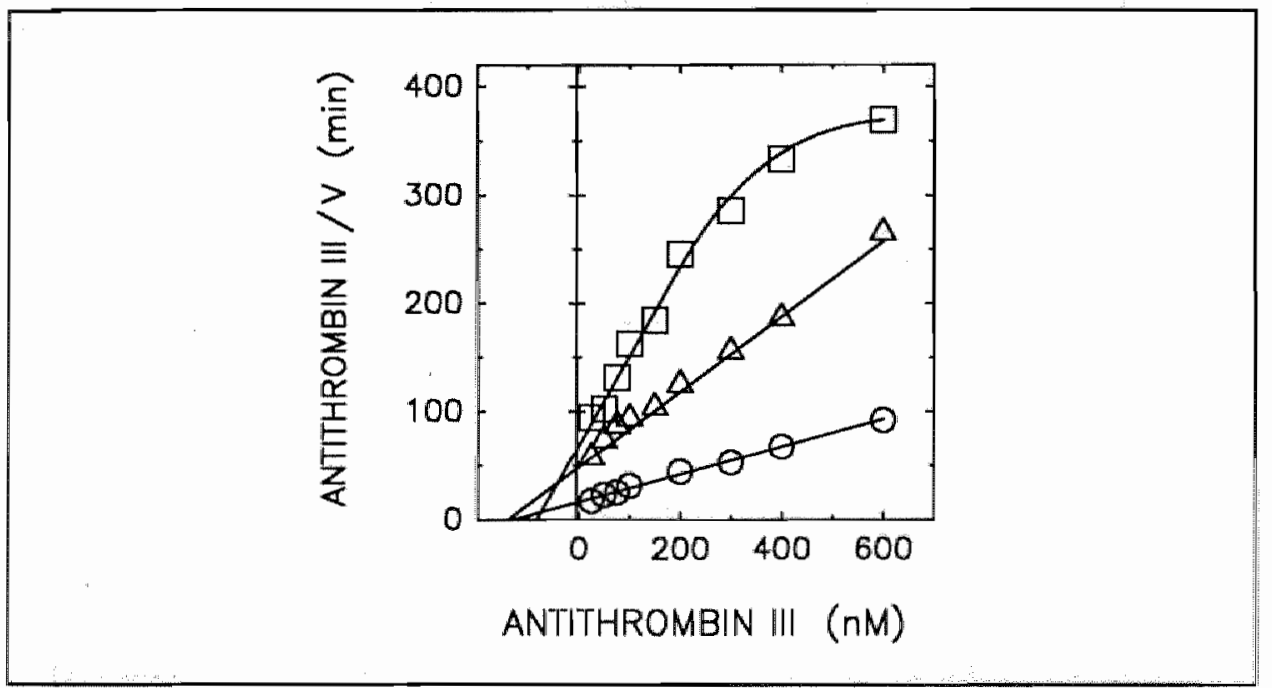

Figure 5. Kinetics of the heparin-catalyzed ATII-thrombin reaction. The ratio of the initial ATIII concentration over the initial rate of thrombin Inactivation in the presence of $50 \mathrm{ng} / \mathrm{m} / \mathrm{heparin}$ and corrected for the heparin-independent reaction is plotted as function of the Initial ATIII concentration. $O$, purified thrombin in the absence of $\mathrm{Ca}^{2+} ; \Delta$, purified thrombin in the presence of $\mathrm{Ca}^{2+}(5.0 \mathrm{mM}) ; \square$, prothrombinase-formed thrombin. 


\section{DISCUSSION}

Kinetic studies with purified thrombin and ATIII have made it clear that the binding of both ATIII and thrombin is required for an effective catalytic action of heparin $(40,41,151,152)$. Consequently, reagents that interfere with the assembly of this ternary complex can be expected to alter the kinetics of the inhibition of thrombin by ATIII. This study was designed to determine whether the kinetics of inhibition of thrombin during its generation in a pure system, consisting of the fully assembled prothrombinase complex and prothrombin "are different from those obtained with exogenous thrombin. From literature one could already predict that $\mathrm{Ca}^{2+}$-ions will cause a reduced rate of inactivation of thrombin during its generation be-cause of their heparin-neutralizing effect (128). Furthermore, an additional effect was to be expected from prothrombin fragment 1.2, fragment 2 and/or fragment 1, which are formed during thrombin generation. In the presence of fragment 2 the heparin-independent inhibition of thrombin by ATIII proceeds about 3 times slower than in its absence (137). It has also been reported that both fragment 1 and fragment 1.2 are potential heparin neutralizing proteins (140).

Studies on the heparin-dependent inhibition of thrombin formed upon human prothrombin activation might be further complicated when meizothrombin, recently demonstrated to be formed during prothrombin activation $(89,90,139)$, is produced as well.

The data presented herein show that inhibition of prothrombinase-formed thrombin activity kinetically differs from that of purified thrombin. When human prothrombin was activated by the prothrombinase complex in the absence of heparin, and STII was added to prevent further thrombin formation, addition of ATIII caused a mono-exponential decay of the amidolytic thrombin activity. However, the same experiment in the presence of heparin revealed a bi-phasic thrombin decay curve. A bi-exponential equation (Equation 1) could be fitted to the data of the latter experiment, resolving the pseudo-first order rate constants, as well as the initial concentrations of a fast and slow disappearing thrombin species. The residuals to the fitted line were randomly distributed around zero and the $95 \%$ confidence intervals of the estimated parameters were quite acceptable. The two inactivated thrombin species were identified by means of an immunoblot technique using rabbit anti-human ATIII $\lg G$ as the indicator antibody. In the presence of heparin the band that comigrated with the ATIII-thrombin complex appeared faster than the band that comigrated with the AT III-meizothrombin (des fragment 1) complex. In the absence of heparin "both complexes appeared with apparently identical rates.

By use of the four-parameter equation to analyze the heparin-dependent decay curves of the thrombin activity we found that the ATIII/meizothrombin(des fragment 1) reaction was not stimulated by heparin, whereas the pseudo-first order rate constant of inhibition of thrombin increased linearly with the heparin 
concentration. We note that there might be a significant difference between the rate constant determined by extrapolating to zero heparin and the rate constant of inhibition of meizothrombin(des fragment 1) (Figure 2, vertical intercepts). The values are $0.065 \mathrm{~min}^{-1}$ and $0.034 \mathrm{~min}^{-1}$, respectively. Interestingly, the former value equals the rate constant of inhibition of purified thrombin (Figure $4 \mathrm{~A}$ ) and is in accord with reported ones $(155,156)$. These findings may reflect a fundamental phenomenon. Indeed, Walker and Esmon (137) have reported that in the absence of heparin the inhibition of meizothrombin(des fragment 1) by ATIII proceeds at about a 3-fold slower rate than the inhibition of thrombin.

However, the heparin-independent rate constant found by extrapolation is inconsistent with the measured value. The best fit to our heparin-independent data was obtained with a mono-exponential decay function. Thus, thrombin and meizothrombin(des fragment 1 ) were inhibited with apparently identical rates $\left(k=3.7 \times 10^{5} \mathrm{M}^{-1} \mathrm{~min}^{-1}\right)$. Because of the discrepancy between the extrapolated and measured rate constant of inhibition of thrombin in the absence of heparin, we tested the "goodness of fit" as follows.

Using the mean rate constant of inhibition of meizothrombin (des fragment $1 》 \mathrm{k}=0.034 \mathrm{~min}^{-1}$, and the initial meizothrombin (des fragment 1) concentration, $3.7 \mathrm{nM}$, obtained from the bi-exponential fit to the experimental data from the heparin-containing experiments (Figure 2), we calculated the residual thrombin concentration at any time, $t$, of the heparin-independent decay curve. Next, we calculated the heparin-independent rate constant of inhibition of thrombin by fitting a mono-exponential decay function to these calculated data. The value thus obtained, $0.035 \pm 0.001 \mathrm{~min}^{-1}$, is identical to the one determined directly from our experimental data.

It has been reported that thrombin and prothrombin fragment 2 form a complex and that this complex resembles meizothrombin(des fragment 1) with respect to its reaction with ATIII (137). We propose that under our conditions of prothrombin activation thrombin remains non-covalently bound to fragment 2 . Thus, a fragment 2 -induced change in thrombin most probably results in a reduced rate of heparin-independent inhibition of prothrombinase-formed thrombin. Previous work suggested that prothrombin fragment 1.2 or fragment 2 either covalently or non-covalently bound to thrombin, markedly reduces the affinity of these complexes for heparin (140). While these findings might explain why the ATIII/meizothrombin(des fragment 1) reaction is not catalyzed by heparin, we note that heparin does catalyze the ATIII/prothrombinase formed thrombin reaction. It appears reasonable to infer that by virtue of a dissociable fragment 2thrombin complex heparin reverses the fragment 2-induced change in the reactivity of thrombin towards ATIII and that, on the other hand, heparin-binding to thrombin is not markedly affected by noncovalently bound fragment 2 .

The present study has also shown that the reaction velocity for the heparindependent purified thrombin/ATIII reaction can be described by the general rate equation for a random-order bireactant enzyme-catalyzed reaction. The same 
working model appears not to describe the kinetics of inhibition of the prothrombinase-formed thrombin. At ATIII concentrations that exceeded the apparent dissociation constant of the heparin-ATIII complex (200 nM) a linear increase of the rate constant with the ATIII concentration was found. We have to emphasize that the data were corrected with the rate constants of the heparin-independent reaction, calculated from the mono-exponential decay curves obtained in the absence of heparin ( $\left.k=3.7 \times 10^{5} \mathrm{M}^{-1} \mathrm{~min}^{-1}\right)$. If this observation indicates a fundamental phenomenon, it can only be caused by prothrombin-activation fragments because the inhibition of purified thrombin, either in the absence or presence of prothrombin, factor $\mathrm{Va}$, phospholipid, $\mathrm{Ca}^{2+}$ and STI-blocked factor $\mathrm{Xa}$ could be described by the same model.

Acknowledgements- We wish to thank Dr. Jan Rosing, and Prof. H Coenraad Hemker for useful discussions and gratelully acknowledge Dr. George Willems and Jan Corsel for making their computer programs avallable to us. 


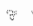





\section{Thrombin Generation and Inactivation in the Presence of Antithrombin III and Heparin $\$$}

The rate constants of Inactivation of factor $\mathrm{Xa}$ and thrombin by antithrombin III (ATIII)/heparin during the process of prothrombin activation were determined. The second order rate constant of inhibition of factor $X a$ alone by ATIII as determined by using the synthetic peptide substrate $\$ 2337$ was found to be $1.1 \times 10^{6} \mathrm{M}^{-1} \mathrm{~min}^{-1}$. Factor $\mathrm{Xa}$ In prothrombln activation mixtures that contalned prothromb $\| \mathrm{n}$, and either saturating amounts of factor Va or phospholipld (20 mol\% dioleoylphosphatldylserine/80 mol\% dloleoylphosphatidylchollne, $10 \mu \mathrm{M}$ ) was Inhiblted by ATIII with a second order rate constant that was essentially the same: $1.2 \times 10^{6} \mathrm{M}^{-1} \mathrm{~min}^{-1}$. When both factor $\mathrm{Va}$ and phospholipld were present during prothrombln actlvation, factor Xa Inhibition by ATIII was reduced about 10 times, with a second order rate constant of $1.3 \times 10^{5} \mathrm{M}^{-1} \mathrm{~m}^{-1} \mathrm{n}^{-1}$. Factor $X a$ In the prothrombln activation $\mathrm{mlx}$ ture that contalned both factor $\mathrm{Va}$ and phosphollpld was even more protected from inhlibition by the ATIII/heparln complex. The flrst order rate constants of these reactions at $200 \mathrm{nM}$ ATIII and normallized to heparin at 1 $\mu \mathrm{g} / \mathrm{ml}$ were $0.33 \mathrm{mln}^{-1}$ and $9.5 \mathrm{mln}^{-1}$ In the presence and the absence of factor $\mathrm{Va}$ and phosphollpld, respectlvely. When prothrombin was varled widely around the $K_{m}$ for prothrombin, this had no effect on the first order rate constants of inhibition. It is our conclusion that factor $\mathrm{Xa}$ when acting In prothrombinase on prothrombin is profoundly protected from Inhibition by ATIII In the absence as well as in the presence of heparin. The second order rate constant $\left(4.5 \times 10^{5} \mathrm{M}^{-1} \mathrm{~min}^{-1}\right)$ of $\mathrm{Inh} / \mathrm{b}$ ition of thrombln activity generated during prothrombin activation was found to be 1] constant during the time course of prothrombin actlvation, 2] Independent of the composition of the prothrombin converting complex, and 3] about 4 times lower than the second order rate constant of inhibition of purlfled $\alpha$ thrombin $\left(1.9 \times 10^{6} \mathrm{M}^{-1} \mathrm{~m}^{-1} \mathrm{n}^{-1}\right)$. Surprisingly, heparin hardly enhanced the ATIII-dependent rate of Inhlbitlon of thrombln actlvity formed during the Initial phase of prothrombin activation. The apparent pseudo-first order rate constant of this reaction at $200 \mathrm{nM}$ ATIII and normallzed to heparin at $1 \mu \mathrm{g} / \mathrm{ml}$ was $0.10 \mathrm{~min}^{-1}$ and independent on the stage of thrombin productlon. The rate constant of the purifled $\alpha$-thrombin/ATIII reaction, extrapo-

$\$$ Lindhout T, Baruch D, Schoen P, Franssen J, Hemker HC. Blochemlstry 25:5962-5969, 1986 
lated to the same ATIII and heparln concentratlons, was $25 \mathrm{~m} / \mathrm{m}^{-1}$. Thls difference between the two reactions of thrombin Inactivation is caused by the fact that melzothrombin(des fragment 1), rather than $\alpha$-thrombin, is the major product during the inlitial phase of prothromblin actlvation.

The plasma protein antithrombin III (ATIII) is an inhibitor of serine proteases involved in the process of blood coagulation. Its action is dramatically enhanced by heparin. The main targets of ATIII are activated blood coagulation factor IX (factor IXa), factor Xa and thrombin (see Reference 103, and references cited therein).

The activation of prothrombin to thrombin is a membrane-mediated process requiring the binding of both factor $\mathrm{Xa}$ and prothrombin to a negatively charged membrane surface (phospholipid vesicies). In addition, activated blood coagulation factor $V$ (factor $V a$ ) that interacts with the membrane, factor $X a$ and prothrombin, greatly increases the $V_{\text {max }}$ of prothrombin activation and lowers the $K_{m}$ for prothrombin (see Reference 87, and references cited therein). Because in vivo both factor $\mathrm{Va}$ and phospholipids are present during factor $\mathrm{Xa}$ catalyzed activation of prothrombin, a number of studies were undertaken to reveal the effects of these so-called accessory components on factor $X_{a}$ inhibition by ATIII. It has been shown that the inhibition of factor $\mathrm{Xa}$ is reduced by phospholipids alone $(157,158)$ and by phospholipids when factor Va is present (107).

Ellis et al (158) used the rate of prothrombin activation as a measure for residual factor Xa activity. Quite unexpectedly, the ATIII carried over in the prothrombin activation assay, as far as we understand, did not affect the thrombin nor the factor Xa activity. Walker and Esmon (137) reported that fragment 2 was found to slow down the rate of inhibition of $\alpha$-thrombin about 3 times. These abservations provoked the investiglation of the kinetics of the ATIII-dependent neutralization of both factor $\mathrm{Xa}$ and thrombin activity under more physiological conditions. Therefore, our purpose was to assess the kinetics of the ATIII-dependent inhibition of factor Xa as part of the prothrombinase complex while acting on prothrombin as well as the kinetics of the ATIIl-dependent inhibition of thrombin activity as a product of the prothrombinase reaction. The basic assumption underlying the data analysis of the experiments presented here was that at any time during the prothrombin activation reaction in the presence of ATIII, the observed rate of thrombin formation equals the actual rate of thrombin formation (which is proportional with the residual factor $X a$ activity) minus the rate of inhibition of the thrombin activity. The same experiments were also performed in the presence of unfractionated heparin.

Our results lead us to question the validity of a number of basic assumptions underlying the current ideas about the effects of factor $\mathrm{Va}$ and phospholipid on the factor Xa/ATIII reaction. Furthermore, a dramatic discrepancy was found 
between the kinetics of the heparin-dependent inhibition of thrombin activity generated during prothrombin activation and of purified $\alpha$-thrombin by ATIII.

\section{EXPERIMENTAL PROCEDURES}

Materials-1,2-Dioleoyl-sn-glycero-3-phosphocholine (DOPC), soybean trypsin inhlibitor (ST), and fatty acid tree human serum albumin (HSA) were purchased from Sigma (St.Louis, USA). S2238 and S2337 were obtained from Kabi Diagnostica (Stockholm, Sweden). Crude heparin (168 USP units/mg) was generously provided by Pharmuka Laboratonies (Gennevilliers, France). All reagents used were of the highest grade commercially available.

Proteins and Phospholipid Vesicle Preparation-Bovine ATIII was prepared by the method of Thaler \& Schmer (146). All other bovine clotting factors were prepared and quantified as previously described (145), 1,2-Dioleoyl-sn-glycero-3-phosphoserine (DOPS) was prepared from DOPC as described earlier (159). Sonicated wesicle solutions were prepared trom mixtures of DOPS (20 mol\%) and DOPC $(80 \mathrm{~mol} \%)$ in a $50 \mathrm{mM}$ Tris-HCL buffer (pH 7.9), containing $175 \mathrm{mM}$ $\mathrm{NaCl}(160)$.

Determination of Inhibition Rate of Purlfied Proteases - The neutralization of factor $\mathrm{Xa}$ and thrombin by ATIII was investigated under pseudo-first order conditions. Factor Xa or thrombin was incubated with ATIII at $37^{\circ} \mathrm{C}$, in $50 \mathrm{mM}$ Tris-HCL (pH 7.9), containing $175 \mathrm{mM} \mathrm{NaCl}$ and $0.5 \mathrm{mg} \mathrm{HSA} / \mathrm{ml}$. At timed intervals atter the addition of the protease, $10 \mu \mathrm{l}$ aliquots were removed, and added to $590 \mu \mathrm{l}$ of substrate solution ( $50 \mathrm{mM}$ Tris-HCL (pH 7.9), containing $175 \mathrm{mM} \mathrm{NaCl}, 20$ ImM EDTA, $0.5 \mathrm{mg} \mathrm{HSAml}$, and $0.22 \mathrm{mM} \mathrm{S2238}$ or $\$ 2337$ ) at $37^{\circ} \mathrm{C}$. After $4 \mathrm{~min}, 300 \mu \mathrm{l}$ of $50 \%$ acetic acid ( $V / V)$ was added, and the absorbance of the mixture was measured at $405 \mathrm{~nm}$ against a blank on an Aminco DW2 spectrophotometer. The rates of thrombin and factor Xa inhibition by ATIII, after sampling into the substrate solution were found to be sufficiently slow not to not result in measurable enzyme inhibition during the conversion of chromogenic substrate. Residual enzymatic activities were calculated from a standard curve of known amounts of thrombin or factor $X a$, constructed under identical conditions, and exponentially plotted vs. reaction time.

Neutralization of Factor Xa and Thrombin by ATIII In Prothrombin Activation Mixtures- Prothrombin was incubated with ATIII in the presence of either factor Va, phospholipid vesicles, or heparin, or with a combination of these, in $50 \mathrm{mM}$ Tris-HCL (pH 7.9), containing $175 \mathrm{~mm}$ $\mathrm{NaCl}, 5$ or $10 \mathrm{mM} \mathrm{CaCl}_{2}$, and $0.5 \mathrm{mg} \mathrm{HSAml}$ at $37^{\circ} \mathrm{C}$ for $4 \mathrm{~min}$. Prothrombin activation was started by the addition of factor $X_{a}$. The final concentrations of the reaction components are listed in Table 1. At timed intervals after the addition of factor $X a, 40 \mu$ aliquols were removed and added $10560 \mu \mathrm{ll}$ of the aforementioned solution of $\$ 2238$. Thrombin concentrations were determined as described above. In separate experiments, STI $(20 \mu \mathrm{g} / \mathrm{ml})$ was added to prothrombin activation mixtures al known intervals after the addition of factor $\mathrm{Xa}$, resulting in an instantaneous and complete inhibilion of thrombin formation. After the addition of $S T I_{n} 40 \mu$ aliquols were removed at regular intervals and assayed for thrombin activity. Control experiments established that STI had no effect on the ATIllthrombin reaction nor on the amidolytic activity of thrombin.

KInetlc Analysis of ATIII/Factor Xa and ATIIIThrombin Reactlons in Prothrombin Activation Mixtures- When thrombin is generated through prothrombinasecatalyzed activation of prothrombin in the presence of ATIIH, the appearance rate of amidolytic active thrombin $\left.{ }^{1}\right), v_{r}$, will vary as function of time, $t$, according to:

$$
\left(w_{p}\right)_{t}=\left(v_{B}\right)_{t}-\left(v_{i}\right)_{t}
$$

" "Amidolytic active thrombin" or "1hrombin activity" is used throughout this paper to indicate that this activity is not necessarily identical with the formation of $a$-thrombin. 
Table 1. Conditions of prothrombin activation. The reactions were pertomed in a butfer containing $50 \mathrm{mMM}$ Tris $\mathrm{HCl}$ (pH 7.9), containing $175 \mathrm{mM} \mathrm{NaCl}$, and $0.5 \mathrm{mg} \mathrm{HSAml}$, at $37^{\circ} \mathrm{C}$.

\begin{tabular}{|c|c|c|c|c|c|c|}
\hline & & Com & sition & & Prothrombin & Thrombin Formation \\
\hline & $F \times a$ & FVa & Phospholipid & $\mathrm{Ca}^{2+}$ & & \\
\hline & $(n M)$ & $(n M)$ & $(\mu M)$ & $(\mathrm{m} / \mathrm{M})$ & $(\mu M)$ & (Illa-min'-1 $\left.\times a^{-1}\right)$ \\
\hline $\mathbb{1}$ & 0.003 & 0.1 & 10 & 5 & 1.0 & 2000 \\
\hline 2. & 1.5 & 20.0 & - & 5 & 6.0 & 2 \\
\hline 3. & 4.0 & $\therefore$ & 5 & 10 & 0.5 & 0.6 \\
\hline
\end{tabular}

Abbreviations: $F X a$ tactor Xa; F Va: factor Va

where $\left(v_{a}\right)_{t}$ is the velocity of thrombin generation at time $t$ and $\left(v_{i}\right)_{t}$ is the velocily of the ATtil/thrombin reaction at time $t$. In all experiments the initial ATIll concentration was significantly Iarger than the protease concentrations, so that the protease/ATIII reactions followed pseudo-first order kinetics over the time course studied. Thus, when after any interval prothrombin activation is blocked, $\left(v_{i}\right)$, can be calculated by multiplying the observed pseudo-first order rate constant of the ATlilthrombin reaction by the thrombin concentration.

It is important to note that the ATIIl/protease reaction is a two step reaction. The reversible interaction between ATIII and thrombin $\left(K_{\mathrm{d}}=1.4 \times 10^{-3} \mathrm{M}\right.$, in the absence of heparin) is followed by the formation of a stable ATIII-thrombin complex, with a rate constant of $k=10.4 \mathrm{~s}^{-1}$ (37). Thus, the reaction can be analyzed by pseudo-first order kinetics only when both the ATIII and protease concentrations are far below their $K_{d}$ value. This condition holds for our heparin-free experiments.

The pseudo-first order rate constant of the ATIII/Lactor Xa reaction can be obtained when $\left(\mathrm{v}_{\mathrm{ag}}\right)_{\mathrm{t}}$ is plotted exponentially $v s$. $t$. The velocity of thrombin generation at time $t, v_{a}$, was callulated from Equation 1 . The appearance rate of amidolytic active thrombin at time $t, v_{p}$, was determined from the slope of the thrombin generation curve at time t.

The same method was used for analysis of the data from the heparin-dependent reactions. Again, the pseudo-first order approach will only work if the thrombin concentration remains far below its saturation value (161). Because the thrombin dissociation constants of the heparindependent reaction, as reported in the literature, range from less than $2 \mathrm{nM}(111)$ to $4 \mu \mathrm{M}(37)$, we pertormed an independent determination of thrombin saturation under our own conditions. In separate experiments prothrombin activation in the presence of heparin and ATIII was stopped at different time intervals by the addition of STI. Samples were taken and assayed for residual thrombin activity. Thus, the inhibition of thrombin could be studied at fixed ATIII and heparin concentrations but varying thrombin concentrations.

Electrophoretic Blotting Procedure-Proteins were subjected to gel electrophoresis in the presence of sodium dodecyl sulfate as described (149). The proteins were then electrophoretically transterred to nitrocellulose sheets (150). The electrophoretic blots were soaked in $0.1 \%$ bowine serum albumin and $0.05 \%$ Tween 20 in phosphate-butfered saline. In essence, the immunalogical detection of ATIII and ATIII/protease complexes were performed as described by Towbin et al (150). The first antisenum was rabbit anti-human ATII, which was obtained from Sigma (St.Louis, USA). We used horseradish peroxidase-conjugated swine anti-rabbit IgG from Dakopatts (Glostrup, Denmark) as indicator antibody. For the color reaction, the blots were soaked in a solution of $50 \mathrm{mM}$ Tris $+\mathrm{HCl}(\mathrm{pH} 7.5)$, containing $0.5 \mathrm{mg} / \mathrm{ml}$ diaminobenzidine tetrahydrochloride, and $0.01 \% \mathrm{H} 2 \mathrm{O} 2$. This solution was prepared freshly, and filtered prior to use. 


\section{RESULTS}

Activation of Prothrombin to Thrombin in the Presence of ATIIThe experimental conditions of prothrombin activation that were used to study the inhibitory action of ATIII are summarized in Table 1 . The reactions were initiated by the addition of factor Xa. Under all conditions the rate of thrombin formation was proportional to the factor Xa concentration and, when performed in the absence of ATIII, linear during the time course of the experiments. In the presence of ATIII, the rate of appearance of thrombin activity decreased in time. We assumed that this was due to the inactivation of factor $X a$ and the inhibition of thrombin activity. A typical curve is shown in Figure 1.

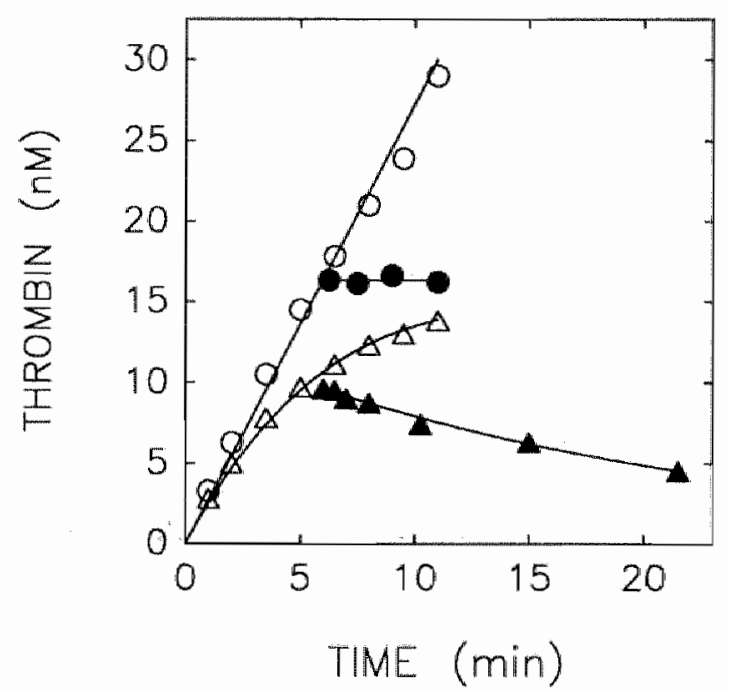

Figure 1. Inhibition of thrombin formation and thrombin activity in prothrombin activation mixtures by $A$ TIII. Prothrombin $(0.50 \mu \mathrm{M})$ was activated by $4.0 \mathrm{nM}$ factor $X \mathrm{a}$ in the presence of $5.0 \mu \mathrm{M}$ phospholipid, and $10 \mathrm{mM} \mathrm{CaCl}_{2}$ either in the absence $(0,0)$ or presence $(\Delta, \Delta)$ of $100 \mathrm{nM}$ ATIII. At timed intervals samples were taken and assayed for thrombin activity. In separate experiments $S T$ $(20 \mu \mathrm{g} / \mathrm{ml})$ was added $6 \mathrm{~min}$ after starting prothrombin activation with factor $X a$. The time courses of thrombin activity then obtained are indicated by the closed symbols.

To distinguish between the action of ATIII on thrombin and on factor Xa, we blocked factor $\mathrm{Xa}$ by the addition of STI. Thus by preventing further thrombin formation the inhibition of thrombin activity can be studied separately. As shown in Figure 1, STI instantaneously and completely inhibited thrombin production, whereas it had no effect on the thrombin activity (upper curve). When STI was added at timed intervals after the start of prothrombin activation in the presence 
of ATIII, the decrease in thrombin activity is solely due to the ATIllthrombin reaction (lower curve). As shown in Figure 2, the reaction followed apparent first order kinetics. We found that the pseudo-first order rate constants of inhibition of thrombin activity $\left(k=0.04 \mathrm{~min}^{-1}\right)$ did not vary with the stage of thrombin production.

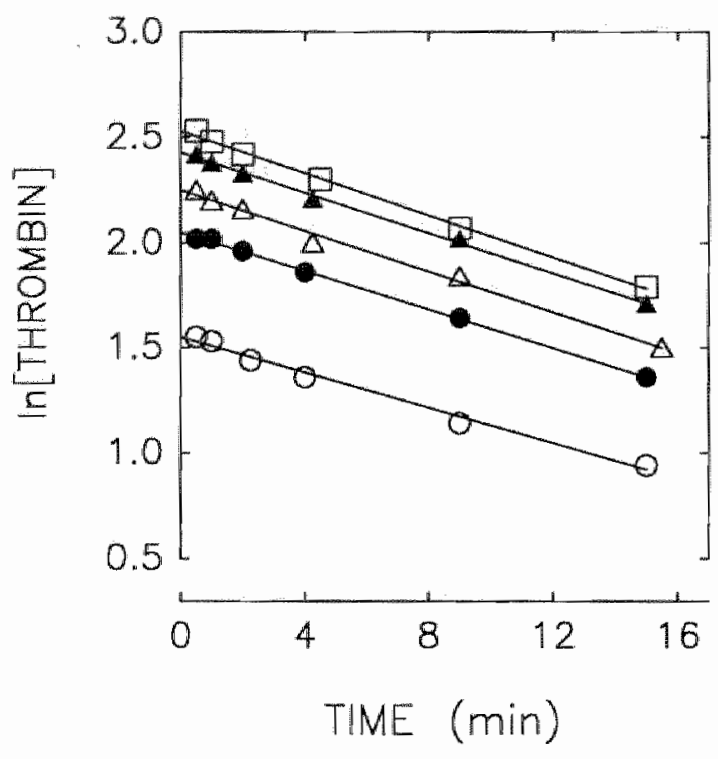

Figure 2. Pseudo-first order plats of inhibition of thrombin activity in prothrombin activation mixtures by ATII. Conditions af prothrombin activation in the presence of ATIII were as given in Figure 1. After the addition of $\mathrm{STH}$, samples were taken and assayed for residual thrombin activity. The oxpressions are various time intervals of addition of $S T$ T: (O) $2 \mathrm{~min},(-) 4 \mathrm{~min},(\Delta) 6 \mathrm{~min},(\Delta) 8$ min, (a) $10 \mathrm{~min}$.

Knowing the rate constant of inhibition of thrombin activity the rate of inhibition of thrombin can be calculated at any known concentration of thrombin, i.e. at any point of the curve of thrombin activity vs. time. From the same curve the rate of appearance of thrombin activity can be determined from the slope at time t. The sum of this rate and the rate of disappearance gives the actual rate of prothrombin activation at any point of the thrombin generation curve. The latter then is a true measure for the residual factor Xa activity at time $t$ (Figure 3). From an exponential plot of the rate of prothrombin activation (prothrombinase activity) vs. time the pseudo-first order rate constant of inhibition of factor Xa by ATIll can be estimated (Figure 3, inset). 


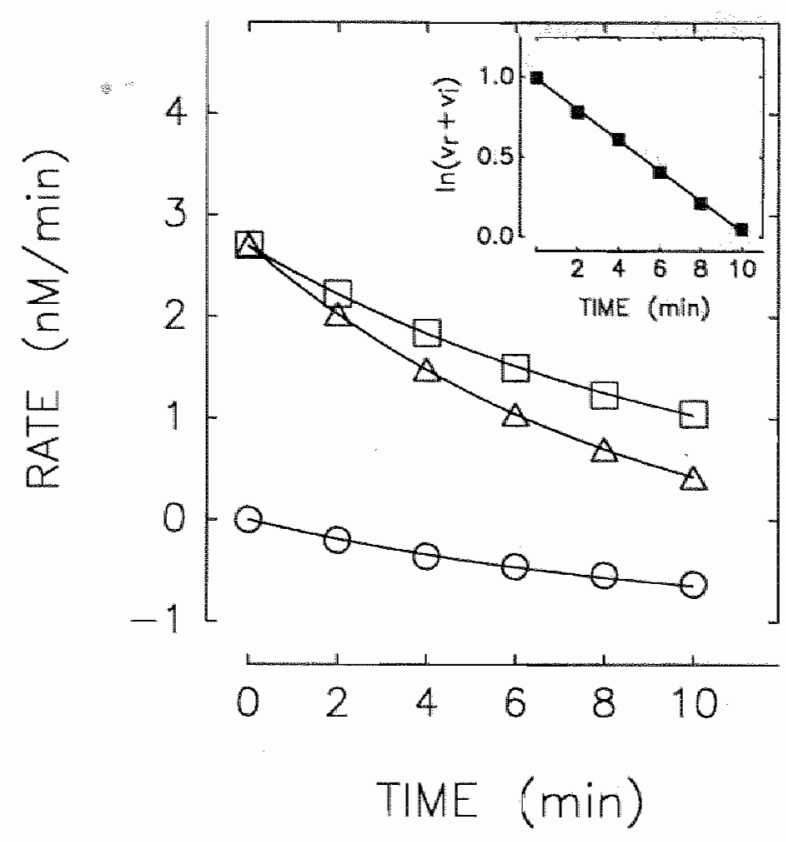

Figure 3. Rate of thrombin formation in the presence of antithrombin III. Prothrombin aclivation in the presence of $100 \mathrm{nM}$ ATIll was carried out as described in Figure 1. The rate of thrombin formation $\left(\Delta_{v} v_{r}\right)$ was calculated from the slope of the thrombin generation curve at the times indicated on the horizontal axis. This rate was corrected for the rate of thrombin inactivalion $\left(O, v_{i}\right)$ and the result $\left(\mathrm{v}_{\mathrm{a}}\right)$ is depicted by the open squares. The inset to the figure shows the exponential plot of $v_{a}$ versus the prothrombin activation time (D).

Table 2. Second order rate constants of inhibition of factor Xa and thrombin by ATIII. The second order rate constants were determined as outlined in the text.

\begin{tabular}{llr}
\hline Reaction Conditions & \multicolumn{2}{c}{ Second Order Rate Constant } \\
\cline { 2 - 3 } & Thrombin & Factor Xa \\
\hline & $\left(\mathrm{M}^{-1} \mathrm{~min}^{-1}\right)$ & $\left(\mathrm{M}^{-1} \mathrm{~min}^{-1}\right)$ \\
& $19.0 \times 10^{5}$ & $11.0 \times 10^{5}$ \\
Free proteases & & \\
$\alpha$-Thrombin in the Presence of & \\
$\quad$ Prothrombinase, Prothrombin and STI & $20.0 \times 10^{5}$ & \\
During Prothrombin Activation by $\$:$ & & $1.3 \times 10^{5}$ \\
F Xa/F Va/PI & $4.3 \times 10^{5}$ & $11.0 \times 10^{5}$ \\
F Xa/F Va & $4.4 \times 10^{5}$ & $12.0 \times 10^{5}$ \\
$\quad$ F Xa/PI & $4.9 \times 10^{5}$ & \\
\hline
\end{tabular}

$\$$ Abbreviations: $\mathrm{F}$ Xa: Iactor Xa; F Va; factor Va; PI: phospholipid 
Inhibition of Thrombin Activity in Prothrombin Activation Mixtures - Rate constants of inhibition of thrombin activity were determined after blocking prothrombin activation by STI (Cf. Figures 1 and 2). The dependency of the pseudo-first order rate constant of inhibition of thrombin activity on the ATIII concentration under different conditions of prothrombin activation is shown in Figure 4. The second arder rate constants of inhibition are listed in Table 2. Under the different conditions of prothrombin activation, we measured identical rate constants of inhibition $\left(4.5 \times 10^{5} \mathrm{M}^{-1} \mathrm{~min}^{-1}\right)$. However, the rate constants were markedly reduced when compared with the inhibition of $\alpha$-thrombin $\left(1.9 \times 10^{6} \mathrm{M}^{-1}\right.$ $\min ^{-1}$ ).

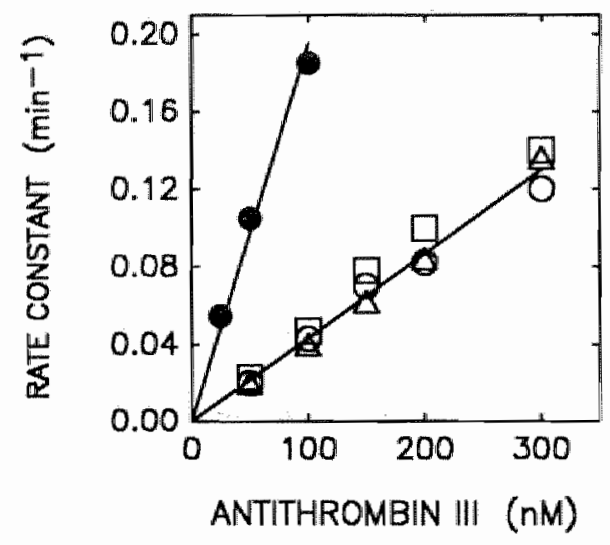

Figure 4. Pseudo-first onder rate constants of inhibition of thrombin activity as function of ATIII

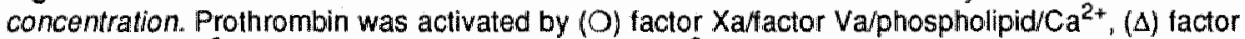
$X a / f a c t o r$ Va/Ca ${ }^{2+}$, and (G) factor $X a / p h o s p h o l i p i d / \mathrm{Ca}^{2+}$. The concentrations of the reactants are listed in Table 1, rows 1,2 and 3 , respectively. ATIII was present at various concentrations. The pseudo-first order rate constants of inthibition of thrombin aclivity were determined as described in Figure 2. The pseudo-tirst order rate constants of inhibition of $\alpha$ thrombin (-) were determined as described under "Experimental Procedures".

It might be questioned whether the prothrombin activation reactants (e.g. factor $\mathrm{Va}$, phospholipid, $\mathrm{Ca}^{2+}$, or prothrombin) caused the reduced rate of inhibition of thrombin activity. To this end, pure $\alpha$-thrombin $(10 \mathrm{nM})$ was added to a mixture containing factor $X a(3.0 \mathrm{pM})$, factor $V a(0.10 \mathrm{nM})$, phospholipid $(10 \mu \mathrm{M})$, $\mathrm{Ca}^{2+}(5.0 \mathrm{mM})$, prothrombin $(1.0 \mu \mathrm{M})$, and STI $(20 \mu \mathrm{g} / \mathrm{ml})$. Because of the presen$\mathrm{ce}$ of STI no thrombin formation occurred. After an incubation of $5 \mathrm{~min}$ at $37{ }^{\circ} \mathrm{C}$, ATIII was added and samples were taken at different time intervals to determine residual $\alpha$-thrombin activity. The ATIII concentrations varied between 50 and 300 $\mathrm{nM}$. The second order rate constant of inhibition of $\alpha$-thrombin under these 
conditions was found to be $2.0 \times 10^{6} \mathrm{M}^{-1} \mathrm{~min}^{-1}$, indicating that the prothrombin activation components had no effect on the rate constant of inhibition (Table 2).

Inhibition of Factor $\mathrm{Xa}$ in Prothrombin Activation Mixtures- Following the aforementioned procedure (Figure 3), inhibition of factor Xa by ATIII was studied in prothrombin activation mixtures of different composition. The ATIII concentration was varied between 50 and $300 \mathrm{nM}$ in order to obtain the second order rate constant of inhibition of factor Xa under these conditions.

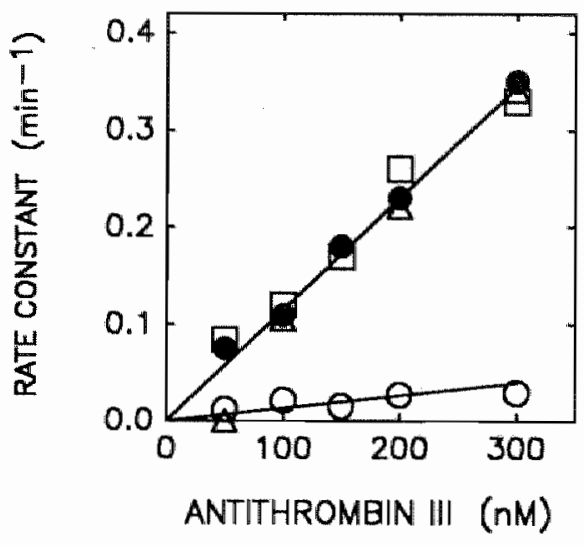

Figure 5. Pseudo-first order rate constants of inhibition of factor Xa as function of ATII

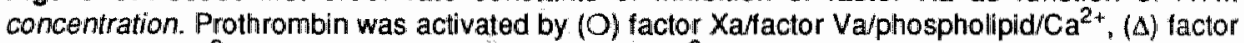
$X a /$ actor $\mathrm{Va} / \mathrm{Ca}^{2+}$, and (O) factor $\mathrm{Xa} /$ phospholipid/Ca ${ }^{2+}$. The concentrations of the reactants are listed in Table 1 , rows 1,2 , and 3 , respectively. ATIII was present at various concentrations. The pseudo-first order rate constants of inhibition of factor Xa were determined as described in Figure 3. The pseudo-first order rate constants of inhibition of free factor Xa (-) were determined as described under "Experimentall Procedures"'.

The dependency of the pseuda-first order rate constant of inhibition of factor Xa under the different conditions of prothrombin activation on the ATIII concentration is shown in Figure 5. The validity of our measuring system is indicated by the observed linear relationships. The second order rate constants are listed in Table 2. When compared with the second order rate constant of inhibition of factor Xa alone "as assayed with the synthetic peptide substrate S2337, it is clearly shown that the inhibition of factor $\mathrm{Xa}$ is reduced only when both factor $\mathrm{Va}$ and phospholipid were present. No reduction of factor $\mathrm{Xa}$ inhibition was found when prothrombin activation was performed in the presence of phospholipid and at a prothrombin concentration of $0.50 \mu \mathrm{M}, i . e$. about 25 times the $\mathrm{K}_{\mathrm{m}}$ value. It is apparent that under these conditions, prothrombin is not a competitive inhibitor of the factor Xa/ATIII reaction. Also when factor $\mathrm{Va}$ and phospholipid were present the second order rate constant of inhibition of factor Xa was found to be indepen- 
dent of the prothrombin concentration when varied between below and above the $\mathrm{K}_{\mathrm{m}}$ (data not shown).

Heparin-Dependent Inhibition of Thrombin and Factor Xa During Prothrombin Activation-Prothrombin $(1.0 \mu \mathrm{M})$ was activated by factor $\mathrm{Xa}$ $(3.0 \mathrm{pM})$ in the presence of factor $\mathrm{Va}(0.10 \mathrm{nM})$, phospholipid $(10 \mu \mathrm{M}), \mathrm{Ca}^{2+}(5.0$ mM), ATIII (200 nM), and varying amounts of heparin (Figure 6). The generation of thrombin activity decreased with increasing amounts of heparin as might be expected from a heparin concentration-dependent stimulation of both the factor Xa/ATIII and thrombin/ATIII reaction.

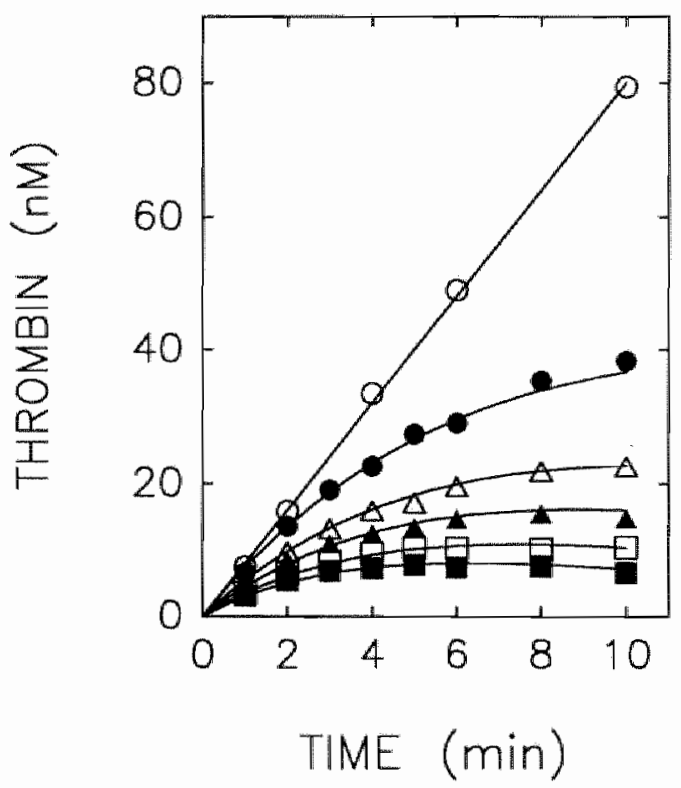

Figure 6. Elfect of heparin on the thrombin generation in the presence of ATII. Prothrombin (1,0 $\mu \mathrm{M}$ ) was activated by $3.0 \mathrm{pM}$ factor $\mathrm{Xa}$ in the presence of $0.10 \mathrm{nM}$ factor $\mathrm{Va}{ } 10 \mu \mathrm{M}$ phospholipid, and $5.0 \mathrm{mM} \mathrm{Ca}^{2+}$, in the absence (O) or presence of $200 \mathrm{nM} \mathrm{ATIII}$ and no heparin (C) or heparin at $100(\Delta), 200(4), 300(0)$, and $500 \mathrm{ng} / \mathrm{ml}(\mathbf{C})$.

The heparin-dependent inhibition of thrombin was assessed as described for the heparin-free system (see Figure 2). Thus, STI was added at different time intervals after prothrombin activation was started in the presence of ATIII and heparin, and the thrombin disappearance was measured during an additional 16 min period. Figure 7 shows the results of a typical experiment performed in the presence of $100 \mathrm{ng} / \mathrm{ml}$ heparin. Each data point is the average $(\mathrm{SD}<3 \%)$ of the residual thrombin activity as a percentage of the thrombin activity originally present at the time of addition of STI. As shown in the inset (Figure 7), the 
reaction followed pselido-first order kinetics, and the pseudo-first order rate constant of inhibition of thrombin was independent of the initial thrombin concentration when varied between 6.6 and $20.3 \mathrm{nM}$. Thus, in the presence of heparin, the stage of thrombin production had no effect on the values of the apparent first order rate constants. It is our conclusion that under our conditions the pseudo-first order approach is also useful and valid for the heparincontaining reaction system.

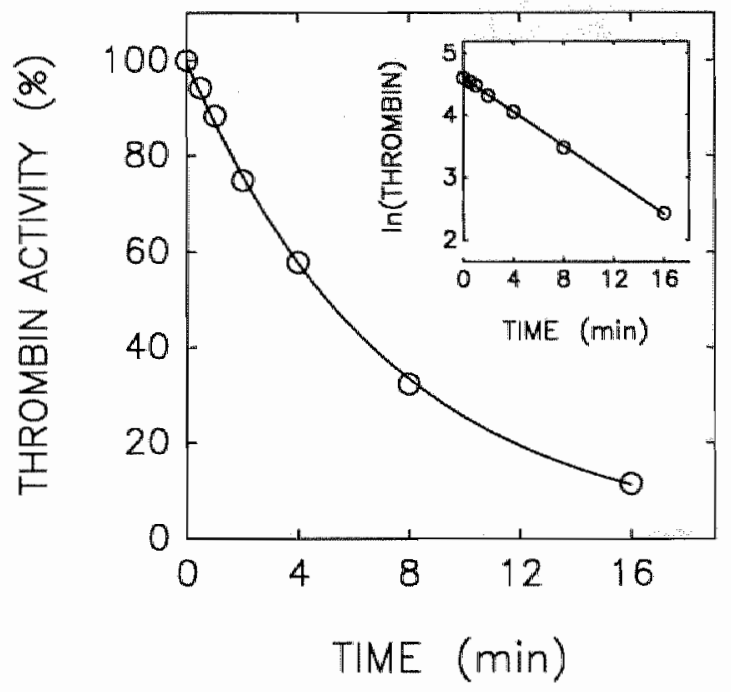

Figure 7. Disappearance of thrombin activity after blocking prothrombinase activity at different stages of thrombin generation. Prothrombin was activated under the conditions of Figure 6 in the presence off $200 \mathrm{nM}$ ATIII and $100 \mathrm{ng} / \mathrm{ml}$ heparin. Prothrombin activation was stopped by adding $S T I(20 \mu \mathrm{g} / \mathrm{ml})$ at $1,2,4$, and $10 \mathrm{~min}$ after initiating the reaction. Initial thrombin concentrations were $6.6,9.3,14.9$, and $20.3 \mathrm{nM}$, respectively. Residual thrombin activity was assayed during an additional 16 min period and given as percentage of the initial thrombin activity.

Figure BA depicts the pseudo-first order rate constant of inhibition of thrombin, formed by the prothrombinase complex, as function of heparin concentration. Surprisingly, under these conditions the thrombin/ATIII reaction is hardly stimulated by heparin. The rate constant when normalized to heparin at $1 \mu \mathrm{g} / \mathrm{ml}$ was $0.10 \mathrm{~min}^{-1}$.

One explanation that might account for the absence of a heparin effect is that some of the prothrombin activation components remove heparin from the thrombin/ATIII reaction. Therefore, we determined the pseudo-first order rate constant of inhibition of purified $\alpha$-thrombin $(5,0$ and $22 \mathrm{nM})$ in a mixture containing $1.0 \mu \mathrm{M}$ prothrombin, $0.10 \mathrm{nM}$ factor $\mathrm{Va}, 10 \mu \mathrm{M}$ phospholipid, $5.0 \mathrm{mM} \mathrm{Ca}^{2+}$, and 
varying amounts of heparin. Under all conditions, the reactions, followed for at least $80 \%$, showed pseudo-first order kinetics. Figure $8 \mathrm{~B}$ shows that the prothrombinase components and prothrombin reduced the heparin-stimulating effect about 7 times. When normalized to heparin at $1 \mu \mathrm{g} / \mathrm{m} /$, the rate constants were $180 \mathrm{~min}^{-1}$ and $25 \mathrm{~min}^{-1}$ in the absence or presence of added prothrombin and prothrombinase components, respectively. It appeared that prothrombin made the major contribution to this phenomenon. However, a 250 -fold difference was observed between the stimulating effect of heparin on the $\alpha$-thrombin/ATIII reaction in the presence of added components and the prothrombinase-formed thrombin/ATIII reaction. As shown below, this discrepancy is explained by the formation of meizothrombin, rather than $\alpha$-thrombin, as the major product of prothrombin activation under these conditions.

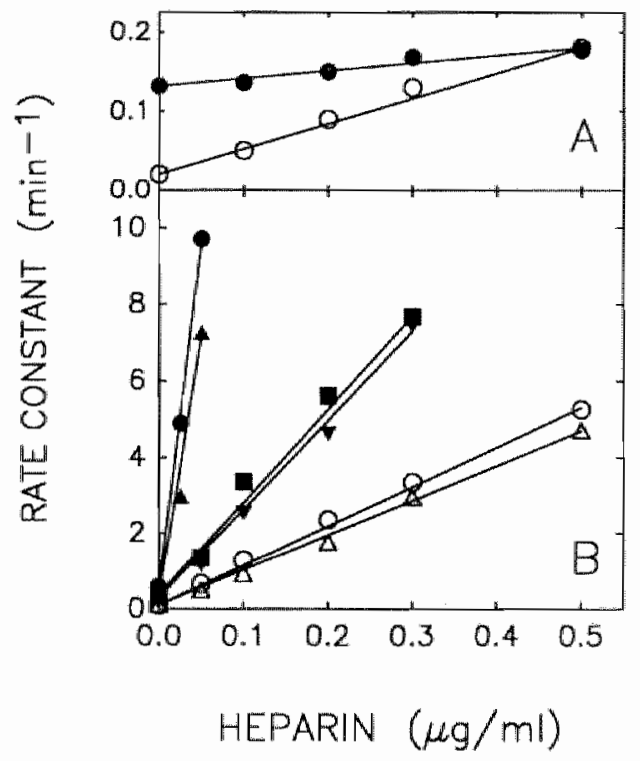

Flgure 8. Pseudo-first order rate constant of inhibition of thrombin and factor Xa activity by ATII

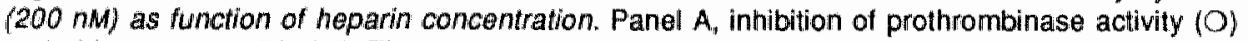
and of formed thrombin ( $)$. The reaction conditions were as given in Figure 6. Panel $B$, inhibition of $12 \mathrm{nM}$ lactor Xa (O), $5.0 \mathrm{nM} \alpha$-thrombin (-), and $22 \mathrm{nM} \alpha$-thrombin ( $\Delta$ ) in the absence of added prothrombinase components and prothrombin. Inhibition of $12 \mathrm{nM}$ factor $X a(\Delta), 5.0 \mathrm{nM}$-thrombin (E), and $22 \mathrm{nM} \alpha$-thrombin ( $\nabla)$ in the presence of $1.0 \mu \mathrm{M}$ prothrombin, $5.0 \mathrm{mM} \mathrm{Ca}{ }^{2+}, 10 \mu \mathrm{M}$ phospholipid, and $0.10 \mathrm{nM}$ factor $\mathrm{Va}$. The pseudo-first order rate constants were determined as described under "Experimental Procedures".

Because we found that in the heparin-containing reaction the apparent first order rate constant of inhibition of thrombin was independent of the thrombin 
concentration, as already demonstrated for the heparin-free reaction, the same mathematical method was used for the analysis of the heparin-dependent ATIIII factor Xa reaction during prothrombin activation. When the heparin concentration was varied between 50 and $500 \mathrm{ng} / \mathrm{ml}$ at a fixed ATIII concentration (200 nM), the pseudo-first order rate constant of inhibition of prothrombinase activity increased proportionally with the heparin concentration (Figure $8 \mathrm{~A}$ ). Under the same conditions we determined the pseudo-first order rate constant of inhibition of free factor $\mathrm{Xa}$ (Figure $\mathrm{BB}$ ). It appears that factor $\mathrm{Xa}$ in the prothrombinase complex is greatly protected from inhibition by the heparin-ATIII. The pseudo-first order rate constant, normalized to heparin at $1 \mu \mathrm{g} / \mathrm{ml}$, was $0.33 \mathrm{~min}^{-1}$, whereas the normalized rate constant for the free factor Xa/ATIII reaction, either in the absence or presence of $1.0 \mu \mathrm{M}$ prothrombin, was $9.5 \mathrm{~min}^{-1}$.

Identification of the Molecular Species with Thrombin Activity During Prothrombin Activation- It has been reported that prothrombin fragment 2 reduced the rate of inhibition of thrombin by ATIII about 3 times. The second order rate constants for ATIII-dependent inhibition of thrombin in the presence of saturating amounts of fragment 2, and the ATIII-dependent inhibition of meizothrombin (des fragment 1) appeared to be identical (137). Therefore, our results showing a reduced rate of inhibition of thrombin activity could be explained by the presence of prothrombin activation products fragment 1.2 and/or fragment 2. Another interesting possibility might be the formation of meizothrombin as an intermediate in prothrombin activation (162). In order to establish the presence of different molecular species with thrombin activity at nanomolar concentrations, we used the following procedure. At timed intervals, samples were removed from prothrombin activation mixtures containing prothrombin $(1.0 \mu \mathrm{M})$, factor $\mathrm{Xa}_{\mathrm{a}}(3.0 \mathrm{pM})$, factor $\mathrm{Va}(0.10 \mathrm{nM})$, and phospholipid $(10 \mu \mathrm{M})$. The samples were incubated with ATIII $(1.0 \mu \mathrm{M})$ and heparin $(1.0 \mu \mathrm{g} / \mathrm{ml})$ at $37^{\circ} \mathrm{C}$ for $10 \mathrm{~min}$, which resulted in complete inhibition of the thrombin activity. Subsequently, the samples were analyzed by polyacrylamide gel electrophoresis in the presence of sodium dodecyl sulfate, followed by a blotting procedure and detection of ATIII by antibodies conjugated with peroxidase as described under "Experimental Procedures"'. The resuits are shown in Figure 9.

In addition to a heavily stained band, comigrating with the large excess of free ATIII, two ATIII containing complexes are visualized: a major band comigrating with the meizothrombin(des fragment 1)/ATIII complex $\left(M_{r}=110,000\right)$ and a minor band comigrating with the $\alpha$-thrombin/ATIII complex $\left(M_{r}=91,000\right)$. Upon reduction the two ATIII containing complexes were found at a position that corresponds to that of the thrombin $B$ chain/ATIII complex $\left(M_{r}=75,000\right)$. Hence we concluded that the major product of prothrombin activation under initial rate conditions was meizothrombin (des fragment 1 ). 


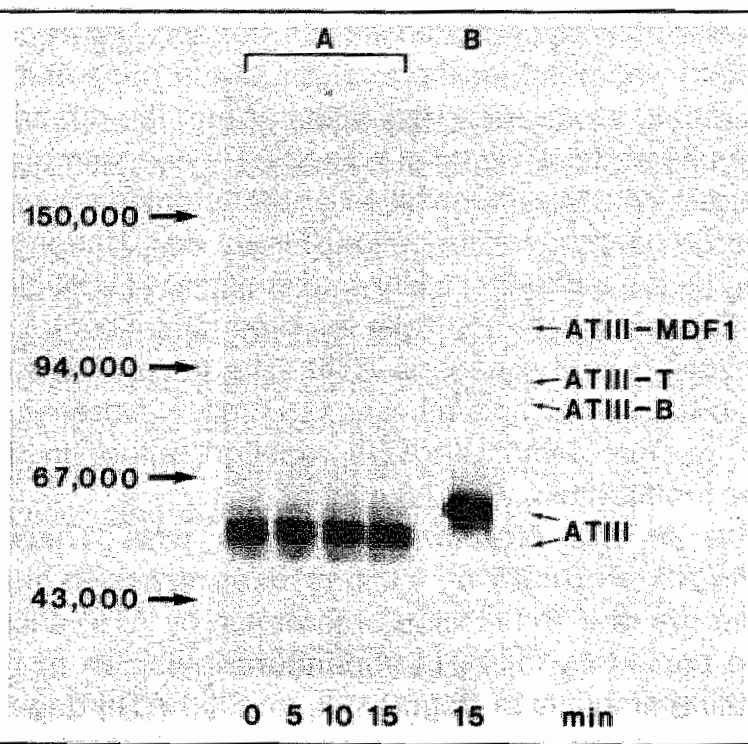

Figure 9. Identification of molecular species with thrombin activity during prothrombin activation. Prothrombin $(1.0 \mu \mathrm{M})$ was activated by $3.0 \mathrm{pM}$ factor $\mathrm{Xa}$ in the presence of $0.10 \mathrm{nM}$ factor $\mathrm{Va}, 10 \mu \mathrm{M}$ phospholipid, and $5.0 \mathrm{mM} \mathrm{CaCl}$. Samples were remaved at the indicated times, incubated with ATIII $(1.0 \mu \mathrm{M})$ and heparin $(1.0 \mu \mathrm{g} / \mathrm{ml})$, and subjected to sodium dodecyl sulfate gel electrophoresis. Panel A, unreduced samples; Panel $B$, disulfide-reduced sample. Abbreviations: MDF1, meizothrombin(des fragment 1 ); $T, \alpha$-thrombin; B, B-chain of $\alpha$-thrombin. Experimental details are given under "Experimental Procedures".

\section{DISCUSSION}

In the present paper, we report the results of a study on the inhibition of factor Xa and thrombin by ATIII/heparin. Whereas other studies have used a synthetic peptide substrate or prothrombin to measure residual factor Xa activity, our approach was to study factor Xa inactivation under its actual working conditions, i.e. during prothrombin activation. An interesting advantage of this approach is that the effects of the reaction constituents like factor $\mathrm{Va}$, phospholipid and prothrombin (and its activation products) can be studied simultaneously on both the inactivation of factor $X a$ and the inhibition of thrombin activity.

Inhibition of Factor $\mathrm{Xa}$ - Our experiments show that when prothrombin activation occurs at a phospholipid surface in the absence of factor $\mathrm{Va}$, factor $\mathrm{Xa}$ is not protected from inactivation by ATIII. Under this condition, the second order rate constant of inthibition of factor Xa was found to be $1.2 \times 10^{6} \mathrm{M}^{-1} \mathrm{~min}^{-1}$ which is identical to the rate constant of inhibition of factor $X a$ alone, as measured with a synthetic peptide substrate (Table 2). Because in the absence of phospholipid 
factor Va did not protect factor Xa from inactivation either, it is evident that protection must arise from the formation of the phospholipid-bound factor Xa/factor Va complex.

Ellis et al (158) concluded that "the protective effect is probably due to the factor Va that altered the binding of factor Xa on the phospholipid surface in such a way that the steric hindrance to ATIII binding is increased, with the large bulk of the factor Va molecule perhaps contributing to this effect". Walker \& Esmon (157) came to the same conclusion. In addition, it was reasoned that since the assay only determined phospholipid-bound factor $\mathrm{Xa}$ and not free factor $\mathrm{Xa}$, only the kinetics of inhibition of phospholipid-bound factor Xa were determined (158). Obviously, this can only be true if during the time of the experiment phospholipidbound factor $X a$ did not exchange with free factor $X a$. We note that this assumption is probably irreconcilable or incompatible with the current knowledge of both the equilibrium and dynamic properties of the factor Xa/phospholipid interaction $(163,164)$. Therefore, it is highly unlikely that Ellis et al $(158)$ have (solely) mo. nitored the inhibition of phospholipid-bound factor Xa.

Our data support this notion. Using previously reported factor Xa/phospholipid binding parameters $(165,166)$ it can be calculated that under our conditions of prothrombin activation in the presence of phospholipid the amount of factor $\mathrm{Xa}$ bound to phospholipid was at least $50 \%$ of the total amount of factor Xa present. In addition, because the $K_{m}$ values for prothrombin in the presence or absence of phospholipid are $0.020 \mu \mathrm{M}$ and $100 \mu \mathrm{M}$ (87), respectively, we can calculate that in the presence of $0.50 \mu \mathrm{M}$ prothrombin all phospholipid-bound factor $\mathrm{Xa}$ is saturated with substrate, whereas in solution the amount of factor Xa-prothrombin complexes is negligible. Therefore, our assay virtually measures thrombin formation by factor Xa bound to the phospholipid surface only. It is worth noting that synthetic peptide substrates at concentrations above their $K_{m}$ value have been reported to compete with ATIII for factor Xa (167). Thus, when factor Xa is saturated with prothrombin, we might expect to find such a competitive action of prothrombin in the factor Xa/ATIII reaction. However, the second order rate constant of factor $\mathrm{Xa}$ inactivation by ATIII during prothrombin activation in the presence of phospholipid was the same as that determined for free factor $\mathrm{Xa}$ (Table 2). This observation, together with the known data on the kinetics of factor $X a / p h o s p h o l i p i d$ interaction, strongly indicate that the hypotheses and conclusions of Ellis et al (158) are untenable. That is, the effect of phospholipid on the kinetics of inhibition of factor Xa by ATIII cannot be explained by assuming that the enzymatic properties towards ATIII are altered when factor Xa is bound to the phospholipid surface. Because of the rapid kinetics of the factor $\mathrm{Xa/phospholipid}$ interaction, the inhibition of free factor $\mathrm{Xa}$ has to be considered as well. In this respect it is important to note the following.

It thas been demonstrated $(164,168)$ that factor Xa has a marked effect on the rate of dissociation of factor Va from a phospholipid surface. The most likely explanation for this effect is that because of the tight association between the two 
phospholipid-bound proteins (145) a complex is produced with two membrane association sites. The overall result is a markedly reduced rate of dissociation of both factor $\mathrm{Va}$ and factor $\mathrm{Xa}$ from the phospholipid surface. Therefore, the protection of lactor Xa from inhibition by ATIII when both factor Va and phospholipid are present might be caused by the reduced rate of dissociation of factor Xa from the phospholipid surface.

In conclusion, our results argue strongly for a partition of factor Xa between the phospholipid surface and ATIII in solution. It is feasible that protection of factor Xa from inhibition by ATIIII depends on both the rate of inhibition of factor $X a$ in solution and the rate of dissociation of factor $X a$ from the phospholipid surface.

Inhibition of Thrombin- The second aim of this study was to reveal whether or not the kinetics of inhibition of $\alpha$-thrombin differ from those of inhibition of thrombin activity formed during the initial phase of prothrombin activation. There has been a report on the effect of prothrombin fragment 2 on the inhibition of $\alpha$-thrombin by ATIII (137). In addition, recent work from our laboratory has indicated that during the initial phase of prothrombin activation by factor $\mathrm{Xa}$ prothrombin is mainly cleaved between $\mathrm{Arg}^{323}$ and $\mathrm{Il}^{324}$, resulting in amidolytic-active meizothrombin (162). We found that the second order rate constant of inhibition of $\alpha$-thrombin by ATIII was about 4 times the rate constant of thrombin activity in the prothrombin activation mixtures and independent of the composition of the prothrombinase complex. It has been reported (137) that fragment 2 slows down the rate of inhibition of $\alpha$-thrombin about 3 times. Therefore, the presence of fragment 2 and/or fragment 1.2 in our activation mixtures might be a plausible explanation for our findings. An alternative explanation is the formation of meizothrombin, because covalently and noncovalently linking of fragment 2 to thrombin gave the same second order rate constants of inhibition (137). Therefore, we analyzed our activation mixtures for the presence of meizothrombin. As shown, a considerable amount of meizothrombin(des fragment 1) was detected (Figure 9). Because meizothrombin appeared to be the main product under the conditions used, it can be questioned whether pure $\alpha$-thrombin can be used as a standard to measure the reaction product of prothrombin activation. However, on basis of functional molar concentrations as assessed by active site titration of meizothrombin preparations obtained by the activation of prothrombin with Echis Carinatus venom and $\alpha$-thrombin preparations, we found no differences between the reactivity of $\alpha$-thrombin and meizothrombin towards the synthetic peptide substrate S2238.

Intriguing is the observation that when heparin is studied in prothrombin activation mixtures, it had hardly any effect on the inhibition of thrombin activity by ATIII. We ruled out that this phenomenon was solely caused by the heparinbinding properties of prothrombin. As yet, it remains to be established to what extent and in which mode fragment 2 and/or fragment 1.2 either covalently or noncovalently bound to $\alpha$-thrombin affects the interaction between heparin and 
thrombin. In the mean time, we have initiated a study on the interaction between meizothrombin and heparin. Our results indicate that in contrast to $\alpha$-thrombin, meizothrombin is unable to bind heparin (140).

Acknowledgements- We are grateful to Dr. Hans Soons for assistance with the electrophoretic blotting procedure and to Dr. Jan Rosing for reading and criticizing the manuscript. 
9

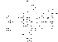

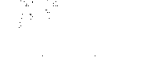

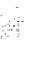

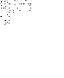

(n)

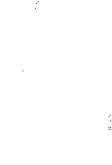

列 


\section{Antithrombin III-dependent Anti-prothrombinase Activity of Heparin and Heparin Fragments $\$$}

Heparin and heparin fragments in the molecular mass range $1,700-20,000$ Da were examined for their ability to accelerate the antithrombln III (ATIII)dependent Inhibition of human factor $\mathrm{Xa}$ and of prothromblnase during human prothrombin activation. The prothromblnase reactlon was modeled by a 3-parameter 2-exponential equation to determine the Initial rate of prothrombin act|vation and the pseudo-first order rate constants of $|\mathrm{nh}| \mathrm{bl}$ tlon of prothrombinase and in situ generated thrombin activity. The catalytic specific actlvitles of the heparins Increased with Increasing molecular size for both the Inhibition of prothrombinase and factor Xa. A 10-fold Increase over the entire $M_{r}$ range was found. In contrast to results obtalned by others (Ellis $V$ et al (1986) Blochem J 233, 161-165; Barrowcllffe TW et al (1987) Blochem $J 243,31-37$ ), all the heparlns showed a 5-fold higher rate of inhlbition of factor $X a$ when compared with the inhlibition of prothrombinase, Indicating that the factor Va-medlated protectlon of factor $\mathrm{Xa}$ from Inhlbition by ATIII/heparin is Independent of the molecular size of the heparln. Our original approach has also revealed a hitherto unrecognlzed phenomenon, namely, In addition to the accelerating effect on the rate of formation of the Inactlve ATlli-factor $X a$ complex, heparins with $M_{r}>$ 4,500 also reduced the Initial rate of thrombin generation, in the presence of ATIII, In a concentratlon-dependent way. We hypothesize that the formation of the dissoclable ternary ATIII/heparIn/factor Xa complex resullts in a (partlal) loss of factor Xa activity towards its natural substrate prothrombin.

ne of the essential zymogen activation reactions of the blood coagulation cascade leading to the formation of insoluble fibrin strands is the activation of prothrombin by prothrombinase, a $\mathrm{Ca}^{2+}$-dependent enzymatic complex composed of the serine protease factor $\mathrm{Xa}$, the non-enzymatic cofactor factor $\mathrm{Va}$, and negatively charged phospholipids (84).

A major inhibitor of coagulation is antithrombin III (ATIII), a plasma protein which forms equimolar complexes with serine proteases of the coagulation

Schoen P, Lindhout T, Willems G, Hemker HC. J Blol Chem 264:10002-10007, 1989 
system (103). In the presence of heparin the rates of inactivation of the proteases are enhanced. Previous studies have monitored the rate constant of inactivation of free factor $\mathrm{Xa}$ as a function of the molecular weight of heparin $(42,36)$. It was shown that although the binding of factor Xa and ATIII to the same heparin molecule is not a prerequisite for the catalysis of the inactivation of this protease. as it is for the inactivation of thrombin, the rate of factor Xa inactivation does increase with increasing heparin molecular weight.

Studies in purified systems have demonstrated that the ATIII-dependent rate of inactivation of factor $\mathrm{Xa}$ is reduced when factor $\mathrm{Xa}$ is bound to a phospholipid surface in the presence of factor $V(169)$ or factor $V a(139,158)$ or when bound to activated platelets (170), i.e. factor $\mathrm{Xa}$ is protected from inactivation by ATIII. It was also shown that factor Xa, as part of the prothrombinase complex, is protected from heparin-catalyzed inhibition by ATIII $(139,169,170)$. However, the effect of the molecular size of heparin on the rate constant of inactivation of prothrombinase, and consequently on the extent of protection, has not been extensively studied. Moreover, the data available are conflicting. In one study it was observed that when factor $\mathrm{Xa}$ is bound to activated platelets the protective effect diminished with decreasing heparin molecular weight (170), whereas in a second study, where factor Xa was bound to a phospholipid surface in the presence of factor $V$, it appeared that the protective effect became more pronounced with decreasing molecular weight (169). The latter observation led to the postulation that the lack of correlation between in vitro anti-factor $\mathrm{Xa}$ activity and antithrombotic action of low molecular weight heparin is caused by different inhibitory actions on free factor $\mathrm{Xa}$ and on factor $\mathrm{Xa}$ in its more physiological form, i.e. as part of the prothrombinase complex (169).

Because the heparin-catalyzed ATIII-dependent inactivation of factor $\mathrm{Xa}$, as part of the prothrombinase, is not thoroughly investigated, we further explored this inhibition of factor Xa. In an attempt to imitate physiological conditions of factor Xa inactivation, we studied the effect of ATIII and heparin on factor Xa during human prothrombin activation in the presence of excess factor $\mathrm{Va}$ and phospholipid. We developed a mathematical model which adequately describes the thrombin generation curves as a time-dependent function of the initial rate of prothrombin activation and the pseudo-first order rate constants of in situ inhibition of factor $X_{a}$ and thrombin.

This approach made it possible to quantitatively assess the effect of heparin and heparin fragments on the inhibition of prothrombinase during prothrombin activation. We observed a correlation between molecular size of the heparin fractions and their catalytic specific activity/mol ATIII-binding site. Furthermore, we present evidence that, in addition to the progressive heparin-catalyzed reaction, heparins of higher molecular weight $\left(M_{r} \geq 6,000\right)$, but not of low molecular weight cause an immediate, ATIII-dependent, inhibition of prothrombinase activity. 


\section{EXPERIMENTAL PROCEDURES}

Materials - The $4^{\text {th }}$ International Standard for Heparin (ISH) was obtained from the National Institute for Biological Standards and Control (Potters. Bar, United Kingdom). The preparation has an activity of 1780 international units of heparin/ampoule of $9.2 \mathrm{mg}$ (171). The high molecular weight heparin (heparin fraction D, batch $\mathrm{AB} 20292)$, the low molecular weight heparin (CY216. batch: $\mathrm{P} 46 \mathrm{XH}$ ), and the synthetic pentasaccharide heparin (IC83.1423, batch: ILS 6388 B) were kindly donated by Choay Institut (Paris. France). Heparin fraction D was isolated from a commercial pig mucosal heparin by ion exchange chromatography on DEAE-Sephacel and has a mean molecular weight of 20,300 . The isolation as well as the physicochemical and biological properties of heparin fraction D are described in detail elsewhere (172). The CY216 was prepared by ethanol extraction of a commercial pig mucosal heparin (173), the mean molecular weight is $4,500(80 \%$ of the material has a molecular weight between 2,400 and 7,$200 ; 50 \%$ of the material is composed of dodeca-, tetradeca-, and hexadecasaccharides) and the specific activities are 200 anti-factor Xa units/mg and 10 to 20 anti-thrombin units/mg dry weight (data provided by Choay Institut). The pentasaccharide, synthesized as described (22), has a molecular weight of 1.714 , and an activity of 4000 anti-factor Xa units/mg diy weight.

High-affinity heparin oligosaccharides were prepared by ATIII-affinity chromatography and gel chromatography of nitrous acid depolymenized heparin (35), and were a gift of Dr. Lindahl, Swedish University of Agricultural Sciences (Uppsala, Sweden). The oligosaccharides used in this study were an octasaccharide fragment, a 10-14 saccharide fragment and a 18-24 saccharide fragment. The (mean) molecular weights of these oligosaccharides were calculated with $M_{r}=300$ for each saccharide unil (35).

The molar concentrations of all heparin preparations used in this study were determined by stoichiometric titration of ATIII $(1.0 \mu \mathrm{MM})$ in $50 \mathrm{mM}$ Tris- $\mathrm{HCl}(\mathrm{pH} 7.5)$ and $100 \mathrm{mM} \mathrm{NaCl}$, as monitored by the intrinsic protein fluorescence enhancement at $\lambda_{e m}=345 \mathrm{~nm}$ and $\lambda_{e x}=285 \mathrm{~nm}$ (174). The chromogenic substrates S2238 and S2337 were purchased from Kabivitrum AB (Stockholm, Sweden). The specific thrombin inhibitor hirudin was obtained from Sigma (St.Louis, USA). All other protein preparations, and the mixed phospholipid vesicles were prepared as previously described $(115,145)$.

DetermInation of Pseudo-First Order Rate Constants of Inhibltion of Factor $X a$ - The inhibition of factor Xa by ATIII and heparin was performed under pseudo first order conditions. Factor $\mathrm{Xa}$ was added to a mixture of ATIII, prothrombin, $\mathrm{CaCl}_{2}$, phospholipid vesicles composed of $20 \mathrm{~mol} \% \mathrm{PS}$ and $80 \mathrm{~mol} \% \mathrm{PC}$, and heparin in $50 \mathrm{mM}$ Tris-HCl (pH 7.9), $175 \mathrm{mM} \mathrm{NaCl}$. and $0.5 \mathrm{mg} \mathrm{HSA} / \mathrm{ml}$ at $37^{\circ} \mathrm{C}$. The final concentrations were $5.0 \mathrm{nM}$ factor $\mathrm{Xa}, 0.40 \mu \mathrm{M} \mathrm{ATIII}, 1.5 \mu \mathrm{M}$ prothrombin, $3.0 \mathrm{mM} \mathrm{CaCl}$, and $50 \mu \mathrm{M}$ phospholipid. The tinal heparin concentrations varied between 1.0 and $20 \mathrm{nM}$. Al timed intervals after the addition of factor $\mathrm{Xa}_{4} 40 \mu \mathrm{ll}$ samples were transferred to cuwettes containing $0.46 \mathrm{ml}$ of $50 \mathrm{mM}$ Tris- $-\mathrm{HCl}(\mathrm{pH} 7.9), 175 \mathrm{mM} \mathrm{NaCl}, 20 \mathrm{mM}$ EDTA,

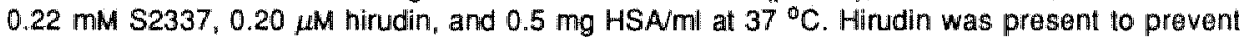
interference of thrombin formed in the first reagent mixture, with the amidolytic factor Xa assay. After sampling into the substrate solution the rate of ATIII-dependent inactivation of factor Xa was sufficiently low not to result in any measurable loss of enzymatic activity during the recording of the absorbance.

The rate of increase of absorbance at $405 \mathrm{~nm}$ was measured on a dual wavelength spectrophotometer (reference wavelength: $500 \mathrm{~nm}$ ) and the residual factor Xa concentrations were calculated from a standard curve constructed under the same conditions. Residual factor Xa was exponentially plotted against reaction time and the pseudo-first order rate constants of inactivation of lactor Xa were calculated as the slopes of these plots.

Prothrombin Actlvation in the Presence of ATIII and Heparin- Human prothrombin was activated by simultaneously adding prothrombin and ATIII to a mixture of factor $\mathrm{Xa}$, faclor $\mathrm{Va}, \mathrm{CaCl}_{2}$, phosphollipid vesicles composed of $20 \mathrm{~mol} \% \mathrm{PS}$ and $80 \mathrm{~mol} \% \mathrm{PC}$, and heparin in $50 \mathrm{mM}$ Tris-HCl ( $\mathrm{pH} \mathrm{7.9)}, 175 \mathrm{mM} \mathrm{NaCl}$, and $0.5 \mathrm{mg} \mathrm{HSA} / \mathrm{ml}$ at $37^{\circ} \mathrm{C}$. The final concentrations were $2.0 \mathrm{pM}$ factor $\mathrm{Xa}, 0.60 \mathrm{nM}$ factor $\mathrm{Va}, 3.0 \mathrm{mM} \mathrm{CaCl}_{2}, 50 \mu \mathrm{M}$ phospholipid, $1.5 \mu \mathrm{M}$ prothrombin, and 
Q.40 fHM ATIIL. The final heparin concentrations varied between 1.3 and $50 \mathrm{nM}$. After 5 min of prothrombin activation, a small aliquot $(3 \mu)$ of soybean trypsin inhibitor (ST) was added to a final concentration of $1.0 \mathrm{mg} / \mathrm{m}$. After the addition of STI no turther prothrombin activation occurred. which made it possible to determine the rate of inactivation of thrombin activity (115). At timed intervals during the experiment $20 \mu$ samples were transferred to cuvettes containing $0.48 \mathrm{ml}$ of 50 mM Tris-HCl (pH 7.9), $175 \mathrm{mM} \mathrm{NaCl}, 20 \mathrm{mM}$ EDTA, $0.24 \mathrm{mM} \mathrm{S.2238}$ and $0.5 \mathrm{mg} \mathrm{HSAml} \mathrm{at} 37^{\circ} \mathrm{C}$. The amount of amidolytic thrombin activity formed was determined in the same way as described for lactor $\mathrm{Xa}$.

KInetlc Analysis of the Inhibltion of Prothrombin Activation and Formed Thrombln Activity - We modeled the prothrombin activation in the presence of ATIII and heparin by as suming that the observed generation of thrombin activity is the result of its wirtual rate of tormation $\left(V_{*}\right)$ and thts rate of inactivation $\left(V_{-1}\right)$ :

$$
V_{a b s}=d \text { Thrombin } / d t=V_{+1}-V_{-1}
$$

Under pseudo-first order conditions the rate of inactivation of thrombin activity is described by:

$$
V_{-1}=k_{1}[\text { Thrombin] }
$$

where $k_{1}$ is the observed pseudo-first order rate constant of inhibition of thrombin activity. Under our condifions the rate of prothrombin activation is directly proportional to the amount of prothrombinase present (i. factor Xa concentration):

$$
V_{+1}=k_{p}[X a]
$$

where $k_{p}$ is the lurnover number, i.e. the number of males of prothrombin converted per min and per mol of factor Xa under optimum conditions. Under pseudo-first order conditions of inactivation of factor Xa, the time-dependent factor Xa concentration ([Xa] $)$ can be modelled by:

$$
[X a]_{l}=[X a]_{b} e^{-k_{2} t}
$$

where $[X a]_{0}$ is the inilial factor $X a$ concentration, $k_{2}$ is an apparent pseudo-first order rate constant of inactivation of factor $\mathrm{Xa}$, and $t$ is the reaction time. Assumption of simple pseudo-first order kinetics was sufficient to describe the inactivation of factor Xa during the bovine prothrombinase reaction by ATIII or ATIII and heparin (139). Substituting the Equalions 2,3, and 4 into Equation 1 yields:

$$
V_{o b s}=d\left[\text { Thrombinydt }=V_{i} e^{-k_{2} t}-k_{1}\right. \text { Thrombin] }
$$

where $V_{i}$ is the initial rate of prothrombin activation $\left(V_{i}=k_{p}[X a l l o)\right.$. Integration of Equation 5 leads to the following:

$$
\text { [Thrombin] }]_{t} V_{1}\left(e^{-k_{2} t}-e^{-k k_{1} t}\right) /\left(k_{1}-k_{2}\right)
$$

Equation 6 describes the observed thrombin activity ([Thrombin], in terms of initial rate of prothrombin activation $\left(V_{i}\right)$, pseudo-first order rate constants of inhibition of thrombin activity $\left(k_{1}\right)$ and factor $\mathrm{Xa}\left(\mathrm{k}_{2}\right)$, and reaction time (t). A close look at the equation reveals that the rate constants of inthibition of thrombin and factor Xa are interchangeable. Thus we optimized the approach by adding STI after 5 min of prothrombin activation. After the addition of STI at time $t^{*}\left(V_{+1}=0\right)$ and integration of Equation 5:

$$
\text { [Thrombin }]_{t}=\left[\text { Thrombin }\left.\right|_{t} e^{-k_{t}\left(t-t^{*}\right)}\right.
$$


According to Equation 7 the rate constant of Inhibition of thrombin activity can be unequivocally determined and hence also the rate constant of inhibition of factor Xa. Equations 6 and 7 were combined in a computer program, which made a non-linear least squares fil of the equations to our experimental thrombin activity data using a modified Gauss-Newton algonithm (148) and estimated the parameters $V_{1}, k_{1}$, and $k_{2}$ and the corresponding $95 \%$ confidence intervals, i.e. approximately $2 \times \mathrm{SE}$ of the estimates.

\section{RESULTS}

Activation of Prothrombin in the Presence of ATIII and HeparinProthrombin was activated in the presence of ATIII and heparin as described under "Experimental Procedures". Figure 1 shows typical examples of thrombin generation curves prior to and after the addition of STI. The amounts of ISH used were $2.6 \mathrm{nM}$ and $10.5 \mathrm{nM}$. Equations 6 and 7 (see "Experimental Procedures") were fitted to the experimental data, and the results are depicted as the solid lines. The inset in Figure 1 shows a semilogarithmic replot of the decay data obtained after the addition of STI. This decay is monophasic, indicating that a single amidolytic active product is generated whose reaction with ATIII should be taken into account, viz. meizothrombin(des fragment 1 ) $^{1}$. Clearly, the equations can be fitted to our experimental data very well. The residuals of the curves fitted to the experimental data varied randomly around zero and were smaller than $2 \%$.

The estimated parameters and their $95 \%$ confidence intervals were: $V_{i}=$ $6.2 \pm 0.2 \mathrm{nM} / \mathrm{min} ; \mathrm{k}_{1}=0.11 \pm 0.01 \mathrm{~min}^{-1} ; \mathrm{k}_{2}=0.14 \pm 0.02 \mathrm{~min}^{-1}$ in the presence of 2.6 $\mathrm{nM} I S H$, and $V_{i}=4.0 \pm 0.2 \mathrm{~nm} / \mathrm{min}^{*} \mathrm{k}_{1}=0.13 \pm 0.01 \mathrm{~min}^{-1} ; \mathrm{k}_{2}=0.37 \pm 0.02 \mathrm{~min}^{-1}$ in the presence of $10.5 \mathrm{nM} \mathrm{ISH}$. The initial rate of prothrombin activation, determined in the absence of ATIII and heparin was $V_{i}=6.7 \mathrm{~nm} / \mathrm{min}$. Hence, it appears that the initial rate of prothrombin activation is reduced in the presence of ATIII and heparin. In addition, according to the pseudo-first order rate constants, the effect of ATIII and heparin on the thrombin generation curves is found in the inactivation of factor $X a\left(k_{2}\right)$ rather then in the inactivation of thrombin $\left(k_{1}\right)$. The effect of heparin and ATIII on the initial rate of prothrombin activation, as well as on the pseudo-first order rate constants of inhibition of thrombin activity and factor $\mathrm{Xa}$, will be further explored in the following sections.

1 Previous work from our laboratory (115) has shown that under the conditions of prothrombin activation used in this study, the major amidolytic active product is meizothrombin(des fragment 1) which is, throughout this paper, referred to as thrombin activity. 


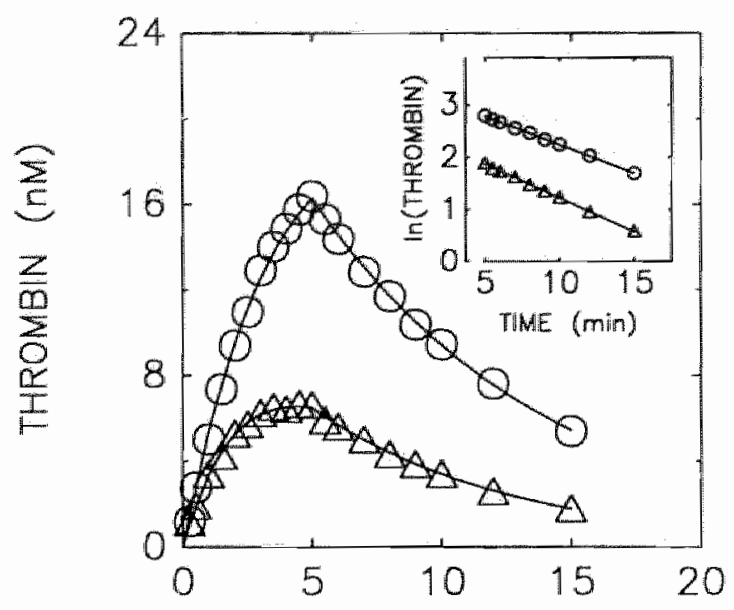

TIME (min)

Figure 1. Time courses of thrombin activity. Prothrombin was activated by factor Xa, factor Va, phospholipid vesicles composed of 20 mol\% PS and 80 mol\% PC, and $\mathrm{CaCl}_{2}$ as described under "Experimental Procedures", in the presence of ATIII and 2.6 (O) or $10.5 \mathrm{nM}(\Delta) \mid \mathrm{SH}$. STI was added at 5 min. The inset shows the semilogarithmic plots of the thrombin decay data obtained after the addition of STH. Equations 6 and 7 were fitted to the data and the resulting curves are indicated by the solid lines.

\section{The Effect of Heparin Fragments of Different Molecular Size on} the Rate Constants of Inhibition of Prothrombinase During Prothrombin Activation-Pseudo-first order rate constants of factor Xa inhibition during prothrombin activation were obtained as outlined above. For the different heparin preparations the rate constants were linearly dependent on the heparin concentrations studied. As an example, Figure 2 shows the pseudo-first order rate constants of inhibition of prothrombinase and the matching $95 \%$ confidence intervals obtained in the presence of standard heparin.

The slopes of such plots, calculated by linear regression analysis, were determined and are shown in Figure 3 as function of the heparin molecular weight, together with their $95 \%$ confidence intervals. The results indicate that up to a $M_{r}$ of approximately 6,000 no clear relationship is seen between the acceleration of inhibition of prothrombinase and the molecular size of the heparin fragments. The observed differences between the rate constants approximate the $95 \%$ confidence intervals, hence the increasing tendency can not be regarded as significant. However, at molecular weights higher than about 6,000 , a significant increase is noted, resulting in a 10 -fold increase in catalytic efficiency over the entire molecular weight range (Table 1). 


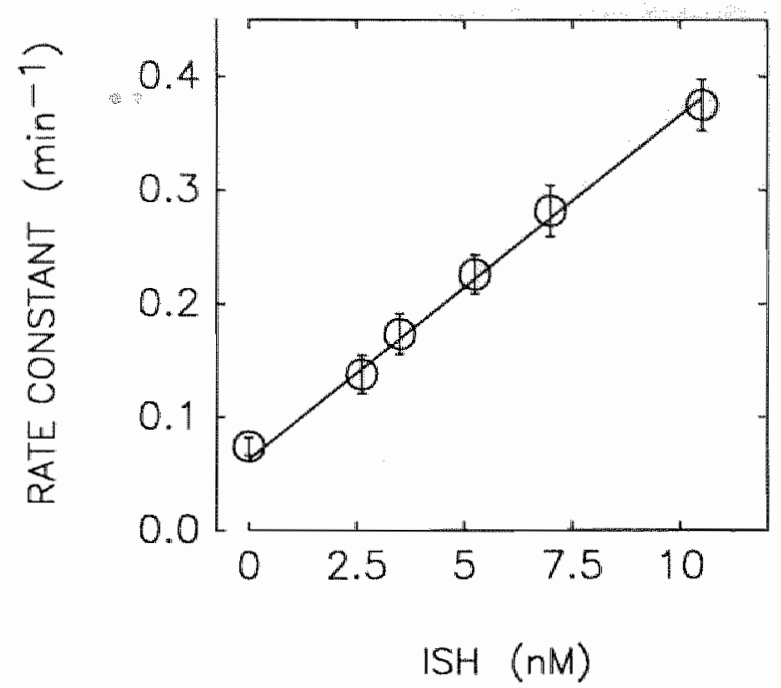

Figure 2. Rate constants of inactivation of prothrombinase during prothrombin activation as function of the concentration of standard heparin. The pseudo-first order rate constants and the 95\% confidence intervals were determined as outlined under "Experimental Procedures"'. The solid line is obtained by linear regression analysis of the data.

\section{Comparison between the Rate Constants of Inhibition of Factor} $X a$ and Prothrombinase- The heparin-dependent pseudo-first order rate constants of inhibition of factor Xa were determined as described under "Experimental Procedures". We reasoned that a comparison between the heparindependent inhibition of factor $\mathrm{Xa}$ and prothrombinase should be made under comparable conditions. Therefore the inhibition of factor $\mathrm{Xa}$ was determined in the presence of phospholipid, $\mathrm{Ca}^{2+}$-ions, and prothrombin. For each heparin fragment the rate constants were linearly dependent on the heparin concentration. The slopes of plots of the pseudo-first order rate constants as function of heparin concentrations were determined by linear regression analysis. The data and their $95 \%$ confidence intervals are also shown in Figure 3 and listed in Table 1. The data show that the rate constants of inhibition of factor $X a$ are related to the heparin molecular weight too. Below a molecular weight of about 6,300 a small, but significant, increase of the acceleration of the inactivation of factor $\mathrm{Xa}$ is observed. Between a molecular weight of 6,300 and 15,000 the catalytic efficiency increases 4 times. 


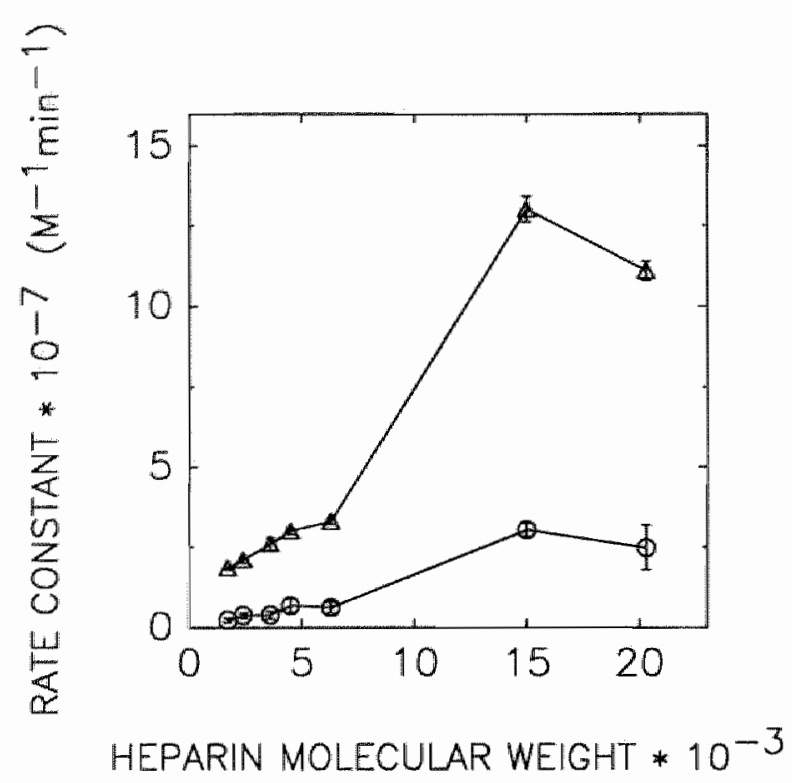

Figure 3. Rate constants of inactivation of prothrombinase during prothrombin activation (O) and of factor Xa ( $\Delta$ ) as function of heparin molecular weight. The rate constants per molar heparin concentration were determined as described in the text. The values of the rate constants with their $95 \%$ contidence intervals are shown.

Table 1. Rate constants of the heparin-dependent inhibition of factor Xa and prothrombinase by ATIII. Observed pseudo-first order rate constants were divided by the molar heparin concentration as determined by stoichiometric tiltration of ATIII.

\begin{tabular}{lccc}
\hline Heparin & $\mathrm{M}_{\mathrm{r}}$ & \multicolumn{2}{c}{$10^{-7} \times$ Rate Constant } \\
\cline { 3 - 4 } & & Factor Xa & Prothrombinase \\
\hline & & $\left(\mathrm{M}^{-1} \mathrm{~min}^{-1}\right)$ & $\left(\mathrm{M}^{-1} \mathrm{~min}^{-1}\right)$ \\
Pentasaccharide & 1,714 & $1.85 \pm 0.05$ & $0.23 \pm 0.07$ \\
Octasaccharide & 2,400 & $2.1 \pm 0.1$ & $0.37 \pm 0.08$ \\
$10-14$ saccharide & 3,600 & $2.6 \pm 0.2$ & $0.39 \pm 0.11$ \\
CY216 & 4,500 & $3.0 \pm 0.1$ & $0.68 \pm 0.22$ \\
$18-24$ saccharide & 6,300 & $3.3 \pm 0.1$ & $0.62 \pm 0.17$ \\
ISH & 15,000 & $13.0 \pm 0.4$ & $3.03 \pm 0.20$ \\
Heparin fraction D & 20,300 & $11.1 \pm 0.3$ & $2.49 \pm 0.70$ \\
\hline
\end{tabular}


When each of the nonenzymatic components were separately examined for an effect on the inhibition of factor $\mathrm{Xa}$, we found, in keeping with earlier work on bovine factor $\mathrm{Xa}$, that phospholipids did not alter the kinetics of inhibition (139). In contrast to the inhibition of bovine factor Xa by bovine ATIII, $\mathrm{Ca}^{2+}+$-ions stimulated the reaction of the human reactants in the presence of heparin (fractions). A slight stimulation (1.2 times) was observed with heparin fragments of $\mathrm{M}_{\mathrm{r}}<4,500$. This stimulation increased with increasing molecular size of the heparin fragment; i.e. the catalytic efficiency of heparin fraction $D$ increased 2.5 times in the presence of $5 \mathrm{mM} \mathrm{Ca}^{2+}$. However, the $\mathrm{Ca}^{2+}$-enhanced accelerating ability was diminished when prothrombin was also present in the reaction mixture. We could demonstrate that prothrombin dose-dependently neutralizes the activity of heparins with $M_{r}>6,300$ (data not shown).

From the data listed in Table 1 it is seen that over the entire molecular weight range the catalytic specific activities of heparin fragments for the inhibition of factor Xa are about 5 times higher compared to their specific activities for the inhibition of prothrombinase. The fluctuation of the ratio's of the specific activities is random, and lies within the experimental errors.

Heparin-Stimulated Inhibition of Initial Rate of Prothrombin Activation - We initially assumed that it would be sufficient to apply a 2-parameter fit, revealing the rate constants of inhibition of thrombin $\left(k_{1}\right)$ and factor $X a\left(k_{2}\right)$, to model our experimental thrombin generation data, and regard the initial rate of prothrombin activation as non-adjustable parameter. However, when $V_{i}$ was determined in the absence of ATIII and heparin, and its value was used to compute $k_{1}$ and $k_{2}$, large deviations between the calculated thrombin generation data and the ones determined experimentally were observed in experiments where heparin molecules of a size greater than hexadecasaccharide were used. Hence, we did not use an independently determined value of $V_{i}$, but computed its value too. Figure 4 shows the initiall rates of prothrombin activation as revealed by the fit procedure, from thrombin generation curves obtained in the presence of ATIII and heparin fraction D, the $4^{\text {th }}$ International Standard for Heparin, or the heparin 18-24 saccharide fragment.

From these data it is seen that each of the three heparins causes a concentration-dependent decrease of the initial rate of prothrombin activation. Inhibition up to nearly $50 \%$ of the initial value can be obtained. The other heparin preparations, pentasaccharide, octasaccharide, 10-14 saccharide and Cr216, had no significant inhibitory effect on the initial rate of prothrombin activation in the range of heparin concentrations we studied.

We hypothesized that the observed anomaly between the rate, as determined in the absence of ATIII and heparin, and the initial rate, revealed by the fitting of Equation 6 to our experimental thrombin generation data in the presence of ATIII and heparins larger than hexadecasaccharide, may be accounted for by the instantaneous formation of the dissociable ternary complex between ATIII, heparin and factor Xa. The formation of this complex results in a 
(partial) loss of factor Xa activity towards its substrate prothrombin. To rule out the possibility that the observed decrease in the initial rate of prothrombin activation is an ATIII-independent effect of heparin, we determined the rate of prothrombin activation in the absence of ATIII, but in the presence of heparin. Thrombin generation was monitored and proceeded linearly for at least $5 \mathrm{~min}$. We found that the rate of prothrombin activation was not affected by any of the heparin fractions used. Thus, the observed inhibition of the initial rate of prothrombin activation is dependent on the presence of both ATIII and heparin.

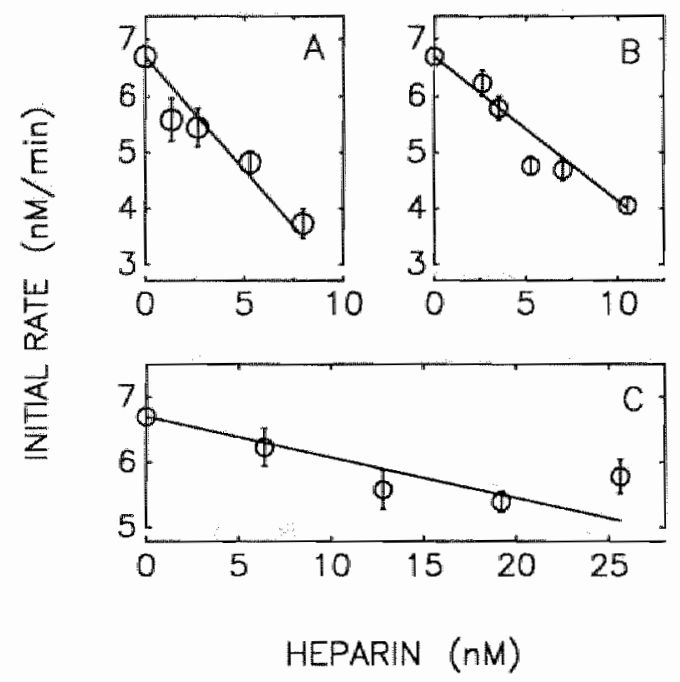

Flgure 4. Initial rates of prothrombin activation as function of heparin concentration. The prothrombinase reaction was inhibited by $0.40 \mu \mathrm{M}$ ATIll in the presence of heparin fraction D (A), $\triangle S H(B)$, and 18-24 saccharide (C). The initial rates and the $95 \%$ confidence intervals were determined as described under "Experimental Procedures". In the absence of heparin and ATIII the initial rate was $6.7 \mathrm{nM}$ thrombin/min.

In addition, the data as shown in Figure 4 suggest a linear decrease of the initial rate of prothrombin activation. From these plots we calculated a reduction of the initial rate of prothrombin activation by $0.38 \mathrm{nM}$ thrombin/min per $\mathrm{nM}$ heparin fraction $\mathrm{D}, 0.26 \mathrm{nM}$ thrombin/min per $\mathrm{nM} I S \mathrm{SH}$, and $0.064 \mathrm{nM}$ thrombin $/ \mathrm{min}$ per $n M$ 18-24 saccharide. Thus, the heparin-induced reduction of the initial rate of thrombin generation seems to increase with increasing heparin chain length.

Effect of Heparin on the Inhibition of Prothrombinase-Formed Thrombin Activity - The fitting of Equation 6 and 7 to the thrombin generation data also revealed the apparent pseudo-first order rate constants of inhibition of formed thrombin activity. We observed no dependency of the rate constants on 
the amount of heparin present for the different heparin preparations. All pseudofirst order rate constants varied randomly around a mean value of $0.137 \mathrm{~min}^{-1}$ with a maximum value of $0.197 \mathrm{~min}-1$ and a minimum value of $0.103 \mathrm{~min}^{-1}$. This observation is not unexpected, because we previously demonstrated that when prothrombin concentrations above $1 \mu \mathrm{M}$ are used to measure prothrombinase activity, the major reaction product with amidolytic activity is meizothrombin(des fragment 1), rather than $\alpha$-thrombin, and at the time we showed that the ATIII= dependent inhibition of meizothrombin(des fragment 1 ) is not catalyzed by heparin (115).

\section{DISCUSSION}

The formation of prothrombinase is essential to the generation of thrombin at a significant rate (84). ATIII and heparin have a potentially important role in the regulation of prothrombinase by inhibiting its formation (inactivation of free factor Xa) and/or by inhibiting its activity once it is formed. Previous reports $(169,170)$ have indicated a differential activity of free factor $\mathrm{Xa}$ and prothrombinase with respect to the heparin-catalyzed reaction with ATIII. That is, factor Va and/or phospholipids appear to protect factor Xa from inhibition by ATIII/heparin. However, conflicting results have been reported regarding the degree of protection $(170,175,176)$, and on the effect of the heparin molecular size on the disparity between the rates of inhibition of free and complexed factor Xa. This disparity was found to increase (170) or decrease (169) with increasing molecular size of heparin.

Our experimental approach presented in this paper is different from the previously reported ones in that we studied the effect of heparin (fragments) and ATIII on fully assembled prothrombinase during prothrombin activation in a well defined reaction system. We very adequately modeled the generation and inactivation of thrombin activity, which allowed the determination of the initial rate of prothrombin activation and the pseudo-first order rate constants of inhibition of generated thrombin activity and of prothrombinase.

Progressive Inhibition of Prothrombinase- The pseudo-first order rate constant of inhibition of prothrombinase during prothrombin activation in the presence of ATIII varied linearly with the heparin concentration. Because the ATIII concentration was much higher than the heparin concentrations and reported values for the dissociation constant of the heparin-ATIII interaction $(46,177)$, it is quite possible that essentially all ATIII-binding sites of heparin were saturated with ATIII. The catalytic constant derived from the slopes of the lines of the rate constants plotted versus the molar concentration of heparin (mol ATIII binding

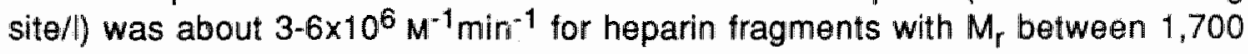
and 6,300 . At molecular weights higher than 6,300 the ability of heparin to 
enhance the inhibition of prothrombinase during prothrombin activation in the presence of ATIII increases 4-6 times. Our results indicate that on a molar basis, heparin fragments with low molecular weight $\left(M_{r}<6,000\right)$ are less effective than fragments of higher $M_{r}$ in inhibiting prothrombinase.

Instantaneous Inhibition of Prothrombinase- Our approach to examining the inhibitory action of ATII/heparin during the prothrombinase reaction resulted in an, until now, unrecognized mode of action of ATIII/heparin on prothrombinase-catalyzed thrombin generation. Evidence was obtained that in addition to the progressive inhibition of prothrombinase, ATII//heparin causes an immediate, partial neutralization of the prothrombinase activity. That is, the initial rate of prothrombin activation decreases with increasing amounts of heparin. Moreover, this direct inhibitory action was much more pronounced for heparin fragments with higher $M_{r}$ than for low $M_{r}$ heparins. In the absence of ATIII none of the heparins studied inhibit prothrombin activation. This rules out that under these conditions heparin inhibits the prothrombinase reaction by disrupting the prothrombinase complex (178). We hypothesize that the initial, very rapid, formation of the ternary complex between factor $\mathrm{Xa}$, heparin and ATIII directly removes factor $X a$ from the prothrombinase complex and thereby reduces the amount of prothrombinase available. Alternatively, the prothrombinase in the dissociable complex with heparin and ATIII may have a reduced activity towards prothrombin. Untortunately, an attempt to further reduce the initial rate of prothrombin activation by increasing the heparin concentration failed because the progressive inhibition of prothrombinase became too fast to give reliable thrombin generation data for the fit-procedure.

Disparity between Rates of Inhibition of Factor $X a$ and Prothrombinase - The pseudo-first order rate constant of inhibition of factor $\mathrm{Xa}$ increases linearly with the concentration of the various heparin fragments. Thus we assumed that all heparin was saturated with ATIII as was the case in the experiments with prothrombinase. The dependency of the catalytic constant on the molecular size of the heparin fragment agrees closely with the data reported for bovine factor $\mathrm{Xa}(36,169)$. That is, the catalytic efficiencies of the heparin fragments, based on their ATIII-binding molar concentration, decreased with decreasing molecular size. The scarce data available on human factor $\mathrm{Xa}$ (169) indicate that $\mathrm{Ca}^{2}{ }^{+}$-ions accelerate the factor Xa-ATIII reaction 1.2 times when unfractionated heparin is present, but not when oligosaccharide fragments of lower $\mathrm{M}_{\mathrm{r}}$ are used. We confirmed that the $\mathrm{Ca}^{2+}$-induced acceleration increased with increasing molecular size of the heparin fragments. However, this stimulation appears to be counterbalanced by the heparin neutralizing property of prothrombin.

Our data clearly indicate a higher catalytic activity of each heparin fragment for factor $\mathrm{Xa}$ inhibition than for the inhibition of prothrombinase. In contrast with the observation of Barrowcliffe et al (169), heparin tragments of high $M_{r}$ are unable to overcome the protective effect of factor Va on the inhibition of factor Xa. 
In fact, the disparity between the catalytic constants when compared under identical conditions was found to be independent of the molecular size of heparin.

In summary, the results presented in this paper suggest that a saccharide sequence additional to the unique pentasaccharide sequence required for ATIII binding (23), stimulates the inhibition of prothrombinase to the same degree as was observed for factor $\mathrm{Xa}$ in the absence of factor $\mathrm{Va}$. In addition, such a nonATIII binding saccharide structure induces: 1] a second mode of action of heparin, i.e. a direct inhibition of the initial rate of thrombin generation, and 2] a $\mathrm{Ca}^{2+}$ stimulated inhibition of factor $X a$.

At present it is unclear which properties of the additional saccharide sequence are responsible for our obsenvations. Is it the length per se which gives these effects or is there an involvement of additional structural features of the heparin chain? In this respect, it has been demonstrated that the bimolecular rate constant of the heparin-catalyzed inactivation of factor Xa by ATIII is dependent on ionic strength in the presence of a high-affinity heparin with $M_{r}=8,000$, whereas an ionic strength independence is seen in the presence of a pentasaccharide (179). This observation is indicative for an electrostatic interaction between factor $\mathrm{Xa}$ and the heparin with $\mathrm{M}_{\mathrm{r}}=8,000$. Thus, an effect of heparin charge density, which is well established for heparin-catalyzed thrombin inactivation $(45,180)$, may contribute to the heparin $M_{r}$ effects we observed. However, we cannot rule out that after the first encounter of heparin and ATIII at the pentasaccharide region, secondary interactions between heparin and ATIII occur (121, 122), which may also contribute to our observations.

The catalytic constants were calculated on basis of molar concentration of ATIII-binding sites and all these sites were saturated with ATIII. Therefore it is our conclusion that although simultaneous binding of ATIII and factor Xa or prothrombinase to the same heparin molecule is not a prerequisite for the acceleration of inhibition, it does increase the catalytic efficiency of the heparin molecule. Moreover, linkage of protease-ATIII-heparin interactions, as recently demonstrated for the reaction with thrombin (46) may also contribute to the involvement of heparin chain length in the heparin-catalyzed inhibition of prothrombinase by ATIII.

Acknowledgement- We are grateful to Dr. U Lindahl for providing the heparin oligosaccharide iragments. 



\section{CHAPTER 7}

\section{Continuous Flow and the Prothrombinase-catalyzed Activation of Prothrombin $\$$}

The activation of prothrombin by prothrombinase was investigated in a continuous flow system at $25^{\circ} \mathrm{C}$. A glass capillary, containing a continuous phospholipld bilayer attached to the Interlor surface, was first perfused with factor Va. The factor Va bound to the phosphollpid surface functioned as sites for the formation of prothrombinase, when subsequently a factor $X a$ and prothrombin contalning solution was perfused. Under the conditions used, steady-state rates of prothrombin activation were attalned after 4 to $15 \mathrm{~min}$. The rates of prothrombinase formation increased with increasing factor $X a$ concentrations and flow rates, which is compatible with the assembly of prothrombinase being dependent on the flux of factor $\mathrm{Xa}$ to the phospholipld-bound factor $\mathrm{Va}$. As long as factor $\mathrm{Xa}$ and prothrombin were present in the fluld phase the assembly of prothrombinase was apparently Irreversible; during at least $20 \mathrm{~m} / \mathrm{n}$ no loss of activity occurred. The steady-state rate of prothrombln activation was linearly dependent on the average surface density of prothrombinase, at $1.0 \mu \mathrm{M}$ prothrombin and a shear rate of $82 \mathrm{~s}^{-1}$ the average rate was $870 \mathrm{~mol}$ thrombln/min per mol prothrombInase. In contrast to observations made In test tube experiments it was found that in this flow system, the formation of $\alpha$ thrombin is favoured above the formation of melzothrombin(des fragment 1).

In vivo blood coagulation is a complex process, which requires actions of and interactions between the vascular wall, blood platelets and the coagulation system. Of the coagulation system many reactions are membrane bound processes, i.e. they take place on either the platelet or endothelial cell membrane. Consequently, during coagulation reactants must be transported from the blood stream to the membrane surface. These transport processes, and therefore the formation and activities of the membrane-bound enzymatic complexes, are dependent on the local flow conditions $(108,109)$.

$\$$ Schoen $P$, Lindhout $T$, Willems $G$, Hemker HC. Thromb Haemostas $64: 542-547,1990$ 
Recently it has been pointed out by Gemmell et al (110) that the progress of coagulation reactions during flow cannot be extrapolated from static, closed systems. They reported on the activation of factor $X$ by membrane-bound tissue factor and factor VII(a), during flow, and found that the steady-state catalytic activity of the enzymatic complex is independent of the concentration of factor VII(a) in the fluid phase. In addition it was shown, that the factor VIII(a) concentration in the perfused solution determined the time required to achieve the steady-state.

In the past, detailed studies have been published on the kinetics and mechanisms of prothrombin activation (see References $77,84,89$, and references therein), however, they were all performed in systems where the dynamic aspects of flow could not be examined. Prothrombinase, a key enzymatic complex in blood coagulation, is a dissociable $\mathrm{Ca}^{2+}$-dependent enzymatic complex composed of the enzyme factor $\mathrm{Xa}$, the non-enzymatic cofactor factor $\mathrm{Va}$, and a suitable phospholipid surface. This complex is a highly efficient activator of prothrombin, which leads to the formation of thrombin. In this paper, we describe the activation of prothrombin by prothrombinase under well-defined flow conditions, obtained by perfusion of reactants through a phospholipid coated glass capillary.

\section{EXPERIMENTAL PROCEDURES}

Caplliarles - Glass capillaries with an internal diameler of $0.58 \mathrm{~mm}$ and a length of $12.7 \mathrm{~cm}$, were obtained from Brand, FRG. They were boiled for $30 \mathrm{~min}$ in $2 \mathrm{mg} / \mathrm{ml}$ Sparkleen (Fisher Scientific Co., Pittsburgh "USA). After extensive washing with deionized water the capillaries were placed overnight in a $30 \%$ chromic acid solution. The capillaries were then again extensively washed and kept in $50 \%$ ethanol. Capillaries were used the same day; prior to use they were dried.

Protelns and Phosphollpld Vesicles-Bovine factor $V$ and factor Va (145) and bovine prothrombin (86) were prepared and quantified as described. Bovine antithrombin III (ATIII) was isolated as reported previously (115). Human prothrombin was purified as described (132), and the molair concentration was determined, after complete activation with Echis Carinatus venom (Sigma, St.Louis, USA) by active site titration with PNPGB (134). Human lactor Xa was prepared by activation of purified factor X (112) with the factor X activating protein from Russell's Viper venom (KabiVitum, Stockholm, Sweden) and isolated as described tor the bovine protein (113). The mollar concentration was determined by active site titration with PNPGB (114).

Meizothrombin(dles fragment 1) was prepared as follows. Human prothrombin (16 $\mu \mathrm{M}$ ) was activated by Echis Canivatus venom $(0.5 \mathrm{mg} / \mathrm{ml})$ in $50 \mathrm{mM}$ Tris. $\mathrm{HCl}(\mathrm{pH} 7.5)$ containing $100 \mathrm{mM} \mathrm{NaCl}$, $10 \mathrm{mM} \mathrm{CaCl}_{2}$, and $10 \mathrm{mM}$ benzamidine- $\mathrm{HCl}_{4}$ After 5 min the conversion of prothrombin was terminated by the addition of EDTA to a final concentration of $20 \mathrm{mM}_{\text {, }}$ and the mixture was applied to a column $(1.5 \times 30 \mathrm{~cm})$ of OAE-Sepharose (Pharmacia "Uppsala, Sweden) equilibrated in $50 \mathrm{mM}$ Tris- $\mathrm{HCl}(\mathrm{pH} 7.5), 100 \mathrm{mM} \mathrm{NaCl}$, and $10 \mathrm{mM}$ benzamidine- $\mathrm{HCl}$ at $4^{\circ} \mathrm{C}$. A linear salt gradient, from 0.10 to $0.60 \mathrm{M} \mathrm{NaCl}$ in $50 \mathrm{mM}$ Tris-HCl $(\mathrm{pH} 7.5), 10 \mathrm{mM}$ benzamidine-HCl $(2 \times 150 \mathrm{mi})$, was applied and meizothrombin(des fragment 1), assessed by its activity on $\$ 2238$, eluted at about $0.25 \mathrm{M}$ $\mathrm{NaCl}$. The fractions with the highest activity were pooled. In these steps, the presence of $10 \mathrm{mM}$ benzamidine-HCI was an absolute requirement; upon its omission the only product was $\alpha$ thrombin. For further use, the benzamidine was rapidly removed by gel filtration. The preparation was applied to a column $(1.6 \times 60 \mathrm{~cm})$ of Sephadex G50 (Pharmacia, Uppsala, Sweden) in $50 \mathrm{mM}$ 
Tris-HCl (pH 7.9), $175 \mathrm{mM} \mathrm{NaCl}$ at $4^{\circ} \mathrm{C}$. Fractions were immediately pooled and stored at $-700^{\circ} \mathrm{C}$. The final preparation was over $95 \%$ pure as judged by SDS polyacrylamide gelelectrophoresis (149). and the concentration of meizothrombin(des tragment 1) was assessed by active site titration with PNPGB.

Small unilaminar vesicles, composed of $75 \%$ egg PC and $25 \%$ brain PS were prepared by sonication in $50 \mathrm{mM}$ Tris- $\mathrm{HCl}(\mathrm{pH} 7.5)$ containing $100 \mathrm{mM} \mathrm{NaCl}(86)$. To determine amounts of phospholipid covering the inner wall of the capillaries, also vesicles were prepared with tracer concentrations of dioleoylphosphatidyl-( $\left.{ }^{14} \mathrm{C}\right)$ serine (specific activity $2.0 \mathrm{GBq} / \mathrm{mmol}$, Amersham, United Kingdom). The vesicle suspension had a specific activity of $97.8 \mathrm{MBq} / \mathrm{mm}$ mol: Radioactivity measurements were performed with a Beckman LS3801 scintillation counter, utilizing a lliquid scintillation cocktail (Formula-989, Biotechnology systems, Boston, USA).

The Activation of Prothrombin by Surtace-Bound Prothrombinase-Capillaries were coated with phospholipid by $20 \mathrm{~min}$ incubation with a $1 \mathrm{mM}$ vesicle suspension, then they were rinsed with Tris-butfer $(50 \mathrm{mM}$ Tris- $\mathrm{HCl}(\mathrm{pH} 7.9)$ containing $175 \mathrm{mM} \mathrm{NaCl}, 3.0 \mathrm{mM} \mathrm{CaCl}$, and $0.5 \mathrm{mg}$ ovalbumin/ml) at a flow rate of $1.2 \mathrm{mumin}$ (wall shear rate $1044 \mathrm{~s}^{-1}$ ) for $2 \mathrm{~min}$. The capillaries were then perfused with factor $V a$, diluted in the Tris-buffer, for $10 \mathrm{~min}$ at a flow rate of $30 \mu \mathrm{l} / \mathrm{min}$ (wall shear rate $26 \mathrm{~s}^{-1}$ ). Immediately hereafter the capillaries were washed with Tris-buffer all allow rate of $30 \mu$ limin during 10 min $_{n}$ and then perfused with a solution of factor Xa and prothrombin in the same Tris-buffer. Drops were collected at the outlet and $20 \mu \mathrm{ul}$ aliquots were immediately diluted in $430 \mu \mathrm{l}$ of $50 \mathrm{mM}$ Tris-HCl (PH 7.9 ), $175 \mathrm{mM} \mathrm{NaCl}, 20 \mathrm{mM}$ EDTA, containing $0.5 \mathrm{mg} \mathrm{HSA} / \mathrm{ml}$ and assayed for thrombin by the addition of $50 \mu$ chromogenic substrate (S2238, Kabivitrum, Stockholm, Sweden). The final concentration $S 2238$ was $0.22 \mathrm{mM}$ and the rate of absorbance increase was recorded at $405 \mathrm{~nm}$ on a dual wavelength spectrophotometer (reference wavelength: $500 \mathrm{~nm}$ ) at $37^{\circ} \mathrm{C}$. The amounts of thrombin formed were calculated from a standard curve constructed with purified human $\alpha$-thrombin (133) under identical conditions.

All pertusions were performed by the use of a syringe pump (Harvard Apparatus Co., Massachusetts, USA) resulting in a continuous laminar flow through the capillaries. The experiments were performed in a climated room at $25 \pm 1{ }^{\circ} \mathrm{C}_{11}$ and the conditions mentioned were routinely applied, unless otherwise indicated.

Determination of Factor Va Bound to the Phosphollpid Coated CaplliarlesAt the end of each experiment the capillaries were emptied and subsequently washed with one capillary volume of $0.2 \%$ Triton $\times 100$ in $50 \mathrm{mM}$ Tris- $\mathrm{HCl}$ (pH 7.9), $175 \mathrm{mM} \mathrm{NaCl}, 3.0 \mathrm{mM} \mathrm{CaCl} 2$. The solutions were mixed and a sample was diluted 10-fold with Tris-bulfer, and assayed for factor Va.

Factor Va Assay - Factor Va samples $(10 \mu l)$ were added to cuvettes, containing a solution of factor $\mathrm{Xa}_{i}$ phospholipid vesicles and $\mathrm{CaCl}_{2}$ in $50 \mathrm{mM} \mathrm{Tris-14Cl}(\mathrm{pH} 7.9), 175 \mathrm{mM} \mathrm{NaCl}$, and $0.5 \mathrm{mg} \mathrm{HSA} / \mathrm{ml}$. After 2 min at $37^{\circ} \mathrm{C}, 10 \mu$ bovine prothrombin was added. The final concentrations were $0.10 \mathrm{nM}$ lactor $\mathrm{Xa}_{1}, 10 \mu \mathrm{M}$ phospholipid, $10 \mathrm{mM} \mathrm{CaCl} \mathrm{Ca}_{2}$, and $0.2 \mu \mathrm{M}$ prothrombin in a final volume of $125 \mu$. After 5 min the conversion of prothrombin was terminated by the addition of $325 \mu$ of 50 mM Tris. $\mathrm{HCl}$ (pH 7.9), $175 \mathrm{mM} \mathrm{NaCl}, 20 \mathrm{mM}$ EDTA, and $0.5 \mathrm{mg} \mathrm{HSA} / \mathrm{ml}$. Hereafler, $50 \mu \mathrm{m} 2.2 \mathrm{mM}$ S2238 was added and the amount of thrombin formed was determined. The amounts of thrombin formed were linearly dependent on the amounts of factor Va present, up to at least 2.0 pM lactor Va in the assay.

In samples derived from the capillaries, $0.01 \%$ Triton $\times 100$ was present. Because the assay was sensitiwe to such an amount of Triton $\times 100$, factor Va reference cunves were constructed in the presence of the same detergent concentration. Each factor Va determination was performed in duplicate, and the differences between the individual values of each duplicate varied between zero and approximately $10 \%$ of the mean values.

Measurement of Melzothrombin(des Fragment 1)-Samples (20 $\mu 1)$ Irom drops collected at the capillary outlet, were immediately dituted in cuvettes, containing $430 \mu 1$ of $50 \mathrm{~mm}$ Tris-HCl (pH 7.9), $175 \mathrm{mM} \mathrm{NaCl}, 20 \mathrm{mM}$ EDTA, $0.5 \mathrm{mg} \mathrm{HSA} / \mathrm{ml}, 4 \mathrm{nM}$ ATIII, and $2 \mu \mathrm{g}$ untractionated heparin/ml (165 USP U/mg) at $37^{\circ} \mathrm{C}$. After $1 \mathrm{~min} 50 \mu \mathrm{Ll} 2.2 \mathrm{mM} \mathrm{S2238}$ was added and the residual amidolytic activity was determined. From previous work it follows that under these conditions $\alpha$ thrombin activity will be completely neutralized, whereas this is not the case for meizothrombin(des 
fragment 1) activity (115). The amounis of meizothrombin(des fragment 1) present in the samples were calculated from the residual amidolytic activities utilizing a standard curve constructed with purifled meizothrombin(des fragment 1).

Theory of Proteln Adsorption to the Interior surface of a Capillary- During laminar flow along the inner wall of a capiliary, in which a fluid phase protein binds to the capillary wall, the transter of the protein occurs in a thin diffusion layer between the butk solution and the surface. It has been derived (181) that, provided the binding capacity of the surface is sufficiently large as compared to the protein content of the boundary layer, and if the binding sites are unitormlly distributed, the rate of protein flow $\left(v_{\mathrm{s}}, \mathrm{mol} / \mathrm{s}\right)$ towards the surface is given by:

$$
v_{s}=0.54\left(\mathrm{D}^{2} / x\right)^{1 / 3} \mathrm{~S}_{\mathrm{b}}
$$

where $\gamma$ is the shear rate $\left(s^{-1}\right), D$ is the diffusion coefficient of the protein $\left(\mathrm{cm}^{2} / \mathrm{s}\right), x$ is the distance from the capillary entrance $(\mathrm{cm})$, and $\mathrm{S}_{\mathrm{b}}$ is the concentration of protein in the fluid phase $(\mathrm{mol} / \mathrm{ml})$. The shear rate is given by:

$$
\gamma=32 \mathrm{Q} /\left(\pi \mathrm{d}^{3}\right)
$$

where $Q$ is the flow rate $(\mathrm{m} / \mathrm{s})$, and $d$ is the internal diameter $(\mathrm{cm})$ of the capillary.

\section{RESULTS}

Determination of the Amounts of Phospholipid Bound to the Interior Surfaces of Capillaries - It has been demonstrated that, when glass coverslips are placed in a vesicle suspension its surface becomes covered with a continuous, planar membrane (182). This technique has been used for the binding of phospholipids to glass capillaries (110). We used virtually the same technique, and in order to verity the formation of a phospholipid bilayer we determined the amounts of phospholipid bound, by use of vesicles containing ${ }^{14} \mathrm{C}$-labelled phosphatidylserine. Clean and dry capillaries were filled with a suspension of the small unilaminar phospholipid vesicles, as outlined under "Experimental Procedures". Non-bound phospholipid was removed by perfusion of Tris-buffer at a flow rate of $1.2 \mathrm{ml} / \mathrm{min}$ for $2 \mathrm{~min}$. The capillaries were emptied, washed with approximately $0.5 \mathrm{ml}$ of scintillant and broken into 3 segments. All was collected in a vial containing scintillant to a tinal volume of $5 \mathrm{ml}$ and the radioactivity was measured.

Our results showed that $6.5 \times 10^{-10}$ mol phospholipid was bound per $\mathrm{cm}^{2}$ $\left(\mathrm{n}=8 ; \mathrm{SD}=0.6 \times 10^{-10} \mathrm{~mol} / \mathrm{cm}^{2}\right)$. Such an amount of phospholipid agrees reasonably well with published data (see Reference 110, and references therein). In addition, we demonstrated the bilayer to be stable. After the removing of nonbound phospholipid, capillaries were perfused for 10 min with $0.15 \mathrm{nM}$ factor $\mathrm{Va}$ followed by a $30 \mathrm{~min}$ pertusion with Tris-buffer at a rate of $30 \mu \mathrm{l} / \mathrm{min}$. The amount of radioactivity retained in the capillaries, assessed as described above, corres- 
ponded with $5.9 \times 10^{-10} \mathrm{mal} / \mathrm{cm}^{2}\left(\mathrm{n}=4 ; \mathrm{SD}=0.9 \times 10^{-10} \mathrm{~mol} / \mathrm{cm}^{2}\right)$ phospholipid bound to the capillary surtaces.

We also established, with the use of the ${ }^{14} \mathrm{C}$-labelled vesicles, that the procedure for the determination of the amounts of factor Va bound to the phospholipid surfaces, removed essentially all bound phospholipid. Again capillaries were filled with the vesicle suspension, and washed as described. Then each capillary was emptied in a vial containing $5 \mathrm{ml}$ of scintillant and washed with one volume of the Tris-buffered Triton $X 100$ solution. By this procedure we recovered an amount of radioactivity corresponding to $6.2 \times 10^{-10} \mathrm{~mol}$ phospholipid/ $/ \mathrm{cm}^{2}$ $\left(\mathrm{n}=4 ; \mathrm{SD}=0.1 \times 10^{-10} \mathrm{~mol} / \mathrm{cm}^{2}\right)$.

Binding of Factor Va to Phospholipid-Coated Capillaries-In order to obtain surface-bound prothrombinase we first adsorbed factor Va to phospholipid coated capillaries. To this end, a phospholipid coated capillary was perfused with $0.15 \mathrm{nM}$ factor Va for $10 \mathrm{~min}\left(30 \mu \mathrm{l} / \mathrm{min}\right.$; wall shear rate $\left.26 \mathrm{~s}^{-1}\right)$ and subsequently washed for $10 \mathrm{~min}$ with buffer $(30 \mu \mathrm{l} / \mathrm{min})$. The amount of factor $\mathrm{Va}$ bound to the phospholipid coated capillary, determined as outlined under "Experimental Procedures", was $2.4 \mathrm{fmol} / \mathrm{cm}^{2}$. Given the interior surface of the capillary $\left(2.31 \mathrm{~cm}^{2}\right)$ and the factor Va influx $(300 \mu \mathrm{l}$ of $0.15 \mathrm{nM})$ it can be calculated that $12 \%$ of the amount of factor Va perfused became bound. We investigated the distribution of the factor Va bound to the phospholipid surface, by breaking a capillary, perfused with factor Va and washed with buffer, into two pieces of approximately equal length. An amount of $2.6 \mathrm{fmol}$ factor Va was bound in the inlet part $(l=6.4 \mathrm{~cm})$ and $2.1 \mathrm{fmol}$ in the outlet part of the capillary $(l=6.3 \mathrm{~cm})$; hence the ratio of the amounts is $1: 0.81$.

The Course of Thrombin Generation by Surface-Bound Prothrombinase- Figure 1 shows thrombin generation obtained by the perfusion of $0.50 \mathrm{nM}$ factor $\mathrm{Xa}$ and $1.0 \mu \mathrm{M}$ prothrombin at a flow rate of $94 \mu \mathrm{l} / \mathrm{min}$ (wall shear rate $82 \mathrm{~s}^{-1}$ ), after a phospholipid-coated capillary had been perfused with a solution of $0.15 \mathrm{~nm}$ factor $\mathrm{Va}$ for $10 \mathrm{~min}$. It is seen that under these conditions thrombin is measurable at the outlet after about $1 \mathrm{~min}$. Then the rate of thrombin formation rapidly increases until a steady-state rate of approximately 5.5 $\mathrm{pmol} / \mathrm{min}$ is obtained, which takes about $4 \mathrm{~min}$. The steady-state thrombin formation is stable for at least $20 \mathrm{~min}_{\text {w }}$ which could suggest that during the course of the perfusion with factor $\mathrm{Xa}$ and prothrombin no significant amount of factor $\mathrm{Va}$ is eluted from the phospholipid coated capillary. In order to verify this we determined the amount of bound factor $\mathrm{Va}$, at the end of the perfusion with factor $\mathrm{Xa}$ and prothrombin, and found $2.5 \mathrm{fmol} / \mathrm{cm}^{2}$. An amount which is identical to the amount of factor $\mathrm{Va}$ bound at the onset of the perfusion with factor $\mathrm{Xa}$ and prothrombin, as determined in the previous section. 


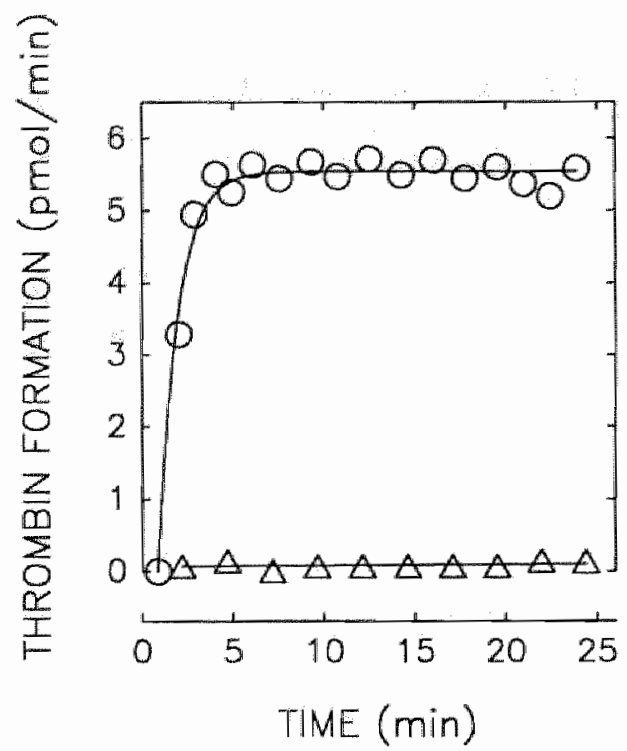

Figure 1. The rate of thrombin formation as function of time. Prothrombin $(1.0 \mu \mathrm{M})$ and factor Xa (0.50 nM) were perfused through a phospholipid coated capillary in the presence of 2.4 fmol factor $\mathrm{Va} / \mathrm{cm}^{2}(0)$, or a capillary which was not coated with phospholipid ( $\left.\Delta\right)$. See the text for further experimental details.

The observed thrombin formation is truly the consequence of prothrombinase-catalyzed activation of prothrombin because in the absence of phospholipids thrombin generation was not detectable (Figure 1). Also when the factor $\mathrm{Va}$ perfusion step was omitted thrombin activity was not measurable. Thus, factor Xa alone did not produce thrombin at detectable rates whether phospholipids were present or not.

The Steady-State Rate of Thrombin Formation as Function of the Amount of Phosphollpid-Bound Factor Va- We were intrigued by the stable steady-state rate of thrombin formation, and we were curious to find out to what extent the steady-state was a measure for the amount of surface-bound prothrombinase. Thus we varied the amount of factor $\mathrm{Va}$ bound, which was achieved by varying the factor Va concentration of the perfused solution. Subsequently we determined the steady-state rates of thrombin formation by perfusion of factor $\mathrm{Xa}$ and prothrombin (Figure 2).

The results demonstrate that the steady-state rate of thrombin formation increases linearly with the amount of bound factor Va up to $2.5 \mathrm{fmol}$ factor $\mathrm{Va} / \mathrm{cm}^{2}$. It is also seen that the steady-state levels are independent of the fluid phase factor Xa concentration when it varies from 0.050 to $0.50 \mathrm{nM}$. In this range of factor Xa concentrations the phospholipid-bound factor Va can thus be saturated 
with factor Xa irrespective of the concentration of the latter. Linear regression analysis of the data revealed that on the average 1 fmol factor $\mathrm{Va} / \mathrm{cm}^{2}$ results in a steady-state rate of thrombin formation of $2.0 \pm 0.1$ (SE) pmol/min. With an interior capillary surface of $2.31 \mathrm{~cm}^{2}$, thrombin is thus generated with a rate of $870 \pm 40$ $\mathrm{mol} / \mathrm{min}$ per mol prothrombinase.

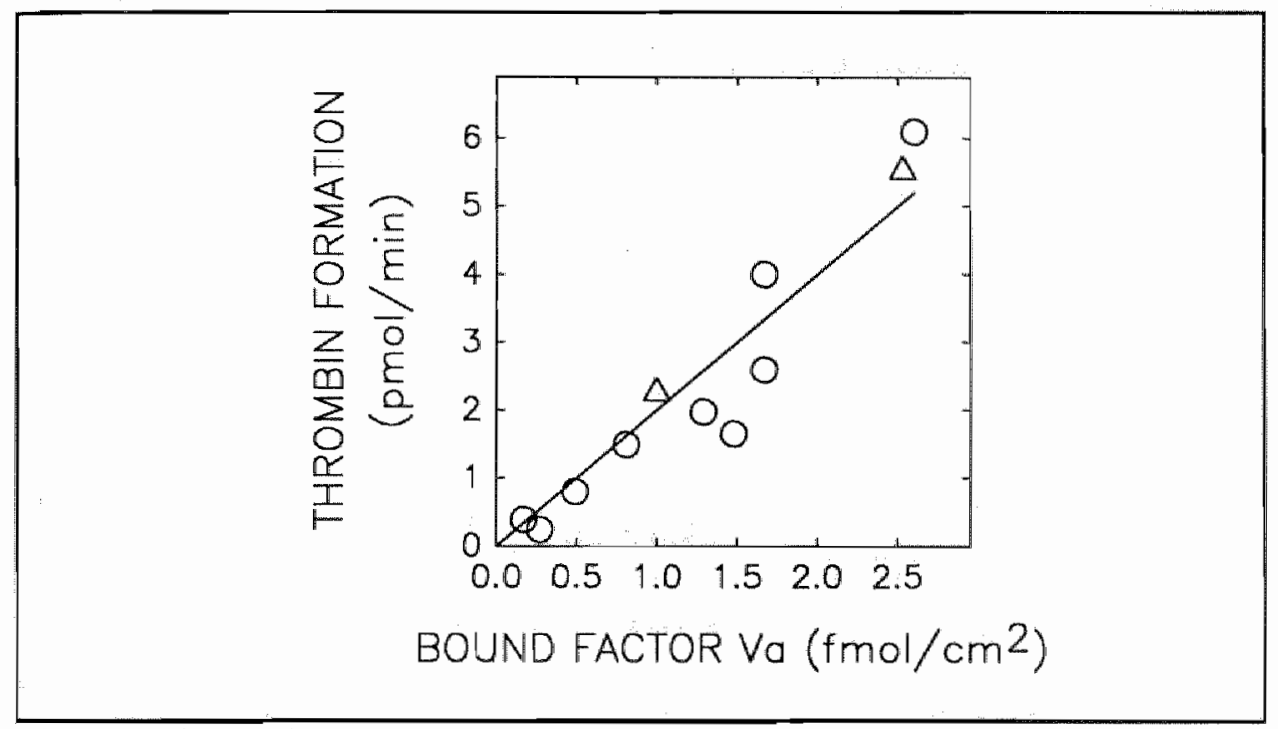

Figure 2. The steady-state thrombin formation as function of the amount of bound factor Va. Phospholipid coated capillaries were perfused with factor Va solutions of variable concentration. Steady-state rates of thrombin formation were determined at fluid phase concentrations of $1.0 \mu \mathrm{M}$ prothrombin and efther $0.050 \mathrm{nM}(O)$ or $0.50 \mathrm{nM}(\Delta)$ factor Xa at a flow rate of $94 \mu / \mathrm{min}$.

\section{The Influence of the Fluid Phase Factor Xa Concentration and} the Flow Rate on the Rate of Generation of Prothrombinase- Although, the steady-state level of prothrombinase activity is not influenced by the fluid phase factor $X a$ concentration, the formation rate of prothrombinase de creases drastically with decreasing factor Xa concentrations, which is shown in Figure 3. In the presence of $0.50 \mathrm{nM}$ factor $X a$ thrombin generation starts at about $1 \mathrm{~min}$ and reaches the steady-state at approximately $4 \mathrm{~min}$. In the presence of $0.050 \mathrm{nM}$ iactor Xa thrombin generation starts at roughly the same time, however it takes about $15 \mathrm{~min}$ before the steady-state is reached. At the steady-state thrombin was generated at an average rate of $5.8 \mathrm{pmol} / \mathrm{min}$ by approximately 6.0 fmol prothrombinase. The first derivatives of the curves reveal that at the onset of thrombin, its rate of formation increases with $5.3 \mathrm{pmol} / \mathrm{min}$ per $\mathrm{min}$ and 0.60 $\mathrm{pmol} / \mathrm{min}$ per min at 0.50 and $0.050 \mathrm{nM}$ factor $\mathrm{Xa}_{\text {n }}$ respectively. Thus, after the lag-phase prothrombinase activity is generated at a rate of $5.5 \mathrm{fmol} / \mathrm{min}(0.50 \mathrm{nM}$ factor $\mathrm{Xa}$ ) and $0.62 \mathrm{fmol} / \mathrm{min}(0.050 \mathrm{nM}$ factor $\mathrm{Xa})$. 


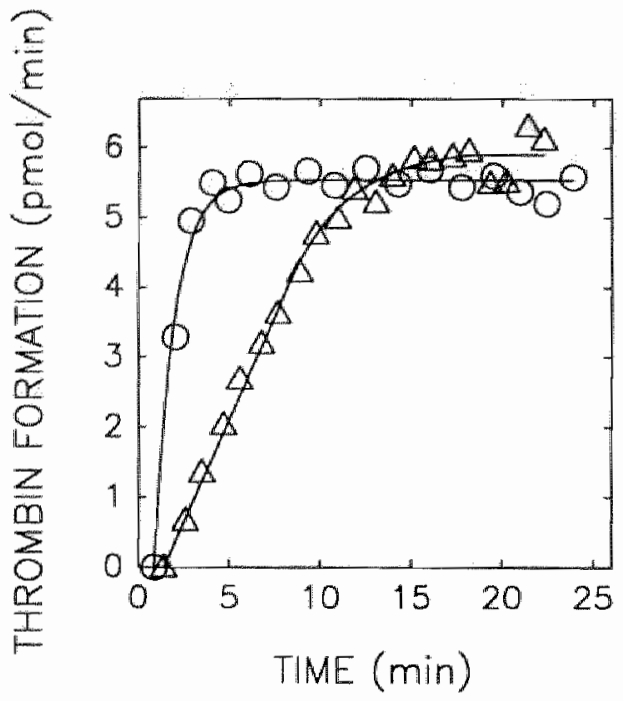

Figure 3. The effect of factor Xa concentration on the course of the rate of thrombin formation. Capillaries containing phospholipid-bound tactor Va were perfused with $1.0 \mu \mathrm{M}$ prothrombin and factor Xa at $94 \mu \mathrm{d} / \mathrm{min}$. The experiments were conducted with $0.50 \mathrm{nM}$ factor $X a$ and 2.5 fmol factor $\mathrm{Va} / \mathrm{cm}^{2}(\mathrm{O})$ or $0.050 \mathrm{nM}$ factor $\mathrm{Xa}$ and 2.6 fmol factor $\mathrm{Va} / \mathrm{cm}^{2}(\Delta)$.

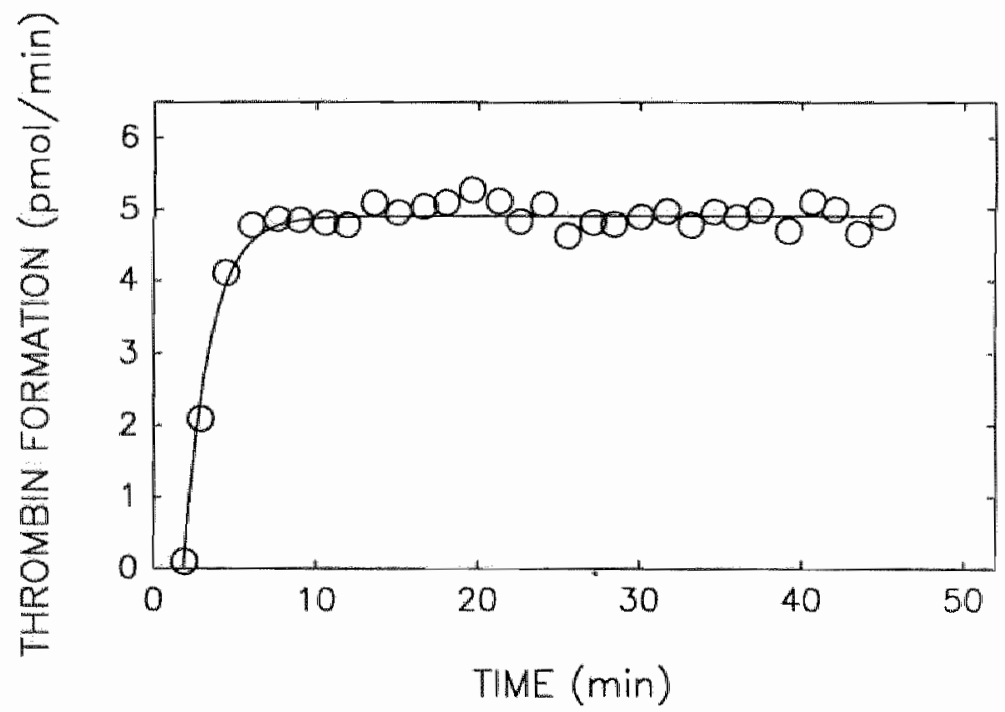

Figure 4. Time course of the thrombin generation rate. Prothrombin $(1.0 \mu \mathrm{M})$ and factor $\mathrm{Xa}(0.50$ $\mathrm{nM}$ ) were perfused at a flow rate of $48.4 \mu \mathrm{l} / \mathrm{min}$ through a factor Va containing phospholipid coated capillary. The amount of factor Va was $3.3 \mathrm{fmol} / \mathrm{cm}^{2}$. 
The rate of formation of prothrombinase is also influenced by the flow rate. This is seen in Figure 4, where thrombin formation was studied at a flow rate of 48.4 $\mu \mathrm{l} / \mathrm{min}$ (wall shear rate $42 \mathrm{~s}^{-1}$ ). Thrombin generation now starts at approximately $2 \mathrm{~min}$ and reaches a steady-state end-level at $7 \mathrm{~min}$, and the prothrombinase activity is generated at a rate of $2.6 \mathrm{~mol} / \mathrm{min}$.

Steady-State Rates of Generation of $\alpha$-Thrombin and Meizothrombin(des Fragment 1) at Varying Prothrombin ConcentrationsWhen prothrombin activation by prothrombinase is monitored via amidolytic activity measurements we cannot discriminate $\alpha$-thrombin and meizothrombin (des fragment 1) as the products formed. It has been shown in static, closed systems that, depending on the prothrombin concentration, large amounts of meizothrombin(des fragment 1) are formed during prothrombin activation by complete prothrombinase $(89,115)$. Therefore we investigated whether the formation of meizothrombin (des fragment 1) also occurs in our continuous flow system.

We assayed the amidolytic thrombin activity determined at the capillary outlet for the presence of meizothrombin(des fragment 1). This was achieved by taking advantage of the fact that $\alpha$-thrombin is rapidly scavenged by ATIII in the presence of heparin, whereas the inhibition of meizothrombin(des fragment 1) by ATIII is slow and is not enhanced by heparin (115). The steady-state rates of $\alpha$ thrombin and meizothrombin (des fragment 1) formation as function of the fluid phase prothrombin concentration are depicted in Figure 5.

Our data show, that up to $0.20 \mu \mathrm{M}$ prothrombin no significant amounts of meizothrombin(des fragment 1) are formed; when the prothrombin concentration increases further up to $1.0 \mu \mathrm{M}$ the relative amount of meizothrombin(des fragment 1) formed increases up to $32 \%$. In addition, the steady-state rates of formation of total thrombin activity ( $\alpha$-thrombin plus meizothrombin(des fragment 1$)$ ) are linearly dependent on the prothrombin concentration up to $0.50 \mu \mathrm{M}$ of prothrombin. A deviation from linearity is seen when the prothrombin concentration increases to $1.0 \mu \mathrm{m}$. Thus during continuous flow the relative rates of formation of $\alpha$-thrombin and meizothrombin(des fragment 1), as well as the overall rates of activation of prothrombin are dependent on the fluid phase prothrombin concentration up to at least $1.0 \mu \mathrm{M}$ of prothrombin. Interestingly, we have previously found that, in vesicle type experiments the rate of prothrombin activation is virtually independent of the prothrombin concentration at concentrations of 0.6 $\mu \mathrm{M}$ and higher (115).

\section{DISCUSSION}

In this study we investigated the prothrombinase-catalyzed activation of prothrombin during laminar flow through capillaries, at $25^{\circ} \mathrm{C}$. The capillaries were provided with a phospholipid billayer attached to the interior surface, and 


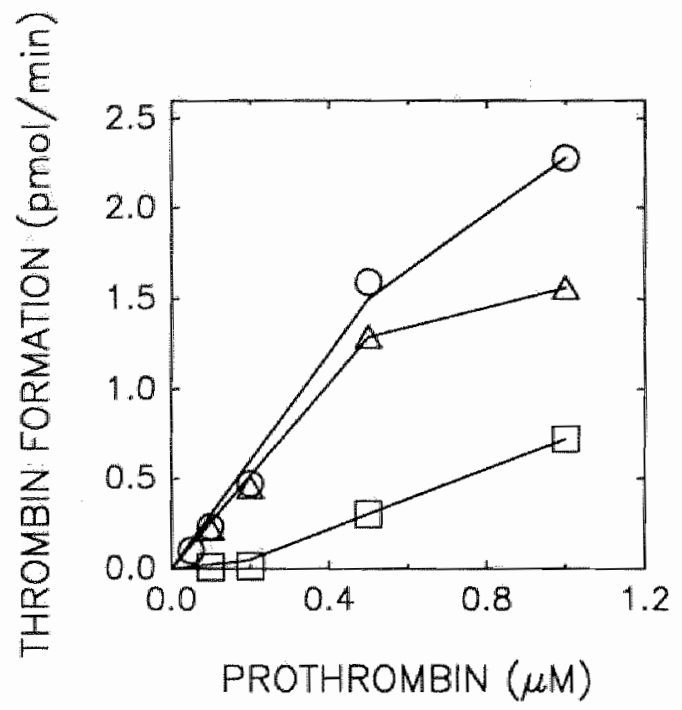

Filgure 5. The steady-state rate of thrombin formalion as function of the prothrombin concentration. Prothrombin was activated by $0.050 \mathrm{nM}$ factor $X \mathrm{a}$ in the presence of 1.9 fmol factor $\mathrm{Va} / \mathrm{cm}^{2}$ at a flow rate of $30 \mu \mathrm{l} / \mathrm{min}$. The amounts of total amidolytic thrombin activity $(O)$, as well as the amounts of $\alpha$-thrombin $(\Delta)$ and meizothrombin(des fragment 1) (O) formed were determined.

then perfused with a factor Va containing solution. The amount of bound factor $V a$ was determined after washing, and we found that significant amounts of factor $V a$ were retained. A factor $V a$ influx of $0.15 \mathrm{nM}$ at a flow rate of $30 \mu \mathrm{l} / \mathrm{min}$ for 10 min resulted in a $12 \%$ factor $V a$ binding of $2.4 \mathrm{fmol} / \mathrm{cm}^{2}$. It has been reported that factor Va-binding to phospholipid vesicles, composed of $20-25 \%$ phosphatidylserine and $75-80 \%$ phosphatidylcholine, is saturated at a phospholipid to protein ratio (mol/mol) varying between 57 and $100(166,183)$. Phospholipid vesicles are highly curved, however, relative to the molecular dimensions of proteins, the phospholipid bilayer attached to a capillary is to be regarded as a plane. Since maximum surface concentration (factor $V$, factor $X$, prothrombin) seems to be independent of the curvature of the surface (184), it can be estimated, from the factor Va-binding data $(166,183)$ and the amount of phospholipid bound to the capillaries $\left(6.5 \times 10^{-10} \mathrm{~mol} / \mathrm{cm}^{2}\right)$, that under the conditions used, less than $0.04 \%$ of the maximum factor Va binding capacity was used.

At such a low surface concentration the adsorption of factor $\mathrm{Va}$ is limited by the diffusion-dependent flux of factor $V a$ towards the surface (184). In which case, according to Equation 1, the adsorption of factor $V a$ in a given time should decrease for increasing distances from the tube entrance. Thus, the inlet part of a capillary should contain a significant higher amount of factor $\mathrm{Va}$ as compared to 
the outlet part. We investigated the distribution of the bound factor Va by breaking a capillary into two pieces of equal length. The observed distribution was almost homogeneous $(1: 0.81)$. A full explanation for the apparent deviation from theory is not yet at hand, however it can be speculated that the phospholipidbound factor Va can diffuse laterally across the surface, as has been described for lipid-bound antibodies in phospholipid monolayers (185).

Factor Va containing phospholipid-coated capillaries were perfused with factor Xa and prothrombin, drops were collected at the capillary outlet and assayed for thrombin. The thrombin concentrations determined where multiplied by the flow rates at which the perfusions with factor $\mathrm{Xa}$ and prothrombin were performed, to obtain the rates of thrombin generation. Thrombin generation showed a short lag-phase followed by an increase of the rate of prothrombin activation, until a steady-state end-level was reached. The obtained steady-state prothrombinase activity was stable for a relatively long period of time (20 min in Figure 1 , $40 \mathrm{~min}$ in Figure 4). Because, at the flow rate and prothrombin concentration employed in the experiment depicted in Figure 1, the steady-state rate of thrombin generation is direct proportional to the amount of surface-bound prothrombinase (Figure 2) the stability of the steady-state indicates, that during the perfusion with factor $\mathrm{Xa}$ and prothrombin the prothrombinase is not washed out. This could be confirmed; after a capillary had been pertused for 25 min with 0.50 $\mathrm{nM}$ factor $\mathrm{Xa}$ and $1.0 \mu \mathrm{M}$ prothrombin at a flow rate of $94 \mu \mathrm{l} / \mathrm{min}$, the factor $\mathrm{Va}$ surface concentration was $2.5 \mathrm{fmol} / \mathrm{cm}^{2}$. In a control experiment the amount of factor $\mathrm{Va}$ at the onset of the perfusion with factor $\mathrm{Xa}$ and prothrombin was 2.4 $\mathrm{fmol} / \mathrm{cm}^{2}$.

Further evidence for a very tight assembly of prothrombinase was found in the observation that the steady-state prothrombinase activity was independent of the factor Xa concentration when it varied 10 -fald from 0.050 to $0.50 \mathrm{nM}$. Apparently the factor $\mathrm{Va}$ bound to the phospholipid surface can be saturated with factor $\mathrm{Xa}$, even in the presence of the very low fluid phase factor Xa concentration of $0.050 \mathrm{nM}$.

It is seen from Figures 3 and 4 that, under the specific conditions, it takes considerable time before the steady-state prothrombinase activity is reached. The time to reach steady-state depends on at least three phenomena. First of all, the capillary content has to be replaced by the solution containing factor $\mathrm{Xa}$ and prothrombin, secondly, factor Xa and prothrombin have to be transferred through the boundary layer to the phospholipid surface, and thirdly, the thrombin formed has to move from the catalytic sites into the bulk solution in order to leave the capillary.

The rate of formation of prothrombinase depended on the fluid phase factor $X a$ concentration and the flow rate. At a flow rate of $94 \mu \mathrm{l} / \mathrm{min}$ and in the presence of $0.050 \mathrm{~nm}$ factor $X a$ the rate of formation of prothrombinase was $0.62 \mathrm{fmol} / \mathrm{min}$, with $0.50 \mathrm{nM}$ factor $X a$ the rate was $5.5 \mathrm{fmol} / \mathrm{min}$ (Figure 3). At a flow rate of 48.4 $\mu / / \mathrm{min}$, in the presence of $0.50 \mathrm{nM}$ factor $\mathrm{Xa}$ the rate of formation of prothrom- 
binase was $2.6 \mathrm{fmol} / \mathrm{min}$ (Figure 4). Because the prothrombin concentrations were at least 2,000 times in excess over the factor $X a$ concentrations, the diffusion limited rate of transport of prothrombin to the phospholipid surface is at least 3 orders of magnitude higher than the diffusion limited rate of transpont of factor $\mathrm{Xa}$ to the surface. Therefore it is well feasible that under these conditions, the time delay required to reach the steady-state prothrombinase activity is dependent on the flux of factor Xa to the phospholipid-bound factor Va. According to Equations 1 and 2 ("Experimental Procedures") the diffusion controlled transfer of factor $X a$ to the surface indeed increases with increasing fluid phase factor $X a$ concentrations and flow rates.

We have previously demonstrated, that if factor $X_{a}$ is present as part of the fully assembled prothrombinase, a significant amount of meizothrombin(des fragment 1) is formed (115). The first step in the formation of this product is the generation of meizothrombin. Meizothrombin is formed when prothrombin is specifically cleaved at only one of the factor Xa-cleavage sites present in prothrombin. This cleavage has as consequence that the thrombin active site becomes exposed. Meizothrombin is very rapidly processed further, and gives rise to the formation of meizothrombin(des fragment 1). Meizothrombin(des fragment 1) is a "dead-end" product, because the protein, lacking the phospholipid- and $\mathrm{Ca}^{2+}$-binding regions, is not as good a substrate for the prothrombinase as prothrombin is. Moreover its reactivity, as compared with thrombin, towards macromolecular substrates ${ }_{1}$ e.g. fibrinogen, antithrombin III, and factor $V$, is greatly reduced.

It has been shown in static, closed systems, that the relative amounts of $\alpha$ thrombin and meizothrombin(des fragment 1) formed depend on the prothrombin concentration $(89,115)$. In keeping with these findings we observed, that also during continuous flow, the relative contribution of meizothrombin(des fragment 1) to the total amidolytic activity increases when the prothrombin concentration increases. However, in contrast to previous work (115), where at $1.0 \mu \mathrm{M}$ prothrombin $84 \%$ of the product was meizothrombin(des fragment 1 ), we observed that during flow the relative amount of meizothrombin(des fragment 1) formed is diminished to $32 \%$. Apparently, during flow the major prothrombin activation product is $\alpha$-thrombin in stead of meizothrombin(des fragment 1).

Acknowlodgement- We thank Ron Blezer for preparing meizothrombin(des fragment 1). 
$a$ 


\section{Flow and the Inhibition of Prothrombinase by Antithrombin III and Heparin $\S$}

Inhibition of prothrombinase by antithrombin III (ATIII) and heparin, was Investigated in a continuous flow system. Phosphollpld-coated capllarles, containing phosphollpld-bound factor $X a$ and factor Va were perfused with $1.0 \mu \mathrm{M}$ prothrombin and $0.50 \mathrm{nM}$ factor $\mathrm{Va}$. At $25^{\circ} \mathrm{C}$ and a flow rate of 32 $\mu \mathrm{l} / \mathrm{min}$ (shear rate $28 \mathrm{~s}^{-1}$ ) the steady-state rates of prothrombin conversion depended IInearly on the surface density of prothrombinase up to $2 \mathrm{fmol} /$ $\mathrm{cm}^{2}$. The average rate of thrombin generation was $952 \pm 43$ (SE) $\mathrm{mol} / \mathrm{m} / \mathrm{n}$ per mol prothrombinase. When ATIII was Included In the perfusate for $\mathbf{1 0}$ $\mathrm{min}$, the free thrombin concentration at the outlet of the capillary was markedly reduced: a $50 \%$ neutralization was obtalned at $0.7 \mu \mathrm{M}$ ATIII. The prothrombinase actlvity, however, was not Inhlblted as could be established after a subsequent perfusion with prothrombin and factor Va. At an ATIII concentration typical of normal plasma $(2 \mu \mathrm{M})$ a slight neutralization of prothromblnase was observed: $10 \%$ neutrallzatlon following a $10 \mathrm{~min}$ perfusion. When during the perfusion with ATIII prothrombin was ommitted from the perfusate, but also when a speciflc and potent thrombin Inhlbitor (hirudin, $2 \mu \mathrm{M}$ ) was included in the perfusate, a more pronounced neutrallzation of prothrombinase was observed; $40 \%$ residual activity was obtalned after a $10 \mathrm{~min}$ perfusion. From thls the suggestlon comes forward that thrombin, continously produced at the surface, consumes ATIII In the boundary layer. In this case the true ATIII concentration In the viclnity of surface-bound prothrombInase will be but a small fraction of the Initlal ATIII concentration In the bulk fluld. Unfractionated heparin and an ultra low molecular weight heparln (pentasaccharlde) dld enhance the ATIIIdependent neutralization of prothromblnase, but to a much lesser extent than observed with small unllaminar phosphollpld vesicles as the catalytlc sites for prothrombinase assembly. The findings reported here support the notion that regulation of prothrombinase by heparin under in vivo condlitions, occurs at the stage of Its formation, l.e. through Inhlbitlon of free factor $\mathrm{Xa}$ and/or the generation of factor $\mathrm{Va}$, rather than by a direct Inhibition of prothromblnase activity.

$\S$ Schoen P, Lindhout T. Blood (in press), 1991 
T he hemostatic process is dependent on the formation of surface-bound enzymatic complexes, consisting of an enzyme and a cofactor bound to a procoagulant phospholipid surface $(71,84)$. Regulation of the coagulation system can be achieved by inthibiting the enzymatic components of these macromolecular complexes. A prime inhibitor of coagulation is antithrombin III (ATHI), a plasma pirotein which forms equimolar, irreversible complexes with the blood coagulation enzymes. Heparin, a potent anticoagulant, catalyzes the covalent bond formation between ATIII and its target enzymes, thrombin and factor Xa (34).

One of the key reactions in coagulation, is the activation of prothrombin by prothrombinase, a $\mathrm{Ca}^{2+}$-dependent enzymatic complex, composed of the enzyme factor $\mathrm{Xa}$, the cofactor factor $\mathrm{Va}$, and a suitable phospholipid surface. It is well established, that the heparin-catalyzed, ATIII-dependent rate of inactivation of factor $\mathrm{Xa}_{\text {" }}$ as part of the prothrombinase, is reduced $(107,170,175)$. We have previously investigated the inhibition of prothrombinase during prothrombin activation, in a well-defined reaction system utilizing purified proteins and phospholipid vesicles $(119,139)$. It was found, that it takes about 5 times more unfractionated or low molecular weight heparin, to obtain rate constants of inactivation of prothrombinase comparable to those of inactivation of free factor Xa (119).

Most recently, we investigated the prothrombinase-catalyzed activation of prothrombin during continuous flow (186). The reaction system utilized a glass capillary containing a phospholipid bilayer attached to the interior surface, which was perfused with factor $\mathrm{Va}$, followed by a perfusion with factor $\mathrm{Xa}$ and prothrombin. The most striking observation was that the steady-state thrombin production, determined at the outlet of the flow reactor, was constant during at least $40 \mathrm{~min}$. Evidence was obtained that the prothrombinase did not dissociate from the phospholipid-coated reactor wall during these experiments. At present, the question to be adressed is, to what extent is prothrombin conversion by prothrombinase inhibited by ATIII (and heparin) during continuous flow? In addition, it must be noted that a study on the regulation of prothrombinase by ATIII/heparin in a continuous flow system, reflecting conditions that might occur during coagulation in flowing blood, is highlly relevant (110).

In order to investigate the inactivation of prothrombinase during continuous How, we developed an assay system, based on the following principal. The steady-state prothrombinase activity of a phospholipid-coated capillary, containing phospholipid-bound factor $\mathrm{Xa}$ and factor $\mathrm{Va}$, was assessed, and then the capillary was perfused with ATIII/heparin. Hereafter, the prothrombinase activity remaining after the perfusion with ATIII/heparin was determined, by remeasuring the steady-state rate of thrombin production. The extent of inhibition of prothrombinase followed from the prothrombinase activities before and after the perfusion containing ATIIl/heparin. 


\section{EXPERIMENTAL PROCEDURES}

Materials - Glass capillaries, with an inner diameter of $0.58 \mathrm{~mm}$ and a length of $127 \mathrm{~mm}$ (volume $=33.6 \mu$ ), were cleaned and coated with phospholipid as described previously (186). The phospholipid vesicle suspension, composed of 75 mol\% egg PC and 25 mol\% brain PS was prepared at a total lipid concentration of $1 \mathrm{mM}$ (86). Human factor Xa (186), prothrombin (186), ATIII (131) and bovine factor $\mathrm{Va}$ (186) were prepared and quantified as described in the indicated references. The heparins used in this study were the $4^{\text {th }}$ International Standard for heparin (an unfractionated (UF) heparin of porcine mucosal origin, Reference 171) and the synthetic pentasaccharide heparin, representing the ATIII-binding domain of heparin (22). The UF heparin has an activity of $193 \mathrm{U} / \mathrm{mg}$, and the pentasaccharide has an activity of 800 anti-factor Xa lu/mg in human plasma. Recombinant desulphato-hirudin variant 1 (CGP39393) was kindly provided by Dr. R.Wallis from Ciba-Geigy Pharmaceuticals (Horsham, United Kingdom).

Inhibition of Prothrombinase During Continuous Flow-Clean and dry capillaries were coated with a phosphollpid bilayer, by incubation with the vesicle suspension. After about 20 min they were rinsed with Tris-buffer (50 $\mathrm{mM}$ Tris-HCl (pH 7.9) containing $175 \mathrm{mM} \mathrm{NaCl}, 3.0 \mathrm{mM}$ $\mathrm{CaCl}_{2}$, and $0.5 \mathrm{mg}$ ovalbumin/ml) at a flow rate of $1.2 \mathrm{ml} / \mathrm{min}$ for $2 \mathrm{~min}$. This, and all subsequent perfusions were performed by the use of a syringe pump (Harvard Apparatus Co., Massachusetts, USA) resulting in a non-pulsatile flow through the capillaries.

Prothrombinase was formed by perfusing phospholipid-coated capillaries with factor $\mathrm{Xa}$ (variable concentrations) and factor Va $(5.0 \mathrm{nM})$ diluted in the aforementioned Tris-buffer, for 10 min. Immediately hereafter, thrombin formation was initiated by perfusion of $1.0 \mu \mathrm{M}$ prothrombin in Tris-buffer, in the presence of $0.50 \mathrm{nM}$ factor Va. Samples $(10 \mu \mathrm{l})$ were collected at the capillary outlets and immediately transterred to cuvettes containing $440 \mu \mathrm{l}$ of $50 \mathrm{mM}$ Tris- $\mathrm{HCl}(\mathrm{pH} 7.9), 175$ $\mathrm{mM} \mathrm{NaCl}, 20 \mathrm{mM}$ EDTA, and $0.5 \mathrm{mg}$ ovalbumin/ml. The amounts of thrombin formed were assessed by a routine method utilizing the chromogenic substrate $S 2238$ (119). All these and subsequent perfusions were performed at a flow rate of $32 \mu / \mathrm{min}$ (wall shear rate $28 \mathrm{~s}^{-1}$ ), and at a temperature of $25 \pm 1^{\circ} \mathrm{C}$ (climated room).

Thrombin concentrations determined at the capillary outtet were multiplied by the fllow rate in order to obtain rates of thrombin generation $(\mathrm{pmol} / \mathrm{min})$. After the steady-state rate of prothrombin conversion was obtained, ATIII with or without heparin was included in the perfusate. In a number of experiments , prothrombin was omitted from the perfusate containing ATIll/heparin. After 10 min, perfusion was continued with the starting solution $(1.0 \mu \mathrm{M}$ prothrombin, $0.50 \mathrm{nM}$ factor $V a)$. In order to maintain flow at the time of switching between perfusates, two syringe pumps were connected to the capillaries, and used alternating. The steady-state rates of thrombin production before and after the perfusion with ATIII and "optionally, heparin were used to determine the extent of inhibition of prothrombinase.

Determination of Factor Xa Surface Concentration- At the end of experiments in the flow reactor, amounts of factor $X a$ bound to the phospholipid-coated capilaries were determined independentlly. Capillaries were emptied and immediately pertused with one capillary volume of $0.2 \%$ Triton $\times 100$ in $50 \mathrm{mM}$ Tris- $\mathrm{HCl}(\mathrm{pH} 7.9), 175 \mathrm{mM} \mathrm{NaCl}, 3.0 \mathrm{mM} \mathrm{CaCl}$. The solutions were mixed, and a sample was difuted 10 -fold in $50 \mathrm{mM}$ Tris-HCl (pH 7.9) containing $175 \mathrm{mM} \mathrm{NaCl}$, $3.0 \mathrm{mM} \mathrm{CaCl}_{2 \text { " and }} 0.5 \mathrm{mg}$ ovalbumin/ml. We have previously demonstrated that this procedure quantitatively removes all phospholipid, and thus also all surface-bound factor Xa, from the capillaries (186).

Aliquots of the diluted samples (10 $\mu$ ) were added to cuvettes, containing a solution of factor Va, phospholipid wesicles and $\mathrm{CaCl}_{2}$ in $50 \mathrm{mM}$ Tris- $\mathrm{HCl}(\mathrm{pH} 7.9), 175 \mathrm{mM} \mathrm{NaCl}$, and $0.5 \mathrm{mg} / \mathrm{ml}$ ovalbumin. After $5 \mathrm{~min}$ at $37^{\circ} \mathrm{C}, 10 \mu \mathrm{ll}$ prothrombin was added. The final concentrations were 0.50 $\mathrm{nM}$ factor $\mathrm{Va}, 10 \mu \mathrm{M}$ phospholipid, $10 \mathrm{mM} \mathrm{CaCl}$, and $0.50 \mu \mathrm{M}$ prothrombin in a final volume of 125 $\mu l$. After 5 min the conversion of prothrombin was terminated by the addition of $325 \mu 1$ of $50 \mathrm{mM}$ Tris- $\mathrm{HCl}(\mathrm{pH} 7.9), 175 \mathrm{mM} \mathrm{NaCl}, 20 \mathrm{mM}$ EDTA, and $0.5 \mathrm{mg}$ ovalbumin/ml. Hereafter, $50 \mu \mathrm{l} 2.2 \mathrm{mM}$ S2238 was added and the amount of thrombin formed was determined. The amounts of thrombin formed were linearly dependent on the amounts of factor Xa present, up to at least 0.25 pM factor 
Xat in the assay. Each factor Xa determination was periormed in duplicate, and the differences between the individual values of each duplicate varied less than $5 \%$ of their mean values.

\section{RESULTS}

Steady-State Rate of Thrombin Formation as Function of Prothrombinase Density at the Capillary Surface- During reactions, catalyzed by enzymes attached to the interior surfaces of tubes, conditions can be found (e.g. at high enzyme density and low flow rates), where product formation determined at the tube outlet, is not a true measure for surface-bound enzyme density, but rather gives information about the diffusion limited transfer of substrate from the bulk fluid to the catalytic surface (187). Because we intended to monitor steady-state rates of thrombin formation as measure for the amounts of prothrombinase, it first of all had to be established under which conditions the steady-state thrombin formation is indeed sensitive to the concentration of surface-bound prothrombinase.

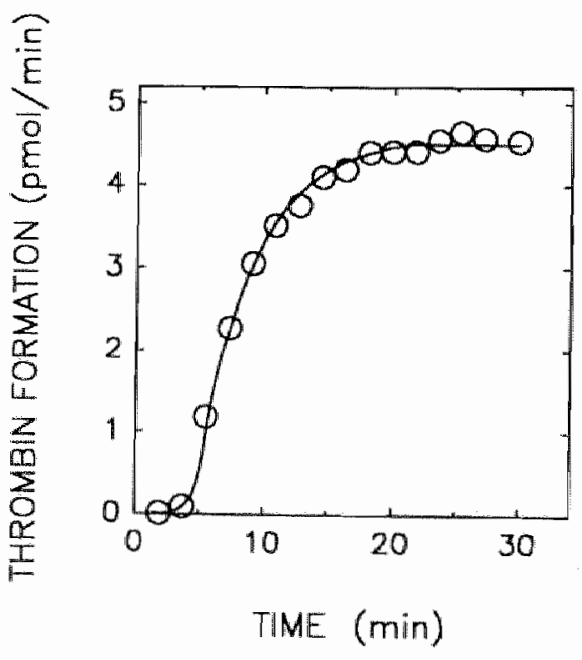

Figure 1. Aate of thrombin formation as function of perfusion time. Prothrombin $(1.0 \mu \mathrm{M})$ and factor $\mathrm{Va}(0.50 \mathrm{nM})$ were perfused through a phospholipid-coated capillary containing prothrombinase, which was preformed by a 10 min perfusion with $100 \mathrm{pM}$ factor $X \mathrm{a}$ and $5.0 \mathrm{nM}$ factor Va. The amount of phospholipid-bound factor $\mathrm{Xa}_{\text {n }}$ assessed after the perfusion with prothrombin and factor Va was $2.1 \mathrm{fmol} / \mathrm{cm}^{2}$. See "Experimental Procedures" for further details. 
To this end, variable concentrations of factor $X a(0-100 \mathrm{pM})$ were perfused through phospholipid-coated capillaries in the presence of an excess of factor $\mathrm{Va}$ $(5.0 \mathrm{nM})$. Subsequently. prothrombin $(1.0 \mu \mathrm{M})$ was perfused in the presence of factor $\mathrm{Va}(0.50 \mathrm{nM})$, and thrombin generation was monitored at the capillary outlet as described under "Experimental Procedures". An example of the thrombin generation curves obtained is given in Figure 1 . It took about 20 min before the rates of thrombin production reached a steady-state. After the steady-state rate of prothrombin conversion was reached, the capillary contents were removed, and the amounts of surface-bound factor $\mathrm{Xa}$ were determined (see "Experimental Procedures"). When the same experiment was performed in the absence of factor Va no measurable thrombin generation occured. Figure 2 shows a replot of the obtained steady-state rates of thrombin generation as function of the surface density of factor Xa.

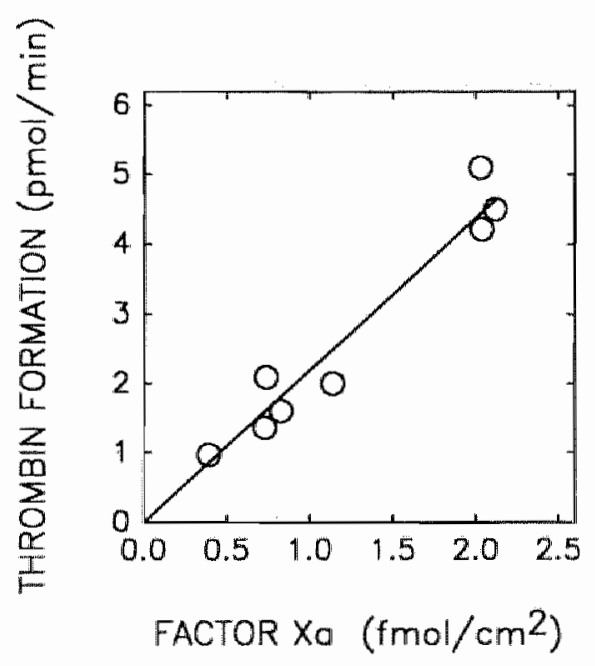

Figure 2. Steady-state rates of thrombin generation as function of factor Xa surface density. Variable concentrations of factor $\mathrm{Xa}(0-100 \mathrm{pM})$ were perfused through phospholipid-coated capillaries in the presence of factor Va $(5.0 \mathrm{nM})$. Subsequently, steady-state rates of prothrombin activation and concentrations of surface-bound factor Xa were assessed as outlined in the text. The solid line was obtained by linear regression analysis.

The data clearly demonstrate that under these conditions, steady-state rates of thrombin generation are dependent on the concentration of surface-bound factor Xa up to a density of about $2 \mathrm{fmol} / \mathrm{cm}^{2}$. When during the perfusion with factor $\mathrm{Xa}$ and factor $\mathrm{Va}$, higher factor $\mathrm{Xa}$ concentrations were used (up to $0.50 \mathrm{nM}$ ), by which the prothrombinase densities at the surface of the capillaries became higher than $2 \mathrm{fmol} / \mathrm{cm}^{2}$, the steady-state rates of thrombin production became es- 
sentially independent of the surface density of factor Xa-factor Va complex. Linear regression analysis of the data depicted in Figure 2, revealed that prothrombin is activated with a avarage rate of $2.2+0.10(\mathrm{SE}) \mathrm{pmol} / \mathrm{min}$ in the presence of $1.0 \mathrm{fmol}$ factor $\mathrm{Xa} / \mathrm{cm}^{2}$. With an interior capillary surface of $2.31 \mathrm{~cm}^{2}$, it is thus found that the average steady-state rate of prothrombin conversion equals $952 \pm$ $43 \mathrm{~mol} / \mathrm{min}$ per mol factor $\mathrm{Xa}$.

Inhibition of Prothrombinase by ATII/UF Heparin During Prothrombin Activation- Further experiments were performed with a surface density of prothrombinase of about $2 \mathrm{fmol} / \mathrm{cm}^{2}$. To this end, prothrombinase was formed by perfusing $100 \mathrm{pM}$ factor $\mathrm{Xa}$ and $5.0 \mathrm{nM}$ factor $\mathrm{Va}$ through phospholipidcoated capillaries during $10 \mathrm{~min}$. Then $1.0 \mu \mathrm{M}$ prothrombin was pertused in the presence of $0.50 \mathrm{nM}$ factor $\mathrm{Va}$, and thrombin generation was measured. The obtained thrombin generation rates are depicted in Figure 3 , as function of perfusion time. After 30 min the composition of the fluid phase was altered: in this case, $2.0 \mu \mathrm{M} \mathrm{ATIII}$ and $1.0 \mu \mathrm{g} / \mathrm{ml}$ UF heparin were included in the perfusate already containing prothrombin and factor Va. Due to the presence of ATIII/heparin the formed thrombin is rapidly inactivated during this perfusion; the observed rate of thrombin formation declines to about $10 \%$.

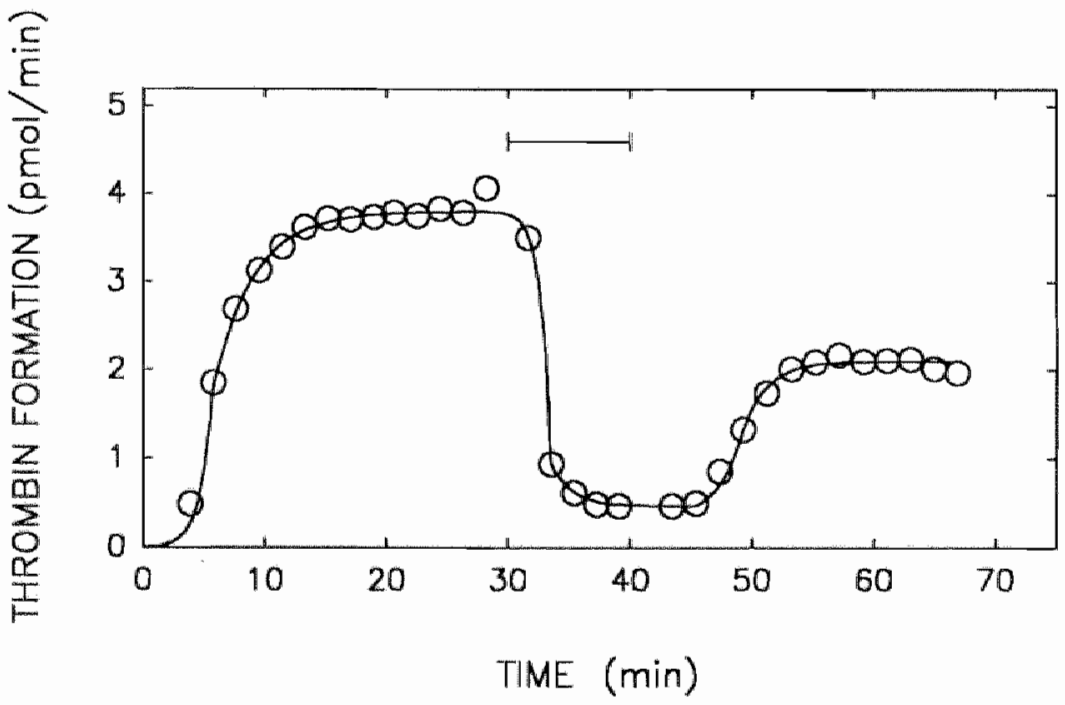

Figure 3. Inhibition of prothrombinase during prothrombin activation. Prothrombin $(1.0 \mu \mathrm{M})$ and factor $\mathrm{Va}(0.50 \mathrm{nM})$ were continuously perfused through a phospholipid-coated capillary containing prothrombinase, which was preformed by a 10 min perfusion with $100 \mathrm{pM}$ factor Xa and $5.0 \mathrm{nM}$ factor Va. During the indicated time interval (horizontal bar), ATIII $(2.0 \mu \mathrm{M})$ and UF heparin (1.0 $\mu \mathrm{g} / \mathrm{m}$ l) were included in the fluid phase. See "Experimental Procedures" for further details. 
In order to investigate whether the prothrombinase became inhibited during the 10 min perfusion with ATII/heparin, we subsequently perfused $1.0 \mu \mathrm{M}$ prothrombin in the presence of $0.50 \mathrm{nM}$ factor $\mathrm{Va}$. Thrombin generation is then restored, until a new steady-state level of thrombin generation is obtained at about $\mathbf{5 0} \mathrm{min}$. From this level of thrombin production it is estimated, that during the $10 \mathrm{~min}$ perfusion with $2.0 \mu \mathrm{M}$ ATIII and $1.0 \mu \mathrm{g} / \mathrm{ml}$ UF heparin the prothrombinase was inhibited by about $44 \%$. Control experiments in the absence of ATIII/heparin showed, that during at least 60 min no loss of prothrombinase activity occured. That is, the rate of thrombin production remained constant during $60 \mathrm{~min}$.

The Inhibition of Prothrombinase During Continuous Flow as Compared to the Inhibition of Prothrombinase in Test-Tube Experiments-We investigated the extent of inhibition of prothrombinase during continuous flow in the absence of heparin, and in the presence of variable concentrations of UF heparin. Experiments were pertormed as outlined in Figure 3. The results obtained are summarized in Table 1. The table also contains the half-life times, and the time periods required for virtual complete $(99 \%)$ inhibition of prothrombinase, utilizing phospholipid vesicles in a static, closed system "at the ATIII and UF heparin concentrations used. These data were extrapolated from the heparin-independent rate constant $\left(0.07 \mathrm{~min}^{-1}\right)$ obtained at $0.40 \mu \mathrm{M} \mathrm{ATIII}$, and the UF heparin-dependent rate constant, $3.0 \times 10^{7} \mathrm{M}^{-1} \mathrm{~min}^{-1}$, of inactivation of prothrombinase as reported previously (119). The calculations with UF heparin were based on the observation that $1 \mathrm{mg}$ UF heparin is equivalent to $29 \mathrm{nmol}$ of ATIIIbinding material, which was determined by stoichiometric titrations of ATIII, monitored by intrinsic fluorescence enhancement (Ct. Reference 131).

Table 1. Inhibition of prothrombinase in the presence of prothrombin by ATIII. ATIII UF heparin, and ATILpentasaccharide.

\begin{tabular}{|c|c|c|c|}
\hline \multirow[t]{2}{*}{ Inhibitors $\$$} & \multicolumn{2}{|c|}{ Continuous Flow } & \multirow{2}{*}{ 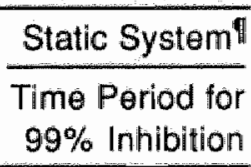 } \\
\hline & $\begin{array}{l}\text { Extent of Inhibition } \\
\text { During } 10 \text { min Perfusion }\end{array}$ & Half-Life Time & \\
\hline & $(\%)$ & (s) & $(\min )$ \\
\hline ATIII $(2.0 \mu \mathrm{M})$ & 10 & 119 & 13.2 \\
\hline ATIII $+1.0 \mu \mathrm{g} \mathrm{UFH} / \mathrm{ml}$ & 44 & 34 & 3.8 \\
\hline ATIII $+2.5 \mu \mathrm{g} \mathrm{UFH} / \mathrm{ml}$ & 43 & 16 & 1.8 \\
\hline ATIII $+5.0 \mu \mathrm{g} \mathrm{UFH} / \mathrm{ml}$ & 86 & 9 & 1.0 \\
\hline $\mathrm{ATIII}+1.0 \mu \mathrm{g} \mathrm{PS} / \mathrm{mI}$ & 57 & 25 & 2.7 \\
\hline
\end{tabular}

$\$$ UFH, unfractionated heparin; PS, pentasaccharide

Data calculated from Reference 119. 
The data as shown in Table 1, demonstrate that during continuous flow prothrombinase is markedly insensitive to inactivation by ATIII and ATIII/UF heparin, when compared to the inactivation of prothrombinase in test-tube experiments. In the latter system, the half-life time of prothrombinase in the presence of $2.0 \mu \mathrm{M}$ ATII is 119 sec hence in a 10 min period prothrombinase is expected to be inhibited by at least $97 \%$. During continuous flow, however, prothrombinase was inhibited by not more than $10 \%$. Also in the presence of UF heparin there is a marked discrepancy between the amounts of prothrombinase inhibited in testtube experiments, and the amounts of prothrombinase actually inhibited during continuous flow. Control experiments verified that heparin alone had no effect on the prothrombinase activity.

Also in the presence of ATIII $(2.0 \mu \mathrm{M})$ and pentasaccharide at a concentration of $1.0 \mu \mathrm{g} / \mathrm{ml}$ (about $0.58 \mu \mathrm{M}$ ), inhibition of prothrombinase is, during continuous fllow and in the presence of prothrombin, in no proportion to the inhibition observed in test-tube experiments. In the flow reactor prothrombinase is inhibited by $57 \%$ during the 10 min perfusion with ATIIl/pentasaccharide, whereas in testtube experiments, prothrombinase is at these ATIII and pentasaccharide concentrations virtually completely (99\%) inhibited in about $2.7 \mathrm{~min}$ (Table 1). The latter is inferred from the pentasaccharide-dependent, pseudo-first order rate constant of inhibition of prothrombinase, $0.23 \times 10^{7} \mathrm{M}^{-1} \mathrm{~min}^{-1}$, as reported previously (119). This observation supports our previous notion that the extent of protection of factor $X a$ during prothrombin activation by prothrombinase, is independent of the heparin molecular size (119).

Effect of ATIII Consumption on the Neutralization of Prothrombinase - The observed insensitivity of prothrombinase to inhibition by ATIII/ heparin during continuous flow, could be caused by a reduced ATIII concentration at the prothrombinase sites. We reasoned that the thrombin produced at the catalytic surface could neutralize part of the ATIII present in the boundary layer. It will depend on the flux of ATIII from the bulk solution to the surface, on the rate of complex formation between ATIII and thrombin, and on the local rate of thrombin production, to what extent ATIII in the boundary layer will be consumed and thus to what extent ATIII will be available for inhibition of prothrombinase. Alternatively, prothrombin could also compete with ATIII for factor Xa, and thus reduces the rate of neutralization of prothrombinase.

A number of experiments were performed in order to investigate these possibilities. First of all, an experiment was carried out in which prothrombin was left out during the perfusion with ATIII. In this case, it was found that prothrombinase was inhibited by $58 \%$. In the presence of prothrombin it had been found that prothrombinase was inhibited by $10 \%$ (Table 1). Thus, apparently, the presence of prothrombin reduces the rate of inactivation of prothrombinase. However, this need not necessarily to be caused by consumption of ATIII in the vicinity of the catalytic sites, but may equally well be due to competion between prothrombin and ATIII for factor Xa. 
This problem was addressed by including $2.0 \mu \mathrm{M}$ hirudin in the fluid phase during a 10 min perfusion with $2.0 \mu \mathrm{M}$ ATIII, $1.0 \mu \mathrm{M}$ prothrombin, and $0.50 \mathrm{nM}$ factor Va. Hirudin is a very specific, tight-binding inhibitor of thrombin (188), and largely reduces all thrombin-dependent reactions ocurring after its formation. Indeed, during this perfusion step, no free thrombin activity could be detected. During this perfusion, prothrombinase was inhibited by $59 \%$. So, the inactivation of prothrombinase in the presence of prothrombin and hirudin equals the inhibition of prothrombinase in the absence of prothrombin. This suggests that 'protection' of prothrombinase by prothrombin does not depend on competition between prothrombin and ATIII for factor Xa, but rather depends on consumption of ATIII by the formed thrombin.

However, the apparent reduction of the rate of inhibition of prothrombinase, because of a lower 'true' ATIII concentration at the prothrombinase sites, as compared to the ATIII concentration in the bulk fluid, is not the sole explanation for the observed reduction of inhibition of prothrombinase during continuous flow, as compared to the inhibition in test-tube experiments. In the absence of prothrombin, prothrombinase in the flow reactor is inhibited by $58 \%$ during the $10 \mathrm{~min}$ perfusion with $2.0 \mu \mathrm{M}$ ATIII. On basis of a pseudo-first order rate constant of 0.35 $\min ^{-1}$, it is calculated that in test-tube experiments prothrombinase is inhibited by $97 \%$ in a 10 min period. Thus, it seems that in the flow reactor the reactivity of prothrombinase towards ATIII is altered as compared to the reactivity of prothrombinase in static, closed systems.

Inactivation of Prothrombinase-Formed Thrombin Activity - During perfusions with ATIII and ATIII/heparin in the presence of prothrombin, the thrombin activity formed is rapidly inactivated. In order to characterize the inactivation of formed thrombin, we searched for conditions, under which no apparent reduction of prothrombinase activity was obtained during a 10 min perfusion with ATIII or ATIII/LIF heparin. It was found, that when prothrombinase was preformed by a 10 min perfusion with $0.50 \mathrm{nM}$ factor $\mathrm{Xa}$ and $5.0 \mathrm{nM}$ factor $\mathrm{Va}, 2.0 \mu \mathrm{M} \mathrm{ATIII}$, either in the absence or presence of $1.0 \mu \mathrm{g} / \mathrm{ml}$ UF heparin (Figure 4) had no effect on the steady-state rate of thrombin generation obtained after the perfusion with ATIII or ATIII/heparin. Because at these concentrations of ATIII and UF heparin, no apparent decrease of the steady-state rates of prothrombin activation is observed, decreases of the overall rates of thrombin generation during perfusions with ATIII/heparin in the presence of prothrombin will be solely due to the inhibition of thrombin activity.

We, subsequently, further characterized the inhibition of prothrombinaseformed thrombin activity during continuous flow, by studying steady-state rates of thrombin generation at variable ATIII and heparin concentrations. Prothrombin $(1.0 \mu \mathrm{M})$ and factor $\mathrm{Va}(0.50 \mathrm{nM})$ were perfused through a phospholipid coated capillary, containing prothrombinase, preformed by the pertusion of $0.50 \mathrm{~nm}$ factor $\mathrm{Xa}$ and $5.0 \mathrm{nM}$ factor $\mathrm{Va}$. After the steady-state rate of thrombin generation was attained, ATIII $(0.20 \mu \mathrm{M})$ was included in the fluid phase, and the rate of 
generation of amidolytic activity stanted to decrease. When a new steady-state was obtained, the fluid phase ATIII concentration was increased, and again the steady-state level of production of amidolytic activity was determined. This procedure was repeated a number of times, until finally the fluid phase contained 2.0 $\mu M$ ATIII. The residual steady-state rates of thrombin generation were then expressed relatively to the steady-state rate in the absence of ATIII (6.0 pmolimin), and plotted against the ATIII concentrations (Figure 5A).

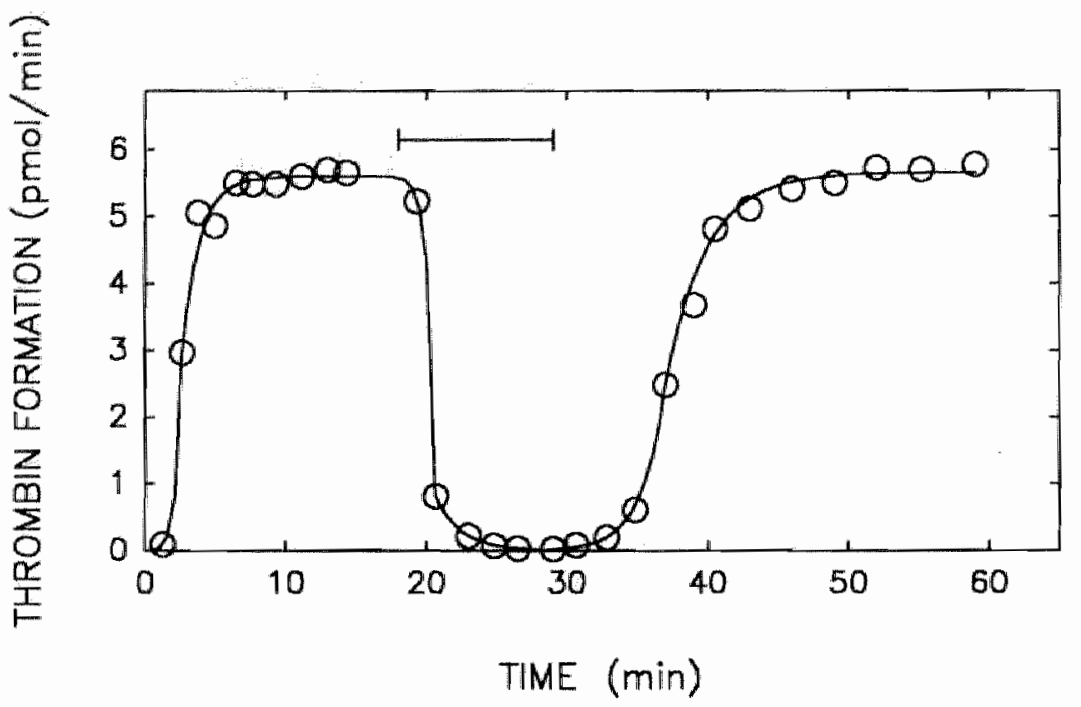

Figure 4. Effect of ATIII/heparin on steady-state rate of prothrombin activation. Prothrombin (1.0 $\mu \mathrm{M})$ and tactor $\mathrm{Va}(0.50 \mathrm{nM})$ were pertused through a phospholipid-coated capillary containing prothrombinase, which was preformed by a 10 min pertusion with $0.50 \mathrm{nM}$ factor $X a$ and $5.0 \mathrm{nM}$ factor Va. During the indicated time intervall (horizontal bar, $11 \mathrm{~min}$ ), the perfusate contained $2.0 \mu \mathrm{M}$ ATIII, $1.0 \mu \mathrm{g} / \mathrm{ml}$ UF heparin, and $0.50 \mathrm{nM}$ factor Va. Hereafter pertusion was continued with $1.0 \mu \mathrm{M}$ prothrombin and 0.50 nM lactor Va. See "Experimental Procedures" for further details.

Since ATIII is also present in samples collected at the tube outlet, decreased levels of thrombin activity not only reflect inhibition within the flow reactor but are also dependent on inhibition within the samples. In order to accurately monitor the inactivation of thrombin we in these instances thoroughly standardized the sampling procedure. Prior to sampling the capillary outlet was wiped. Then a calibrated microcapillary was held against the outlet of the flow reactor, and an aliquot of $10 \mu \mathrm{l}$ was collected. The sample was then immediately mixed into a cuvette containing $440 \mu \mathrm{l}$ of Tris-butfer containing $20 \mathrm{mM}$ EDTA and $50 \mu \mathrm{l}$ of chromogenic substrate S2238 (see "Experimental Procedures"). Due to the 50fold dilution of the samples, and the presence of excess chromogenic substrate 
in the cuvettes, the rates of thrombin neutralization in the cuvettes were sulficiently low not to result in measurable enzyme inhibition during the recording of the absorbances.

Essentially the same procedure was followed to study the effect of UF heparin on the ATIII-dependent inactivation of prothrombinase-formed thrombin activity during continuous flow. At the steady-state rate of thrombin generation in the absence of inhibitor $(5.7 \mathrm{pmol} / \mathrm{min})$, ATIII $(0.50 \mu \mathrm{M})$ and increasing concentrations of UF heparin were included in the fluid phase. Subsequently, the residual steady-state rates of overall thrombin generation were expressed relatively to the steady-state rate in the absence of ATIII, and they were plotted against the UF heparin concentrations (Figure 5B).

The data demonstrate, that in the absence of heparin, about $0.7 \mu \mathrm{M}$ ATIII is required to obtain $50 \%$ inhibition of the formed thrombin. Moreover, the data suggest, that at plasma ATIII concentrations (about $3.0 \mu \mathrm{M}$ ) the free thrombin activity within the bulk fluid will be very low. In the presence of $0.50 \mu \mathrm{M} \mathrm{ATIII}$, the inactivation of formed thrombin activity is enhanced by the presence of UF heparin (a 2 times lower thrombin level is obtained at about $0.2 \mu \mathrm{g} / \mathrm{ml}$ ). At UF heparin concentrations higher than $0.2 \mu \mathrm{g} / \mathrm{ml}$ the steady-state rates of generation of amidolytic activity gradually decline, until about $80 \%$ of the thrombin activity is inactivated.
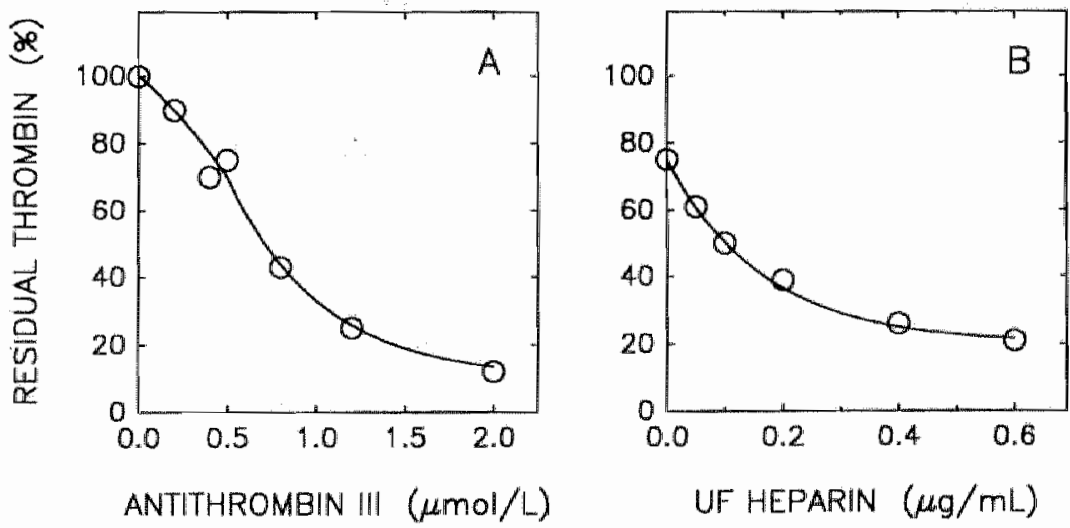

Figure 5. Inhibition of prothrombinase-formed thrombin activity during continuous flow. Panel A: residual steady-state rates of thrombin generation in the presence of variable concentrations of ATII, relative to the steady-slate rate in the absence of ATIII. Panel B: residual steady-state rates of thrombin generation in the presence of $0.50 \mu \mathrm{M}$ ATIII, and variable concentrations of UF heparin, relative to the steady-state rate in the absence of ATIII and heparin. 


\section{DISCUSSION}

In this study we investigated the ATIII-dependent anti-prothrombinase activity of heparin during prothrombin activation in a continuous flow reactor. Phospholipid-coated capillaries, containing phospholipid-bound factor $\mathrm{Xa}$ and factor $\mathrm{Va}$, were perfused with mixtures, composed of prothrombin, factor $\mathrm{Va}$, ATIII, and UF heparin or pentasaccharide. In keeping with our previous work (110) it was observed that as long as one of the protein components of prothrombinase remains present in the fluid phase (factor Va or factor Xa), no dissociation of preformed prothrombinase occurs, which resulted in a stable prothrombinase activity during the whole time-periods of the experiments.

When during perfusions with prothrombin and factor Va, ATIII with or without heparin was included in the fluid phase, the steady-state rates of thrombin generation rapidly decreased (Figure 1). Under conditions were no measurable loss of prothrombinase activity occured (Figure 4), decreases of the steady-state rates of thrombin generation reflected the inactivation of prothrombinase-formed thrombin activity. From studies in closed, static systems it is known that during prothrombin activation by prothrombinase significant amounts of meizothrombin (des fragment 1) can be formed (89). This activation product is equally reactive with ATIII as in situ prothrombinase-formed $\alpha$-thrombin. However, whereas inactivation of $\alpha$-thrombin is catalyzed by UF heparin, inactivation of meizothrombin(des fragment 1) is not (115). We observed, that the ATIII-dependent inactivation of the amidolytic activity generated can be stimulated by heparin, until $80 \%$ of the activity has been neutralized (Figure 5B). Thus, the major prothrombin activation product is $\alpha$-thrombin rather than meizothrombin(des fragment 1).

The rapid inactivation of formed thrombin by ATIII (Figure 5A), and the catalytic effect of heparin hereupon (Figure $5 B$ ), suggest that there are no major, qualitative differences between the inactivation of in situ prothrombinase-formed thrombin activity, in either test-tube experiments or during continuous flow. This judgment, however, can not be kept up for the inactivation of prothrombinase during prothrombin activation. Under conditions, were, in test-tube experiments, $97 \%$ inhibition of prothrombinase is obtained in a 10 min period $(2.0 \mu \mathrm{M} \mathrm{ATIII)}$, during continuous flow prothrombinase is only inhibited by $10 \%$ during a $10 \mathrm{~min}$ perfusion with $2.0 \mu \mathrm{M}$ ATIIII (Table 1). In the presence of UF heparin the discrepancy between the rates of inactivation of prothrombinase during continuous flow and in test-tube experiments is even more pronounced. In the presence of $5.0 \mu \mathrm{g} / \mathrm{ml}$ UF heparin (which corresponds to about $1 \mathrm{U} / \mathrm{ml}$ ) a $86 \%$ inhibition of prothrombinase is obtained in the flow reactor, during a 10 min perfusion. At this heparin dosage, prothrombinase in test-tube experiments is completely inactivated within $1 \mathrm{~min}$. The usage of pentasaccharide instead of UF heparin, does not alter the observed discrepancy between the inactivation of prothrombinase in the flow reactor and in test-tube experiments (Table 1). Thus, during prothrombin 
inactivation in the flow reactor prothrombinase is rather insensitive to ATIIIf heparin.

The basic assumption underlying this notion, is that the observed steadystate rates of thrombin generation are sensitive to the surface concentration of prothrombinase. In our experimental approach, prothrombinase was formed by the perfusion of factor $\mathrm{Va}(5.0 \mathrm{nM})$ and variable concentrations of factor $\mathrm{Xa}(\leq 0.50$ nM). Because the affinity of factor $V a$ for a phosphatidy/serine/phosphatidylcholine phospholipid surface $\left(K_{d}=10^{-9} M\right.$, Reference 71$)$ is about 3 orders of magnitude higher than the affinity of factor $X a$ for such a surface $\left(K_{d} \approx 10^{-6} M\right.$, Reference 71), and because factor $\mathrm{Va}$ is at least 10 times in excess over factor $\mathrm{Xa}$, it is most likely, that the first event in the formation of prothrombinase is the binding of factor $\mathrm{Va}$ to the phospholipid surface. Subsequently, factor $\mathrm{Xa}$ is complexed by phospholipid-bound factor $\mathrm{Va}$. It is therefore well feasible, that in case too high factor $X a$ concentrations are employed, the rate of prothrombin conversion, at the surface of the flow reactor, will actually exceed the diffusionlimited rate of prothrombin flux from the bulk solution to the catalytic surface. In this case, the observed rate of thrombin formation will not be a true measure for the amount of prothrombinase at the surface, and consequently a reduction of the surface density of prothrombinase by ATIII/heparin may not be accompanied by a reduction of the steady-state level of thrombin production. Therefore, it was investigated under what conditions, with respect to factor $\mathrm{Xa}$ concentration in the first perfusion, steady-state rates of thrombin formation depend on the surface density of prothrombinase (Figure 2).

It was found, that when solutions containing factor $X a$ between $O$ and 100 $\mathrm{pM}$ and $5.0 \mathrm{nM}$ factor $\mathrm{Va}$, were perfused during $10 \mathrm{~min}$ at a wall shear rate of 28 $\mathrm{s}^{-1}$, the steady-state rate of thrombin generation was linearly dependent on the amount of surface-bound prothrombinase. The surface densities of prothrombinase (factor $\mathrm{Xa}$ ) were determined seperately, immediately after the steady-state rates of thrombin generation had been obtained. It was found that prothrombin is converted with an average rate of $952 \pm 43$ (SE) $\mathrm{mol} / \mathrm{min}$ per mol prothrombinase. This turnover rate is the same as previously reported (186), and compares well with the turnover rate of phospholipid vesicle-bound prothrombinase in static systems $(86,90)$.

From experiments performed in the presence of hirudin or in the absence of prothrombin during the perfusions with ATIIl, we obtained circumstantial eviden$c e$ which suggests that the lack of inhibition of prothrombinase during prothrombin activation is not caused by a competition between the substrate (prothrombin) and the inhibitor (ATIII) for the enzyme (factor Xa). The data rather seem to indicate that in the presence of prothrombin, the inhibition of prothrombinase is suppressed through consumption of ATIII in the boundary layer by the thrombin activity that is continously generated at the surface. Thus, the 'true' ATIII concentrations in the vicinity of the cataiytic sites might be but a tiny fraction of the ATIII concentration in the bulk fluid. It must be noted, that the experiments described 
here were performed at a low shear rate $\left(28 \mathrm{~s}^{-1}\right)$. At high shear rates, the local ATIII concentrations will be raised by virtue of a more rapid convection into and through the tube. Whether under such conditions thrombin production will still "protect" prothrombinase from inactivation by ATIII/heparin needs further investigation.

In conclusion, during continuous flow and in the presence of physiological levels of prothrombin, inhibition of prothrombinase by ATIII/heparin is most modest. This supports the notion, that in a physiological environment, the heparin-dependent regulation of coagulation does not depend on the neutralization of prothrombinase activity, but on the inhibition of prothrombinase formation, i.e. by either scavanging thrombin, necessary for the activation of factor $V(61)$, or scavanging free factor $\mathrm{Xa}$ (189).

Acknowledgements- We like to thank Ron Blezer for excellent technical assistance and Dr. George Willems for fruitful discussions. 
क 



\section{General Discussion}

\section{$\mathbf{O}_{\text {ne of the regulatory mechanisms of blood coagulation is the inhibition of }}$} enzymes of the coagulation system by the plasma protein antithrombin III (ATIII), its main targets being factor $X a$ and thrombin (103). ATIII functions as a substrate for factor $X a$ and thrombin, however it resists complete conversion by the enzymes. The catalytic cycles terminate at the acylenzyme intermediates, in which ATIII is covalently bound to factor $X a$ or thrombin (26). Their reaction requires the formation of a dissociable, non-covalent complex prior to covalent bond formation. The antithrombotic drug heparin catalyzes the ATIII-dependent inactivation of factor $\mathrm{Xa}$ and thrombin, by enhancing the formation of non-covalent complex between inhibitor and enzyme (34).

Heparin, is a mixture of linear glycosaminoglycans, synthesized in mast cells, which are heterogeneous with respect to their sequences of monosaccharides, their molecular weights and their binding to ATIII. This heterogeneity is, at least partly, caused by incomplete modification reactions occurring during the heparin biosynthesis (18). Heparin binding to ATIII is dependent on the presence of a specific pentasaccharide sequence in the heparin chains (16). It has been suggested, that specific sulfation reactions conclude the formation of the pentasaccharide structure (120). Support of this notion was found in Chapter 2 of this study, in which we demonstrated, that in the non ATIll-binding fraction of heparin a number of molecules are present which only lack specific sulfate groups of an otherwise correct pentasaccharide region.

Heparin is a valuable drug for the treatment and prevention of thrombotic and thromboembolic diseases (190), however, its usage carries bleeding as a side effect. Since 1976, it is known from in vitro studies, that low molecular weight (LMW) heparin fractions have little effect on tests of overall clotting, such as the APTT (KCCT), but maintained their potency as measured by anti-factor Xa assays $(13,191,192)$. Because in 1971, it had been postulated that regulation of coagulation by means of ATIII could be more dependent on the inactivation of factor Xa than on the inactivation of thrombin (48), it was suggested that heparin preparations with high anti-factor Xa/APTT ratios would maintain the efficacy of unfractionated (UF) heparin preparations (exerting an antithrombotic effect through their preserved anti-factor Xa function), while causing less bleeding because of their reduced action on overall clotting (6). Studies on the heparin structure-function relationship revealed that the pentasaccharide sequence, 
necessary for the interaction with ATIII, is sufficient to obtain catalysis of the inactivation of factor Xa. The heparin-catalyzed inactivation of thrombin, however, depends on the simultaneous binding of both proteins, which requires a heparin chain length of at least 18 saccharide units $(35,36)$. Because LMW heparins consist of chains with a length of 2 to 30 saccharides, their lower anticoagulant activity as determined by APTT, is thought to be caused by a lower anti-thrombin specific activity as compared to that of UF heparin.

However, during the recent past, a number of studies have appeared, which seriously question this model of the mode of action of heparin. First of all, there is now good evidence that inhibition of in vitro coagulation by UF and LMW heparins is primarily dependent on their ability to accelerate thrombin, rather than factor $\mathrm{Xa}$ inactivation, and secondly (very) low molecular weight heparins, which only express anti-factor $X a$ activity are poor antithrombotic drugs (57-59). Recently it has also been recognized, that the heparin-catalyzed inactivation of factor $X_{a}$ is enhanced in the presence of calcium ions $(119,127)$. Moreover, the $\mathrm{Ca}^{2+}$-mediated effect increases with increasing heparin chain lengths. At present it is unclear to what extent the potencies of LMW heparin fractions, as measured by anti-factor $X a$ assays $(13,191,192)$, are affected by the presence of free $\mathrm{Ca}^{2+}$. ions.

LMW heparin preparations have unknown distributions of their ATIII-binding molecules, with variable sensitivities towards the $\mathrm{Ca}^{2+}$-dependent stimulating effect. Therefore, we investigated the catalytic capacities of LMW heparin preparations, intended for either clinical use or standardization, towards the inactivation of factor $\mathrm{Xa}$ and thrombin using purified proteins of human origin in the presence of $4 \mathrm{mM} \mathrm{Ca}^{2+}$ (Chapter 3). We observed that both the anti-thrombin and anti-factor Xa activities of the LMW heparin preparations were decreased, as compared to those of UF heparin preparations. Consequently, the specific anti-factor $\mathrm{Xa}$ anti-thrombin ratios were rather independent of heparin molecular weight.

Thus, taking all together, in the present situation the antithrombotic efficacy of (LMW) heparin actually cannot be predicted from currently available laboratory tests. Based on studies from our laboratory, recently a new principal for the determination of antithrombotic potentials has been suggested by Hemker et al (193), which relies on the determination of the surface under thrombin generation curves, obtained in clotting plasma.

The laboratory tests presently in vogue, neglect the fact that platelets contain a potent heparin antagonist, platelet factor 4 (PF4). Studies with isolated heparin oligosaccharides $(35,68)$ have demonstrated that the anti-thrombin and anti-factor $\mathrm{Xa}$ activities of heparin chains consisting of 18 or more monosaccharide units $\left(M_{1} \geq 5,400\right)$ are readily neutralized by $P F 4$, and that the anti-factor $X a$ activities of the smaller heparin oligosaccharides become increasingly resistant towards neutralization, as the heparin molecular weight decreases from 5,400 downwards. Differential neutralization patterns of LMW heparins will in- 
fluence their availability in the presence of activated platelets, and thus have consequences for their in vivo activity and their in vitro standardization. Therefore we, as described in Chapter 3 , investigated the PF4-dependent neutralization of the anti-factor $\mathrm{Xa}$ and anti-thrombin activities of LMW heparin preparations, intended for either clinical use or standardization. Our findings demonstrated that the anti-thrombin activities of LMW heparin preparations are completely neutralized by relative low amounts of PF4. Neutralization of the anti-factor Xa activities of LMW standard heparin, Fraxiparine, Enoxaparin, and CY222 showed that, respectively, $0 \%, 5 \%, 10 \%$, and $15 \%$ of their activities could not be neutralized by PF4. Moreover, a large molar excess of PF4 was required to obtain the levels of maximum neutralization. From our data, it follows that because increasing amounts of these LMW heparins are required to obtain equal rate constants of inactivation of thrombin and/or factor $\mathrm{Xa}$, complete PF4 release at a normal platelet count, could result in too low PF4/oligosaccharide ratios to obtain levels of maximum neutralization of the anti-protease activities. This could provide a reasoning for the results obtained by Béguin et al (63), and Hemker et al (194), who reported on the mode of action of (LMW) heparin in platelet rich plasma activated by trace amounts of tissue factor. At $L M W$ heparin dosages giving antithrombin activities comparable to those obtained in the presence of UF heparin, they demonstrated that, while the action of UF heparin is abolished after the platelets become activated, the activity of LMW heparin persists. Consequently, it at present seems that, in order to have predictive value, any ex vivo assay of the antithrombotic potential of heparin will also have to take heparin neutralization, occurring when platelets become activated, into account. Therefore we feel that the hypothesis, that "thrombin generation in platelet-rich plasma is putatively the best predictor of in vivo antithrombotic action" (194), really deserves further attention.

Whether the therapeutic effect of LMW heparin is superior to that of UF heparin, is a question which will have to be carefully investigated in future clinical investigations. Still laboratory research can support the quest for an advantageous heparin, that maintains or improves its undoubted efficacy and has a reducedincidence of unwanted side-effects. Therefore attention returned to the question: How does heparin work?

Heparin catalyzes the inactivation of thrombin and factor Xa by ATIII. Much of our current knowledge about heparin and its function has arrived from studies with purified proteins in simple enzyme/inhibitor mixtures. However, coagulation is a complex process, which requires actions of and interactions between the vascular wall, blood platelets and the coagulation system. Enzymes, activated cofactors, and procoagulant surfaces are generated in a heterogeneous mixture of other components. One of the essential reaction systems in coagulation is prothrombin activation by prothrombinase, an enzymatic complex composed of the enzyme factor $\mathrm{Xa}$, the cofactor factor $\mathrm{Va}$ and a suitable phospholipid surface. The majority of the studies, presented in this thesis were designed to investigate the 
inactivation of thrombin and factor $X a$ in model systems, reflecting conditions occurring during in vivo coagulation. That is, we investigated the ATIII/heparindependent inactivation of in situ prothrombinase-formed thrombin activity, and of factor Xa during prothrombin activation, both in test-tube experiments and in a flow reactor, where prothrombinase is localized at the surface of a phospholipidcoated capillary.

Prothrombin activation by prothrombinase, composed of purified proteins and vesicles containing anionic phospholipids, results in the formation of meizothrombin(des fragment 1) and thrombin (see Reference 89 for a review). The relative amounts of meizothrombin(des fragment 1) and thrombin formed are dependent on the concentration of prothrombin. E.g. at $0.10 \mu \mathrm{M}$ of prothrombin, thrombin contributes for about $60 \%$ to the amidolytic activity generated, whereas at $1.0 \mu \mathrm{M}$ prothrombin about $20 \%$ of the product formed is thrombin (Chapter 4 ). Whether the formation of meizothrombin or meizothrombin(des fragment 1) has any physiologic importance, is as yet unknown, and it must be noted that in the plasma milieu meizothrombin or meizothrombin(des fragment 1) seems to be hardly detectable (195). Moreover, in a continuous flow system, in which solutions of reactants were perfused through phospholipid-coated glass capillaries, the major product formed appeared to be thrombin rather than meizothrombin(des fragment 1). At $1.0 \mu \mathrm{M}$ prothrombin we observed that, during continuous flow, $70 \%$ (Chapter 7 ) to $80 \%$ (Chapter 8 ) of the product formed is $\alpha$ thrombin.

From the ATIII/heparin-dependent inhibition of prothrombinase-formed thrombin and meizothrombin(des fragment 1) (Chapter 4), circumstantial evidence was obtained, that in these reaction mixtures thrombin is non-covalently complexed by prothrombin fragment 2, which results in an equal reactivity of prothrombinase-formed thrombin and meizothrombin(des fragment 1) with respect to inhibition by ATIII. However, whereas the ATIII-dependent inactivation of meizothrombin (des fragment 1 ) is not catalyzed by heparin, the inactivation of prothirombinase-formed thrombin is. Apparently heparin reverses the fragment 2induced change in reactivity of thrombin towards ATIII, although the kinetics of inactivation of in situ prothrombinase-formed thrombin remained different as compared to the kinetics of inactivation of purified thrombin, especially with respect to saturation of the reaction with ATIII.

In Chapters 5 and 6 the inactivation of prothrombinase by ATIII and heparin is described. The decrease of the rate of prothrombin activation, corrected for the rate of inactivation of prothrombinase-formed thrombin activity, was used as parameter for the inactivation of prothrombinase. In summary, our data indicated, that:

1) During prothrombin activation by a fully assembled prothrombinase complex, rate constants of inhibition of factor $X a$ are diminished as compared to those of free factor Xa. Traditionally this effect is denoted as protection. 
2) Protection of factor $X_{a}$ is only observed in the presence of factor $\mathrm{Va}$ and phospholipids. Neither of these two components could separately influence the rate constant of inactivation of factor $\mathrm{Xa}$.

3) The extent of protection is independent of the prothrombin concentration.

4) The extent of protection is independent of the heparin molecular weight.

Although the factor Va/phospholipid-mediated protection of factor Xa from inactivation by ATIII (and heparin) is clear-cut, the precise mechanism as such is unrevealed. Inactivation of factor Xa by ATIII or ATIII/heparin requires a noncovalent interaction between the enzyme and the inhibitor, followed by covalent bond formation between factor Xa and ATIII (33). At present, two alternate mechanisms accounting for the protection of factor Xa seem possible. [1] As result of the complexation of factor $\mathrm{Xa}$, by factor $\mathrm{Va}$ and phospholipid, the noncovalent interaction and/or the covalent bond formation between factor Xa and ATIII is hampered (steric hindrance). [2] Alternatively, factor Xa complexed by factor Va (and/or phospholipid) is virtually unaccessible to ATIII or ATIII/heparin. In this case, factor $\mathrm{Xa}$ inhibition requires the dissociation of prothrombinase, and thus "protection" arises, because the dissociation is highly unfavorable. Whereas the first mechanism is a static model, the second mechanism requires a dynamic equilibration between complexed and non-complexed factor Xa. Thus, intuitively, the second mechanism seems very plausible. However, others $(169,170)$ have considered the first mechanism the ultimate explanation for the protective effect.

We found no protection of factor $\mathrm{Xa}$ in the absence of factor $\mathrm{Va}$. In view of the proposed mechanisms of protection, it can be hypothesized that either phospholipid-bound factor $\mathrm{Xa}$ is as good a substrate for ATIII as free factor $\mathrm{Xa}$ is (mechanism 1), or that dissociation of factor Xa from phospholipid is not as unfavorable as dissociation of factor $\mathrm{Xa}$ from the prothrombinase complex (mechanism 2). In this respect, it is interesting to note, that factor Va lowers the dissociation constant of factor Xa for phospholipid vesicles by $2-3$ orders of magnitude $(71,145)$, and thus this could provide an explanation for the protection observed in the presence of factor $\mathrm{Va}$. In addition, as the association of prothrombinase is independent of prothrombin $(71,196)$, the second model seems to be compatible with our observation that factor Xa protection is independent of prothrombin. It is unclear why in the first model, protection should be independent of (the presence of) prothrombin. Because, in the first model the prothrombinase itself is accessible to ATIII, increasing amounts of prothrombin should be expected to result in increasing competition between ATIII and prothrombin for prothrombinase, and thus result in increasing levels of protection. This, however, is never encountered.

In Chapter 8 the anti-prothrombinase activity of ATIII (and heparin) was studied during prothrombin activation in the flow reactor. The latter had previously been characterized in the work described in Chapter 7 . It was found that in the presence of a (near) physiologic level of prothrombin, the rate of inhibition 
of prothrombinase at the wall of the flow reactor, was markedly reduced as compared to the rate of inhibition of phospholipid vesicle-bound prothrombinase (test-tube experiments, Chapters 5 and 6). Part, but not all, of this effect was shown to be due to the presence of prothrombin. This, however, was not the consequence of competition between ATIII and prothrombin for prothrombinase, but it rather was due to consumption of ATIII in the boundary layer at the wall of the capillaries, by the thrombin locally generated. Such a phenomenon can only be found in systems where the dynamic aspects of flow influence the reactions taking place. Thus, in order to obtain further insight in the mechanism of heparin action more studies under various conditions in such systems will be needed.

In vivo blood flows through the vasculature, of which the endothelial cells form a barrier between the blood and the surrounding tissues. The endothelial cell layer contains many proteins at its surface, a number of which have been identified to support the non-thrombogenic properties of endothelial cells, e.g. thrombomodulin (99). In addition, the endothelial cell surface contains glycosaminoglycans, such as heparan sulfate (105), which can localize ATIII at the surface, and thus potentially promote the inactivation of thrombin and factor $\mathrm{Xa}$ in the vicinity of the endothelial cells. In this respect, regulation of prothrombinase at the surface of endothelial cells, during continuous flow would be an interesting topic for future research.

The findings reported in this thesis are in agreement with the notion that regulation of coagulation by heparin predominantly occurs during the formation of prothrombinase, and not through progressive inhibition of already formed prothrombinase. Inhibition of prothrombinase formation can be achieved by either scavenging thrombin, necessary for the activation of factor $V(61,197)$ and factor VIII (197), or scavenging free factor Xa (189). In conclusion, the aim of antithrombotics seems to be suppression of thrombin formation, rather than neutralization of massive amounts of formed thrombin. It is precisely this activity which heparin has in common with another established class of antithrombotics, the oral anticoagulants. 
w 



\section{REFERENCES}

1 Jaques LB. Addendum: the discovery of heparin. Sem Thromb Hemost 4:350. 353,1978

2 Holmer E, Mattsson C, Nilsson S. Anticoagulant and antithrombotic effects of heparin and low molecular weight heparin fragments in rabbits. Thromb Res 25:475485, 1982

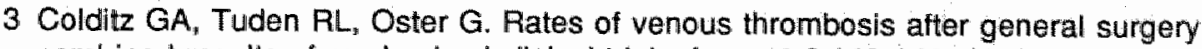
combined results of randomized clinical trials. Lancet 2:143-146, 1986

4 Merton RE, Thomas DP. Experimental studies on the relative efficacy of dermatan sulphate and heparin as antithrombotic agents. Thromb Haemostas 58:839-842, 1987

5 Collins $R$, Scrimgeaur $A$, Yusuf $S$, Peto $R$. Reduction in fatal pulmonary embolism and venous thrombosis by perioperative adminstration of subcutaneous heparin. $N$ Engl J Med 318:1162-1173, 1988

6. Thomas DP. Heparin in the prophylaxis and treatment of venous thrombosis. Semin Haematol 15:1-17, 1978

7 Wessler S, Gitel SN. Heparin: New concepts relewant to clinical use. Blood 53: $525-544,1979$

8 Hirsh $\sqrt{ }$. Heparin therapy in venous thromboembolism. Ann NY Acad Scl 556: 378-385, 1989

9 Brinkhous KM, Smith HP, Warner ED, Seegers WH. The inhibition of blood clotting. An unidentified substance which acts in conjunction with heparin to prevent the conversion of prothrombin to thrombin. Am J Physiol 125:683-687, 1939

10 Abildgaard U. Highly purified antithrombin III with heparin colactor activity prepared by disc electrophoresis. Scand J Clin Lab Invest $21: 89-91,1968$

11 Lam LH, Silbert JE, Rosenberg RD. The separation of active and inactive forms of heparin. Blochem Blophys Res Commun 69:570-577, 1976

12 Hök M, Björk I, Hopwood J. Lindahl U. Anticoagulant activity of heparim; Separation of high-activity and low-activity heparin species by affinity chromatography on immobilized antithrombin. FEBS Letters 66:90-93, 1976

13 Andersson LO, Barrowcliffe TW, Holmer E, Johnson EA, Síms GEC. Anticoagulant properties of heparin fractionated by affinity chromatography on matrix-bound antithrombin III and by gel filtration. Thromb Res 9:575-583, 1976

14 Casu B. Structure and biological activity of heparin. Adv Carbohydr Chem Blochem 43:51-134, 1985

15 Merton RE, Thomas DP. Havercroft SJ, Barrowcliffe TW, Lindahl U. High and low affinity heparin compared with unfractionated heparin as antithrombotic drugs. Thromb Haemostas $51: 254-256,1984$

16 Choay J. Structure and activity of heparin and its fragments: An overview. Sem Thromb Hemost 15:359-364, 1989

17 Choay J. Chemically synthesized heparin-derived oligosaccharides. Ann NY Acad Scil 556:61-74, 1989

18. Lindahl U, Kusche $M$, Lidholt K, Oscarsson LG. Biosynthesis of heparin and heparan sulfate. Ann NY Acad Scll 556:36-50, 1989 
19 Jacobsson KG, Lindahl U. Degradation of heparin proteoglycan in cultured mouse mastocytoma cells. Blochem J 246:409-415, 1987

20 Choay d. Lormeau JC, Petitou M, Sinaÿ P. Fareed J. Structural studies on a bilologically active hexasaccharide obtained from heparin. Ann NY Acad Scl 370:644-649, 1981

21 Thunberg $L$, Backstrom $G$, Lindahi U. Further characterization of the antithrombinbinding sequence in heparin. Carbohydr Res 100:393-410, 1982

22 Choay J, Petitou M, Lormeau JC, Sinaÿ P. Casu B, Gatti G. Structure-activity relationship in heparin; A synthetic pentasaccharide with high affinity for antithrombin $I I I$ and eliciting high anti-factor $X a$ activity. Biochem Blophys Res Commun $116.492-499,1983$

23 Atha $\mathrm{DH}_{\mathrm{y}}$ Lormeau JC, Petitou $\mathrm{M}_{1}$ Rosenberg RD, Choay J. Contribution of 3-O- and 6-O-sulfated glucosamine residues in the heparin-induced conformational change in antithrombin III. Blochem lstry 26:6454-6461, 1987

24. Linhardt $R$ J, Loganathan D, Al-Hakim A, Wang HM, Walenga JM, Hoppensteadt D, Fareed J. Oligosaccharide mapping of low molecular weight heparins: structure and activity differences. J Med Chem 33:1639-1645, 1990

25 Barlow $\mathrm{GH}$. The determination of molecular weight distributions on heparin samples. Sem Thromb Hemost 11:26-28, 1985

26. Carrell RW, Christey PB. Boswell DA. Serpins: antithrombin and other inhibitors of coagulation and fibrinolysis. Evidence from amino acid sequences. In: Thrombosis and Haemostasis 1987 (Eds. Verstraete M, Vermylen J, Lijnen R, Arnout J) Leuven University Press, Leuven 1987, pp 1-15

27 Björk I, Jackson CM, Jörnvall $H$, Lavine KK, Nordling $K$, Salsgiver WJ. The active site of antithrombin. Release of the same proteolytically cleaved form of the inhibitor

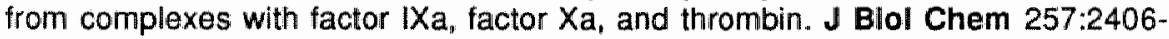
2411,1982

28 Rosenberg RD, Damus PS. The purification and mechanism of action of human antithrombin-heparin cofactor. J Blol Chem 248:6490-6505, 1973

29 Sun XJ, Chang JY. Heparin binding domain of human antithrombin III inferred from the sequential reduction of its three disulfide linkages. An efficient method for structural analysis of partially reduced proteins. J Blol Chem 264:11288-11293, 1989

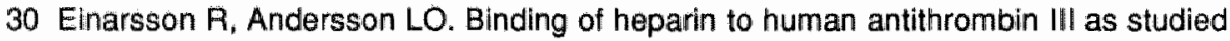
by measurements of tryptophan fluorescence. Blochim Blophys Acta 490:104111,1977

31 Olson ST, Srinivasan KR, Björk I, Shore JD. Binding of high affinity heparin to antithrombin III. Stopped fllow kinetic studies of the binding interaction. J Blol Chem 256:11073-11079, 1981

32 Villanueva GB, Allen N. Refolding properties of antithrombin III. Mechanism of binding to heparin. J Blol Chem 258:14048-14053, 1983

33 Craig PA, Olson ST, Shore JD. Transient kinetics of heparin-catalyzed protease inactivation by antithrombin III. Characterization of assembly, product formation. and heparin dissociation steps in the factor Xa reaction. J Blol Chem 264:54525461, 1989 
34 Shore JD, Olson ST, Craig PA, Choay J, Björk I. Kinetics of heparin action. Ann NY Acad Scl 556:75-80, 1989

35 Lane DA, Denton J. Flynn AM, Thunberg $L$, Lindahl U. Anticoagulant activities of heparin oligosacchaides and their neutralization by platelet factor 4 . Blochem $\mathrm{J}$ 218:725-732, 1984

36 Danielsson $A_{*}$ Raub $E$, Lindahl U, Bjork I. Role of ternary complexes, in which heparin binds both antithrombin and protelnase, in the acceleration of the reactions between antithrombin and thrombin or factor Xa. $J$ Blol Chem $26 \%: 15467-15473_{4}$ 1986

37 Olson ST, Shore JD. Demonstration of a two-step reaction mechanism for inhibition of $\alpha$-thrombin by antithrombin $1 / 1$ and identification of the step affected by heparin. $J$ Biol Chem 257:14891-14895, 1982

38 Peterson CB, Blackburn MN. Antithrombin conformation and the catalytic role of heparin. II. Is the heparin-induced conformational change in antithrombin required for rapid inactivation of thrombin? J Blol Chem 262: 7559-7566 1987

39 Peterson $C_{B}$, Blackburn MN. Antithrombin conformation and the catalytic role of heparin. I. Does cleavage by thrombin induce structural changes in the heparinbinding region of antithrombin? J Blol Chem 262:7552-7558, 1987

40 Olson ST, Shore JD. Transient kinetics of heparin-catalyzed protease inactivation by antithrombin III. The reaction step limiting heparin turnover in thrombin neutralization. J Blol Chem 261:13151-13159, 1986

41 Hoylaerts $M$, Owen WG, Collen D. Involvement of heparin chain length in the heparin-catalyzed inhibition of thrombin by antithrombin III. $\mathbb{J}$ Blol Chem 259; 5670-5677, 1984

42 Ellis V. Scully MF, Kakkar VV. The relative mass dependence of the anti-factor Xa properties of heparin. Blochem $\mathbf{J}$ 238:329-333, 1986

43 Olson ST, Björk !, Craig PA, Shore JD, Choay J. Role of high-affinity pentasaccharide in acceleration of antithrombin 111 inhibition of thrombin and factor $X \mathrm{a}$. Thromb Haemostas 58:8, 1987 (abstract)

44 Hurst RE, Menter JM, West SS, Settine JM, Coyne EH. Structural basis for the anticoagulant activity of heparin. 1. Relationship to the number of charged groups. Blochemistry 18:4283-4287, 1979

45 Hurst RE, Poon MC, Griffith Ml. Structure-activity relationships of heparin. Independence of heparin charge density and antithrombin-binding domains in thrombin inhibition by antithrombin and heparin cofactor II. J ClIn Invest 72:1042-1045. 1983

46 Olson ST. Transient kinetics of heparin-catalyzed protease inactivation by antithrombin III. Linkage of protease-inhibitor-heparin interactions in the reaction with thrombin. I Blol Chem 263:1698-1708, 1988

47 Kelton JG, Hirsh $J$. Bleeding associated with antithrombotic therapy. Sem In Haematol 17:375-379, 1980

48 Yin ET, Wessler S, Stoll PJ. Blological properties of the naturally occuring plasma intinibitor to activated factor $X$. J Blol Chem 246:3703-3711, 1971

49 Yin ET, Wessler $S$, Stoll $P J$. Identity of plasma-activated factor $X$ inhibitor with antithrombin III and heparin cofactor. J Blol Chem 246:3712-3719, 1971

50 Thomas DP. Current status of low molecular weight heparin. Thromb Haemostas $56: 241-242,1986$ 
5. Hirsh $J$, Ofosu $F$, Buchanan M. Rationale behind the development of low molecular weight theparin derivatives. Sem Thromb Hemost 11:13-16, 1985

52 Fareed J, Walenga JM, Hoppensteadt D, Racanelli A, Coyne E. Chemical and biological heterogeneity in low molecular weight heparins: Implications for clinical use and standardization. Sem Thromb Hemost 15:440-463, 1989

53 Haas 5 , Blümel $G$. An objective evaluation of the clinical potential of low molecular weight heparins in the prevention of thromboembolism. Sem Thromb Hemost $15: 424-434,1989$

54 Messmore HL. Clinical potential of low molecular weight heparins. Sem Thromb Hemost 15:405-408, 1989

55 Aiach $M$, Michaud $A$. Balian JL, Lefebvre $M$, Woler $M$, Fourtillan J. A new low molecular weight heparin derivative. In vitro and in vivo studies. Thromb Res $31: 611-621,1983$

56 Bergquist D, Hedner U, Sjorin E, Holmer E. Anticoagulant effects of two types of low molecular weight heparin administered subcutaneously. Thromb Res 32:381-391, 1983

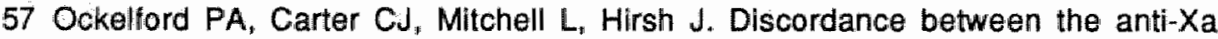
activity and antithrombotic activities of an ultra low molecular weight heparin fraction. Thiromb Res 28:401-409, 1982

58 Walenga JM, Fareed J, Petitou M, Samama $M$, Lormeau JC, Choay J. Intravenous antithrombotic activity of a synthetic heparin pentasaccharide in a human serum induced stasis thrombosis model. Thromb Res 43:243-248, 1986

59 Thomas DP. Merton RE, Gray E, Barrowcliffe TW. The relative antithrombotic effectiveness of heparin, a low molecular weight heparin, and a pentasaccharide fragment in an animal model. Thromb Haemostas 61:204-207, 1989

60 Béguin $S$, Lindhout $T$. Hemker HC. The mode of action of heparin in plasma. Thromb Haemostas $60: 457-462,1988$

61 Pieters J, Lindhout T. The limited importance of factor Xa inhibition to the anticoagulant property of heparin in thromboplastin-activated plasma. Blood 72:20482052,1988

62 Béguin $\mathrm{S}$, Lindhout $\mathrm{T}$, Hemker HC. The effect of trace amounts of tissue factor on thrombin generation in platelet rich plasma, its inhibition by heparin. Thromb Haemostas 61:25-29, 1989

63 Béguin S, Mardigulan J, Lindhout T, Hemker HC. The mode af action of low molecular weight heparin preparation (PK10169) and two of its major components on thrombin generation in plasma. Thromb Haemostas 61:30-34, 1989

64 Ofosu FA, Sie P, Modi GJ, Fernandez F, Buchanan MR, Blajchman MA, Boneu B, Hirsh $\mathrm{J}$. The inhibition of thrombin-dependent positive-feedback reactions is critical to the expression of the anticoagulant effect of heparin. Blochem $\mathbf{J} 243: 579-588$, 1987

65 Otosu FA, Hirsh J, Esmon CT, Modi GJ, Smith LM, Anvari N, Buchanan MR, Fenton JW, Blajchman MA. Unfractionated heparin inhibits thrombin-catalysed amplification reactions of coagulation more efficiently than those catalysed by factor $X a$. Blochem J 257:143-150, 1989

66 Holt JC, Niewiarowski S. Blochemistry of $\alpha$-granule proteins. Sem Hematol 22: $151-163,1985$ 
67 Cowan SW. Bakshi EN, Machin Ku, Isaacs NW. Binding of heparin to human platelet factor 4. Blochem J 234:485-488, 1986

68 Denton J, Lane DA. Thunberg L, Slater AM, Lindahl U. Binding of platelet factor 4 to heparin oligosaccharides. Blochem $\mathbb{J} 209: 455-460,1983$

69 Sixma JJ. Role of blood platelets, plasma proteins and the vessel wall in haemostasis. In: Haemostasis and Thrombosis (Eds. Bloom AL, Thomas DP) Churchill Livingstone, Edinburgh 1987, pp 283-302

70 Jackson CM, Nemerson Y. Blood coagulation. Ann Rev Blochem 49:765-811. 1980

71 Mann KG, Jenny RJ, Krishnaswamy S. Cofactor proteins in the assembly and expression of blood clotting enzyme complexes. Ann Rev Blochem 57:915-956, 1988

72 Nemerson $Y$. Tissue factor and hemostasis. Blood 71:1-8, 1988

73 Rosing J, v Rijn JLML, Bevers EM, v Dieijen G, Comfurius P, Zwaal RFA. The role of activated human platelets in prothrombin and factor $X$ activation. Blood 2:319-332, 1985

74 de Groot PG, Reinders JH, Sixma JJ. Perturbation of human endothelial cells by thrombin or PMA changes the reactivity of their extracellular matrix towards platelets. J Cell Blal 104:697-704, 1987

75 Stern DM, Kaiser E, Nawroth PP. Regulation of the coagulation system by vascular endothelial cells. Haemostasis $18: 202-214,1988$

76 Altieri DC. Edgington TS. Sequential receptor cascade for coagulation proteins on monocytes. Constitutive biosynthesis and functional prothrombinase activity of a membrane form of factor VNa. J Blol Chem 264:2969-2972, 1989

77 Tracy PB. Regulation of thrombin generation at cell surfaces. Sem Thromb Hemost 14:227-233, 1988

78 Zwaal RFA, Bevers EM, Comfurius P, Rosing J, Tilly RHJ, Verhallen PFJ. Loss of membrane phospholipid asymmetry during activation of blood platelets and sickled red cells; Mechanism and physiological significance. Mol Cell Blochem 91:2331,1989

79 Smith GF. Fibrinagen- "The specific thrombin substrate. In: The Thrombin (Ed. Machovich R) CRC Press Inc., Boca Raton, Florida 1984, pp 55-82

80 Blombäck B. Specificity of thrombin and its action on fibrinogen. Ann NY Acad Scl 485:120-123, 1986

81 Pieters $\mathrm{J}$, Lindhout $\mathrm{T}$, Hemker HC. In situ generated thrombin is the only enzyme that effectively activates factor $V$ and factor VIII in thromboplastin-activaled plasma. Blood 74:1021-1024, 1989

82 Laposata M, Dovnarsky DK, Shin HS. Thrombin-induced gap formation in confluent endothelial cell monolayers in vitro. Blood 62:549-556, 1983

83 Hemker HC, Lindhout T. A clotting scheme for 1984. Nouv Rev Fr Hematol $26: 227-231,1984$

84 Tans $\mathrm{G}_{,}$Rosing J. Multicomponent enzyme complexes of blood coagulation. In: Blood Coagulation (Eds. Zwaal RFA, Hemker HC) Elsevier, Amsterdam 1986, pp 59-85

85 Nesheim ME, Taswell JB, Mann KG. The contribution of bowine factor $V$ and factor $\checkmark a$ to the activity of prothrombinase. $J$ Blol Chem 254:10952-10962, 1979 
86 Rosing J, Tans $Q$, Govers Pliemslag JWP, Zwaal RFA, Hemker HC. The role of phospholipids and factor $V a$ in the prothrombinase complex. I Biol Chem $255: 274-283,1980$

87 v Fijn JLML, Govers-Riemslag JWP, Zwaal RFA, Rosing J. Kinetic studies of prothrombin activation: Effect of factor $V a$ and phospholipids on the formation of the enzyme-substrate complex. Blochemistry $23: 4557-4564,1984$

88 suttie JW, Jackson CM. Prothrombir structure, activation and biosynthesis. Physiol Rev 57:1-70, 1977

89 Rosing J. Tans G. Meizothrombin, a major product of factor Xa-catalyzed prothrombin activation. Thromb Haemostas 60:355-360, 1988

90 Krishnaswamy $S$, Church WR, Nesheim ME, Mann KG. Activation of human prothrombin by human prothrombinase. Influence of factor $\mathrm{Va}$ on the reaction mechanism. J Blol Chem 262:3291-3299, 1987

91 Boskovic DS, Giles AR, Nesheim ME. Studies of the role of factor Va in the factor Xa-catalyzed activation of prothrombin, fragment 1.2-prethrombin 2, and dansyl-1glutamyl-glycyl-1-arginine-meizothrombin in the absence of phospholipid. J Blol Chem 265:10497-10505, 1990

92 Doyle MF, Mann KG. Multiple active forms of thrombin. IV. Relative activities of meizothrombins. J Blol Chem 265:10693-10701, 1990

93 Lorand L. Activation of blood coagulation factor XIII. Ann NY Acad Scl 485:144158,1986

94 Muszbek $L$, Laki $K$. Interaction of thrombin with proteins other than fibrinogen (thrombin-susceptible bonds). Activation of factor XIII. In: The Thrombln (Ed. Machovich R) CRC Press Inc., Boca Raton, Florida 1984, pp 83-102

95 Bauer KA, Rosenberg RD. The pathophysiology of the prethrombotic state in humans: Insights gained from studies using markers of hemostatic system activation. Blood 70:343-350, 1987

96 Reutelingsperger CPM, Hornstra G, Hemker HC. Isolation and partial purification of a novel anticoagulant from arteries of human umbilical cord. Eur $\mathrm{J}$ Blochem $151: 625-629,1985$

97 Andree HAM, Reutelingsperger CPM, Hauptmann R, Hemker HC. Hermens WT, Willems GM. Binding of vascular anticoagulant a (VAC $\alpha$ ) to planar phosphollipid bllayers. J Bllol Chem 265:4923-4928, 1990

98 Reutelingsperger CPM, Kop JMMM, Hornstra $G$, Hemker HC. Purification and characterization of a novel protein from bovine aorta that inhibits coagulation. Inhibition of the phospholipid-dependent factor Xa-catalyzed prothrombin activation, through a high-aftinity binding of the anticoagulant to the phospholipids. Eur J Blochem 173:171-178, 1988

99 Dittman WA, Majerus PW. Structure and function of thrombomodulin: A natural anticoagulant. Blood 75:329-336, 1990

100 Esmon $\mathrm{CT}$. The roles of protein $\mathrm{C}$ and thrombomodulin in the regulation of blood coagulation. J Blol Chem 264:47.43-4746, 1989

101 Sakata $Y$, Curriden S, Lawrence D, Griffin JH, Loskutoff DJ. Activated protein C stimulates the fibrinolytic activity of cultured endothelial cells and decreases antiactivator activity. Proc Natl Acad ScI USA 82:1121-1125, 1985 
102 Rapaport SI. Inhibition of factor VIla/tissue factor-induced blood coagulation: With particular emphasis upon a factor Xa-dependent inhibitory mechanism: Blood 73:359-365, 1989

103 Harpel PC. Bllood proteolytic enzyme inhibitors: Their role in modulating blood coagulation and fibrinolytic enzyme pathways. In: Hemostasils and Thrombosis. Basic Principles and Clinical Practice, $2^{\text {nd }}$ edition (Eds. Colman RW, Hirsh J, Marder VJ, Salzman EWJ JB Lippincott Company, Philadelphia 1987, pp 219-234

104 Broze GJ, Girard TJ, Nowotny WF. Regulation of coagulation by a multivalent Kunitz type inhibitor. Blochemistry 29:7539-7546, 1990

105 Machovich $\mathrm{A}$. Choices among the possible reaction routes catalyzed by thrombin. Ann NY Acad Scll 485:170-183, 1986

106 Marcum JA, McKenney JB, Rosenberg RD. Acceleration of thrombin-antithrombin complex formation in rat hindquarters via heparin-like molecules bound to the endothelium. J Clin Invest $74: 341-350,1984$

107 Marciniak $\mathrm{E}$. Factor $\mathrm{Xa}$ inactivation by antithrombin III: Evidence for biological stabilization of factor $\mathrm{Xa}$ by factor $\mathrm{V}$-phospholipid complex. $\mathrm{Br} \mathrm{J}$ Haematol 24: $391-400,1973$

108 Goldsmith HL, Turitto VT. Rheological aspects of thrombosis and haemostasis: Basic principles and applications. Thromb Haemostas $55: 415-435,1986$

109 Leonard EF. Rheology of thrombosis. In: Hemostasis and Thrombosis. Basic Principles and Clinical Practlice, $2^{\text {nd }}$ edition (Eds Colman RW. Hirsh J, Marder VJ, Salzman EW) JB Lippincott Company, Philadelphia 1987, pp 1111 1122

110 Gemmell $\mathrm{CH}$, Turitto VT, Nemerson $Y$. Flow as a regulator of the activation of factor $X$ by tissue factor. Blood 72:1404-1406, 1988

111 Pletcher $\mathrm{CH}$, Nelsestuen $\mathrm{G}$. The rate-determining step of the heparin-catalyzed antithrombin/thrombin reaction is independent of thrombin. J Blol Chem 257 : $5342-5345,1982$

112 Mertens $K$, Bertina RM. Pathways in the activation of human coagulation factor $X$. Blochem J 185:647-658, 1980

113 Lindhout T, Kop-Klaassen BHM, Hemker HC. Activation of decarboxyfactor $X$ by a protein from Russell's viper venom. Purification and partial characterization of activated decarboxyfactor X. Blochim Blophys Acta 533:327-341, 1978

114 Smith RL. Titration of activated bovine factor $X$. J Blol Chem 248:2418-2423, 1973

115 Schoen $P$, Lindhout $T$. The in situ inhibition of prothrombinase-formed human $\alpha$ thrombin and meizothrombin(des. F1) by antithrombin III and heparin. $\mathrm{J}$ Blol Chem 262:11268-11274, 1987

116 Casu B, Gennaro V. A conductimetric method for the determination of sulfate and carboxyl groups in heparin and other mucopolysaccarides. Carbohyd Res 39:168-176, 1975

117 Olson ST, Shore JD. Binding of high affinity heparin to antithrombin II.. Characterization of the protein fluorescence enhancement. $J$ Blal Chem 256:1106511072,1981 
118 Duggleby $R G$. A nonlinear regression program for small computers. Anal Blochem $110: 9-18,1981$

119 Schoen $P$. Lindhout $T$, Willems $G$, Hemker HC. Antithrombin III-dependent antiprothrombinase activity of heparin and heparin fragments. J Blol Chem 264: 10002-10007, 1989

120 Kusche $M$, Bảckström $G$, Riesenfeld $J$, Petitou $M$, Choay J, Lindahl U. Biosynthesis of heparin: $\mathrm{O}$-sulfation of the antithrombin-binding region. $\mathrm{J}$ Blol Chem 263 : $15474-15484,1988$

121 Stone $A$, Beeler D, Oosta $G$, Rosenberg RD. Circular dichroism spectroscopy of heparin-antithrombin interactions. Proc Natl Acad Scl USA 79: 7190-7194, 1982

122 Petitou M, Lormeau JC, Choay J. Interaction of heparin and antithrombin III; The role of O-sulfate groups. Eur J Blochem 176:637-640,1988

123 Atha $\mathrm{DH}_{\text {, Lormeau }} \mathrm{JC}_{\text {, Petitou } M}$, Rosenberg RD, Choay $\mathrm{J}$. Contribution of monosaccharide residues in heparin binding to antithrombin III Blochemistry 24:6723-6729, 1985

124 Thunberg L, Lindahl U, Tengblad A, Laurent TC, Jackson CM. On the molecularwelght-dependence of the anticoagulant activity of heparin. Blochem $\mathrm{J} 181: 241$. 243,1979

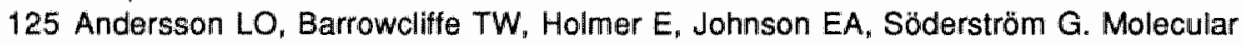
weight dependency of the heparin potentiated inhibition of thrombin and activated factor $X$. Effect of heparin neutralization in plasma. Thromb Res 15:531-541, 1979

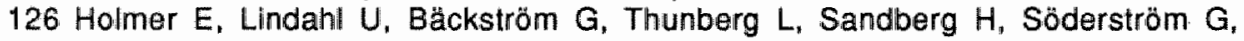
Andersson LO. Anticoagulant activities and effects on platelets of a heparin fragment with high affinity for antithrombin. Thromb Res 18:861-869, 1980

127 Barrowcliffe TW, Shirley YL. The effect of calcium chloride on anti-Xa activity of heparin and its molecular weight fractions. Thromb Haemostas 62: $950-954$, 1989

128 Speight MO, Griffith MV. Calcium inhibits the heparin catalyzed antithrombin III/ thrombin reaction by decreasing the apparent binding affinity of heparin for thrombin. Arch Blochem Blophys 225:958-963, 1983

129 Levine SP, Wohl H. Human platelet factor 4: purification and characterization by affinity chromatography. Purification of human platelet factor 4 . J Blol Chem 251: 324-328, 1976

130 Mclaren $\mathrm{KM}_{*}$ Holloway L, Pepper DS. Human platelet factor 4 and tissue mast cells. Thromb Res 19:293-297, 1980

131 Schoen $P_{\text {." Wielders }}$, Petitou $M$, Lindhout T. The effect of sulfation on the anticoagulant and antithrombin III-binding properties of a heparin fraction with low affinity for antithrombin III. Thromb Res 57:415-423, 1990

132 Hendrix $H$, Lindhout T, Mertens $K$, Engels W, Hemker HC. Activation of human prothrombin by stolchiometric levels of staphylocoagulase. J Blol Chem 258: 3637 3644,1983

133 Miller-Andersson $M_{*}$ Gaffney PJ, Seghatchian MJ. Preparation and stability of a highly purified human thrombin standard. Thromb Res 20:109-122, 1980

134 Chase T. Shaw E. Comparison of the esterase activities of trypsin, plasmin and thrombin on guanidinobenzoate esters. Titration of the enzymes. Blochemistry 8:2212-2224, 1969 
135 Petitou M, Lormeau JC, Perly B, Berthault P, Bossennec V; Sie P, Choay J. Is there a unique sequence in heparin for interaction with heparin cofactor II? Structural and biological studies of heparin-derived oligosaccharides. J Blol Chem 263:86858690,1988

136 Walz DA, Hung GL. In vivo studies on the binding of heparin and its fractions with platelet factor 4. Sem Thromb Hemost 11:40-47, 1985

137 Walker FJ, Esmon CT. The effect of prothrombin fragment 2 on the inhibition of thrombin by antithrombin III. J Blol Chem 254:5618-5622, 1979

138 Morita $T$, Iwanaga $S$, Suzuk $T$. The mechanism of activation of bovine prothrombin by an activator isolated from Echis carinatus venom and characterization of the new active intermediates. J Blochem 79:1089-1108, 1976

139 Lindhout T, Baruch D, Schoen P, Franssen J, Hemker HC. Thrombin generation and inactivation in the presence of antithrombin III and heparin. Blochemlstiry $25: 5962-5969,1986$

140 Pieters $J$, Franssen J, Visch $C$, Lindhout T. Neutralization of heparin by prothrombin activation products. Thromb Res 45:573-580, 1986

141 Nesheim ME, Blackburn MN, Lawler CM, Mann KG. Dependence of antithrombin III and thrombin binding stoichiometries and catalytic activity on the molecular weight of affinity-purified heparin. J Blol Chem 261:3214-3221, 1986

142 Hemker HC, Willems GM, Béguin S. A computer assisted method to obtain the prothrombin activation velocity in whole plasma independent of thrombin decay processes. Thromb Haemostas 56:9-17, 1986

$143 \mathrm{Jesty} \mathrm{J}$. Analysis of the generation and inthibition of activated coagulation factor $X$ in pure systems and in human plasma. J Blol Chem 261:8695-8702, 1986

144 Soons $H$, Janssen-Claessens $T$, Hemker HC, Tans $G$. The effect of platelets in the activation of human blood coagulation factor IX by factor Xla. Blood 68:140-148. 1986

145 Lindhout T, Govers-Riemslag JWP, vd Waart P, Hemiker HC , Rosing J. Factor Va. factor Xa interaction. Effects of phospholipid vesicles of varying composition. Blochemlstry 21:5494-5502, 1982

146 Thaler $\mathrm{E}$, Schmer G. A simple two-step isolation procedure for human and bovine antithrombin II/III (heparin cofactor): a comparison of two methods. Br J Haematol $31: 233-243,1975$

147 Miller-Andersson $M$, Borg H, Andersson LO.Purification of antithrombin III by affinity chromatography. Thromb Res 5:439-452, 1974

148 Gill $P E_{\text {s }}$ Murray W. Algorithms for the solution of the non-linear least squares problem. SIAM J Num Anal 15:977-992, 1978

149 Laemmli UK.Cleavage of structural proteins during the assembly of the head of the bacteriophage T4. Nature $227: 680-685,1970$

150 Towbin $H$, Stachelin T, Gordon J. Electrophoretic transfer of proteins from polyacrylamide gels to nitrocellulose sheets: Procedures and some applications. Proc Natl Acad Scl USA $76: 4350-4354,1979$

151 Griffith MJ. Kinetics of the heparin-enhanced antithrombin III/thrombin reaction. Evidence for a template model for the mechanism of action of heparin. $J$ Blol Chem 257:7360-7365, 1982 
152 Nesheim ME. A simple rate law that describes the kinetics of the heparin-catalyzed reaction between antithrombin III and thrombin. J Blol Chem 258: 14708-14717. 1983

153 Rosenberg RD, Oosta GM, Jordan RE, Gardner WT. The interaction of heparin with thrombin and antithrombin. Blochem Blophys Res Commun 96:1200-1208, 1980

154 Evington JRN, Foldman PSA, Luscombe M, Holbrook JJ. Multiple complexes of thrombin and heparin. Blochim Blophys Acta 871:85-92, 1986

155 Downing MR, Bloom JW, Mann KG. Comparison of the inhibition of thrombin by three plasma protease inhibitors. Blochemilstry 17:2649-2654, 1978

156 Griffith $M J$. Kinetic analysis of the heparin-enhanced antithrombin $1 / 1 /$ thrombin reaction. Reaction rate enhancement by heparin-thrombin association. $J$ Blol Chem 254:12044-12049, 1979

157 Walker $F_{J}$, Esmon CT. The effects of phospholipid and factor Va on the inhibition of factor Xa by antithrombin III. Blochem Blophys Res Commun 90: 641-647, 1979

158 Ellis V, Scully MF, Kakkar VV. Inhibition of prothrombinase complex by plasma proteinase inhibitors. Blochemistry $23: 5882-5887,1984$

159 Comfurius P. Zwaal RFA. The enzymatic synthesis of phosphatidylserine and purification by CM-cellulose column chromatography. Blochim Blophys Acta $488: 36-42,1977$

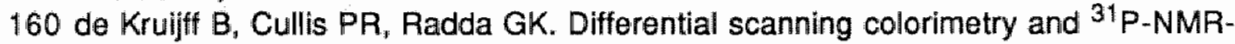
studies on sonicated and unsonicated phosphatidylcholine liposomes. Blochim Blophys Acta 406:6-20, 1975

161 Griffith MJ. Heparin-catalyzed inhibitor/protease reactions: Kinetic evidence for a common mechanism of action of heparin. Proc Natl Acad Scl USA 80:54605464,1983

162 Rosing $\mathrm{J}$, Zwaal RFA, Tans G. Formation of meizothrombin as intermediate in factor Xa-catalyzed prothrombin activation. J Blol Chem 261:4224-4228, 1986

163 Weil GL, Bloomfield VA, Resnick RM, Nelsestuen GL. Kinelic and mechanistic analysis of prothrombin-membrane binding by stopped-flow light scattering . Blochemistry $21: 1949-1959,1982$

164 Pusey ML, Nelsestuen GL. Membrane binding properties of blood coagulation factor $V$ and derived peptides. Blochem Istry 23:6202-621:0, 1984

165 Nelsestuen $\mathrm{GL}$. Broderius $\mathrm{M}$. Interaction of prothrombin and blood-clotting factor $X$ with membranes of varying composition. Blochemistry 16:4172-4177, 1977

166 vd Waart $\mathrm{P}$, Bruls $\mathrm{H}$, Hemker HC, Lindhout $\mathrm{T}$. Interaction of bovine blood clotting factor $\mathrm{Va}$ and its subunits with phospholipid vesicles. BlochemIstry 22:24:7. 2432,1983

167 Ceustermans R, Hoylaerts $\mathrm{M}_{\text {, }}$ de Mol M, Collen D. Preparation, characterization, and turnover properties of heparin-antithrombin 111 complexes stabilized by covalent bonds. J Blol Chem 257:3401-3408, 1982

168 Pusey ML, Mayer LD, Wei GJ, Bloomfield VA, Nelsestuen GL. Kinetic and hydrodynamic analysis of blood clatting factor $V$-membrane binding. Blochemistry $21: 5262-5269,1982$ 
169 Barrowcliffe TW, Havercroft SJ, Kemball-Cook G, Lindahl U. The effect of Ca ${ }^{2+}$. phospholipid, and factor $V$ on the anti-(factor $X a)$ activity of heparin and ts highaffinity oligosaccharides. Blochem $\mathbb{J} 243: 31-37 ; 1987$

170 Ellis V, Scully MF, Kakkar VV. The acceleration of the inhibition of platelet prothrombinase complex by heparin. Blochem J 233"161-165, 1986

171 Thomas DP, Curtis AD, Barrowcliffe TW. A collaborative study designed to establish the $4^{\text {th }}$ Internationall Standard for heparin. Thromb Haemostas $52: 148-153$, 1984

172 Sache $E_{0}$ Maillard M, Bertrand H, Maman M, Kunz M, Choay J, Fareed J, Messmore $H$. Studies on a highly active anticoagulant fraction of high molecular weight isolated from porcine sodium heparin. Thromb Res $25: 443-458,1982$

173 Choay J, Lormeau JC, Petitou M, Sinaÿ P, Casu B, Oreste P. Torri G, Gatti G. Anti$\mathrm{Xa}$ active heparin oligosaccharides. Thromb Res $18: 573-578,1980$

174 Nordenmann B, Björk 1. Binding of low-affinity and high-affinity heparin to antithrombin. Ultraviolet difference spectroscopy and circular dichroism studies. Blochemistry 17:3339-3344, 1978

175 Miletich JP, Jackson CM, Majerus PW. Properties of the factor Xa binding site on human platelets. J Blol Chem 253:6908-6916, 1978

176 Teitel JM, Rosenberg RD. Protection of factor Xa from neutralization by the heparinantithrombin complex. J Clln Invest $71: 1383-1391,1983$

177 Radoff S, Danishefsky I. High-activity heparin: chain length, affinity for antithrombin, and anticoagulant activity. Arch Blochem Blophys 215:163-170, 1981

178 Ofosu FA, Blajchman MA, Modi G, Cerskus AL, Hirsh J. Activation of factor X and prothrombin in antithrombin-lll depleted plasma: The effects of heparin. Thromb Res 23:331-345, 1981

179 Olson ST, Björk I, Craig PA, Shore JD, Choay J. Role of high-affinity pentasaccharide in acceleration of antithrombin 111 inhibition of thrombin and factor Xa. Thromb Haemostas 58:8, 1987 (abstract)

180 Heuck CC, Schiele U, Horn D, Fronda D, Ritz E. The role of surface charge on the accellerating action of heparin on the antithrombin III-inhibited activity of $\alpha$-thrombin.

$\mathrm{J}$ Blol Chem 260:4598-4603, 1985

181 Bird RB, Stewart WE, Lightfoot EN. Transport phenomena, John Wiley \& Sons, Inc. New York 1960, pp 46, 363

182 Brian AA, McConnell HM. Allogenic stimulation of cytotoxic T cells by supported planar membranes. Proc Natl Acad Scl USA 81:6159-6163, 1984

183 Higgins DL, Mann KG. The interaction of bovine factor $V$ and factor $V$-derived peptides with phospholipid vesicles. J Blol Chem 258:6503-6508, 1983

184 Hermens WT, Kop JMM, Willems GM. Adsorption of coagulation factors II, $V$, and $X$ at phospholipid membranes. In: Coagulatlon and Ilplds (Ed. Zwaal RFA) CRC Press, Inc., Boca Raton 1988, pp 73-97

185 Subramaniam S, Seul M, McConnell HM. Lateral diffusion of specific antibadies bound to lipid monolayers on alkylated substrates. Proc Natll Acad Scl USA 83:1169-1173, 1968

186 Schoen P, Lindhout T, Willems G, Hemker HC. Continuous flow and the prothrombinase-catalyzed activation of prothrombin. Thromb Haemostas 64:542-547, 1990 
187 Laidler KJ, Bunting PS. The kinetics of immobilized enzyme systems. Method Enzymol 64:227-248, 1980

188 Stone SR, Hofsteenge J. Kinetics of the inhibition of thrombin by hirudin. Blochemistry $25: 4622-4628,1986$

189 Hemker $\mathrm{HC}$, Choay $J$, Béguin $\mathrm{S}$. Free factor $\mathrm{Xa}$ is on the main pathway of thrombin generation in clotting plasma. Blochlm Blophys Acta 992:409-411, 1989

190 Anonymous. Prevention of venous thrombosis and pulmonary embolism, consensus conference. JAMA 256:744-749, 1986

191 Lane DA, Macgregor IR, Michalski R, Kakkar VV. Anticoagulant activities of four unfractionated and fractionated heparins. Thromb Res 12:257-271, 1978

192 Barrowcliffe TW, Johnson EA, Eggleton A, Kemball-Cook G, Thomas DP. Anticoagulant activities of high and low molecular weight heparin fractions. Br J Haematol $41: 573-583,1979$

193 Hemker $\mathrm{HC}$, Wielders S, Béguin S. The thrombin potential. A parameter to assess the effect of antithrombotic drugs on thrombin generation. In: Fraxlparlne: Second International Symposium. Recent Pharmacologlcal and Cilnical

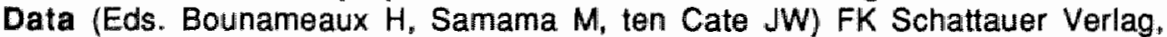
Stuttgart 1990, pp 89-101

194 Hemker HC, Béguin S, Pieters J, Lindhout $T$. The ex vivo correlate of the antithrombotic action of heparin. Ann NY Acad Sci 556:146-157, 1989

195 Tans G, Janssen-Claessen T, Thomassen MCLGD, Hemker HC, Rosing J. Melzothrombin formation during factor $\mathrm{Xa}$-catalyzed prothrombin activation. $\mathrm{Br} J$ Haematol 76(supplement 1):25, 1990 (abstract)

196 Nesheim ME, Eid S. Mann KG. Assembly of the prothrombinase complex in the absence of prothrombin. J Blol Chem 256:9874-9882, 1981

197 Lindhout T, Blezer $\mathrm{R}$, Hemker HC. The anticoagulant mechanism of action of recombinant hirudin (CGP 39393) in plasma. Thromb Haemostas 64: 464-468, 1990 
w 


\section{DE ANTISTOLLENDE AKTIVITEIT VAN HEPARINE Biochemische Studies in Systemen Bestaande uit Gezuiverde Bloedplasma Eiwitten}

B

loedstolling is een strikt gereguleerd proces, waarin het plasmaeiwit antitrombine III (ATIII) een uitermate belangrijke rol speelt. ATIII remt geaktiveerde stollingseiwitten waarbij de inaktivering van factor Xa en trombine het meest belangrijk is. De werking van ATIII berust op het feit dat het als substraat voor factor Xa en trombine dient, de katalytische cycli worden echter niet geheel doorlopen, maar eindigen in een toestand waarin ATIII covalent gebonden blijft aan factor Xa of trombine (acylenzym intermediair). De eerste stap tijdens de inaktiveringsreaktie is de vorming van een dissocieerbaar, niet-covalent complex tussen ATIII en het enzym. Heparine katalyseert de ATIII-afhankelijke inaktivering van factor $\mathrm{Xa}$ en trombine door de vorming van het niet-covalente complex te stimuleren (Hoofdstuk 1).

Heparine bestaat uit glycosaminoglycanen die gesynthetiseerd worden in mestcellen. De gevormde heparinemoleculen zijn heterogeen met betrekking tot hun monosaccharide samenstelling, hun molecuulgewicht en hun ATIII-bindend vermogen. Deze heterogeniteit wordt, op zijn minst gedeeltelijk, veroorzaakt door niet-aflopende reakties tijdens de biosynthese. De binding van heparine aan ATIII is afhankelijk van de aanwezigheid van een specifieke pentasaccharide structuur in het heparine. Deze sequentie bevat een aantal specifiek gesulfateerde monosacchariden, waarvan de sulfatering geacht wordt de biosynthese van heparine af te sluiten (Hoofdstuk 1). Daar ook deze reaktles nietaflopend zijn lijkt het redelijk te veronderstellen, dat de niet-ATHII-bindende fraktie van heparine een aantal moleculen bevat die, een of meerdere specifieke sulfaat groepen missen in een overigens correct pentasaccharide-domein.

Deze hypothese is onderzocht in Hoofdstuk 2. Een heparine preparaat zonder antistollende aktiviteit, dat een lage affiniteit voor ATIII had, werd chemisch overgesulfateerd en daama gefraktioneerd middels ATIII-affiniteits chromatografie. Door gebruik te maken van de intrinsieke fluorescentie van ATIII kon aangetoond worden dat het overgesulfateerde materiaal ATIII-bindings eigenschappen vertoonde. De aftiniteit tussen het overgesulfateerde materiaal en ATIII $\left(K_{d}=6.4 \times 10^{-8} \mathrm{M}\right)$ was 10 keer lager dan de affiniteit van natuurlijk heparine voor ATIII ( $\left.K_{d}=0.63 \times 10^{-8} M\right)$. Het overgesulfateerde materiaal was ook in staat om de inaktivering van trombine en factor Xa door ATIII te versnellen. Van het over- 
gesulfateerde en het natuurlijke heparine waren de frakties met hoge affiniteit voor ATIII bijna even aktief met betrekking tot de inactivering van trombine. Het natuurlijke heparine was echter ongeveer 3 maal aktiever in de inaktivering van factor Xa. Uit deze resultaten hebben wij geconcludeerd dat, alhoewel de interaktie met ATIII niet volledig van eenzelfde kwaliteit was als met natuurlijk heparine, sulfatering van heparine met lage affiniteit voor ATIII leidt tot een specifieke wijziging (middels het vervolmaken van pentasaccharide-domeinen) van de eigenschappen van dit materiaal.

Heparine is een veel gebruikt middel voor de behandeling en profylaxe van trombotische en trombo-embolische aandoeningen, het gebruik echter, kan gepaard gaan met hemorrhagische incidenten. Het is sinds 1976 bekend dat laag molecuul gewicht (LMW) heparine frakties weinig invloed hebben in globale stolbepalingen zoals de APTT (KCCT), maar wel effectief zijn in anti-factor Xa bepalingen. In 1971 was het naar voren gebracht dat regulatie van de bloedstolling door ATIII, wel eens meer zou kunnen afhangen van de inaktivering van factor Xa dan van de inaktivering van trombine. Daarom werd de gedachte geopperd dat LMW heparine preparaten wel eens even effectief als nietgefraktioneerde (UF) heparine zouden kunnen zijn (het antitrombotisch effect zou afhangen van hun gehandhaafde anti-factor $X_{a}$ aktiviteit), terwijl zij minder aanleiding tot bloedingen zouden kunnen geven (door hun verminderde aktiviteit op globale stolbepalingen). Door het bestuderen van de struktuurfunktie relatie van heparine werd het bekend, dat de pentasaccharide sequentie benodigd voor de interaktie met ATIIl, volstaat om de inaktivering van factor Xa te katalyseren. De heparine-gekatalyseerde inaktivering van trombine door ATIII vereist echter het gelijktijdig binden van beide eiwitten aan éên en hetzelfde heparine molecuul. Dit mechanisme funktioneert slechts dan, wanneer de heparine keten minimaal 18 saccharides lang is. Omdat LMW heparine preparaten bestaan uit ketens met een lengte van 2 tot 30 saccharides, wordt algemeen gedacht dat hun lagere aktiviteit in APTT bepalingen veroorzaakt wordt door een lagere anti-trombine specifieke aktiviteit (Hoofdstuk 1).

Van LMW heparine preparaten is echter (vooralsnog) de verdeling van de ATIII-bindende fraktie onbekend. Bovendien is de anti-factor $\mathrm{Xa}$ en de antitrombine aktiviteit gevoelig voor de aanwezigheid van $\mathrm{Ca}^{2+}$-ionen. Voor de antifactor Xa aktiviteit is de mate van gevoe ligheid sterk afhankelijk van de heparine ketenlengte en de oorsprong van het factor Xa (humaan of bovine). Daarom hebben wij een aantal LMW heparine preparaten, bedoeld voor klinisch gebruik en standaardisering onderzocht op hun vermogen de inaktivering van humaan factor Xa en trombine door humaan ATIII te katalyseren in de aanwezigheid van $4.0 \mathrm{~mm} \mathrm{CaCl} 2$ (Hoofdstuk 3).

Onder deze kondities nemen zowel de anti-factor $X a$ als de anti-trombine aktiviteit af bij een afnemend gemiddeld molecuul gewicht van heparine. Het gevolg is, dat de verhouding tussen de anti-factor Xa en anti-trombine aktiviteit nogal onveranderlijk is. Deze verhoudingen waren 0.46 voor de $4^{e}$ Interna- 
tionale Standaard voor (niet-gefraktioneerde) heparine, 0.32 voor de $1^{e}$ internationale Standaard voor LMW heparine, 0.42 voor CY216 (Fraxiparine) en 0.50 voor Enoxaparine. CY222, een ultra laag molecuul gewicht preparaat, had slechts een 2 keer hogere verhouding (0.98). Verdere analyse van CY216, en frakties hiervan verkregen middels gelfiltratie, toonde aan dat de heparine moleculen met een molecuul gewicht groter dan het gemiddelde verantwoordelijke zijn voor de anti-trombine, en voor een groot deel ook voor de anti-factor $X a$ aktiviteit. De resultaten suggereerden dat depolymerisatie van heparine niet leidt tot een toegenomen anti-factor Xa/anti-trombine verhouding, omdat in de aanwezigheid van $4 \mathrm{~mm} \mathrm{Ca}^{2+}$-ionen de factor $X a$ afbraakkonstanten verlaagd zijn in vergelijking met die van natuurlijk heparine.

Een ander aspect van de momenteel gebruikte laboratoriumbepalingen van heparine is, dat het verwaarloosd wordt dat bloedplaatjes een potente heparine antagonist bevatten, plaatjes factor 4 (PF4). PF4 bevindt zich in de $\alpha$ granula, en komt vrij tijdens bloedplaatjes-aktivatie. Neutralisatie van heparine door PF4 is afhankelijk van de heparine ketenlengte: alleen die maleculen groter dan 18 sacchariden worden volledig en met hoge affiniteit door PF4 gebonden. Verschillen in neutralisatie patronen tussen LMW heparine preparaten kunnen leiden tot een verschillende beschikbaarheid in de aanwezigheid van geaktiveerde bloedplaatjes. Dit kan gevolgen hebben voor de werking (in vivo) en standaardisering (in vitro) van LMW heparine preparaten. Derhalve is de neutralisatie van (LMW) heparine preparaten door PF4 onderzocht; dit is eveneens beschreven in Hoofdstuk 3. De resultaten tonen aan dat bij een overmaat PF4 alle anti-trombine aktiviteit en minstens $85 \%$ van de anti-factor $X a$ aktiviteit van LMW heparine geneutraliseerd wordt. Omdat van LMW heparine preparaten hogere doseringen gebruikt moeten worden om afbraakkonstanten te verkrijgen die vergelijkbaar zijn met die van UF heparine, is het mogelijk dat de hoeveelheid PF4 die vrijkomt bij maximale aktivering van een normale plaatjes dichtheid, niet voldoende is om alle LMW heparine te neutraliseren. Dit ligt in de lijn van bevindingen gedaan in dit laboratorium (Béguin \& Hemker) en ondersteunt de veronderstelling dat trombinegeneratie in plaatjes rijk plasma voorlopig de beste voorspellende waarde heeft voor de in vivo effectiviteit van (LMW) heparine.

Of het therapeutisch effect van LMW heparine preparaten superieur is aan die van niet-gefraktioneerde preparaten kan slechts beantwoord worden door uitputtend (toekomstig) klinisch onderzoek. Nochtans, fundamenteel biochemisch onderzoek kan het zoeken naar een heparine met een equivalent of verbeterd antitrombotisch potentieel en een gereduceerd hemorrhagisch risiko ondersteunen. Allereerst is het daarom belangrijk de vraag te kunnen beantwoorden: Hoe werkt heparine?

Heparine katalyseert de inaktivering van trombine en factor Xa door ATIII. Veel van de huidige kennis en inzichten over heparine en zijn werking is verkregen uit studies met gezuiverde eiwitten in eenvoudige enzym/remmer 
mengsels. Bloedstolling is echter een complex proces dat gepaard gaat met aktiviteiten van en interakties tussen de vaatwand, bloedplaatjes en het stollingssysteem. Enzymen, geaktiveerde cofactoren en procoagulante oppervlakken worden gegenereerd in een heterogeen mengsel van velerlei componenten. Een van de essentiele stollingsreakties is de aktivering van protrombine door protrombinase, een enzymatisch complex bestaande uit het enzym factor Xa, een eiwit cofactor (factor $\mathrm{Va}$ ) en een geschikt phospholipide oppervlak. De meerderheid van de studies weergegeven in dit proeischrift werden ontworpen om de inaktivering van trombine en factor $\mathrm{Xa}$ te onderzoeken in modelsystemen die reaktieomstandigheden, zoals die zich voor kunnen doen tijdens het in vivo stollingsproces, nabootsen. Dat wil zeggen: de ATIII/heparine-afhankelijke inaktivering van protrombinase-gevormd trombine en van factor $\mathrm{Xa}$ tijdens protrombine aktivering werd onderzocht, zowel in reageerbuis experimenten als in een in vitro stromingsmodel waar het protrombinase gelokaliseerd was aan het oppervlak van een capillair bekleed met een phospholipide bilaag.

In Hoofdstuk 4 is de inaktivering van, door het protrombinase geaktiveerde, protrombine beschreven. Gevonden is, dat protrombinase-gekatalyseerde protrombineaktivering niet slechts leidt tot trombine vorming, maar dat ook meizotrombine(des fragment 1) ontstaat. In de afwezigheid van heparine waren de tweede orde reaktiekonstanten van inaktivering van trombine en meizotrombine (des fragment 1) identiek, $k=3.7 \times 10^{5} \mathrm{M}^{-1} \mathrm{~min}^{-1}$. De afbraakkonstante van gezuiverd trombine was $6.5 \times 10^{5} \mathrm{M}^{-1} \mathrm{~min}^{-1}$. In de aanwezigheld van heparine was verdwijning van de amidolytische aktiviteit bi-exponentieel en kon beschreven worden door een 4-parameter vergelijking. Hierdoor konden de pseudo-eerste orde afbraakkonstanten van de heparine-gekatalyseerde inaktivering van trombine en meizotrombine(des fragment 1) bepaald worden én de samenstelling van het reaktiemengsel met betrekking tot beide. Het bleek dat de verhouding tussen de hoeveelheden trombine en meizotrombine(des fragment 1) die gevormd werden afhankelijk van de initiële protrombine koncentratie was. De afbraakkonstanten gaven aan dat de vorming van het ternair complex tussen heparine, ATIII en trombine verstoord is in het gebruikte reaktiemengsel, en dat de vorming van het ternair complex met meizotrombine(des fragment 1) zo goed als onmogelijk is.

Het is reeds sinds 1973 bekend dat factor Va en phospholipide factor Xa beschermen tegen inaktivering door ATIII (Hoofdstuk 1). In dit proefschrift is de kinetiek van de ATIII- en ATIII/heparine-afhankelijke inaktivering van factor Xa tijdens protrombine aktivering onder verschillende omstandigheden onderzocht. Deze studies zijn gebaseerd op een model van protrombine aktivering in de aanwezigheid valn ATIII, waarin de waargenomen trombinevormingssnelheid de resultante is van de snelheid waarmee protrombine geaktiveerd wordt en de snelheid waarmee het gevormde trombine verdwijnt.

In Hoofdstuk 5 is het onderzoek beschreven waarin dit model ontwikkeld is met bovine stollingseiwitten. De tweede orde snelheidskonstante van factor Xa inaktivering door ATIII, bepaald met het chromogene substraat S2337, was 
$1.1 \times 10^{6} \mathrm{M}^{-1} \mathrm{~min}^{-1}$. Factor Xa tijdens protrombine aktivering in de aanwezigheid van verzadigende hoeveelheden factor $V a$ of phospholipide $(20 \mathrm{~mol} \%$ PS $/ 80$ mol\% PC) werd met eenzelfde tweede orde reaktiekonstante door ATIII geinaktiveerd: $k=1.2 \times 10^{6} \mathrm{M}^{-1} \mathrm{~min}^{-1}$. In de aanwezigheid van zowel factor $\mathrm{Va}$ als phospholipide was de reaktiekonstante van factor Xa voor ATIII 10 keer lager: $k=1.3 \times 10^{5} \mathrm{M}^{-1} \mathrm{~min}^{-1}$. Tijdens protrombine aktivering in de aanwezigheid van factor $\mathrm{Va}$ en phospholipide was factor Xa zelfs meer beschermd tegen inaktivering door ATIII in de aanwezigheid van heparine. Genormeerd naar $1 \mu \mathrm{g} / \mathrm{ml}$ was de pseudo-eerste orde snelheidskonstante van factor $\mathrm{Xa}$ inaktivering door $200 \mathrm{nM} \mathrm{ATIII,} 0.33 \mathrm{~min}^{-1}$ in de aanwezigheid van factor Va en phospholipide en $9.5 \mathrm{~min}^{-1}$ in de afwezigheid hiervan. De pseudo-eerste orde inaktiveringskonstanten van protrombinase waren onafhankelijk van de protrombine koncentratie. Omdat ook in dit reaktiesysteem meizotrombine(des fragment 1 ), in plaats van $\alpha$-trombine, het voornaamste produkt is tijdens de initiele fase van protrombine aktivering had heparine nauwelijks invloed op de ATIII-afhankelijke inaktivering van het geaktiveerde protrombine.

In Hoofdstuk 6 zijn heparine preparaten en heparine fragmenten, die liggen in een molecuul massa bereik van 1,700 tot $20,000 \mathrm{Da}$, onderzocht op hun katalyserend vermogen in de ATIII-afhankelijke inaktivering van humaan factor $\mathrm{Xa}$ en van protrombinase tijdens protrombine aktivering. $\mathrm{De}$ protrombinase reaktie werd volgens het model beschreven in Hoofdstuk 5, geanalyseerd. Dit model leidde tot een 3-parameter vergelijking, die een funktie was van de initiële snelheid van protrombine aktivering en de pseudo-eerste orde inaktiveringskonstanten van protrombinase en van het gevormde trombine. De specifieke katalytische aktiviteiten van de heparines in de reakties met zowel factor $\mathrm{Xa}$ als protrombinase namen toe met toenemende gemiddelde molecuul gewicht. In tegenstelling tot resultaten van andere onderzoeksgroepen vertoonden alle heparines een ongeveer 5 keer hogere specifieke aktiviteit in de reaktie met factor $\mathrm{Xa}$ dan in de reaktie met protrombinase, aangevende dat onder deze omstandigheden de factor Va/phospholipide-afhankelijke bescherming van factor Xa onafhankelijk van de heparine grootte is. Door onze oorspronkelijke aanpak werd bovendien een tot nu toe onbekend fenomeen waargenomen. Namelijk bovenop het effect dat heparine heeft op de vorming van het inaktieve factor Xa-ATIII complex, reduceren heparines met $M_{r}>4,500$ de initiële snelheid van protrombine aktivering in de aanwezigheid van ATIII. De grootte van het effect is afhankelijk van de heparine koncentratie. Onze hypothese is dat door de (snelle) vorming van het dissocieerbaar ATIII/heparine/factor Xa-complex de aktiviteit van factor $\mathrm{Xa}_{\mathrm{a}}$ ten opzichte van zijn natuurlijk substraat protrombine, (gedeeltelijk) verloren gaat.

Er zijn meerdere mechanismen voorstelbaar die verantwoordelijk zijn voor de bescherming van factor Xa tegen ATIII/heparine. Naar onze mening is het meest waarschijnlijke model, die waarin factor Xa gecomplexeerd door factor $\mathrm{Va}$ (en/of phospholipide) ontoegankelijk geacht wordt voor ATIll. Inaktivering van 
factor Xa treedt slechts dan op als het protrombinase dissocieert, en de "bescherming" wordt dus in feite veroorzaakt door de bijzonder ongunstige dissociatie van het protrombinase (Hoofdstuk 9).

Het meeste van onze huidige kennis inzake bloedstolling en de daarbi] optredende reakties zijn verkregen uit studies in statische, gesloten systemen. Bloed, het medium waarin bloedstolling daadwerkelijk optreedt, is echter een dynamische vloeistof dat zich vrijelijk door het bloedvatenstelsel beweegt. Terwijl de rheologie van het bloed zelf uitputtend onderzocht is, is er weinig bekend over het verloop van bloedstollingsreakties aan een oppervlak tijdens stroming. Recentelijk is een eerste poging ondernomen om de aktivering van factor $X$ door weefsel factor en factor VIla in een open laminair stromingsmodel te beschrijven (zie Hoofdstuk 1). Vanwege het belang van een dergelijke aanpak hebben wij een soortgelijk stromingmodel ontwikkeld om de aktivering van protrombine door protrombinase, en het effect van heparine en ATIII hierop te bestuderen.

In Hoofdstuk 7 is het onderzoek beschreven waarin het modelsysteem is ontwikkeld en gekarakteriseerd. De binnenzijde van glazen capilairen werden voorzien van een phospholipide bilaag, en vervolgens geperfuseerd met factor $\mathrm{Va}$. Bij perfusie van factor $\mathrm{Xa}$ en protrombine maakte het gebonden factor $\mathrm{Va}$ assemblage van protrombinase mogelijk. De snelheid waarmee protrombinase werd gevormd nam toe met toenemende factor Xa koncentraties en stromingssnellheden, hetgeen verenigbaar is met een assemblage van protrombinase die ashangt van de flux van factor $X a$ vanuit de stromende vloeistof, door de stilstaande grenslaag naar het phospholipide-gebonden factor $\mathrm{Va}$. Mits factor $\mathrm{Xa}$ en protrombine aanwezig waren in de stromende vloeistof, was het protrombinase (schijnbaar) irreversibel; gedurende minstens 20 minuten trad geen verlies van protrombinase aktiviteit op. De snelheid van protrombine aktivering was lineair afhankellijk van de oppervlaktedichtheid aan protrombinase. In de aanwezigheid van $1.0 \mu \mathrm{M}$ protrombine, bij een atschuitsnelheid ("shear rate") van $82 \mathrm{~s}^{-1}$, was de gemiddelde snelheid van trombine vorming $870 \mathrm{~mol} / \mathrm{min}$ per mol protrombinase. In tegenstelling tot hetgeen waargenomen is in reageerbuis experimenten bleek dat in dit stromingsmodel de vorming van $\alpha$-trombine de voorkeur had boven de vorming van meizotrombine(des fragment 1).

In Hoofdstuk 8 werd de remming van protrombinase door ATIII en heparine in dit stromingsmodel onderzocht. Capillairen die met een phospholipide bilaag bedekt waren en phospholipide-gebonden factor Xa en factor $\mathrm{Va}$ bevatten werden geperfuseerd met $\$ .0 \mu \mathrm{M}$ protrombine in de aanwezigheid van $0.50 \mathrm{nM}$ factor $\mathrm{Va}$ (afschuifsneiheid $28 \mathrm{~s}^{-1}$ ). Ook hier was de snelheid van protrombine omzetting rechtevenredig met de oppervlaktedichtheid van protrombinase. Vervolgens werd ATIII aan het perfusaat toegevoegd, ten gevolge waarvan de vrije trombine koncentratie aan de capillair uitlaat drastisch gereduceerd werd: $50 \%$ remming werd verkregen in de aanwezigheid van $0.7 \mu \mathrm{M}$ ATIII. Echter uit de perfusie van vervolgens enkel protrombine bleek dat de protrombinaseraktiviteit 
nauwelijks geremd kon worden. Bij een plasma ATIII koncentratie ( $2 \mu \mathrm{M}$ ) werd een lichte remming van protrombinase waargenomen: $10 \%$ van de aktiviteit verdween gedurende een 10 minuten durende perfusie. Als tijdens de perfusie met ATIII protrombine werd weggelaten uit het perfusaat, of als een specifieke en krachtige trombine remmer (hirudine; $2.0 \mu \mathrm{M}$ ) werd toegevoegd aan het perfusaat, werd een meer uitgesproken remming van protrombinase waargenomen: $40 \%$ restaktiviteit kon bepaald worden na een 10 minuten durende perfusie. Hieruit koncludeerden wij dat trombine, kontinu geproduceerd aan het opperviak, het ATIII in de grenslaag consumeert. De 'echte' ATIII koncentratie in de nabijheid van de enzymatische complexen is derhalve niet meer dan een fraktie van de initiële ATIII koncentratie in de vloeistofstroom. Niet-gefraktioneerde heparine en pentasaccharide versnelden weliswaar de ATIII-afhankelijke inaktivering van protrombinase, doch in een geringere mate dan waargenomen met een protrombinase geassembleerd aan het oppervlak van kleine unilaminaire phospholipide vesicles. Om meer inzicht te verkrijgen in het werkingsmechanisme van heparine onder fysiologisch relevante omstandigheden, zullen er meer studies, onder uiteenlopende omstandigheden in een dergelijk stromingsmodel uitgevoerd moeten worden.

De bevindingen weergegeven in dit proefschrift zijn in overeenstemming met het denkbeeld dat regulering van de bloedstolling door heparine, onder in vivo omstandigheden voornamelijk plaatsvindt tijdens de vorming van protrombinase en niet door een directe remming van eenmaal gevormd protrombinase. De vorming van protrombinase kan geremd worden door het wegvangen van trombine, dat benodigd is voor de aktivering van factor $V$ en factor VIII, of door het wegvangen van het vrije factor $X a$. Concluderend kunnen we stellen, dat het doel van antitrombotische therapie veelaleer het onderdrukken van trombinevorming lijkt dan het enkel wegvangen van reeds gevormd trombine. Het is precies deze aktiviteit die heparines gemeen hebben met een andere, gevestigde groep antitrombotica, namelijk die van de orale antistollingsmiddelen. 
Pieter Schoen is op 7 januari 1963 geboren in Haarlem. Hij behaalde het diploma Atheneum-B in 1981, aan het Antonius Doctor College te Kerkrade. Hierna studeerde hij aan de Zuidlimburgse Laboratorium School te Sittard. In 1985 behaalde hij het getuigschrift HLO-chemie, biochemische differentiatie, met extra aantekeningen voor analytische en organische chemie. Op 1 juli 1985 is hij aangesteld als analist bij de vakgroep Biochemie van de Faculteit der Geneeskunde aan de Rijksuniversiteit Limburg. Op 1 mei 1987 is hij bij dezelfde vakgroep in dienst getreden als Assistent-in-Opleiding, alwaar hij onder leiding van Dr. Th. Lindhout en Prof.Dr. H.C. Hemker gewerkt heeft aan het onderzoek dat beschreven is in dit proeischrift. 